\title{
G protein-coupled receptors encoded by members of the cytomegalovirus UL33 gene family : characteristics of and structural requirements for constitutive signaling
}

Citation for published version (APA):

Gruijthuijsen, Y. K. (2004). G protein-coupled receptors encoded by members of the cytomegalovirus UL33 gene family : characteristics of and structural requirements for constitutive signaling. [Doctoral Thesis, Maastricht University]. Datawyse / Universitaire Pers Maastricht. https://doi.org/10.26481/dis.20040408yg

Document status and date:

Published: 01/01/2004

DOI:

$10.26481 /$ dis.20040408yg

Document Version:

Publisher's PDF, also known as Version of record

Please check the document version of this publication:

- A submitted manuscript is the version of the article upon submission and before peer-review. There can be important differences between the submitted version and the official published version of record. People interested in the research are advised to contact the author for the final version of the publication, or visit the DOI to the publisher's website.

- The final author version and the galley proof are versions of the publication after peer review.

- The final published version features the final layout of the paper including the volume, issue and page numbers.

Link to publication

\footnotetext{
General rights rights.

- You may freely distribute the URL identifying the publication in the public portal. please follow below link for the End User Agreement:

www.umlib.nl/taverne-license

Take down policy

If you believe that this document breaches copyright please contact us at:

repository@maastrichtuniversity.nl

providing details and we will investigate your claim.
}

Copyright and moral rights for the publications made accessible in the public portal are retained by the authors and/or other copyright owners and it is a condition of accessing publications that users recognise and abide by the legal requirements associated with these

- Users may download and print one copy of any publication from the public portal for the purpose of private study or research.

- You may not further distribute the material or use it for any profit-making activity or commercial gain

If the publication is distributed under the terms of Article $25 \mathrm{fa}$ of the Dutch Copyright Act, indicated by the "Taverne" license above, 
G PROTEIN-COUPLED RECEPTORS ENCODED BY MEMBERS OF THE

CYTOMEGALOVIRUS UL33 GENE FAMILY 
(C) Yvonne Gruijthuijsen, Maastricht 2004

Cover design: Fred Greve

Cover photos: Yvonne Gruijthuijsen

Front: Expression RCMV pR33-EGFP in transiently-transfected COS-7 cells Back: Expression KSHV GPCR-EGFP in transiently-transfected COS-7 cells

Production: Datawyse, Maastricht, The Netherlands

ISBN: $90-5278-407-8$ 


\section{G PROTEIN-COUPLED RECEPTORS}

\section{ENCODED BY MEMBERS OF THE}

\section{CYTOMEGALOVIRUS UL33 GENE FAMILY}

CHARACTERISTICS OF AND STRUCTURAL REQUIREMENTS FOR CONSTITUTIVE SIGNALING

\section{PROEFSCHRIFT}

ter verkrijging van de graad van doctor aan de Universiteit Maastricht, op gezag van de Rector Magnificus Prof. mr. G.P.M.F. Mols volgens het besluit van het College van Decanen, in het openbaar te verdedigen op donderdag 8 april 2004 om 16.00 uur

door

Yvonne Krystyna Gruijthuijsen

geboren te Eindhoven op 30 september 1973

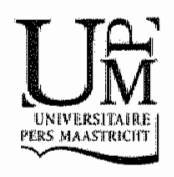




\section{Promolor:}

Prof. dr. C.A. Bruggeman

Co-promotor:

Dr. C. Vink

\section{Beoordelingscommissie:}

Prof. dr. H.A. Struiker Boudier (voorzitter)

Prof. dr. M.H. Hofker

Dr. W.G. Melchers (Katholieke Universiteit Nijmegen)

Prof. dr. T. Mertens (Universität Ulm. Duitsland)

Prof. dr. F.C.S. Ramaekers

Prof. dr. W.J.M. Spaan (Universiteit Leiden)

The investigations described in this thesis were carried out at the Department of Medical Microbiology, Maastricht University, Maastricht, The Netherlands and at the Division of Medicinal Chemistry. Free University, Amsterdam. The Netherlands. The work was supported by a grant (901-02-224) from The Netherlands Organization for Scientific Research (NWO, Medical Sciences). 
Aan

Arnold, Anka, Oma

In Herinnering

Aan Mijn Grootouders 



\section{Contents}

Preface

p. 9

Chapter 1 Rat Cytomegalovirus R89 is a Highly Conserved Gene

p. 15

Which Expresses a Spliced Transcript

Chapter 2 Herpesvirus-Encoded G Protein-Coupled Receptors:

p. 31

Stimulators of Viral Replication, Immune Evadors or

Directors of Movement?

Chapter 3 The Rat Cytomegalovirus R33-Encoded G Protein-

p. 61

Coupled Receptor Signals in a Constitutive Fashion

Chapter 4 Constitutive Signaling of the Human

p. 85

Cytomegalovirus-Encoded Receptor UL33 Differs

From That of Its Rat Cytomegalovirus Homolog R33

by Promiscuous Activation of $G$ Proteins of the $G_{q / 11}$ $G_{i / 0}$ As Well As $G_{s}$ class

Chapter 5 Mutational Analysis of the Rat Cytomegalovirus R33Encoded G Protein-Coupled Receptor: Identification of Amino Acid Residues Critical for Cellular Localization and Ligand-Independent Signaling

Chapter 6 Summary and General Discussion

Samenvatting en Algehele Discussie

Dankwoord

Curricullum Vitae

Publicaties

p.158 

PREFACE 


\section{Background}

The highly species-specific cytomegaloviruses (CMVs) induce both acute and life-long latent infections in their hosts (13). This ability to establish life-long infections is likely the result of a high level of adaptation of these betaherpesviruses to the host's immune system. To subvert the defense system. CMVs employ a variety of sophisticated strategies in which immune processes such as apoptosis, humoral immunity, antigen presentation as well as interferon and chemokine signaling are corrupted (1). Interestingly, most of the viral immunomodulatory proteins that distort these processes are mimics of cellular host proteins. Probably, these viral mimics are encoded by genes, which have been captured from the host by an ancestral virus. Over time, these genes have evolved under various selection pressures to become well-adapted to subserve the needs of the infecting virus.

The mimics of cellular chemokines and chemokine-binding $G$ proteincoupled receptors (GPCRs) form the largest known class of host-related viral immunomodulatory genes. The human CMV (HCMV) genome even comprises four GPCR genes, which are designated US27, US28, UL33, and UL78 $(7,8)$. In contrast to US27 and US28, which are unique for HCMV, both UL33 and UL78 are conserved among all betaherpesvirus genomes sequenced to date, including those of the human herpesviruses 6 (HHV-6; 12, 14, 15) and 7 (HHV-7; 18). This indicates that the members of the UL33 and UL78 gene families are of great importance in the pathogenesis of betaherpesvirus infections. However, as a consequence of the strict host species-specificity of the betaherpesviruses, the possibilities to study the in vivo function of these HCMV. HHV-6 and -7 genes and their gene products are limited. Therefore, in vivo models will be required to gain a full understanding of the contribution of these genes, in physiological relevant
situations.

In our laboratory, a rat CMV (RCMV)/rat infection model has been developed to study the pathogenesis of CMV infections. RCMV was isolated in 1982 from wild rats and has since then been successfully passed on rat embryo fibroblasts in vitro as well as laboratory rats in vivo $(4,5)$. In order to further validate the RCMV/rat infection model, the characteristics of RCMV infection in rats were carefully examined $(6,16,17,21,22,23,25,26)$ and the full $230-\mathrm{kb}$ RCMV genomic sequence was determined (24). Comparison of this genomic sequence with that of HCMV ( 7$)$ and murine CMV (MCMV) (20) indicated that these genomes are colinear and that the majority of the CMV open reading frames (ORFs) are conserved among these CMV species (24). Together, these findings indicated that the RCMV/rat infection model represents a suitable tool to study
the role of CMV genes in the pathogenesis of CMV infection.

\section{Outline and aims of the thesis}

At the time the investigations described in this thesis were initiated, the unraveling of the genomic sequence and coding content of the RCMV genome 
Was still in progress. The analysis of the RCMV genome allowed comparison of this sequence with that of related herpesviruses, such as HCMV and MCMV. Also, RCMV counterparts of conserved herpesvirus genes were identified. The RCMV R89 gene is such a highly conserved gene. This gene is the homolog of the herpes simplex virus 1 (HSV-1) UL15 gene, which encodes the putative terminase subunit $(9,10,11)$. This terminase subunit is essential for cleavage of replicated concatemeric herpesvirus DNA into unit-length genomes as well as their packaging into preformed herpesvirus capsids $(2,19)$. As would be expected from the critical role of this protein in herpesvirus replication, the UL15 gene is one of the bestconserved herpesvirus genes. In addition, the UL15 gene represents one of the few HSV-1 genes that are spliced (9). The first part of this thesis was aimed at the transcriptional characterization of the RCMV genomic region predicted to comprise the homolog of the HSV-1 UL15 gene, the results of which are presented in Chapter 1.

Through similar analyses of other conserved genomic regions, the RCMV homolog of the putative HCMV GPCR-encoding gene, UL33, was identified (3), This gene, termed R33, was demonstrated to be of significant biological importance in vivo, as reviewed in Chapter 2. To investigate the functional properties of the proteins putatively encoded by the R33 and UL33 genes, we set out to evaluate whether these genes encode chemokine-binding GPCRs, as reported in Chapters 3 and 4 . Since we found the R33- and UL33-encoded proteins, pR33 and pUL33, respectively, to act as functional GPCRs, we further delineated the intracellular signaling pathways in which these receptors participate. Interestingly, both receptors modulated several signal transduction pathways in a ligand-independent, constitutive fashion. Moreover, pUL33 was able to trigger additional signaling pathways that were not activated by pR33. Intrigued by these findings, we sought to determine the structural requirements for the constitutive behavior of pR33 as well as for the differential constitutive signaling by pR33 and pUL33, as described in Chapters 4 and 5 . Finally, a comprehensive overview and a general discussion of the results described in this thesis are given in Chapter 6.

\section{References}

1. Alcami A, Koszinowski UH. (2000) Viral mechanisms of immune evasion. Trends Micrabiol. 8, 410-8.

2. Baines JD, Poon AP, Rovnak J, Roizman B. (1994) The herpes simplex virus 1 UL15 gene encodes two proteins and is required for cleavage of genomic viral DNA. J Virol. 68, 8118-24.

3. Beisser PS, Vink C, Van Dam JG, Grauls $G$, Vanherle SI, Bruggeman CA. (1998) The R33 $G$ protein-coupled receptor gene of rat cytomegalovirus plays an essential role in the pathogenesis of viral infection. J Virol. 72, 2352-63.

4. Bruggeman CA, Meijer $H$, Dormans PH, Debie WM, Grauls GE, van Boven CP. (1982) Isolation of a cytomegalovirus-like agent from wild rats. Arch Virol. 73, 231-41. 
5. Bruggeman CA, Meijer H, Bosman F, van Boven CP. (1985) Biology of rat cytomegalovirus infection. Intervirology $24,1-9$.

6. Bruning JH, Bruggeman CA, van Boven $C P$, van Breda Vriesman Pl. (1986) Passive transfer of cytomegalovirus by cardiac and renal organ transplants in a rat model. Transplantation 41,695-8.

7. Chee MS, Bankier AT, Beck S, Bohni R, Brown CM, Cerny R, Horsnell T, Hutchison CA 3rd, Kouzarides T, Martignetti JA, et al. (1990) Analysis of the protein-coding content of the sequence of human cytomegalovirus strain AD169. Curr Top Microbiol Immunol. 154, 125-69.

8. Chee MS, Satchwell SC, Preddie E, Weston KM, Barrell BG. (1990) Human cytomegalovirus encodes three $G$ protein-coupled receptor homologues. Nature 344, 774-7.

9. Costa RH, Draper KG, Kelly TJ, Wagner EK. (1985) An unusual spliced herpes simplex virus type 1 transcript with sequence homology to EpsteinBarr virus DNA. J Virol. 54, 317-28.

10. Davison AJ. (1992) Channel catfish virus: a new type of herpesvirus. Virology $186,9-14$.

11. Dolan A, Arbuckle M, McGeoch DJ. (1991) Sequence analysis of the splice junction in the transcript of herpes simplex virus type 1 gene UL15. Virus Res. $20,97-104$.

12. Dominguez $G$, Dambaugh TR, Stamey FR, Dewhurst $S$, Inoue $N$, Pellett PE. (1999) Human herpesvirus 6B genome sequence: coding content and comparison with human herpesvirus 6A. J Virol. 73, 8040-52.

13. Fields BN, Knipe DM. Howley PM, (EDs in Chief; 1996) Fields Virology. Third edition, Lippincott-Raven Publishers, Philadelphia, New York, USA.

14. Gompels UA, Nicholas I, Lawrence $G$, Jones $M$. Thomson BJ, Martin ME, Efstathiou S, Craxton M. Macaulay HA. (1995) The DNA sequence of human herpesvirus-6: structure, coding content, and genome evolution. Virology 209, 29-51.

15. Isegawa $Y$, Mukai $T$, Nakano $K$, Kagawa M. Chen J, Mori $Y$, Sunagawa $T$, Kawanishi K, Sashihara J. Hata A, Zou P. Kosuge H, Yamanishi K. (1999) Comparison of the complete DNA sequences of human herpesvirus 6 variants $A$ and $B$. J Virol 73:8053-63

16. Kloover 15 , Hillebrands $\mu$, de Wit $G$, Grauls $G$, Razing J, Bruggeman $C A_{r}$ Nieuwenhuis P. (2000) Rat cytomegalovirus replication in the salivary glands is exclusively confined to striated duct cells. Virchows Arch. 437 , 413-21.

17. Kloover JS, van den Bogaard $A E$, van Dam JG, Grauls GE, Vink $C_{\text {, }}$ Bruggeman CA. (2002) Persistent rat cytomegalovirus (RCMV) infection of the salivary glands contributes to the anti-RCMV humoral immune response. Virus Res. $85,163-72$.

18. Nicholas 1. (1996) Determination and analysis of the complete nucleotide sequence of human herpesvirus. I Virol. 70, 5975-89.

19. Przech AJ, Yu D. Weller SK. (2003) Point mutations in exon I of the herpes simplex virus putative terminase subunit, UL15, indicate that the most 
conserved residues are essential for cleavage and packaging. J Virol. 77. 9613-21.

20. Rawlinson WD, Farrell $H E_{n}$ Barrell BG. (1996) Analysis of the complete DNA sequence of murine cytomegalovirus. J Virol. 70, 8833-49.

21. Stals et al., 1990 Stals FS, Bosman F, van Boven CP, Bruggeman CA. (1990) An animal model for therapeutic intervention studies of CMV infection in the immunocompromised host. Arch Virol. 114, $91-107$.

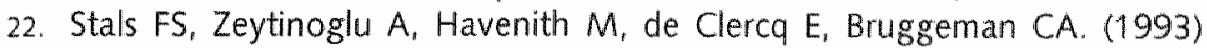
Rat cytomegalovirus-induced pneumonitis after allogeneic bone marrow transplantation: effective treatment with (S)-1-(3-hydroxy-2-phosphonylmethoxypropyl)cytosine. Antimicrob Agents Chemother. 37, 218-23.

23. Stals $F S_{r}$ Wagenaar SS, Bruggeman CA. (1994) Generalized cytomegalovirus (CMV) infection and CMV-induced pneumonitis in the rat: combined effect of 9-(1,3-dihydroxy-2-propoxymethyl)guanine and specific antibody treatment. Antiviral Res. 25, 147-60.

24. Vink C, Beuken $E_{1}$ Bruggeman CA. (2000) Complete DNA sequence of the rat cytomegalovirus genome. I Virol. 74, 7656-65.

25. Vossen $R C$, Derhaag J $G$, Slobbe-van Drunen $M E$, Duijvestijn $A M$, van Dam-Mieras MC, Bruggeman CA. (1996) A dual role for endothelial cells in cytomegalovirus infection? A study of cytomegalovirus infection in a series of rat endothelial cell lines. Virus Res. 46, 65-74.

26. Vossen RC, Persoons MC, Slobbe-van Drunen ME, Bruggeman CA, van Dam-Mieras MC. (1997) Intracellular thiol redox status affects rat cytomegalovirus infection of vascular cells. Virus Res. $48,173-83$. 
GPCRS Encoded by Members of the CMV UL3 3 Cene Family 


\section{CHAPTER 1}

\section{Rat Cytomegalovirus R89 is a Highly Conserved Gene Which Expresses a Spliced Transcript}

Virus Research (2000) 69: 119-130 


\section{Abstract}

In all sequenced herpeswirus, genomes, a homolog of the herpes simplex virus type 1 UL15 gene has been identified. This gene encodes a protein that is involved in viral genome maturation. Although transcription of the alphaherpesvirus UL15 gene has been analyzed in detail, not much is known about the expression of its betaherpesvirus homologs. We therefore set out to characterize transcription of the rat cytomegalovirus counterpart of UL15, R89. Here we report that $R 89$ consists of two exons separated by a $4.7-\mathrm{kb}$ intron. The spliced R89 transcript, which is expressed at late times postinfection (p.i.), has the capacity to encode a protein of 670 amino acids with a calculated molecular mass of $77.1 \mathrm{kDa}$. The predicted amino acid sequence of this protein is highly similar to that of the proteins predicted to be encoded by the human cytomegalovirus UL89 and murine cytomegalovirus M89 genes ( 64.3 and $84.5 \%$ overall identity, respectively). The region between $R 89$ exon 1 and exon 2 was found to contain five additional genes, r90, R91, R92, R93 and R94, the latter two of which are conserved among all herpesviruses. We show that these genes are transcribed in a highly complex fashion, resulting in numerous mono- and polycistronic mRNAs.

\section{Introduction}

Herpesviruses have large genomes and exhibit complex patterns of gene expression. The vast majority of herpesvirus genes produce unspliced transcripts of which the expression is regulated by promoter-control regions upstream of the transcription initiation site. Although nested transcripts that share either polyadenylation sites or cap sites are commonly found, spliced herpesvirus transcripts are rare. One of the few herpesvirus genes that expresses spliced transcripts is herpes simplex virus type 1 (HSV-1) UL15, which is conserved among all sequenced herpesviruses. Like six other essential HSV-1 genes (UL6, UL17, UL25, UL28, UL32 and UL33), UL15 was presumed to be involved in viral DNA maturation $(1,2,3,4,5,19,22,23,24,25,28,31)$. The putative role of UL15 in this process was emphasized by the finding of homology between UL15 and the ATP-binding terminase $g \mathrm{p} 17$, a protein required for cleavage and packaging of
bacteriophage T4 DNA (12).

The UL15 gene consists of two exons separated by a large intron, in which two open reading frames (ORFs) are located (11). These ORFs, UL16 and UL17, have an orientation opposite to that of the UL.15 gene (11) and are conserved among all herpesviruses. The UL15 homologs of several betaherpesviruses, such as human cytomegalovirus (HCMV) (10), murine cytomegalovirus (MCMV) (20), rat cytomegalovirus (RCMV) (27) and human herpeswirus type 6(HHV-6) (14) and $H H V-7(18)$, were predicted to have a similar intron-exon structure as $\mathrm{HSV}-1$ UL15. However, these predictions were based exclusively on sequence alignments and not on transcription data. Therefore, we set out to characterize transcripts from the UL15 homolog of one of the members of the subfamily of
Betaherpesvirinae, rat cytomegalovirus (RCMV). We here report the nucleotide 
sequence of the genomic region of RCMV that contains the UL15 homolog (R89). as well as transcription of both $R 89$ and its neighbouring genes.

\section{Materials and methods}

Virus and cell culture. Growth and infection of primary rat embryo fibroblasts (REF) with RCMV (strain Maastricht) was done as described previously (9).

Cloning and sequencing. All RCMV DNA fragments were cloned into plasmid pUC119. Both strands of the plasmid inserts were sequenced using the Thermosequenase Cycle Sequencing kit (Amersham) with Cy5- labeled primers. and an ALFexpress automated DNA sequencer (Pharmacia Biotech). Sequence analysis was done using the program PC:Gene (version 2.11; Intelligenetics). Potential transcription initiation sites were predicted using the program "Promoter Prediction by Neural Network' (http://www.fruitfly.org/seq-tools/promoter.html) (21). The naming system for RCMV ORFs has previously been described (27). In short, the prefix ' $R$ ' indicates that an ORF has a homolog in HCMV', whereas the prefix ' $r$ ' indicates that an ORF does not have a homolog in HCMV. The nucleotide and amino acid sequence data presented in this paper have been deposited in the GenBank database under Accession No. AF232689.

Northern blot analysis. Poly(A) + RNA from RCMV- as well as mockinfected cells was isolated at immediate-early (IE) (in the presence of cycloheximide), early ( $E$ ) (in the presence of phosphonoacetic acid) and late (L) times of infection of primary rat embryo fibroblasts (REFs) using a Quick Prep Micro mRNA Purification Kit (Pharmacia Biotech), as previously described (7). Poly $(A)+$ RNA from mock-infected cells was isolated in a similar fashion as $L$ MRNA, except that RCMV infection was omitted. Infections with RCMV were done with a multiplicity of infection of either 1 (for isolation of $M R N A$ at IE and E times) or 0.01 (for isolation of mRNA at $L$ times). Electrophoresis of RNA and transfer to Hybond-N+ membranes (Amersham) has been described previously (8). The R88-specific probe (probe I in Fig. 4B) was made using a 790-bp BgAlBamHI fragment. To generate R89 exon 1 - and exon 2-specific probes, a 482 - bp A/L-PSt fragment and a 492-bp Sad-SaA fragment were used, respectively (probes VIII and II, respectively). The r90-specific probe III was generated using a 107-bp Xhol fragment. The R91, R92, R93, R94, and R95 probes were made using a 116-bp 5ad-BamHI fragment (probe IV), a 326-bp BamHI-Aadil fragment (probe V), a 511-bp Sad fragment (probe VI), a 357-bp BamHI-Pst fragment (probe VII), and a 411 -bp Hindl fragment (probe $(X)$, respectively. A strandspecific, antisense probe of $R 89$ exon 2 was generated by linear DNA amplification, as follows. First, a 500-bp A/LA-SaA fragment from exon 2 was made blunt-ended by incubation with DNA polymerase I Klenow fragment (Klenow; Pharmacia Biotech) and dNTPS. Then, the fragment was cloned into Hindl- and BamHI-digested, Klenow-treated plasmid pUC119. A clone with the R89 exon 2 
insert in the correct orientation, i.e. with the $5^{\prime}$ end of the coding strand proximal to the ECoRI site of pUC119, was selected. This plasmid was linearized with ECoRI, and used in a 'run off' linear amplification by incubation with Taq DNA polymerase, the universal reverse sequencing primer and labeled dNTPS for 30 cycles ( 1 min at $95^{\circ} \mathrm{C}, 30 \mathrm{~s}$ at $55^{\circ} \mathrm{C}$ and $30 \mathrm{~s}$ at $72^{\circ} \mathrm{C}$ ). Other labeling, hybridization and detection experiments were performed using digoxigenin DNAlabelling and chemoluminescence detection kits (Boehringer Mannheim) and the Dig Easy Hyb hybridization solution (Boehringer Mannheim).

Reverse transcriptase (RT)-PCR. The splice junction of the R89 transcript was subjected to RT-PCR. First, poly(A) + RNA from both RCMV (late)-and mockinfected cells was purified as described above. Then, the RNA was treated with DNase I (Pharmacia Biotech), after which CDNA was generated using a Superscript Plasmid System for CDNA Synthesis and Plasmid Cloning (Gibco BRL). The following primers were used for amplification of the R89 splice junction from the CDNA: 5'-GACGAGGATCCTGCTGAAGAACATCATCGGC-3' (R89-EX1-5J) and 5'CAGCAAAGCTTGGTCGTGTTCTGGGCCAG-3' (R89-EX2-5J). The sequence in italics from R89-EX1-SJ is homologous to a sequence from exon 1, located at a distance of $205 \mathrm{bp}$ from the predicted splice junction. The sequence in italics from R89-EX2-SJ is homologous to a sequence from exon 2 , located at a distance of $105 \mathrm{bp}$ from the predicted splice junction. The sequences in bold print represent restriction sites for BamHI (in R89-EX1-SJ) and Hindll (in R89-EX2-SJ). The PCR reaction was carried out essentially as described previously (6). The resulting $0.3-$ kb PCR product was purified, digested with BamHI and Hindil, cloned into the corresponding sites of pUC119, and sequenced.

\section{Results}

The RCMV homolog of HSV-1 UL15. We have recently determined the complete nucleotide sequence of the RCMV (Maastricht) genome (27). The HSV-1 UL15 homolog of RCMV was localized between nucleotides 119000 and 127000 of the 229 896-bp RCMV genome (Fig. 1). The gene was termed R89, in analogy to the nomenclature of the corresponding genes of HCMV and MCMV, UL89 and $M 89$, respectively $(10,20)$. On the basis of sequence alignments, RCMV R89 was predicted to consist of two exons separated by a $4.7-\mathrm{kb}$ intron (Fig. 1). R89 has the potential to encode a 670-amino acid protein with a calculated molecular mass of $77.1 \mathrm{kDa}$. As shown in Fig. 2 and Table 1, the amino acid sequence of this protein is very similar to that of its homologs from other herpesviruses (Fig. 2). More specifically, of all amino acid sequences predicted to be encoded by RCMV. the R89-derived sequence was found to have the highest level of similarity with its counterparts from MCMV and HCMV (84.5 and 64.3\% overall identity, respectively). In the alignment of Fig. 2, several small gaps are seen in the betaherpesvirus sequences in comparison with the alphaherpesvirus (HSV-1) sequence. Interestingly, one of these gaps 'aligns' with a part of the UL15encoded amino acid sequence that has been reported to represent a potential 


\section{RCMV genome}

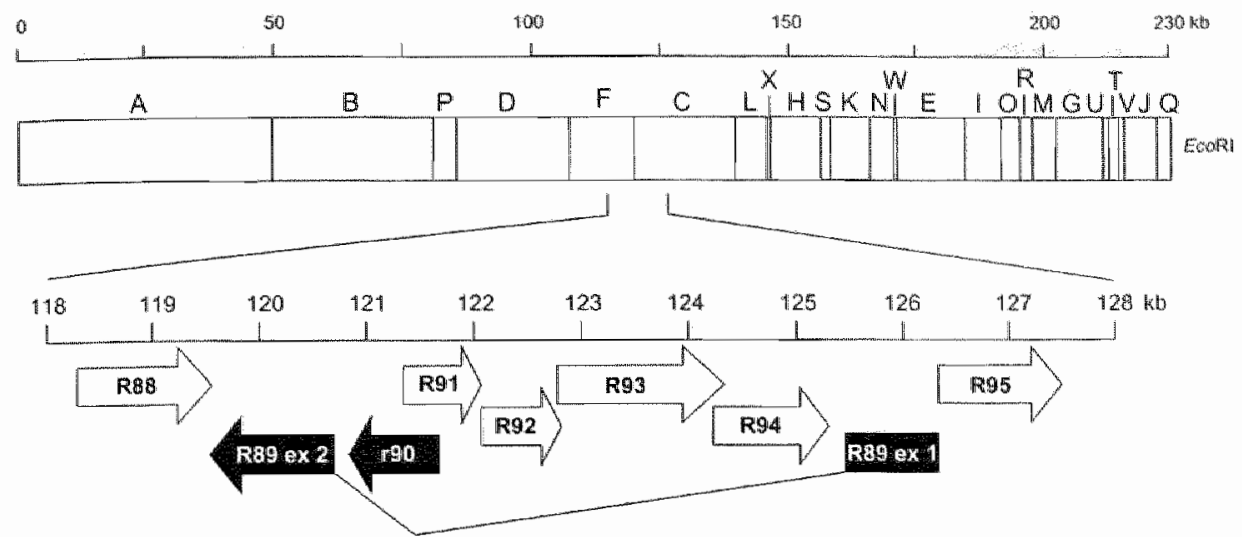

Fig. 1. Restriction map of the RCMV (Maastricht) genome and position of ORFs R88 through R95. The EcoRl restriction map was determined by Meijer et al. (1986). The exact positions of each ORF (arrows) within the RCMV genome are listed in Table 1. The direction of the arrows indicate the orientation of the sense strand of the corresponding ORF. ORFs running from left to right are shown as open arrows, whereas ORFs running in the opposite direction are shown in black. R89 ex 1, R89 exon 1; R89 ex 2 . R89 exon 2.

nuclear localization signal (residues 182-189: PPKKRAKV) (5). It has previously been demonstrated that amino acid residue Met $^{443}$ of HSV-1 UL.15 is used as an alternative translation initiation codon, resulting in the synthesis of a second, truncated UL15 gene product of $30 \mathrm{kDa}$ (UL15.5) $(4,5,30,31)$. It is remarkable that this Met residue is not conserved among all herpesviruses; at the position corresponding to $\mathrm{Met}^{443}$, a Leu residue is present in the CMV sequences (Fig. 2), whereas an lle residue is present in the HHV-6 and -7 sequences (data not shown). Apparently, the synthesis of truncated proteins homologous to UL15.5 is not an essential feature within the herpesvirus family. In accordance with this, the UL15.5 protein has been shown to be dispensable for HSV-1 replication in cell culture (31).

Within the R89 intron, five potentially proteincoding ORFs were identified (Fig. 1). One of these ORFs, r90, is conserved exclusively between RCMV and MCMV, and is similarly orientated as R89, running from right to left within the RCMV genome. The other four ORFs in the R89 intron, R91 through R94, have an orientation opposite to that of R89 and r90. R92 is conserved among the gammaand betaherpesviruses, whereas homologs of R91, R94 and R95 are found exclusively in the betaherpesvirus subfamily. Homologs of ORFs R93 and R94 have been identified in all sequenced herpesviruses and show similarity with HSV1 genes UL17 and UL16, respectively. The salient features of RCMV ORFs R88 through R95 are listed in Table 1. It is remarkable that each of the ORFs within the R89 intron partially overlap with at least one of their neighboring ORFs. A particularly large region of overlap is seen between r 90 and R91 (287 bp). 


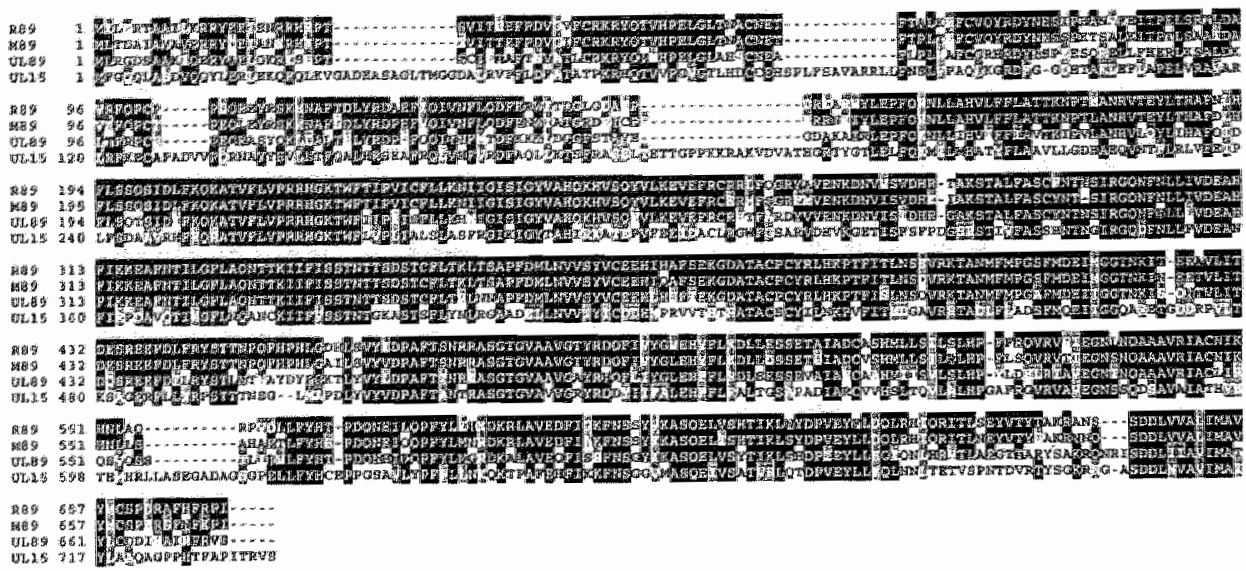

Fig. 2. Alignment of the amino acid sequences predicted to be encoded by the (putative) spliced transcripts derived from RCMV R89, MCMV M89, HCMV UL89 and HSV-1 UL15. The alignment was carried out using a CLUSTAL W Multiple Sequence Alignment Program kversion 1.8, Human Genome Sequencing Center, Houston, TX thttp//dot.mgen bcm tmcedu/9331/multi-align/multialign.html]) (Thompson et al. 1994). Numbers to the left of the sequences indicate the positions of amino acid residues withinthe polypeptides. Blocks of identical (white letters in black boxes) and similar (white letters in grey boxes) were generated with program BOXSHADE (version 3.21. The EMBnet foundation. The Netherlands (http//www.ch.embnet.org/software/BOX-form.htmli), with the fraction of sequences that must agree for shading set to 0.5. The MCMV. HCMV and HSV-1 sequences are from Rawlinson et al. (1996), Chee et al. (1990) and McGeoch et al. (1988), respectively. Splicing of the transcripts of both MCMV M89 and HCMV UL89 has not been determined experimentally. The MCMV M89 amino acid sequence was generated by translation of the combined sequences of M89 exon 1 and 2 as defined by Rawlinson et al. (1996). In the sequence alignment, a gap is introduced between amino acids 296 and 297 of the MCMV sequence. Interestingly, an Asm residue is invariantly present at the corresponding position of the other herpeswirus sequences. By defining the boundaries of M89 exon 1 and exon 2 in a way different than has been reported previously (Rawlinson et al., 1996). three additional nucleotides are introduced at the exon 1-exon 2 boundary. As a consequence, M89 would also encode a conserved Asn residue, between the Thr en Ser residues at positions 296 and 297 , respectively.

Transcription of $R 89$. The putative exon-intron structure of the $R 89$ gene and the tight packing of ORFs within the R88-R95 region would predict transcription of this region to occur in a highly complex fashion. To investigate transcripts derived from the R88-R95 genomic region, we first set out to identify transcripts derived from putative exons 1 and 2 of R89 by Northern blot analysis. As shown in Fig. 3A, both exon 1 - and exon 2-specific transcripts were observed at late (L) times postinfection (p.i.) (lane 4 and 8), but not at immediate early (IE) or early (E) times. This indicates that R89 is a late RCMV gene, which is in accordance with the putative role of the R89-encoded protein in viral DNA maturation. Two major exon 1 -specific transcripts were identified with lengths of approximately $4.6 \mathrm{~kb}$ (transcript $M$ ) and $7 \mathrm{~kb}$ (transcript $N$ ), respectively (Fig. $3 \mathrm{~A}_{\text {s }}$ lane 4). Larger exon 1 transcripts of approximately $10 \mathrm{~kb}$ (transcript $P$ ) and $>10$ $\mathrm{kb}$ (transcript $\mathrm{E}$ ), respectively, were also observed. However, these transcripts have a considerably lower abundance than the 4.6- and 7-kb mRNAs and are difficult to detect in Fig. 3A. Since transcripts. P and E could clearly be distinguished on the original autoradiograph as well as on autoradiographs that had been exposed for 
prolonged periods of time (data not shown), their positions are indicated with an asterisk in Fig. 3A.

Transcription from the $R 89$ exon-2 region was also found to be complex; as much as five exon 2-specific transcripts were found with lengths of approximately $3.5 \mathrm{~kb}$ (transcript F), $5.5 \mathrm{~kb}$ (transcript G), $7 \mathrm{~kb}$ (transcript $\mathrm{C}$ ), $10 \mathrm{~kb}$ (transcript D) and $>10 \mathrm{~kb}$ (transcript E), respectively (Fig. 3A, lane 8). To determine which of these transcripts represent sense R89 exon 2 mRNAs, we employed a strand-specific (antisense) exon 2 probe. As shown in Fig. 3A (lane 9), only the large, $>10-\mathrm{kb}$ exon 2 transcript hybridized with the strand-specific probe. With regard to the predicted splicing of R89 exon 1 to exon 2, it is possible that the sense, $>10-k b$ exon 2 transcript represents a spliced R89 MRNA, since a transcript of similar length was also detected with the exon 1 probe. It is clear, however, that many putatively overlapping transcripts are generated from both the R89 exon 1 and exon 2 region of the RCMV genome. Although consensus polyadenylation sites $\left(5^{\prime}\right.$-AATAAA- $\left.3^{\prime}\right)$ were not found directly $3^{\prime}$ of R89 exon 2 , predicted transcription initiation sites, as determined by the program 'Promoter Prediction by Neural Network' (21), were identified at $1620,883,653$, and 230 bp upstream of the translation initiation codon of R89 exon 1 . However, the exact termini of the R89 transcripts were not determined experimentally.

RCMV expresses spliced $R 89$ transcripts. To further investigate potential splicing of R89 exon 1 to exon 2, we performed a reverse transcriptase (RT)-PCR assay. This assay was designed such as to amplify the predicted splice junction of exon 1 and 2, yielding a 310 bp fragment. As shown in Fig. 3B, a $0.3-\mathrm{kb}$ fragment was indeed produced (lane 4). The amplification of this fragment was dependent on RCMV infection, since it was only generated with mRNA from RCMV-infected cells and not with mRNA from mock-infected cells (lanes 1 and 2). In addition, the generation of the $0.3-\mathrm{kb}$ fragment depended on the use of reverse transcriptase, indicating that it was derived from MRNA rather than DNA. The fragment was cloned and sequenced, and was found to represent the predicted exon 1 -exon 2 splice junction. The genomic sequences at the exon-intron boundaries were found to read $5^{\prime}$-GAAC-GTGA-3' (at the exon 1 -intron junction) and $5^{\circ}$-GCAG-AGCA-3' (at the intron-exon 2 junction). Like the previously characterized spliced transcripts from the major IE region of RCMV (6), splicing of the R89 transcript conforms to the consensus $5^{\prime}-\mathrm{GT}-1 / 1--\mathrm{AG}-3^{\prime}$ for splice donor and acceptor sites (asindicated in bold print in the junction sequences). The positions of exon 1 and exon 2 within the RCMV genome are listed in Table 1. We conclude that RCMV R89 is a late gene that consists of at least two exons separated by a large intron of $4717 \mathrm{bp}$. Previously, the HSV-1 UL15 gene was reported to be transcribed into a spliced mRNA with a length of $2.7-\mathrm{kb}$ (11). Our data suggest that spliced transcripts from the RCMV homolog of UL15, R89, may be much larger (>10 kb). It is, however, possible that smaller, minor spliced R89 transcripts are also expressed, albeit at a level that does not allow detection by Northern blot analysis.

Transcription of ORF R88. RCMV R88 is a member of a family of conserved betaherpesvirus genes $(10,14,18,20,27)$. Nevertheless, the function 
of any of these genes is yet unknown. To characterize transcripts derived from ORF R88, Northern blot analysis was performed using an R88-specific probe. The genomic position from which this probe was derived is depicted in Fig. 4B. The R88-specific probe (probe 1) reacted with at least five RNA species with lengths of approximately $2.8 \mathrm{~kb}$ (transcript A), $4.5 \mathrm{~kb}$ (transcript B), $7 \mathrm{~kb}$ (transcript $\mathrm{C}$ ), $10 \mathrm{~kb}$ (transcript D) and $>10 \mathrm{~kb}$ (transcript E), respectively (Fig. 4A, lane 2). Of these transcripts, transcript $A$ is most abundantly transcribed. This transcript did not hybridize to any of the other probes used in our study (Fig. 3A and 4), and is therefore likely to be represent a sense R88 mRNA that is transcribed from left to right on the RCMV genome (Fig. 4B). As shown in Fig. 3A, transcripts with lengths similar to those of transcripts $C, D$ and $E$ also hybridized to the R89-specific probes. These transcripts maytherefore contain sequences derived from both R88 and R89. We hypothesize that transcript $E$ represents the putative spliced $R 89$ transcript that was described above. In light of its size $(>10 \mathrm{~kb}$ ), it is not surprising that this transcript also comprises R88 sequences. Neither consensus polyadenylation sites nor predicted transcription initiation sites were identified in the vicinity of the R88 ORF within the RCMV genome.

Table 1

Map locations and features of RCMV ORFS. R88 through R95

\begin{tabular}{|c|c|c|c|c|c|c|c|}
\hline \multirow[t]{2}{*}{ ORF } & \multirow[t]{2}{*}{ Strand } & \multicolumn{2}{|c|}{ Position } & \multirow{2}{*}{$\begin{array}{l}\text { Length } \\
\text { (aa) }\end{array}$} & \multirow{2}{*}{$\begin{array}{l}\text { MM } \\
(\mathrm{kDa})\end{array}$} & \multicolumn{2}{|c|}{ Identity $(\%)$ with } \\
\hline & & From & To & & & MCMV & HCMV \\
\hline R88 & & 118278 & 119582 & 435 & 47.6 & 54.5 (M88) & 28.1 (UL88) \\
\hline $\operatorname{RBgEX2}^{\mathrm{e}}$ & $C$ & 119585 & 120706 & 374 & 42.5 & $89.0(M 89-E \times 2)$ & 69.8 (UL89) \\
\hline r9o & $c$ & 120861 & 121646 & 262 & 27.7 & $21.1(\mathrm{mg})$ & \\
\hline R91 & & 121360 & 122079 & 240 & 24.9 & 33.3 (M91) & 15.8 (UL91) \\
\hline $\mathrm{R} 92$ & & 122079 & 122792 & 238 & 26.2 & $81.2(\mathrm{M} 92)$ & 45.0 (ULS2) \\
\hline R93 & & 1.22758 & 124281 & 508 & 56.3 & 51.1 (M93) & 27.9 (UL93) \\
\hline $\mathrm{R} 94$ & & 124241 & 125269 & 343 & 37.1 & $51.4(\mathrm{M94})$ & 33.0 (UL94) \\
\hline R89EX1 & $\mathrm{C}$ & 125423 & 126310 & 296 & 34.6 & $78.8(M 89-E X 1)$ & 57.4 (UL89) \\
\hline 1295 & & 126309 & 127484 & 392 & 42.7 & 65.5 (M95) & 41.3 (UL95) \\
\hline
\end{tabular}

"Abbreviations and symbols: aa, number of amino acids of the proteins predicted to be encoded by the Corresponding ORFs; $M M$, molecular mass of these proteins. " $\mathrm{A}$ ' $\mathrm{C}^{\prime}$ indicates that the corresponding ORFs run from left to right " "From' RCMV (Maastricht) genome (Vink et al., 2000) (see Fig. 1); other "In columns 'MCMV' and 'HCMV', the porcendicate the limits of the ORFs on the RCMV genome. been determined with amino acid sequentage of identity is shown when significant similarity had respectively; the names of MCMV (Smith) ORFs predicted to be encoded by MCMV or HCMV (Chee et al. 1990) that show similarity with RCMV ORFs al., 1996) and HCMV (AD169) ORFs identity was determined by using the alignment prov OR.Fs are shown in brackets. The percentage of R89 exon 1 (R89 EXI) and exon 2. (R89 EX2) molecular mass of $70.1 \mathrm{kDa}$. 
Transcription of ORFS 190 and R91. As with R88, the functions of (homologs of) ORFs 190 and R91 have not yet been established. As shown in Fig. $4 \mathrm{~A}$, the use of the r90-specific probe (probe III) resulted in a high level of nonspecific hybridization. This was inferred from the reactivity of this probe with mRNA purified from mock-infected cells (lane 3). The relatively poor quality of probe III was likely caused by a combination of the labeling procedure (random priming) and the small size of the DNA fragment used for labeling (107 bp). Nevertheless, three RCMVspecific transcripts of approximately 2.2 (transcript $H$ ). 3.0 (transcript 1) and $4.8 \mathrm{~kb}$ (transcript J) could be detected with the r90 probe (lane 4). A transcript of similar length as transcript I was also seen after hybridization with the R91 probe (probe IV), suggesting that this MRNA species comprises both $r 90$ and R91 sequences (lane 6 ). With regard to their lengths, the 190- and R91-derived transcripts were also expected to contain sequences from adjacent ORFs. However, none of the other ORF-specific probes appeared to hybridize to transcripts of lengths similar to that of the r90-and R91 transcripts, indicating that transcript $\mathrm{H}, \mathrm{I}$ and $\mathrm{J}$ may be spliced. We did not find either consensus polyadenylation sites or predicted transcription initiation sites near ORFs r90 and R91, which is in agreement with the putative spliced nature as well as lengths of transcripts derived from these ORFs.

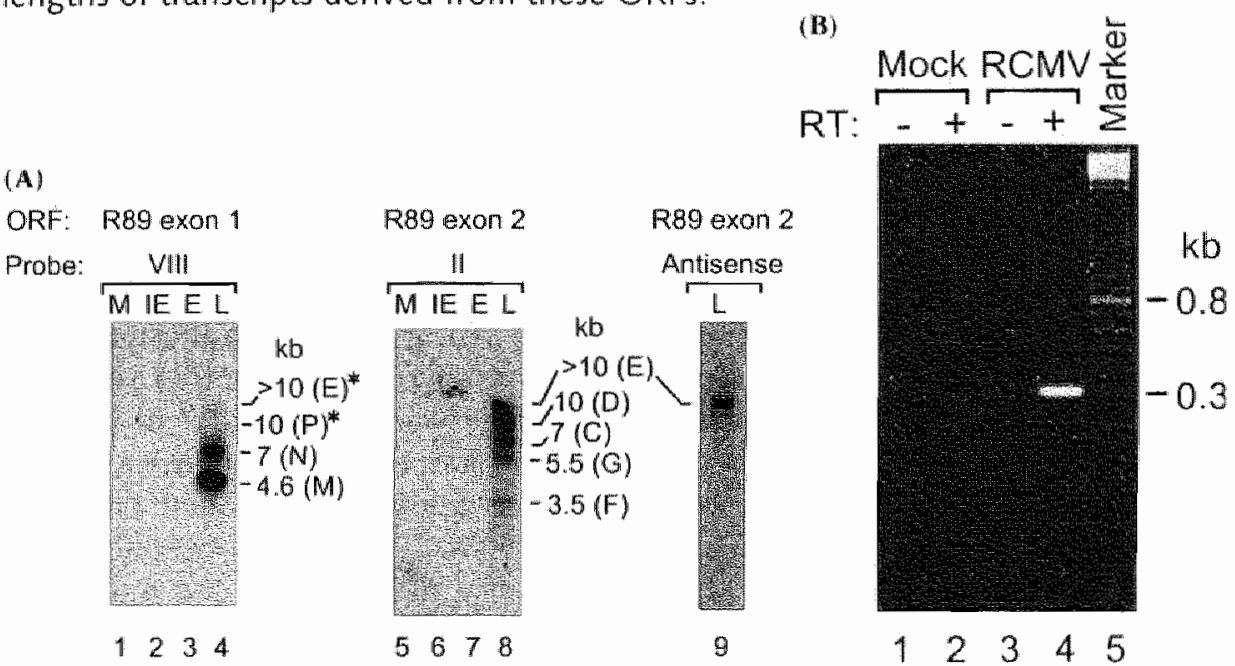

Fig. 3. Expression and splicing of RCMV R89 mRNA. (A) Autoradiographs of Northern blots that were hybridized with either an R89 exon 1-specific probe (probe VIII, lanes 1-4) or an exon 2-specific probe (probe II; lanes 5-8). The MRNA was purified from mock-infected REFs (M) or RCMV-infected REFs, either at immediate early (IE), early (E) or late (L) times p.i., as indicated above the lanes. Lane 9 is similar to lane 8 , but instead was generated using a strand-specific (Antisense) R89 exon 2 probe. The approximate lengths of transcripts are shown on the right of each panel (in kb): the capital letters in brackets refer to transcripts drawn schematically in Fig. 4B. The transcripts marked with an asterisk (*) are clearly visible on the original autoradiographs, although they can hardly be seen on the photograph. (B) The R89 transcript is spliced. A photograph is shown of an ethidium bromide-stained agarose gel on which the products of RT-PCR were separated. RT-PCR was carried out on mRNA from either mock- (Mock) or RCMV (RCMV)-infected REFs at late times p.i.., as described in Section 2. The procedure was carried out either with $(+R T)$ or without $(-R T)$ incubation with reverse transcriptase, as indicated above the lanes. Lane 5 (Marker) contains a molecular mass reference (100-bp marker). The lengths of marker fragments are shown on the right in $\mathrm{kb}$. The arrow on the left points to the $0.3 \mathrm{~kb}$ RT-PCR product that represents the $R 89$ exon 1 -exon 2 splice junction fragment (see text). 
Transcription of ORFS R92 through R94. As described above, RCMV ORF $\mathrm{R} 92$ has homologs in the betaherpesvirus as well as gammaherpesvirus subfamilies. ORFs R93 and R94 are conserved among all herpesvirus family members, representing the homologs of HSV-1 UL17 and UL16, respectively. Although the function of UL16 and its homologs is yet enigmatic, UL17 was reported to be essential for virus replication by playing a role in the cleavage and packaging of viral DNA (22). We identified three major R92 transcripts (Fig. 4A, lane 8). Two of these, transcript $M$ (approximately $4.6 \mathrm{~kb}$ ) and $N$ (approximately 7 $\mathrm{kb})$, also appeared to react with probes generated from ORFs R93, R94, R98 exon 1 and R95 (Fig. 3A, lane 4; Fig. 4A lanes 10, 12 and 14). On the basis of the orientation of ORFs R93 through R95, we hypothesize that these partly overlapping mRNAs are transcribed from left to right on the RCMV genome (Fig. $4 \mathrm{~B}$ ). The other major transcript (transcript $\mathrm{K}$ ) has an estimated length of $2.9 \mathrm{~kb}$. Since transcripts of similar length were not observed with probes other than the R92 probe, it is likely that transcript $K$ represents a spliced transcript. However, this was not investigated further. Although two putative transcription initiation sites were predicted within the R92 ORF, between the position of the R92 probe and the R93 translational start, such sites were not predicted immediately $5^{*}$ of the R92 ORF.

A minor $3.6-\mathrm{kb}$ transcript (transcript $L$ ) was observed with probes derived from ORFs R92, R93 and R94, respectively (Fig. 4A, lanes 8, 10, and 12). Given the orientation of $R 92$ through $R 94$, we predict this mRNA species to be transcribed from left to right on the viral genome, and to contain complete ORFs R92, R93 and R94 (Fig. 4B). Another mRNA that is likely to be transcribed from left to right is transcript $O$ (Fig. $4 \mathrm{~B}$ ). This transcript has a length of approximately $2.0 \mathrm{~kb}$ and hybridizes with the R94-specific probe (Fig. 4A, lane 12) and also, albeit weakly, with the R93-specific probe (lane 10). It is probable that transcript O contains the complete R94 coding region, but only part of the R93 sequence (Fig. 4B). Interestingly, four transcription start sites were predicted $5^{\prime}$ of the R94 ORF, at a distance of $1171,954,444$ and $436 \mathrm{bp}$, respectively, from the R94 start codon. The latter two transcription initiation sites, which are positioned within the R93 probe sequence, share a TATA box (5'-TATATAA-3') which is located 16 and $24 \mathrm{bp}$, respectively, upstream of the predicted first nucleotide of the transcripts. The position of these theoretical initiation sites is in agreement with the length of transcript $O$ as well as the level of hybridization of this transcript with the R93 and the R94 probes (compare lanes 10 and 12). In addition, a consensus polyadenylation site (5'-AATAAA-3') is present 35 bp downstream of the R94 stopcodon. As indicated in Fig. 4B, this polyadenylation site may define the $3^{\prime}$ ends of both transcript $O$ and transcript $L$. Transcripts with a similar structure as transcripts $O, L$ and $M$ have previously been identified in studies on transcription of the HSV-1 UL15-UL17 genes (Costa et al., 1985) and the HCMV UL93-UL99 genes (29). Like R94, HSV-1 UL17 and HCMV UL94 were found to be transcribedboth mono- and polycistronically. Remarkably, an HCMV UL94 transcript was previously identified with a length similar to that of R94 transcript $O$ $(2.0 \mathrm{~kb})(29)$. The cap site of the UL94 transcript was mapped $30 \mathrm{bp}$ downstream of a consensus TATA element and approximately 300 bp upstream of the 

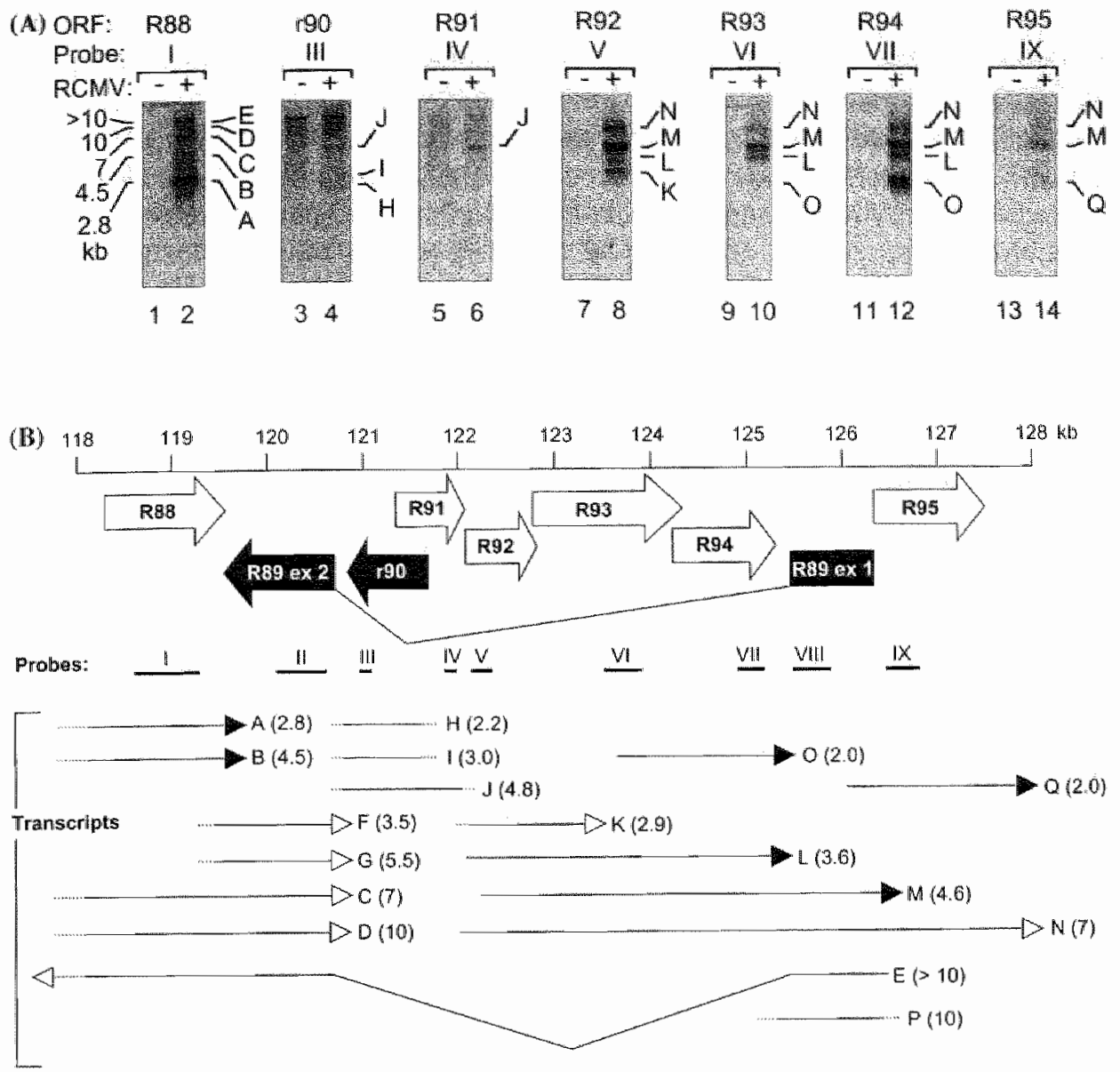

Fig. 4. Transcription of genes neighboring RCMV R89. (A) Autoradiographs of Northern blots that were hybridized with probes (probes I, III to VII and IX) that were deriwed from either ORF RB8, 190 or R91 through R95. In the odd-numbered lanes, mRNA purified from mock-infected REFs (-) was separated, whereas in the even-numbered lanes, mRNA from RCMV-infected REFs at late times p.i. (DD) was separated. The numbers of the probes, and ORFs from which these probes were derived are shown above the autoradiographs. The position of each probe is depicted in (B). On the left, sizes of transcripts are indicated in $\mathrm{kb}$. Each of the major transcripts are noted with a capital letter, which refers to the traniscripts drawn schematically in (B). (B) The position of probes and transcripts derived from ORFS R88 through R95. The schematical drawing of ORFs R88 through R95 is similar to that shown in Fig. 1. The position of each probe is depicted with a bar, accompanied by the name of the probe. Transcripts are shown either as arrows (when their orientation was predicted) or as a line (when their orientation was not predicted). Open arrowheads as well as interrupted lines indicate that the ( $3 \%$ or $5 \%$ ) end of a transcript could not be determined. For example, transcript $H$ has a length of approximately $2.2 \mathrm{~kb}$, but was found to hybridize exclusively to probe 111 . Since the probes that are adjacent to probe III (probe II and IV) are less than $1.5 \mathrm{~kb}$ apart, it could be expected that these probes would also hybridize to transcripts hybridizing to probe 111 . Because this is not the case, egr. due to splicing, the exact boundaries of transcript $H$ could not be predicted. Transcripts that appear to extend outside the R88-R95 region of the RCMV genome are also shown as either interrupted lines ar arrows with open arrowheads. 
predicted U194 start codon. This cap site corresponds with the predicted transcription start of R94 transcript O. Another apparent similarity between R94 and UL94 is the presence of a consensus polyadenylation signal immediately downstream of these ORFs (29).

HCMV has previously been reported to express polycistronic mRNAs of 4.4 and $5.0 \mathrm{~kb}$, which contain sequences of UL92, UL93 and UL94 (Wing and Huang, 1995). These transcripts are likely to have a similar structure as the polycistronic transcripts $L$ and $M$ of RCMV (Fig. 4B). HCMV and RCMV further correspond in expressing large mRNAs that start in the vicinity of the UL92/R92 ORFs and extend several kb's downstream of the UL95/R95 ORFs.

Transcription of ORF R95. As mentioned before, R95 sequences were represented in at least two RCMV transcripts (transcripts $M$ and $N$ ) spanning various ORFs. In addition, an R95-specific mRNA of approximately $2.0 \mathrm{~kb}$ was

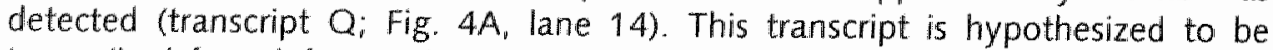
transcribed from left to right on the viral genome, since a transcription initiation site was predicted at 324 bp upstream of the R95 startcodon, with a TATA box sequence $\left(5^{\circ}\right.$-TATATAAAT $\left.-3^{\prime}\right)$ located 24 bp upstream of the predicted first nucleotide of the mRNA. A cap site similar to that predicted for $\mathrm{R} 95$ has previously been mapped for HCMV UL95, at approximately 473 bp upstream of the UL95 start codon (29). However, unlike UL95, R95 was found to have a consensus polyadenylation site ( $5^{\prime}$-AATAAA-3') positioned $418 \mathrm{bp}$ downstream of the R95 stopcodon. This difference between R95 and UL95 may explain why HCMV transcripts with a similar size as the $2.0-\mathrm{kb}$ R95 transcript (transcript Q) were not detected (29).

\section{Discussion}

In this study, we have shown that of all RCMV genes, R89 has the highest level of similarity with its counterparts from the other sequenced herpesviruses. We have also demonstrated R89 to be transcribed into an MRINA that is spliced in a similar fashion as its homolog from HSV-1 (UL15) (11, 13). Thus, the betaherpesvirus $R 89$ gene not only conserves primary sequence, but also genomic structure with its counterpart from the alphaherpesvirus HSV-1. In light of the similarities between R89 and UL15, it is possible that R89 plays an essential role in viral replication, similarly as has been demonstrated for $\operatorname{UL} 15(4,5,30)$.

The R89 gene was found to contain five additional ORFs within its intron. Two of these, R93 and R94, are conserved among all herpesviruses, illustrating the importance of these genes in herpesvirus biology. In agreement with this, the HSV-1 counterpart of R93, UL17, was shown to be essential for viral replication, and, like UL15, play a role in viral DNA maturation (22). The function of yet unknown.

The overall structure of the RCMV genomic region containing ORFs R89 through $\mathrm{R} 95$ is very similar to that of the corresponding regions of both MCMV (Rawlinson et al., 1996) and HCMV (Chee et all., 1990). Nevertheless, HCMV 
differs from the rodent CMVs by not having a counterpart of RCMV ORF r 90 . since a considerable part of the r90 ORF (36.5\%) overlaps with ORF R91, which is conserved among all sequenced betaherpesviruses, it is questionable whether $r 90$ is actually protein-coding. Nevertheless, the MCMV homolog of $\mathrm{r} 90, \mathrm{m90}$, which overlaps by $21.8 \%$ with $M 91$, was classified as a potential membrane glycoprotein gene on the basis of sequence alignments (20). The question whether ORFs are protein-coding or not will have to be determined experimentally, for instance by using antibodies directed against the predicted polypeptides.

We have investigated the expression of transcripts from the $R 89$ region of the RCMV genome by Northern blot analysis, and demonstrated the synthesis of a complex set of mRNAs, including various polycistronic transcripts. It is likely that this complex pattern of transcription is caused by the relatively tight packing of ORFs within the R88-R95 genomic region as well as the opposite orientation of the $R 89$ exons with respect to most of the neighboring ORFs. It is clear, however, that a complete understanding of the transcriptional program of the RCMV R88R95 genomic region will require the use of numerous strandspecific probes, mapping of the $5^{\prime}$ and $3^{\prime}$ termini of all identified transcripts, elucidation of the kinetics of transcription of these mRNAs, and also detection of the polypeptides that they may encode.

\section{Acknowledgements}

We thank Rien Blok for critically reading the manuscript.

\section{References}

1. Addison C, Rixon FJ, Palfreyman JW, O'Hara M, Preston VG. (1984). Characterisation of a herpes simplex virus type 1 mutant which has a temperature-sensitive defect in penetration of cells and assembly of capsids. Virology 138, 246-259.

2. Addison C, Rixon FJ, Preston VG. (1990). Herpes simplex virus type 1 UL28 gene product is important for the formation of mature capsids. $\%$ Gen. Virol 71, 2377-2384.

3. al-Kobaisi MF, Rixon FJ, McDougall I, Preston VG. (1991). The herpes simplex virus UL33 gene product is required for the assembly of full capsids. Virology 180, 380-388.

4. Baines JD, Cunningham $C$, Nalwanga D, Davison A. (1997). The U(L)15 gene of herpes simplex virus type 1 contains within its second exon a novel open reading frame that is translated in frame with the $U(L) 15$ gene product. J. Virol. 71, 2666-2673.

5. Baines JD, Poon AP, Rovnak J, Roizman B. (1994). The herpes simplex virus 1 UL15 gene encodes two proteins and is required for cleavage of genomic viral DNA. J. Virol. 68, 8118-8124. 


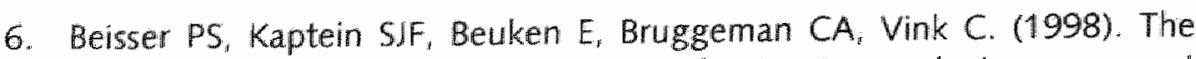
Maastricht strain and England strain of rat cytomegalovirus represent different Betaherpesvirus species rather than strains. Virology 246, 341351.

7. Beisser PS, Vink C, van Dam IG, Grauls G, Vanherle SIV, Bruggeman CA. (1998). The R33 G protein-coupled receptor gene of rat cytomegalovirus plays an essential role in the pathogenesis of viral infection. /. Virol. 72 , 2352-2363.

8. Brown T. Mackey K. (1997). Analysis of RNA by Northern and slot blot hybridization. In: Ausubel FM, Brent R, Kingston RE, Moore DD, Seidman $J G$, Smith JA, Struhl K. (Eds.), Current Protocols in Molecular Biology. Wiley, New York, pp. 491-4916.

9. Bruggeman CA, Meijer H, Bosman F, van Boven CPA (1985). Biology of rat cytomegalovirus infection. Intervirology 24, 1-9.

10. Chee MS, Bankier AT, Beck S. (1990). Analysis of the protein-coding content of the sequence of human cytomegalovirus strain AD169. Curr. Top. Microbiol. Immunol. 154, 125-169.

11. Costa RH, Draper KG, Kelly TJ, Wagner EK. (1985). An unusual spliced herpes simplex virus type 1 transcript with sequence homology to Epstein-Barr virus DNA. /. Virol. 54, 317-328.

12. Davison AJ. (1992). Channel catfish virus: a new type of herpesvirus. Virology 186, 9-14.

13. Dolan A, Arbuckle M, McGeoch DJ. (1991). Sequence analysis of the splice junction in the transcript of herpes simplex virus type 1 gene UL15. Virus Res. 20, 97-104.

14. Gompels UA, Nicholas J, Lawrence G, et al. (1995). The DNA sequence of human herpesvirus-6: structure, coding content, and genome evolution. Virology 209, 29-51.

15. McGeoch DJ, Dalrymple MA, Davison $\mathrm{Al}_{\mathrm{r}}$, et al. (1988). The complete DNA sequence of the long unique region in the genome of herpes simplex virus type 1. \%. Gen. Virol 69, 1531-1574.

16. Meijer $H_{4}$ Dreesen JC, Van Boven CP. (1986). Molecular cloning and restriction endonuclease mapping of the rat cytomegalovirus genome. J. Gen. Virol. 67. 1327-1342.

17. Myers $E$, Miller W. (1988). Optimal alignments in linear space. CABIOS 4, $11-17$.

18. Nicholas J. (1996). Determination and analysis of the complete nucleotide sequence of human herpesvirus 7. J. Viro/. 70, 5975-5989.

19. Poon AP, Roizman B. (1993). Characterization of a temperature-sensitife mutant of the UL15 open reading frame of herpes simplex virus 1.1 . Virol. $67.4497-4503$.

20. Rawlinson WD, Farrell HE, Barrell BG. (1996). Analysis of the complete DNA sequence of murine cytomegalovirus. \%. Virol. 70, 8833-8849.

21. Reese $M G$. Harris NL, Eeckman FH. (1996). Large scale sequencing specific neural networks for promoter and splice site recognition. In: 


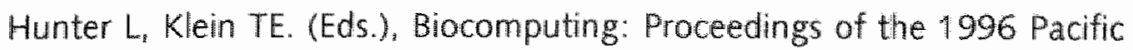
Symposium. World Scientific Publishing, Singapore.

22. Salmon $B$, Cunningham $C_{r}$ Davison AJ, Harris WI, Baines JD. (1998). The herpesvirus 1 UL 17 gene encodesvirion tegument proteins that are required for cleavage and packaging of viral DNA. / Virol. 72,3779 3788.

23. Sherman G, Bachenheimer $S L$, (1987). DNA processing in temperaturesensitive morphogenic mutants of HSV-1. Virology 158, 427-430.

24. Sherman $G_{r}$ Bachenheimer SL. (1988). Characterization of intranuclear capsids made by ts morphogenic mutants of HSV-1. Virology 163, 471480.

25. Tengelsen LA, Pederson NE, Shaver PR, Wathen MW, Homa FL. (1993). Herpes simplex virus type 1 DNA cleavage and encapsidation require the product of the UL28 gene: isolation and characterization of two UL28 deletion mutants. 1. Virol. 67, 3470-3480.

26. Thompson JD, Higgins DG, Gibson TJ. (1994). CLUSTAL W: improving the sensitivity of progressive multiple sequence alignment through sequence weighting, positions-specific gap penalties and weight matrix choice. Nucleic Acid's Res. 22, 4673-4680.

27. Vink C, Beuken E, Bruggeman CA. (2000). The complete DNA sequence of the genome of rat cytomegalovirus. 1. Virol. 74:7656-65.

28. Weller SK, Carmichael EP, Aschman DP, Goldstein DJ, Schaffer PA. (1987). Genetic and phenotypic characterization of mutants in four essential genes that map to the left half of HSV-1 UL DNA. Virology 161, 198-210.

29. Wing BA, Huang ES, (1995). Analysis and mapping of a family of $3^{3}$ coterminal transcripts containing coding sequences for human cytomegalovirus open reading frames UL93 through UL99. 1. Virol. 69, $1521-1531$.

30. Yu D, Sheaffer AK, Tenney DJ, Weller SiK. (1997). Characterization of ICP6: lacZ insertion mutants of the UL15 gene of herpes simplex virus type 1 reveals the translation of two proteins. J. Virol. 71, 2656-2665.

31. Yu D, Weller SK. (1998). Genetic analysis of the UL15 gene locus for the putative terminase of herpes simplex virus type 1. Virology 243, 32-44. 
GPCRs encoded by members of the CMV UL33 gene family 


\section{CHAPTER 2}

Herpesvirus-Encoded G Protein-Coupled Receptors:

Immunomodulators, Stimulators of Viral Replication, or Directors of Movement?

In: Progress in Protein Research (2004)

F. Columbus (Ed.) Nova Science Publishers Inc. NY USA in press 


\section{Herpesviruses and $G$ protein-coupled receptors}

\subsection{The Herpesviridae}

Herpesviruses are large, double-stranded DNA viruses which are highly disseminated in nature. Most animal species are known to yield at least one herpesvirus and at present eight distinct human herpesviruses (HHVs) have been isolated: herpes simplex virus 1 (HSV-1 or HHV-1), herpes simplex virus 2 (HSV-2 or HHV-2), varicella-zoster virus (VZV or HHV-3), Epstein-Barr virus (EBV or HHV4), human cytomegalovirus (HCMV or HHV-5), HHV-6, HHV-7 and Kaposi"s sarcoma-associated herpesvirus (KSHV or HHV-8).

All herpesviruses share a common architecture of the virion. A typical herpesvirus virion consists of an icosahedrical capsid of approximately $100-110 \mathrm{~nm}$ in diameter containing the linear DNA genome. The size of the genomic DNA is variable and ranges from approximately $120 \mathrm{~kb}$ for $V Z V$ to approximately $240 \mathrm{~kb}$ for HCMV. The herpesvirus capsid is surrounded by an asymetrically-distributed, amorphous structure, which has been designated the tegument or matrix. The outer layer of the virion is formed by the envelope which contains various viral glycoproteins.

On the basis of genomic sequences and biological properties, the family of Herpesviridae can be divided in three distinct subfamilies, the Alpha- , Beta- and Gammaherpeswirinae. Despite the differences between individual members of the herpesvirus family with respect to host range, cellular tropism, time course of lytic replication and pathology, all family members share significant biological properties. For example, all herpesviruses specify a large array of enzymes which are involved in nucleic acid metabolism and synthesis of (viral) DNA and proteins. In addition, the assembly of newly synthesized herpesvirus capsids takes place in the rucleus. Each herpesvirus irreversibily destructs the infected cell as infectious progeny virus is produced during lytic replication. Finally, all herpesviruses are able to establish life-long, latent infections in their hosts during which only a few viral genes are expressed.

The ability to establish latent infections is likely the result of a long coevolution of herpesviruses and their hosts. These viruses represent the evolutionary oldest group of animal viruses and phylogenetic analysis of genes conserved among different herpesvirus species indicated that the three herpesvirus subfamilies arose 180 to $220 \mathrm{My}$ ago (53). As a consequence of this long-lasting relationship with their hosts, herpesviruses have developed a high level of adaptation to their host's immune system, which is exemplified by the wide range of sophisticated strategies that herpesviruses use to subvert anti-viral charges by the immune system. Various immunological and biochemical processes such as apoptosis, antigen presentation by major histocompatibility complex (MHC) molecules, and interferon and chemokine signaling pathways, are corrupted by herpesviruses (for a recent review, see 2). The viral proteins that distort these processes can be divided into two subsets. One subset includes molecules with structures that are unrelated to cellular host proteins, such as ICP47 of the HSV's 
which inhibits intracellular peptide transporters, crucial for antigen presentation $(42,30)$. The other subset includes viral proteins that are mimics or homologs of cellular host proteins, such as BCRF1, the IL-10 homolog of EBV (91). These viral mimics probably represent host genes that have been hijacked during ancestral virus infections. Over time, these genes have evolved under various selection pressures and have become well adapted to subserve the needs of the infecting virus. The largest known class of host-related, viral immunomodulatory genes is represented by mimics of either chemokines or chemokine receptors, which belong to the superfamily of $G$ protein-coupled receptors (GPCRs). In light of the crucial function of GPCRs in communication between the extracellular and intracellular milieu, we will focus in this chapter on the putative functions of the herpevirusencoded GPCRs in the pathogenesis of viral infection.

Tabel 1. Herpesvirus genes encoding (putative) GPCRs

\begin{tabular}{|c|c|c|c|c|c|c|c|c|c|}
\hline \multirow{2}{*}{$\begin{array}{l}\text { herpesvins } \\
\text { subfamily } \\
\gamma \text {-herpesviruses }\end{array}$} & \multirow{2}{*}{\begin{tabular}{|l} 
gencrs \\
othadinovir uses \\
Iymphocryptoviruses \\
\end{tabular}} & \multirow{2}{*}{$\begin{array}{l}\text { vinus } \\
\text { KSHV } \\
\text { HVS } \\
\text { RRV } \\
\text { YHV68 } \\
\text { EHV-2 } \\
\text { EBV }\end{array}$} & \multicolumn{7}{|c|}{ gene family } \\
\hline & & & $\begin{array}{l}\text { ORF74 } \\
\text { ECRF3 } \\
\text { ORF74 } \\
\text { ORF74 } \\
\text { ORF74 }\end{array}$ & $\begin{array}{l}\text { E6 } \\
\text { BILF1 } \\
\end{array}$ & E1 & & & & \\
\hline p-herpesviruses & $\begin{array}{l}\text { cytamegalowiruses. } \\
\text { roseolaviruses }\end{array}$ & $\begin{array}{l}\text { HCMV } \\
\text { RCMV } \\
\text { MCMV } \\
\text { HHVEA } \\
\text { HHV6B } \\
\text { HHV-7 }\end{array}$ & & & & US 28 & US 27 & $\begin{array}{l}\text { U.33 } \\
R 33 \\
M 33 \\
U 12 \\
U 12 \\
W 12\end{array}$ & $\begin{array}{l}\text { UL78 } \\
R 78 \\
\text { M78 } \\
\text { U51 } \\
\text { U51 } \\
\text { U51 }\end{array}$ \\
\hline
\end{tabular}

\section{$1.2 \mathrm{G}$ protein-coupled receptors}

GPCRs are members of a large and functionally diverse superfamily of transmembrane receptors that play a fundamental role in cellular communication. The genes encoding GPCRs represent the single largest gene family, with likely more than 1000 members in the human genome. Beside the thousands of GPCR genes that have currently been identified in the genomes of both eukaryotes and prokaryotes, GPCR genes have also been found in the genomes of poxviruses and herpesviruses.

GPCRs are composed of a central core domain consisting of seven transmembrane (7-TM) helices (TM I through VII) connected by three intracellular (i1, i2, and i3) and three extracellular (e1, e2, and e3) loops. The majority of these receptors are activated after binding of an extracellular stimulus. This stimulus can be as diverse as organic odorants, lipids, nucleotides, nucleosides, peptides, proteins and photons. Upon activation, the GPCR undergoes a conformational change which allows it to interact with intracellular GTP-binding proteins (G 
proteins). Through this interaction a GPCR may modulate a wide variety of intracellular signaling cascades, depending on which class(es) of $G$ protein it activates.

At present, four main classes of $G$ proteins are known: the $G_{q / 1,}, G_{s,} G_{i / 0}$ and $G_{1 / 1}$ class. Upon activation by a GPCR, G proteins dissociate into an a and $a$ By subunit and each subunit is able to initiate or modulate specific intracellular signaling pathways. For example, the a subunits of the $G_{q / 1}$ class of $G$ proteins stimulate phospholipase C (PLC). Subsequently, this stimulation results in a rise of intracellular inositol phosphates (nsP) which is often followed by calcium mobilization from intracellular stores, as well as diacylglycerol (DAG), which in turn stimulates protein kinase $C(P K C)$. The $\alpha$-subunits of $G_{s}$ and $G_{1}$ proteins on the other hand, modulate the activity of adenylate cyclase (AC). By either stimulating $\left(G \alpha_{5}\right)$ or inhibiting ( $\left.G \alpha_{i / O}\right)$ AC. intracellular CAMP levels are increased or decreased, respectively, resulting in modulation of the levels of the transcription factor CREB (CAMP responsive element binding protein). The a subunits of $G_{12 / 33}$ proteins, activate another GTP-binding protein, RhoA, which may stimulate various intracellular mitogen-activated protein kinases (MAPKs). The $\beta \gamma$ subunits modulate various signaling routes mediated by $\mathrm{PLC}, \mathrm{Pl}_{3} \mathrm{~K}$ and $\mathrm{RhoA}$. Besides this well known classical signaling through $G$ proteins, GPCRs may activate a variety of other, less well-defined, signal transduction pathways.

A separate group among the GPCRs is formed by the chemokine receptors. These receptors were initially identified on the surface of inflammatory cells as proteins that bind and initiate chemotactic responses to inflammatory chemotactic cytokines (44). Chemokine receptors are expressed on a wide range of leukocytes, as well as on endothelial cells, neurons and possibly other cell types. These receptors are thought to function in signaling pathways leading to degranulation, lymphocyte homing, T-cell activation, mitogenic effects, hematopoiesis and chemotaxis in addition, chemokine receptors have been identified as co-receptors for cellular entry of primate lentiviruses, such as human immunodeficiency virus (HIV) $(9,60,80)$.

The ligands of chemokine receptors, i.e. the chemokines, constitute a large superfamily of chemoattractant cytokines that play a role in inflammatory reponses against various pathogens. They can modulate the movement of peripheral blood leukocytes by stimulating chemotaxis, leukocyte adhesion and transmigration. through their chemokine receptors. Chemokines are classified into four groups according to the position of the conserved cysteine (C) residues within their predicted amino acid sequences. The first group consists of the $\alpha$ chemokines, which have an intervening non-conserved amino acid residue $(X)$ between the first and second conserved $C$ residue and are therefore also nominated as CXCLS (in which the $\mathrm{L}$ stands for ligand). The chemokine receptors binding CXCLs are known as $\alpha$ chemokine receptors or CXCRs. The second group comprises the $\beta$ chemokines, which contain two adjacent, conserved $C$ residues. Correspondingly, they are also termed CCLs and their receptors $\beta$ chemokine receptors or CCRs. The members of the third chemokine dass, the $\gamma$ chemokines or CLs, only comprise a single conserved $C$. Likewise, their receptors are termed CRS or $\gamma$ chemokine receptors. The chemokines from the fourth class contain three intervening, non- 
conserved amino acids between the first two conserved $C s$ and are thus called $C X_{3} C L S$ or $\delta$ chemokines. The $\delta$ chemokine receptors binding these proteins are denoted $\mathrm{CX}_{3} \mathrm{CRs}$.

\section{Gammaherpesvirus homologs of $\mathrm{G}$ protein-coupled receptors}

\subsection{Gammaherpesviridae}

The members of the family of Gammaherpesvirinae are also known as lymphoproliferative herpesviruses because of their transforming abilities in lymphoblastoid cells. The Gammaherpesvirinae family can be subdivided into the family of lymphocryptoviruses, or gamma-1-herpesviruses and the family of rhadinoviruses, or gamma-2-herpesviruses. EBV, the common representative of the lymphocryptoviruses, is frequently associated with infectious mononucleosis disease and, to a lesser extent, with nasopharyngeal carcinomas as well as lymphomas such as Burkitt's, Hodgkin's, T and B cell lymphomas.

The family of rhadinoviruses includes HHV-8, herpesvirus saimiri (HVS), murine gammaherpesvirus 68 ( $\gamma H V 68$ ), equine herpesvirus 2 (EHV2) and rhesus rhadinovirus (RRV). HHV-8 is better known as Kaposi's sarcoma-associated virus (KSHV) because of its implication in the development of Kaposi's sarcoma (KS). Apart from its presence in various forms of KS, KSHV has also been detected in a rare subset of malignant lymphomas like primary effusion lymphoma (PEL) and in a significant percentage of patients with multicentric Castleman's disease. The genomes of the members of the lymphocrypto- as well as the rhadinoviruses contain many genes with oncogenic potential. Among these genes are those encoding homologs of cellular chemokine receptors, like the KSHV GPCR encoded by open reading frame (ORF) 74 and the EBV GPCR encoded by ORF BILF1.

\subsection{The KSHV ORF74-encoded G protein-coupled receptor family}

ORF74 of KSHV (18) is well-conserved among the genomes of all known members of the rhadinovirus family, including HVS (ECRF3; 1,67$)$. EHV-2 (ORF74; 13, 89), RRV (ORF74; 26), and $\gamma H$ HV86 (ORF74; 50, 61, 78, 95) (Table 1). The HVS ECRF3-encoded receptor was the first viral GPCR to be functionally characterized as a calcium-mobilizing receptor, responding to chemokines such as IL-8 (CXCL8), GROa (CXCL1) and NAP-2 (CXCL7) (Table 2; 1, 67). At present, however, the KSHV ORF74-encoded GPCR is the best-known representative of this GPCR family. Initially, KSHV ORF74 was identified as an HVS ECRF3 homolog on cloned KSHV DNA fragments, which were isolated from Kaposi's sarcoma (KS) and primary effusion lymphoma (PEL) specimens from KSHV-infected individuals (18). Later studies confirmed that KSHV ORF74 was transcribed during lytic replication of the virus and that transcripts were detectable in virus-infected 
lymphoid cells as well as in KS, PEL and other lymphoma tissues $(22,40,47,64)$. In these tissues, the KSHV ORF74 gene is expressed predominantly as a bicistronic transcript which also comprises the K14 ORF. ORF74 is also transcribed, albeit at low levels, as a monocistronic transcript, which only contains the ORF74 coding sequence (64).

Like the HVS ECRF3 GPCR, the KSHV GPCR is a functional chemokine receptor that is able to bind a broad range of CXCLS: GROa (CXCL1), MGSA (KC,

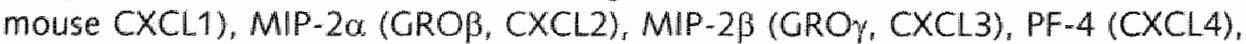
ENA78 (CXCL5), NAP-2 (CXCL7), IL-8 (CXCL8), IP-10 (CXCL10), and SDF-1 $\alpha$ (CXCL12) $(4,33,35,36,79$; Table 2). In addition, the KSHV GPCR was found to activate multiple intracellular signaling pathways in a ligand-independent, constitutive fashion in various cell types, as depicted schematically in Figure 1 ( 4 , $5,23,51,59,62,71,72,82,83,84,85)$. Among the signaling molecules that are constitutively activated by the KSHV GPCR are $G$ proteins of the $G_{0 / 11}, G_{i / 0}$ and $G_{13}$ class $(4,23,59,83,84)$. Although the exact signaling pathways that are activated may vary depending on the cell type in which the KSHV GPCR is expressed, several prominent characteristics of constitutive KSHV GPCR signaling have been delineated. One of these is the ligand-independent activation of PLC $(4,5)$, which leads to a rise in intracellular InsP levels as well as the activation of PKC (Figure 1). In addition, more downstream signaling molecules such as protein kinase $B$ (AKT) and $\mathrm{p44/42MAPK}$ can be activated (84). As a result of the continuous stimulation of PLC, intracellular calcium stores can become depleted, causing both homologous as well as heterologous desensitization of responses through calciummobilizing receptors (51)

Other signaling pathways which have been demonstrated to be activated by the KSHV GPCR in a constitutive fashion are the Go13-RhoA and the pertussis toxin (PTX)-sensitive $\mathrm{G}_{i / 0^{-}}$AC-CAMP axis, as depicted in Figure $1(23,83)$. In addition, the free $\beta \gamma$ subunits of the KSHV GPCR-activated G proteins, stimulate the $\mathrm{PI}_{3} \mathrm{~K}-\mathrm{AKT}$ signaling axis in a constitutive manner $(59,72)$. It has become apparent that the different KSHV GPCR-activated signaling routes often converge at certain downstream molecules such as protein kinases and transcription factors (Figure 1). Among the protein kinases that have been found to be constitutively activated by the KSHV GPCR, albeit often through different signaling routes, are AKT, p38MAPK, P44/42MAPK, ERK2, RAFTK (pyk2), JNK/SAPK and lyn kinase $(5,14,59,62,72,84)$. Transcription factors that have been shown to be activated in KSHV GPCR-expressing cells are NF-KB, AP-1, NFAT, CREB and hypoxia inducable factor 1a (HIF-1a) $(4,14,59,62,71,72,82,83,85)$. Again, this (in)activation of different transcription factors by the KSHV GPCR may result from multiple and sometimes different, cell type-dependent signaling cascades.

interestingly, constitutive signaling by the KSHV GPCR is modulated through binding of various chemokines $(23,33,34,35,36,51,59,62,79,72$, 84). In general, GRO $\forall$ acts as an agonist and thus enhances the KSHV GPCRmediated intracellular responses $(23,36,79,72)$, whereas $I P-10$ functions as an inverse agonist by inhibition of these responses $(23,35,5 \%, 62,79,59,84)$. In addition, IL-8, MIP-2 $\alpha$, MIP-2 $\beta$, ENA78 and NAP2 have been shown to behave as (partial) agonists, whereas SDF-1 $\alpha$ as well as the KSHV-encoded chemokine 
VMIPII act as inverse agonists on certain KSHV GPCR-mediated signaling pathways (Table 2) $(33,36,59,79)$.

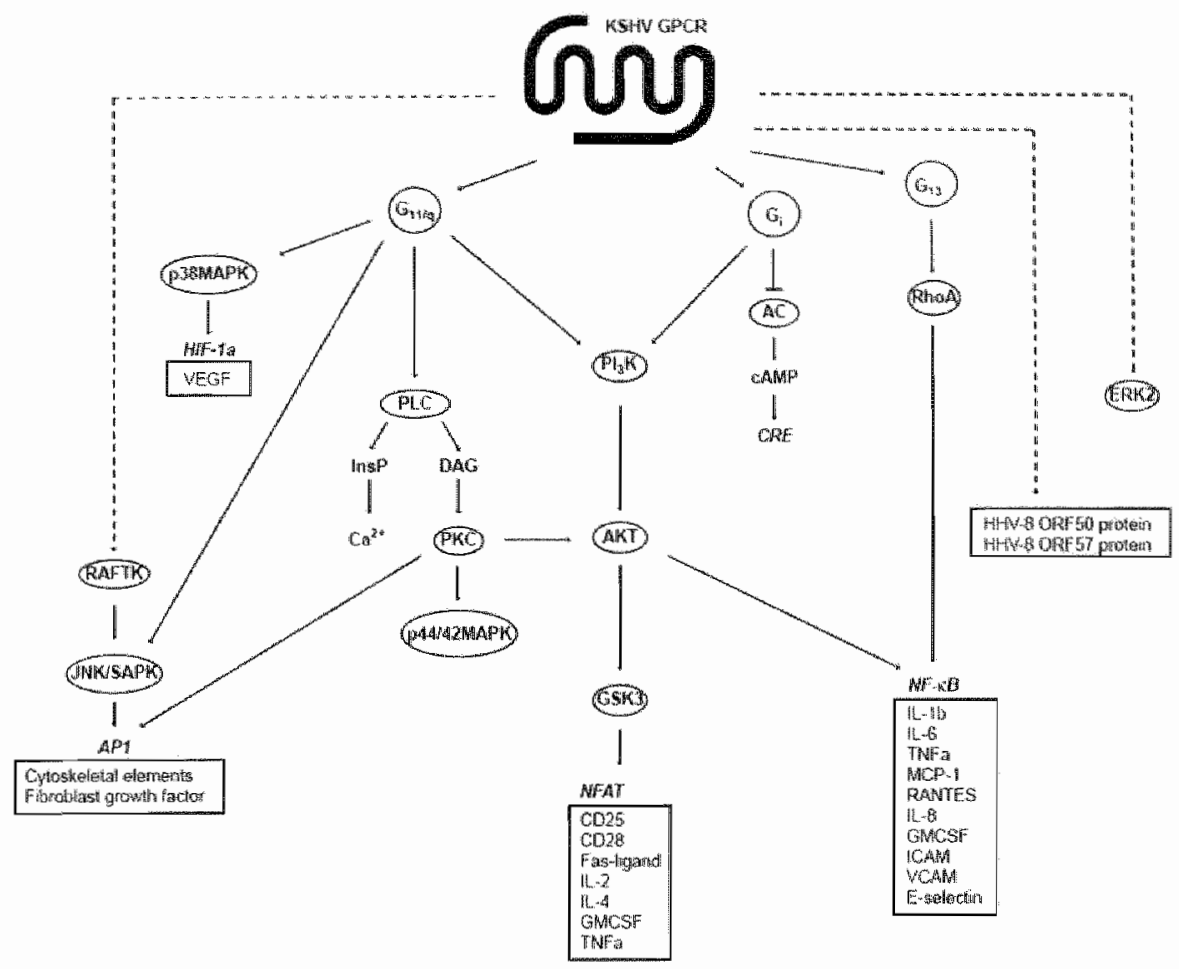

Fig. 1. Schematic representation of signaling by HCMV pUS28. Signaling path ways are indicated by an $(w)$ if an activating effect, or by an ( 1 ) if inhibitory effect on subsequent signaling parameters has been observed. A dashed line is given when the preceeding signaling route is unknown. Proteins, such as $G$ proteins, $G$ protein subunits and kinases, are indicated by their encircled names, whereas promoter elements and transcriptionfactors are indicated in italic type. The rectangle box represents the cellutar response, shown to be mediated via the indicated pathway.

At present, the biological relevance of constitutive signaling by the KSHV GPCR is still unclear. However, analogous to the oncogenic effects of constitutive signaling by mammalian GPCR mutants, signaling by the KSHV GPCR has been implicated in the development of Kaposi's sarcoma (KS) and other lymphoproliferative disorders in KSHV-infected individuals. This notion is supported by several different observations. Both KSHV ORF74-derived mRNA and protein have been detected in KS, PELs and other lymphomas $(18,22,40,47$, 64). Furthermore, expression of the KSHV GPCR in transiently transfected NRK$49 \mathrm{~F}$ cells promotes proliferation and clustering of these cells (4). In stablytransfected NIH 3 T3 cells, the KSHV GPCR acts as an oncogene by inducing 
transformation $(5,26,95)$. Moreover, injection of these GPCR-transformed cells into nude mice induced the formation of highly vascularized tumors which resemble human $\mathrm{KS}(5,26)$.

Nevertheless, since only a very small fraction of cells within lymphomas express the ORF74-encoded GPCR, it is unlikely that this expression is directly responsible for the lymphoproliferative disorders observed in KSHV-infected individuals $(22,47)$. It is more likely that the constitutive induction of various proangiogenic and proinflammatory factors by the KSHV GPCR contributes to the formation of KS and other lymphomas in an autocrine or paracrine fashion $(19,47$, 71, 72, 82). Indeed, the transforming potential in NIH 3 T3 cells is accompanied by a switch to an angiogenic phenotype of the cells through the induction of both vascular endothelial growth factor (VEGF) and Kaposi's spindle cell growth factor secretion. These effects are mediated through constitutive INK/SAPK and p38MAPK signaling (Figure 1) $(5,26)$. In addition, the culture medium of these transfected cells stimulated growth and microtubule-formation of untransfected HUVEC cells (5). Other studies confirmed the induction of VEGF via P38MAPKHIF1a pathways (85) and reported additional KSHV GPCR-activated signaling pathways, independent of VEGF production, which induce proangiogenic and proinflammatory factors. For example, signaling to $\mathrm{NF}-\mathrm{KB}$ via $\mathrm{Pl}_{3} \mathrm{~K}-\mathrm{AKT}$ was reported to (i) prevent cells from serum deprivation-induced apoptosis (59) and (ii) upregulate NF- $\mathrm{kB}$-dependent expression of inflammatory cytokines (RANTES, IL-6, IL-8, GMCSF, TNF-1 $\alpha$ and MCP-1) as well as adhesion molecules (VCAM-1. ICAM-1, E-selectin) (71, 82). Additionally, signaling via JNK/SAPK results in constitutive induction of AP-1-dependent fibroblast growth factor (82), and signaling to NFAT increases expression of cell surface molecules (CD25, CD29, Fas ligand), proinflammatory factors (IL-2, IL-4) and proangiogenic factors (GMCSF, TNF-1 $\alpha)(72,82)$.

Interestingly, DNA microarray analysis of KSHV ORF74-transfected BJAB B cells and SLK endothelial cells revealed that a remarkable degree of cell-type specificity exists with regard to the genes whose transcription is constitutively upregulated (75). In endothelial cells, the expression of IL-6 and GROQ was most highly upregulated. Also, transcriptional upregulation was seen of several genes affecting endothelial and vascular growth, such as those encoding plasminogen, thrombomodulin, the urokinase-type plasminogen activator receptor and, to a modest extent, VEGF (75). By contrast, the most highly upregulated genes in B cells were those encoding the CCLs MIP-1 $\alpha$ (CCL3) and MIP-1 $\beta$ (CCL4) (75). These results indicate that signaling by the KSHV GPCR in these two target cell types differs considerably and may contribute differentially to the pathogenesis of
KSHV-related endothelial and lymphoproliferative lesions (75).

Another line of evidence which links tumor formation to the KSHV GPCR, stems from studies with transgenic mice $(41,43,98)$. Transgenic mice expressing the KSHV GPCR in hematopoietic cells develop angioproliferative lesions, which resemble KS lesions, in multiple organs $(41,98)$. Interestingly, transgenic mice expressing either a mutant KSHV GPCR that has lost constitutive signaling abilities or a mutant that was constitutively active, but unable to bind any ligands, did not develop KS-like disease (43). This indicates that induction of KS-like disease in 
these mice does not only require constitutive signaling activity of the KSHV GPCR but also modulation of this activity by binding of endogenous chemokines (43)

The fact that the ORF74 genes are well-conserved among all rhadinoviruses indicates that they might serve a crucial function in rhadinovirus replication and survival. Recently, several reports have shed some light on this aspect. Chiou and co-workers (22) demonstrated that many KSHV promotors are responsive to KSHV GPCR-induced transactivation. In addition, Cannon and coworkers (14) showed that expression of the KSHV GPCR in the presence of GROV upregulated the transcription of KSHV ORFs 50 and 57. Both ORF50 and ORF57 encode strong transactivators that are capable of inducing of lytic KSHV replication (14). Together, these data suggest that the KSHV GPCR might be of significance for the induction of lytic KSHV replication. Moreover, two recent studies on the murine $\gamma H V 68$ counterpart of the KSHV GPCR indicated that this protein is involved in the induction of lytic viral replication in vivo $(50,61)$. In both studies, the replication characteristics of murine $\gamma H V 68$ was compared with those of $\gamma$ HV68 knock-out strains in which the ORF74 gene was disrupted $(50,61)$. In vitro, the wild type virus and the deletion mutant viruses appeared to replicate with similar efficiencies $(50,61)$. However, stimulation of cells with GROo increased virus production in wild type-infected, but not in deletion mutantinfected cells (50). In vivo, no differences were observed between the knock-out and will type virus strains with regard to acute replication or establishment of latency $(50,61)$. By contrast, the deletion mutant viruses showed a remarkable decrease in efficiency to reactivate from latency as compared to that of the wild type virus $(50,61)$. Taken together, these data emphasize the importance of the rhadinovirus ORF74-encoded receptors for replication and survival of their respective viruses in vivo.

\subsection{Other gammaherpesvirus-encoded $G$ protein-coupled receptors}

In addition to ORF74, the EHV-2 genome comprises two other ORFs, E1 and $E 6$, that putatively encode GPCRs (89). As of yet, no counterparts of E1 have been identified in any of the sequenced gammaherpesvirus genomes (Table 1). The E1-encoded receptor shows the highest degree of homology to eukaryotic chemokine receptors, sharing $47 \%$ identity with the eotaxin receptor, CCR3 (13). This suggests that the $\mathrm{E} 1$ gene has been acquired by EHV -2 relatively recently (13). This hypothesis is further supported by the location of E1 within the EHV-2 genome, namely distal to the conserved core blocks of gammaherpesvirus genes (89). In accordance with its high level of similarity to CCR3, the E1 -encoded GPCR was found to respond to the CCL eotaxin (CCL11, table 2) (13). More specifically, eotaxin was able to induce calcium mobilization as well as chemotaxis in HEK293 cells stably transfected with E1. Apart from eotaxin, CCR3 also binds other CCLS such as RANTES (CCL5) and MCP-3 (CCL9). However, these and several other CXCLs and CCLs were unable to elicit a calcium response in E1-transfected cells, suggesting that the E1-encoded protein is a highly specific receptor (13). 
Counterparts of the EHV-2 E6 ORF are not found within the other rhadinowirus genomes. However, this E6 ORF shares homology to the EBV BILF1 ORF, which is conserved among all lymphocryptoviruses sequenced to date (Table 1). Phylogenetic analyses indicated that EBV and the other lymphocryptoviruses diverged from the lineage that gave rise to EHV-2 and the other rhadinoviruses approximately $95 \mathrm{My}$ ago, and that EHV-2 diverged from the rhadinoviruses about 75 My ago (53). Therefore, it could be speculated that an ancestral gammaherpesvirus predecessor may have carried an EBV BILF1 precursor. Subsequently. BILF 1 may have been lost from the rhadinoviruses other than EHV2, probably due to the lack of selection pressure. The ORF74 precursor on the other hand, may have been acquired by an ancestral thadinovirus genome after the divergence of EBV but before that of EHV-2.

Up until now, no information was available about the putative GPCRs encaded by the BILF1-like ORFs. However, recent data from our laboratory indicate that the EBV BILF1-encoded protein represents a functional GPCR, activating $G$ proteins in a constitutive fashion (Beisser, unpublished results). In transiently transfected COS-7 cells, expression of the BILF1 GPCR resulted in constitutive inhibition of CRE-mediated transcription as well as stimulation of NF$\beta B$-mediated transcription. These BILF1 GPCR-dependent effects were mediated by the specific interaction with $G$ proteins of the $G_{i, 0}$ class. It was of interest to note that the BILF1 GPCR did not constitutively stimulate PLC. This is in contrast to the activation of PLC through the $G_{q / 1}$ proteins by the KSHV GPCR as well as the other constitutively active betaherpesvirus GPCRs which will be discussed in the following paragraphs.

\section{Betaherpesvirus homologs of $G$ protein-coupled receptors}

\subsection{Betaherpesviridae}

Human cytomegalovirus (HCMV) is the prototype of the cytomegalovirus genus of the betaherpesvirus family. HCMV is endemic in human populations with a seroprevalence depending on the geographic region and ranging from $50 \%$ to $80 \%$. Although HCMV infections in immunocompetent individuals are usually asymptomatic, infections of immunocompromised individuals (e.g. AIDS patients and organ transplant recipients) can be life-threatening. Among the complications induced by CMV are interstitial pneumonitis, hepatitis, retinitis and destructive inflammatory lesions at various other locations.

The betaherpesviruses $H H V-6 A / B$ and $H H V-7$ belong to the roseolavirus genus and are human pathogens of emerging clinical significance. Primary infections of both viruses are linked to the development of exanthem subitum (roseola), a common childhood exanthem. Although overt clinical disease is infrequent in healthy adults, both viruses reactivate with immunosuppression and are of major concern regarding solid organ transplant rejection. In addition, HHV- 
6A/B has been linked to a variety of human diseases including multiple sclerosis, although the significance of these associations is unclear. The view that HHV-6A and $H H V-6 B$ are distinct betaherpesviruses is supported by the presence of significant genetic differences in both strains as well as variations in monoclonal antibody reactivity, cell tropism and disease manifestations $(45,81)$.

Like gammaherpesviruses, betaherpesviruses encode homologs of both chemokines and chemokine receptors (Table 1). The HCMV genome carries four GPCR genes, which are designated US27, US28, UL33 and UL78 $(20,21)$. In contrast to US27 and US28, which are unique for HCMV, both UL33 and UL78 are conserved among all betaherpesviruses sequenced to date, including RCMV (Maastricht strain, 6, 7, 93, 94), MCMV (77), HHV-6A (37), HHV-6B $(25,45)$ and HHV-7 (68).

\subsection{HCMV US27- and US28-encoded G protein-coupled receptors}

Among the putative GPCRs encoded by betaherpesviruses, the HCMV US28-encoded protein ( $p$ US28) is the best characterized. It was first identified in 1993 as a viral chemokine receptor in conjuction with the cloning and characterization of the human chemokine receptor CCR1 $(32,66)$. The amino acid sequence derived from US28 was found to be $33 \%$ identical to that of CCR1. In accordance with this homology to CCRs, pUS28 was demonstrated to bind the CCLS MCP-1 (CCL2), MIP-1 $\alpha$, MIP-1 $\beta$ and RANTES with high affinity when expressed in transfected HEK293, K562 and COS-7 cells $(32,49,66)$. In addition, pUS28 was shown to bind MCP-1, MIP- $1 \alpha$, MIP-1 $\beta$. RANTES and MCP-3 (CCL7) in HCMV-infected fibroblasts and endothelial cells in vitro $(10,11,12,92)$. This broad binding repertoire makes pUS28 a rather promiscous receptor (Table 2). The ability of pUS28 to bind and sequester a variety of CCLs, has lead to the hypothesis that pUS28 might function as a "chemokine sink" in vivo $(11,12,55$, 76). By ellimination of chemoattractants, pUS28 would reduce the immune response at sites of HCMV infection and thus contribute to immune evasion.

However, it is rather unlikely that pUS28 merely functions as a chemokine sink. Upon binding of CCLs, pUS28 was shown to trigger mobilization of intracellular calcium and induce intracellular signal transduction pathways which are linked to cell activation $(10,32,92)$. These effects were mediated by interaction of pUS28 with the $G$ protein subunits $G \alpha_{i}$ and $G \alpha_{16}$, as schematically depicted in Figure $2(10)$. This provides convincing evidence that pUS28 is a true GPCR and suggests that pUS28 has a more diverse function than just sequestering CCLS.

Interestingly, pUS28 does not exclusively bind CCLS (Table 2). This receptor also selectively recognizes the only known chemokine of the $\mathrm{CX}{ }_{3} \mathrm{CL}$ class, fractalkine $\left(\mathrm{CX}_{3} \mathrm{CL}-1 ; 48\right)$. Fractalkine is an unusual chemokine as it is expressed as an integral membrane protein. The molecule consists of a soluble chemokine-like domain, which is attached to a transmembrane segment by a mucin-like stalk. Since fractalkine is expressed on membranes of putative CMV target cells, such as endothelial cells, Kledal and co-workers (48) hypothesized that the highly 
specialized pU528-fractalkine interaction could be involved in cell-to-cell transfer of HCMV. More specifically, circulating HCMV-infected cells expressing pUS28 may bind fractalkine expressed on endothelial cells. Binding and subsequent fusion of both cells would thus enable transfer of the virus. It was suggested previously, that pUS28 might also be implicated in cell-to-cell transfer of other viruses, by acting as a entry co-factor or by promoting membrane fusions $(69,73,74,80)$. Like several other chemokine receptors, pUS28 can be used together with CD4 for entry of HIV into target cells $(73,80)$. Furthermore, cell surface expression of pUS28 enhances membrane fusions with cells expressing envelop proteins of HIV1 (env), human $T$ cell-lymphotropic virus (HTLV-1, gp46 and gp21) and rhabdovirus (VSV.G) (74). Nevertheless, pUS28-mediated HIV-entry appears to be rather inefficient as compared to that mediated by CCR5 $(69,74)$.

in addition to its agonist-dependent signaling activities, pUS28 was also shown to signal in a constitutive, ligand-independent fashion in transfected COS-7 cells (15). Like the KSHV GPCR, pUS28 activates the PLC pathway, leading to a constitutively high turnover of phosphatidylinositol. This pUS28-mediated, constitutive increase in intracellular InsP levels also occurs in HCMV-infected fibroblasts in vitro (57). Furthermore, pUS28 constitutively stimulates both NF-KBand CRE-mediated transcription $(15,96)$. Constitutive activation by pUS28 is predominantly achieved by interaction with $G$ proteins of the $G_{q m a}$ class (Figure 2). Stimulation of PLC by pUS28 is due to the actions of the $G \alpha_{q}$ and $G \alpha_{11}$ subunits, whereas the stimulatory effect on NF-KB is mediated by $\beta \gamma$ subunits (15). Interestingly, neither $G \alpha_{16}$ nor $G \alpha_{i}$ subunits seem to be involved in pUS28mediated constitutive signaling pathways, although these subunits were implicated in agonist-dependent pUS28 signaling $(10,15)$. Other signaling routes that are activated by pUS28 are MAPK signaling pathways. However, while agonistdependent signaling of pUS28 results in the activation of ERK2, agonistindependent signaling does not. Instead, constitutive signaling by pUS28 stimulates CRE-transcription by another MAPK signaling axis, the p38-MAPK pathway (96). It is still not known how pUS28 stimulates NF-KB but it is clear that p38-MAPK, ERK2, nor Ga-CAMP-PKA pathways are not involved (96). Although, the observed differences in agonist-dependent and agonist-independent pUS28 signaling pathways are intruiging, it can not be excluded that these differences originate in the different experimental approaches (eg cell types) that were used to delineate them $(10,15,32,57,92,96)$.

As described above, the constitutive activity of the KSHV GPCR can be modulated both positively and negatively by binding of chemokines, which are thus acting as agonists and inverse agonists, respectively. In the case of pUS28 however, none of the previously identified CCL agonists, RANTES, MCP-1, MIP$1 \alpha$ and MIP-1B, were able to modulate the constitutive activity in either transfected or HCMV-infected cells $(15,57)$. Interestingly, a soluble form of fractalkine, did modulate constitutive signaling by pUS28 and seemed to be acting as a (partial) inverse agonist in the InSP. NF-KB and CRE assays on US28transfected COS-7 cells $(15,96)$. Similarly, a partial inverse agonistic effect of fractalkine was observed on constitutive InsP turnover in HCMV-infected, pUS28expressing cells in vitro (57). 


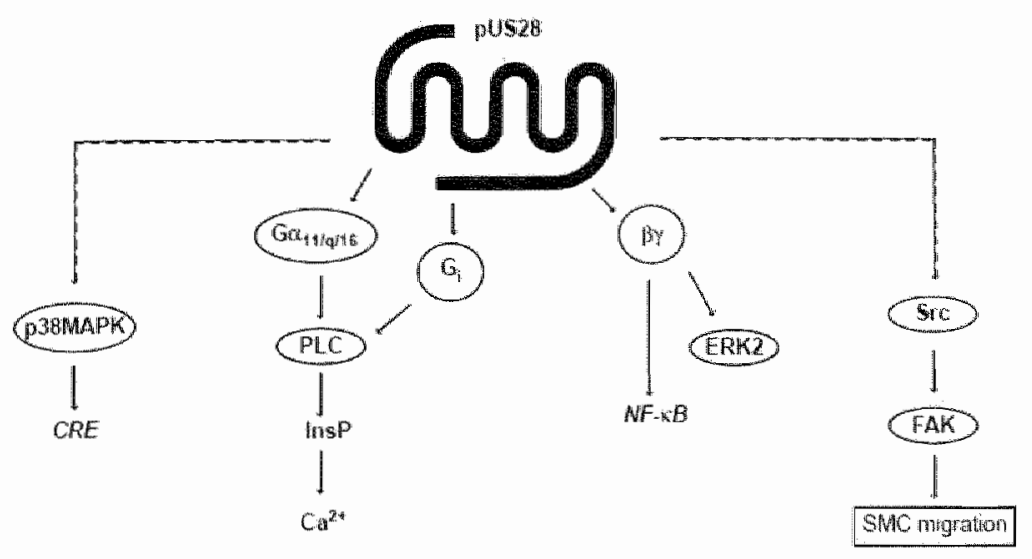

Fig. 2. Schematic representation of signaling by the KSHV GPCR. Signaling pathways are indicated by an $(\downarrow)$ if an activating effect, or by an $(\perp)$ if inhibitory effect on subsequent signaling parameters has been observed. A dashed line is given when the preceeding signaling route is unknown. Proteins, such as $G$ proteins, $G$ protein subunits and kinases, are indicated by their encircled names, whereas promoter elements and transcriptionfactors are indicated in italic type. Transcription of genes encoding one of the proteins named in the rectangle boxes, has been demonstrated to be upregulated via the indicated signaling routes.

Apart from signaling in a constitutive fashion, pUS28 also appears to be endocytized in a constitutive manner, which is independent from its signaling abilities $(58,27,97)$. Although the endocytic process is ligand-independent, it also occurs, with similar kinetics, when either RANTES or fractalkine are bound (27, 29). Constitutive endocytosis of pUS28 is followed by recycling of the receptors back to the cell membrane $(27,29)$. Interestingly, it was noted that steady state levels of pUS28 at the cell surface were reduced after binding of fractalkine, but not of RANTES. Since the endocytic kinetics of RANTES-bound, fractalkine-bound and ligand-free receptors were similar, fractalkine-binding apparently inhibited receptor recycling back to the cell surface $(27,29)$. This mechanism could explain how fractalkine partially inhibits pUS28-mediated constitutive signaling. By using pUS28 receptor mutants that were unable to constitutively endocytize, but were still signaling in a constitutive fashion, it was shown that fractalkine did not display inverse agonistic properties (97). Unexpectedly, these experiments showed quite the opposite. Binding of soluble fractalkine to these mutant receptors resulted in a substantial stimulation of constitutive pUS 28 signaling. Thus, fractalkine acted as an agonist. It was therefore concluded that constitutive endocytosis of pUS28, camouflages the agonistic properties of fractalkine and may mask agonistic properties of other putative (partial) inverse agonists (97). Inverse agonists are 
regarded as interesting pharmaceutical leads for silencing the potentially pathogenic signaling of constitutively active GPCRs. Recently, such a possibly therapeutic lead, a non-peptidergic inverse agonist, was identified for pUS28 (17). However, care should be taken when applying such putative inverse agonists for therapeutic as well as research purposes if the observed inverse agonistic effect is dependent on particular processes like endocytosis and/or recycling. As these processes can vary substantially for a given receptor in different celltypes, the ligand displaying the favoured inhibiting, inverse agonistic effect in a certain cell type in vitro, could evoke an undesirable agonistic stimulation of the targeted receptor in another cell type in vivo.

Another interesting feature of pUS28 was identified by Streblow et al. (86). They demonstrated that HCMV infection of primary artery smooth muscle cells (SMCS) resulted in cellular migration, whereas an HCMV mutant that lacks a functional US28 gene was unable to induce migration. The expression of pUS28 in SMCS in the presence of RANTES or MCP-1 was sufficient to promote SMC migration both by chemokinesis (random movement of cells stimulated by ligandbinding) and chemotaxis (directed movement of cells after ligand-binding). This effect was mediated by the successive activation of Src and focal adhesion kinase (FAK, Figure 2) (88). It was hypothesized that HCMV may be using SMCs as cellular vehicles to disseminate in vivo. HCMV-infected SMCs may migrate in a pUS28-dependent fashion to sites of inflammation where infiltrating macrophages can acquire the virus. These macrophages may subsequently disseminate the virus throughout the body $(86,88)$. The ability of pUS28 to induce SMC migration may also have implications for vascular diseases, such as restenosis, solid organ transplant vascular sclerosis and atherosclerosis. Each of these processes involves endothelial cell damage and inflammatory cell infiltration, followed by the migration of SMCs and stenosis of the vessel. By expression of pUS28, HCMV may induce the migration of SMCs to sites of atherosclerosis or stenosis $(87,88)$. Since HCMV is able to infect various cell types in numerous tissues in vivo, it will be interesting to investigate whether cells other than SMCS, such as leucokytes, are similarly stimulated to migrate upon expression of HCMV pUS28.

Despite this wealth of information regarding pUS28, little is known about US27 and the putative US27-encoded protein, pUS27. The US27 gene is transcribed as a late mRNA $(8,92)$ and the amino acid sequence encoded by the US27 ORF displays $40 \%$ identity with the amino acid sequence of pUS28. Therefore, it has been suggested that US27 and US28 might have arisen by a gene duplication event (21). Both in US27-transfected and HCMV-infected cells, pUS27 displays a similar expression pattern as pUS28. The pUS27 protein is located at the cell surface as well as in intracellular organelles of the perinuclear region and colocalizes with pUS28 (28). This could indicate that, similar to pUS28, pUS27 is subjected to extensive endocytosis and recycling. Interestingly, pUS27 was also detected in enveloped viral particles in HCMV-infected cells, suggesting that this putative receptor could form an integral part of the virion and might be delivered directly to the cell surface of newly infected cells (28). Unlike pUS28, pUS27 did not have a significant effect on either cell-to-cell fusion (73) or HIV-entry (80). 
As of yet, no ligands have been identified for pUS27. Indirect evidence by Bodaghi et al. (12) suggested that pUS27 might be a low affinity receptor for RANTES and, like pUS28, internalize this chemokine in HCMV-infected cells. However, such an activity has not yet been confirmed by conventional pUS27 ligand-binding studies. The putative pUS27 receptor was shown not to be constitutively active in transiently transfected $\operatorname{COS}-7$ cells with regard to Ins $\mathrm{P}$ turnover and NF-KB-mediated transcription (96). Both the KSHV GPCR, RCMV PR33, and the EBV BILF-1 receptor have been demonstrated to constitutively inhibit CRE-mediated transcription (38, Beisser, unpublished results). However, to reliably detect such an activity, assay conditions need to be altered as compared to those used for the detection of CRE stimulation $(3,38)$. It would therefore be worthwhile to investigate if, under these altered conditions, expression of pUS27 might indeed result in constitutive inhibition of CRE.

As a consequence of the strict host species-specificity of the CMVs as well as ethical considerations, it is not possible to study the function of HCMV pUS27 and pUS28 in physiological relevant situations in vivo. Thus, while both US27 and US28 were shown to be dispensible for HCMV replication in vitro $(12,92)$, it is still unknown whether or not these genes play an essential role in vivo. If the US27and US28-encoded GPCRs do have important functions, however, the question arises why their genes have not been conserved throughout the betaherpesvirus subfamily. It is possible that the genes from the unique short (US) region of the HCMV genome, such as US27 and US28, have been acquired by an ancesteral betaherpesvirus genome after divergence from other primate betaherpesviruses, like HHV-6 and HHV-7, as well as the non-primate CMVs, like RCMV and MCMV. Conversely, the US genes may have been lost during evolution by all betaherpesviruses except the primate CMVs due to differences in selection pressure.

\subsection{The UL33 G protein-coupled receptor family}

The fact that the HCMV UL33 gene has homologs in all currently known betaherpesviruses genomes (Table 1), underlines the biological relevance of the UL33 gene family. The best characterized members of this family are HCMV UL33 $(20,21,96,97), \operatorname{MCMVM} 33(24,77,96), \operatorname{RCMV} R 33(6,38,39,46)$, and the U12 genes of HHV $-6 A(37), H H V-6 B(25,45)$ and HHV $-7(65,68)$. The UL33 gene family members analysed to date are transcribed either in the early phase of virus replication, like UL33 and M33 (24), or in the late phase, such as R33 and HHV-6B U12 $(6,45)$. On the basis of sequence alignments, it was predicted by Davis-Poynter et al. (24) that the UL33 gene family members of MCMV, HCMV, HHV -6 and HHV -7 may be expressed as spliced transcripts. Indeed, the transcripts of M33, UL33 (24) as well as HHV-6B U12 (45) and HHV-7 U12 (65) were demonstrated to be spliced. By contrast, the RCMV R33 gene was found to be transcribed into an unspliced mRNA (6).

In order to study the biological significance of the UL33 family members, recombinant CMVs were generated that carry either a disrupted UL33 (52), M33 
(24) or R33 gene (6) in their genomes. In cell culture, each of these mutant viruses replicated with similar efficiency as the corresponding wild type (WT) viruses (6, 24, 52). However, during in vivo infection, significant differences were observed between animals infected with either the recombinant MCMV or RCMV strains and those infected with the WT viruses. In contrast to their WT counterparts, M33-and R33-deleted viruses could not be detected within the salivary glands of infected mice and rats, respectively $(6,24)$. This indicated that M33 and R33 play a role in virus dissemination to, or replication in, the salivary glands $(6,24)$. Furthermore, it was shown in the RCMV/rat model, that R33 also has a more general function: a significantly lower mortality was seen among rats infected with R33-deleted RCMV than among those infected with WT RCMV (6). These results emphasize the importance of the UL33-like genes in the pathogenesis of betaherpesvirus infections.
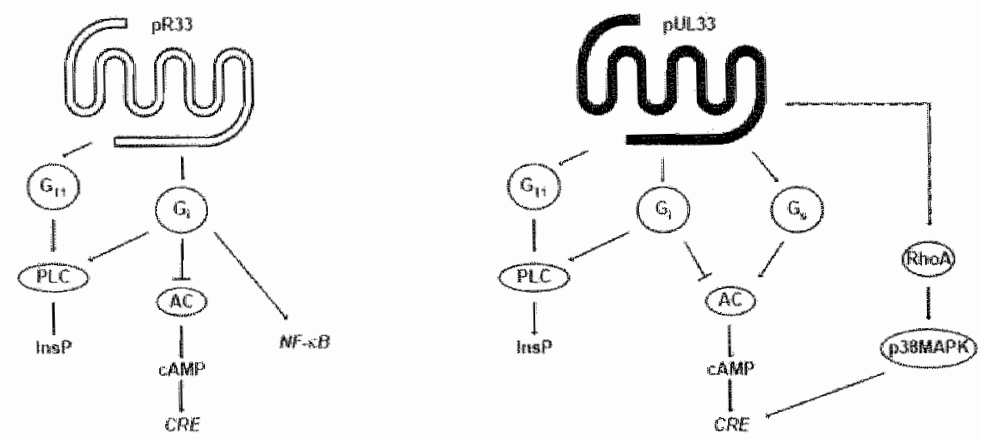

Fig. 3. Schematic representation of signaling by RCMV PR33 and HCMV pUL33. Signaling pathways are indicated by an ( $\downarrow$ ) if an activating effect, or by an ( 1$)$ if inhibitory effect on subsequent stignaling parameters has been observed. A dashed line is given when the preceeding signaling route is unknown. Proteins, such as $G$ proteins, G protein subunits and kinases, are indicated by their encircled names, whereas promoter elements and franscriptionfactors are indicated in italic type.

The predicted amino acid sequences of the proteins encoded by the UL33like genes were found to share the highest level of similarity with the sequences of CCRs. In accordance with this similarity, both HHV-6B pU12 and HHV-7 pU12 were reported to bind CCLs. In response to binding of several CCLS (RANTES, MIP-1 $\alpha, M I P-1 \beta$, and MCP-1), HHV-6B pU12 mediated the release of calcium from intracellular stores (45). Recently, Nakano et al. (65) demonstrated that the HHV-7 pU12 is a calcium mobilizing receptor for the CCL MIP-3B (ELC/CCL19). No response was observed however, when either RANTES or MIP-1 $\beta$ were added to stably HHV-7 U12-transfected cells (65). This indicates that HHV-7 pU12 is a more selective receptor than its counterpart from $\mathrm{HHV}-6 \mathrm{~B}$. We have previously demonstrated that both RCMV pR33 and HCMV pUL33 were also unable to bind RANTES $(16,38)$. Moreover, no specific binding or modulation of receptor activity 
was observed after addition of the CCLs, such as MIP-1a, eotaxin, Teck (CCL25), MCP-1, CTack (eskine/CCL27), and MEC (CCL28) or the CXCLSIL-8, GRON, IP10 and IP-9 (I-TAC/CXCL11), to R33- or UL33-transfected COS-7 cells (16, 38, unpublished results). Together, these data suggest that HHV -7 pU12, HCMV pR33, and RCMV pR33 may represent highly selective chemokine receptors. In light of the specific interaction of HHV-7 pU12 with MPP-3 3 , it is interesting to note that MIP-3 $\beta$ is a highly selective chemokine for mammalian CCR7. The interaction between CCR-7 and MIP-3 $\beta$ is of vital importance for homing of leukocytes to secondary lymfoid organs such as the spleen and lymph nodes (63). It will be interesting to investigate whether HHV -7 pU12 interferes in this process.

As mentioned above, no chemokines or other ligands have yet been identified which bind one of the CMV-encoded members of the pUL33 family. Nevertheless, pUL33, pR33 as well as PM33 have been shown to be functional GPCRs since they signal in a ligand-independent, constitutive fashion, activating a broad range of $G$ proteins $(16,38,96)$. Although constitutive signaling by pU12 of HHV-6 (A/B) or HHV-7 has not yet been reported, it is still possible that these receptors may also signal in a ligand-independent fashion.

The first pUL33-ike receptor for which constitutive signaling activity was identified, was the RCMV R33-encoded receptor, pR33 (38). Constitutive signaling by pR33 is marked by activation of $G$ proteins of the $G_{\mathrm{g} / 11}$ and the $G_{1 / 0}$ class. The pR33-mediated activation of $G_{q / 11}$ stimulates $P L C$ resulting in an intracellular rise of DAG and InsP. Constitutive activation of PTX-sensitive $G_{i / 0}$ proteins by pR33, inhibits $A C$ and results in a reduced activation of CRE-driven transcription. At the same time, the interaction of $p R 33$ with $G_{i / 0}$ enhances $N F-k B$ activation and co-stimulates PLC activity (38).

Constitutive signaling by HCMV pUL33 differs in some respects from that of $\mathrm{pR} 33$, as depicted schematically in Figure 3. Although both receptors stimulate PLC by interaction with $G_{q / 11}$ and $G_{i / 0}$ proteins $(16,38$ ), they exhibit profound differences in modulation of CRE-mediated transcription. As opposed to the pR33mediated inhibition of CRE, PUL33, like PM33, enhances CRE-driven transcription $(16,38,96)$. CRE modulation by pUL33 results from the activation of both the AC-inhibiting $G_{i j 0}$ as well as -stimulating $G_{s}$ proteins, whereas CRE modulation by pR33 is entirely dependent on the inhibiting $G_{i ; 0}$ proteins (16). Additionally, pUL33 also activates the p38-MAPK pathway to CRE, like pM33 and pUS28 (96). This activation of $\mathrm{p} 38-\mathrm{MAPK}$ is the consequence of constitutive signaling to the small GTP-binding protein RhoA, via By subunits. Another difference between $\mathrm{pR} 33$ and pM33 on one hand, and pUL33 on the other, is that both pR33 and pM33 stimulate NF-kB-mediated transcription, whereas pUL33 does not $(38,96)$.

It was speculated by Waldoer et al. (96), that differences in signaling between PR33, pM33 and pUL33 might be due to differences found in the socalled DRY motif of these proteins. This motif, located in the predicted second intracellular loop, is found in most GPCRs known to date, and was shown to be critical for the interaction of GPCRs with $G$ proteins. Additionally, it has been noted that mutation of the aspartic acid residue (D) of this motif in some GPCRs may result in a constitutively active receptor. Interestingly, while pUL33 comprises a 'normal' DRY motif, both $\mathrm{pR} 33$ and $\mathrm{pM} 33$ carry an $N$ residue instead of a $D$ 
residue within this motif; i.e they possess an NRY motif. Nevertheless, mutating the pR33 NRY motif to DRY resulted in a mutant receptor with similar signaling characteristics as the wild type pR33 receptor (39). This observation has lead to two important conclusions: (i) the neutral asparagine residue $(\mathbb{N})$ in the motif is not critical for constitutive signaling by pR33, and (ii) the asparagine residue is not the structural determinant for the observed differences in constitutive signaling by pR33 and pUL33, as was previously suggested. Interestingly, replacement of the pR33 asparagine residue (N) by alanine (A) resulted in an impaired ability of the resulting mutant to stimulate PLC via $G_{q / 13}$ proteins. However, the ability to inhibit CRE driven transciption via $G_{i j o}$ proteins was preserved. This implies that proper $\mathrm{G}_{\mathrm{q} ; 11}$ activation by the pUL33-like receptors is determined by the presence of a polar residue at the corresponding aspartic acid position of the common DRY motif.

Both native and protein-tagged versions of pUL33 $(28,52,96)$, pR33 (38), pM33 (96) and HHV-7 pU12 (65) were found to co-localize with the cell membranes of transiently transfected cells, as would be expected for functional GPCRS. The majority of all of these receptors, however, is present within cytoplasmic vesicles in the perinuclear region of cells. A similar distribution of protein was found for pUL33 in HCMV-infected fibroblasts in vitro $(28,52)$. This indicates that the observed expression patterns do not represent an artefact as a result of the transient transfection system. Furthermore, the intracellular vesicles in which the pUL33 protein accumulated, were identified as endocytic organelles, such as multivesicular endosomes and lysosomes (28). This suggests that pUL33, like pUS28 and pUS27, may also be subjected to extensive endocytosis. This specific sorting of pUL33-like proteins to endocytic compartments in the absence of other viral proteins suggests that these proteins might contain intrinsic trafficking signals that could be of importance for their incorporation into (viral) membranes.

Recently, two regions within the C-terminal tail of pR33 were identified that might comprise such trafficking signals $\$ 16,39)$. Elimination of two consecutive arginine residues $\left(R^{32 \pi}\right.$ and $\left.R^{328}\right)$ from the membrane-proximal part of the pR33 $\mathrm{C}$-terminus, either by truncation of the $\mathrm{C}$-terminus or by point mutation of either one of both residues, resulted in proteins that were predominantly retained intracellularly in the endoplasmic reticulum (ER) (39). Interestingly, these two consecutive arginines are the only conserved residues within the highly divergent $C$ terminal sequences of the pUL33 family of proteins. Substitution of the pR33 C-terminal sequence, by the pUL33 C-terminal sequence, carrying the RR motif, resulted in a chimeric receptor which displayed similar expression and signaling characteristics as pR33 (16). Therefore, we concluded that efficient pR33 cell surface expression is dependent on the presence of the two arginine residues. Furthermore, in light of its conserved nature, it is likely that the RR motif of the other pUL33 family members plays a similar role as that of $\mathrm{PR} 33$.

In addition to the common RR motif, a more unique KRF motif was identified within the membrane proximal part of the C-termini of both $p R 33$ and PM33. This motif might also be implicated in proper cell surface expression of these receptors, since a KRF motif within the C-terminal tail of CCR5 was found to 
be involved in proper expression of this CCR on the cell surface (90). Additionally, replacement of the $C$-terminal region of $p R 33$ comprising the KRF motif with the corresponding C-terminal region of pUL33, which lacks a KRF motif, resulted in a pR33/pUL33 chimeric receptor that was retained in the ER (16). However, a direct involvement of the KRF motif of $p R 33$ and $p M 33$ in cell surface expression has not yet been confirmed. Therefore, the importance of this motif for cell surface expression of $\mathrm{pR} 33$ and $\mathrm{pM} 33$ remains speculative.

It is interesting to note that pUL33 also co-localizes with intracellular membranes from which HCMV virions are budding (28). This suggests that pUL33 might be part of enveloped viral particles. Indeed, pUL33 was shown to be present in purified virions which were harvested from HCMV-infected fibroblasts (52). As to the possible functions of the presence of pUL33 in the virion envelop, one could speculate that pUL33 might bind specific proteins, such as glycosaminoglycanbound chemokines, on the celf surface of putative target cells and thus might facilitate the enveloped virion to recognize, attach or enter these cells. Alternatively, by fusion of the viral envelope with the cell membrane of the target cell, pUL33 might be delivered to the cell surface and directly engage in (constitutive) intracellular signaling thus promoting a modified intracellular environment favoured by the virus.

\subsection{UL78 G protein-coupled receptor family}

Like the UL33 gene family, the UL78 gene familly has members in all betaherpesvirus genomes and includes HCMV UL78, MCMV M78, RCMV R78, and the U51 ORFs of HHV-6A, HHV-6B and HHV-7 (Table 1). As with the UL33like genes, the position as well as orientation of the UL78-like ORFs within the betaherpesvirus genomes are conserved. However, in contrast to the UL33-like sequences, the sequences of members of the UL78 family are rather divergent. Furthermore, the amino acid sequences significantly resemble neither chemokine receptors nor any other of the thousands of GPCRs currently known. The notion that the UL78-like genes have the potential to encode GPCRS was based on three main characteristics: (i) the presence of a 7-TM core domain within the predicted amino acid sequences; (ii) the presence of conserved cysteine residues within the predicted first and second extracellular loop; (iii) the presence of a conserved (D/E)R(L/I) motif in the predicted second intracellular loop regions.

Despite the relatively low level of sequence similarity with known chemokine receptors, the HHV-6A-encoded pU51 protein was shown to specifically bind RANTES with high affinity in stably transfected $\mathrm{K} 562$ cells (56). In addition "the CCLS MCP-1, MCP-3, MCP-4 (CCL13), eotaxin, and the KSHVencoded chemokine VMIPII, could compete for RANTES binding by pU51 (56). This shows that at least one member of the UL78-encoded protein family is a broad spectrum CCR and suggests that the other family members might have similar properties despite their divergent sequences.

The fact that UL.78-like genes are present in all known betaherpesviruses indicates that these genes may play a crucial role in betaherpesvirus infection. 
Indeed, it was shown in both the RCMV/rat and MCMV/mouse models that the $R 78$ and $M 78$ genes serve important functions during in vivo infection $(7,70)$. This was established by studying RCMV strains from which the R78 sequence was deleted and an MCMV strain from which the $M 78$ sequence was deleted. These RCMV and MCMV mutant viruses displayed a reduced production of progeny virus in vitro $(7,70)$. Additionally, replication of the recombinant viruses was shown to be impaired in vivo $(46,70)$. Significantly lower amounts of virus were detected in the spleen of rats infected with the recombinant RCMV strain than in those infected with the wild type strain (46). In mice, lower amounts of recombinant MCMV were detected in both spleen and salivary glands as compared to the amounts of wild type virus in these organs (70). Together, these data indicate that $R 78$ and $M 78$ are not essential genes, but do play a role in efficient replication of RCMV and MCMV, respectively. Moreover, deletion of RCMV R78 or MCMV M78 resulted in a reduced virulence of the mutant viruses in comparison with the respective wild type viruses. While $70 \%$ to $80 \%$ of the animals died after infection with wild type MCMV or RCMV, respectively, $100 \%$ of the animals survived after infection with either one of the mutant viruses $(7,46$, 70).

Beisser and co-workers (7) noted an interesting morphological phenomenon during infection of fibroblasts with the R78-deletion mutants. Unlike will type RCMV-infected fibroblasts, fibroblasts infected with the mutants strains developed a syncytium-like appearance (7). It was hypothesized that R78 may play a role, either directly or indirectly, in stabilizing cell-cell contacts (7). In fibroblasts infected with $R 78$-deleted viruses, contacts between neighboring cells may become unstable, leading to cell membrane fusions. Morphological changes were also observed in epithelial cells that were stably transfected with the R78 counterpart of HHV-6A, U51. Cells expressing pU51 showed moderately increased spreading and flattening which was independent of cell growth or viability (56). It is well known that ligand-induced signaling by chemokine receptors induces various morphological changes to the cell. This, for instance, allows chemokine receptor-expressing cells to migrate or degranulate. Thus, it is tempting to speculate that the R78- and pU51-dependent influence on cellular morphology might be induced through signaling by these (putative) receptors.

Within transfected HEK293 and $143 \mathrm{tk}$ cells, HHV-6A pU51 was found to accumulate predominantly intracellularly and could not be detected on the cell surface (54). However, in transfected T-lymphocytes, pU51 was detectable on the cell surface (54). In addition, pU51 was present on the surface of HHV-6A- as well as HHV-6B-infected cord blood mononuclear cells in vitro (54). Therefore, it was suggested that pU51 might require cell-specific functions, present in $T$ lymphocytes, for high expression levels at the cell surface. Similar to HHV-6A pU51, MCMV pM78 was demonstrated to localize predominantly within intracellular vesicles of MCMV-infected cells (70). Although both proteins failed to be detected on the cell surface, it is still feasible that they might be expressed, albeit at very low concentrations, on the cell membrane of these cells. 
Tabel 2. Properties of the GPCRs encoded by herpesvirus genes.

\begin{tabular}{|c|c|c|c|c|c|c|}
\hline \multirow[t]{2}{*}{ Whas: } & \multirow[t]{2}{*}{ gente } & \multirow{2}{*}{$\begin{array}{l}\text { Constitulue } \\
\text { sjgenathig }\end{array}$} & \multicolumn{3}{|c|}{ Pharvanogy } & \multirow[t]{2}{*}{ shoty } \\
\hline & & & $\begin{array}{l}\text { binding } \\
\text { chernokines }\end{array}$ & agonisits & $\begin{array}{l}\text { maverse } \\
\text { agonishs }\end{array}$ & \\
\hline KSth & ORF74 & yes & 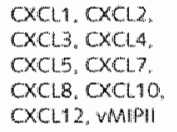 & 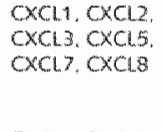 & $\begin{array}{l}\text { OW10 } \\
\text { OXCL12 } \\
\text { MaPl }\end{array}$ & 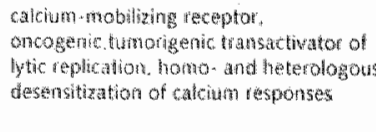 \\
\hline HWS & ECRF 3 & & $\begin{array}{l}\mathrm{CXCL}, \mathrm{CXCL} . \\
\mathrm{CXCLB}\end{array}$ & 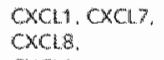 & & Galcium-mobilining receptor \\
\hline REL & ORF? & yes & $\mathrm{xCl}$ & $\mathrm{xCl}$ & & toncogenic \\
\hline HYGB & ORF74 & & CxCl. $\mathrm{CxCl} 1 \mathrm{O}^{\circ}$ & $\operatorname{Cxcin} \theta^{\circ}$ & cxcl10 & 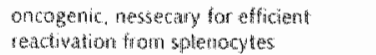 \\
\hline $\mathrm{EH}_{\mathrm{H}} \mathrm{V}-2$ & OfF 74 & & & & & \\
\hline EHV-2 & $\mathrm{EI}$ & & cLl1 & CClit & & aclicium mobifing receptor \\
\hline $\mathrm{EH}-2$ & E6 & & & & & \\
\hline EBV & BLF -1 & yes & & & & \\
\hline HCMV & US28 & yes & $\begin{array}{l}\mathrm{CCL} 2, \mathrm{CCL} 3 \\
\mathrm{CCL} 4, \mathrm{CCL} 5 \\
\mathrm{CCl}, \mathrm{CX}_{3} \mathrm{Cl}\end{array}$ & $\begin{array}{l}\mathrm{CCH}_{2}, \mathrm{CCL}_{3} \\
\mathrm{CCl}_{5}, \mathrm{CCl}_{3} \\
\mathrm{CX}_{3} \mathrm{CH}^{2}\end{array}$ & $\begin{array}{l}\text { CX, } \\
\text { VUF } 2274\end{array}$ & 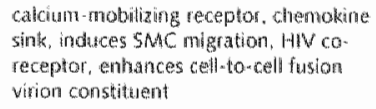 \\
\hline HCMN & U133 & yes & & & & vition constituent \\
\hline RCMV & 83 & yes & & & & $\begin{array}{l}\text { wifulence factor "debernisant wallwary } \\
\text { gland tropism }\end{array}$ \\
\hline MCMU & $M 33$ & yes & & & & $\begin{array}{l}\text { wirulence factor, determinant salivally } \\
\text { gland tropism }\end{array}$ \\
\hline HHW. 6 A & 012 & & & & & \\
\hline WHV-6B & 042 & & $\begin{array}{l}\mathrm{CCL} 2, \mathrm{CCL}_{3} \\
\mathrm{CCL}, \mathrm{CCL} 5\end{array}$ & $\begin{array}{l}\mathrm{CCl} 2, \mathrm{CCL} 3 \\
\mathrm{CCl} 4, \mathrm{CCL} 5\end{array}$ & & adcium mobilizang receptor \\
\hline HHW 7 & $\cup 12$ & & CCl19 & cclla & & aalcium-mobilizing seceptor \\
\hline HCMV & U178 & & & & & \\
\hline RCMV & $R 78$ & & & & & $\begin{array}{l}\text { wirulence facto, nessecary for efficient } \\
\text { replication, deter mitant spleen thopism }\end{array}$ \\
\hline MCMV & $M 78$ & & & & & $\begin{array}{l}\text { wirion constituen, wirutence factor, } \\
\text { messecary for efficiant reptication, } \\
\text { determinant spateen tropism }\end{array}$ \\
\hline$H H W-G A$ & U5.1 & & $\begin{array}{l}\text { CCL2, CCL5, } \\
\text { CCL7, CCL11, } \\
\text { CCL13, vMIPII }\end{array}$ & & & \\
\hline HIN -60 & US:1 & & & & & \\
\hline HHW -7 & U5:1 & & & & & \\
\hline
\end{tabular}

"at least not with regard to $\mathrm{PLC}, \mathrm{NF}=\mathrm{KB}$ or CREB stimulation in COS-7 cells (97), "fractalkine $(\mathrm{CX}, \mathrm{CL})$ has a partial inverse agonistic effect on constitutive pUS28 signaling in COS-7 cells $(15,96)$. However, fractalkine has an agonistic effect on constitutive signaling by a puS28 mutant which is equally efficient in constitutive signaling and binding of fractalkine but is unable to endocytize and recycle (97). teircumstantial evidence by using cells infected with either a deletion mutant virus or the wild type virus.

The RCMV R78, MCMV M78 as well as HHV-6A U51 genes were all shown to be transcribed with early kinetics $(7,54,70)$. Interestingly, M78dependent effects were observed on viral transcripts of the immediate early class. In contrast to wild type MCMV, the M78-deletion mutant failed to efficiently activate immediate early viral mRNA accumulation upon infection of cells in vitro (70). This failure to accumulate the earliest class of viral mRNAs might explain why the M78-deletion mutant, and possibly also the R78-deleted RCMV mutant, displays impaired growth characteristics in vitro. Since $p M 78$ was present in MCMV virions and the M78-dependent effects were observed on a class of transcripts which arise before $M 78$ is transcribed, Oliveira and Shenk (70) concluded that the virion-associated $\mathrm{pM} 78$ must mediate the effect. They 
postulated that upon MCMV infection, the virion-associated $p M 78$ receptor might be delivered directly to the cell surface, where its putative signaling functions might modulate cellular and viral transcription.

The HHV-6A U51-encoded protein was also demonstrated to influence transcription. In stably U51-transfected epithelial cells, transcriptional downregulation of RANTES, but not IL-8, was observed (56). Therefore, one could speculate that $p M 78$, pU51 and their counterparts, initiate signaling pathways that modulate transcription, such that transcription of some genes, like the RANTES gene, is repressed, whereas that of others, like the viral immediate early genes, is stimulated. However, it has hitherto not been reported that a member of the pUL78 protein family activates or inhibits intracellular signaling pathways either in a ligand-dependent or -independent fashion. Although pU51 of HHV-6A was shown to bind various chemokines, future challenges will be to determine whether the members of the pUL78 protein family actually function as (chemokinebinding) GPCRs and to delineate the signaling pathways in which these proteins act.

\section{References}

1. Ahuja SK, Murphy PM. (1993) Molecular piracy of mammalian interleukin-8 receptor type $B$ by herpeswirus saimiri. $J$ Biol Chem. 268, 20691-4.

2. Alcami A, Koszinowski UH. Viral mechanisms of immune evasion. (2000) Trends Microbiol 8, 410-8.

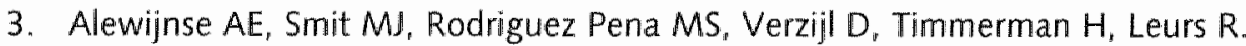
(1997) Modulation of forskolin-mediated adenylyl cyclase activation by constitutively active $G(S)$-coupled receptors. FEBS Lett. 419,171-4.

4. Arvanitakis L, Geras-Raaka E, Varma A, Gershengorn MC, Cesarman E. (1997) Human herpesvirus KSHV encodes a constitutively active G-protein-coupled receptor linked to cell proliferation. Nature $385,347-50$.

5. Bais C, Santomasso B, Coso O, Arvanitakis L, Raaka EG, Gutkind IS, Asch AS,

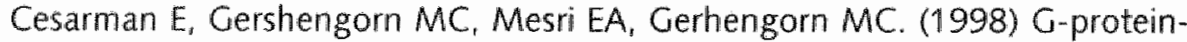
coupled receptor of Kaposi's sarcoma-associated herpesvirus is a viral oncogene and angiogenesis activator. Nature 391:86-9. Erratum in: Nature 392, 210.

6. Beisser PS, Vink C, Van Dam JG, Grauls G, Vanherle SI, Bruggeman CA. (1998) The R33 G protein-coupled receptor gene of rat cytomegalovirus plays an essential role in the pathogenesis of viral infection. / Virol. 72, 2352-63.

7. Beisser PS, Grauls $G$, Bruggeman CA, Vink C. (1999) Deletion of the R78 G protein-coupled receptor gene from rat cytomegalovirus results in an attenuated, syncytium-inducing mutant strain. J Virol. 73, 7218-30.

8. Beisser PS, Goh CS, Cohen FE, Michelson S. (2002) Viral chemokine receptors and chemokines in human cytomegalovirus trafficking and interaction with the immune system. CMV chemokine receptors. Curr Top Microbiol Immunol. $269,203-34$. 
9. Berger EA. (1997) HIV entry and tropism: the chemokine receptor connection. AIDS. 11 Supp/A, S3-16.

10. Billstrom MA, Johnson GL. Avdi NJ, Worthen GS. (1998) Intracellular signaling by the chemokine receptor US28 during human cytomegallovirus infection. $)$ Virol. $72,5535-44$.

11. Billstrom MA, Lehman LA, Scott Worthen G. (1999) Depletion of extracellular RANTES during human cytomegalovirus infection of endothelial cells. Am $/$ Respir Cell Mol Biol. 21, 163-7.

12. Bodaghi $B$, Jones TR, Zipeto D, Vita $C$, Sun $L$, Laurent $L$, Arenzana-Seisdedos F, Virelizier IL, Michelson S. (1998) Chemokine sequestration by viral chemoreceptors as a novel viral escape strategy: withdrawal of chemokines from the environment of cytomegalovirus-infected cells. I Exp Med. 188, 85566.

13. Camarda G, Spinetti G, Bernardini G, Mair C, Davis-Poynter N, Capogrossi MC, Napolitano M. (1999) The equine herpesvirus 2 E1 open reading frame encodes a functional chemokine receptor. J Virol. 73:9843-8.

14. Cannon $\mathrm{M}_{\mathrm{r}}$. Philpott $\mathrm{N} J$, Cesarman E. (2003) The Kaposi's sarcoma-associated herpesvirus $G$ protein-coupled receptor has broad signaling effects in primary effusion lymphoma cells. J Virol. 77, 57-67.

15. Casarosa $P$, Bakker RA, Verzijl $D$, Navis $M$, Timmerman $H$, Leurs $R$, Smit $M J$. (2001) Constitutive signaling of the human cytomegalovirus-encoded chemokine receptor US28. I Biol Chem. 276, 1133-7.

16. Casarosa $P$, Gruijthuijsen $Y K$, Michel $D$, Beisser $P S$, Holl J, Fitzsimons $C P$, Verzijl D, Bruggeman CA, Mertens T, Leurs R, Vink C, Smit MJ. (2003a) Constitutive signaling of the human cytomegalovirus-encoded receptor UL33 differs from that of its rat cytomegalovirus homolog R33 by promiscuous activation of $\mathrm{G}$ proteins of the $\mathrm{Gq}$, Gi as well as Gs class. $J$ Biol Chem. 278, 50010-23.

17. Casarosa $P$, Menge WM, Minisini $R$, Otto $C$, van Heteren J, Jongejan $A$, Timmerman H, Moepps B, Kirchhoff F, Mertens T, Smit MJ, Leurs R. (2003b) Identification of the first nonpeptidergic inverse agonist for a constitutively active viral-encoded G protein-coupled receptor. J Brol Chem. 278, 5172-8.

18. Cesarman E, Nador RG, Bai F, Bohenzky RA, Russo JJ, Moore PS, Chang Y, Knowles DM. (1996) Kaposi's sarcoma-associated herpesvirus contains $G$ proteim-coupled receptor and cyclin D homologs which are expressed in Kaposi's sarcoma and malignant lymphoma. J Virol. 70, 8218-23.

19. Cesarman E, Mesri EA, Gershengorn MC. (2000) Viral G protein-coupled receptor and Kaposi's sarcoma: a model of paracrine neoplasia? J Exp Med. 191. 417-22.

20. Chee MS, Bankier AT, Beck $S_{v}$ Bohni $R_{n}$ Brown $C M_{t}$ Cerny $R_{x}$ Horsnell $T$, Hutchison CA 3rd, Kouzarides T, Martignetti JA, et al. (1990) Analysis of the protein-coding content of the sequence of human cytomegalovirus strain AD169. Curr Top Microbiol Immunol. 154, 125-69.

21. Chee MS, Satchwell SC, Preddie E, Weston KM, Barrell BG. (1990) Human cytomegalovirus encodes three $G$ protein-coupled receptor homologues. Nature. 344,774-7. 
22. Chiou CJ Poole L, Kim PS, Ciufo DM, Cannon IS, ap Rhys CM, Alcendor DI, Zong JC, Ambinder RF. Hayward G5. (2002) Patterns of gene expression and a transactivation function exhibited by the VGCR (ORF74) chemokine receptor protein of Kaposi's sarcoma-associated herpesvirus. JVirol. 76, 3421-39.

23. Couty JP. Geras-Raaka E, Weksler BB, Gershengorn MC. (2001) Kaposi's sarcoma-associated herpesvirus $G$ protein-coupled receptor signals through multiple pathways in endothelial cells. J Biol Chem. 276, 33805-11.

24. Davis-Poynter NJ, Lynch DM, Vally $H$, Shellam GR, Rawlinson WD, Barrell BG, Farrell HE. (1997) Identification and characterization of a $G$ protein-coupled receptor homolog encoded by murine cytomegalovirus. / Virol. 71, 1521-9.

25. Dominguez $G$, Dambaugh $T R$, Stamey FR, Dewhurst $S_{\text {s }}$ Inoue $N$, Pellett PE. (1999) Human herpesvirus $6 \mathrm{~B}$ genome sequence: coding content and comparison with human herpesvirus 6A. I Virol. $73,8040-52$.

26. Estep RD, Axthelm MK, Wong SW. A (2003) G protein-coupled receptor encoded by rhesus rhadinovirus is similar to ORF74 of Kaposi's sarcomaassociated herpesvirus. / Virol. 77, 1738-46.

27. Fraile-Ramos A, Kledal TN, Pelchen-Matthews A, Bowers K, Schwartz TW, Marsh M. (2001) The human cytomegalovirus US28 protein is located in endocytic vesicles and undergoes constitutive endocytosis and recycling. Mo/ Bio/ Cell. 12, 1737-49.

28. Fraile-Ramos $A$, Pelchen-Matthews $A$, Kledal TN, Browne $H$, Schwartz TW, Marsh M. (2002) Localization of HCMV UL33 and US27 in endocytic compartments and viral membranes. Traffic. 3, 218-32.

29. Fraile-Ramos A, Kohout TA, Waldhoer M, Marsh M. (2003) Endocytosis of the viral chemokine receptor US28 does not require beta-arrestins but is dependent on the clathrin-mediated pathway. Traffic. 4, 243-53.

30. Fruh $K$, Ahn $K_{\text {, Djaballah }} H_{\text {, Sempe }}$, van Endert PM. Tampe $R_{\text {s }}$ Peterson PA, Yang $Y$. (1995) A viral inhibitor of peptide transporters for antigen presentation. Nature. 375, 415-8.

31. Gao JL, Kuhns DB, Tiffany HL, McDermott D, Li X, Francke U, Murphy PM. (1993) Structure and functional expression of the human macrophage inflarnmatory protein 1 alpha/RANTES receptor. J Exp Med. 177, 1421-7.

32. Gao $\mathrm{IL}$. Murphy PM. (1994) Human cytomegalovirus open reading frame US28 encodes a functional beta chemokine receptor. I Biol Chem. 269, $28539-42$.

33. Geras-Raaka E, Varma A, Clark-Lewis I, Gershengorn MC. (1998) Kaposi's sarcoma-associated herpesvirus (KSHV) chemokine VMIP-II and human SDF1 alpha inhibit signaling by KSHV G protein-coupled receptor. Biochem Biophys Res Commun. 253, 725-7.

34. Geras-Raaka E, Arvanitakis L, Bais C, Cesarman E, Mesri EA, Gershengorn MC. (1998) Inhibition of constitutive signaling of Kaposi's sarcoma-associated herpesvirus $\mathrm{G}$ protein-coupled receptor by protein kinases in mammalian cells in culture. / Exp Med. 187, 801-6.

35. Geras-Raaka E, Varma A, Ho H, Clark-Lewis I, Gershengorn MC. (1998) Human interferon-gamma-inducible protein $10(\mathrm{IP}-10)$ inhibits constitutive 
signaling of Kaposi's sarcoma-associated herpesvirus $G$ protein-coupled receptor. J Exp Med. 188, 405-8.

36. Gershengorn MC, Geras-Raaka E, Varma A, Clark-Lewis 1. (1998) Chemokines activate Kaposi's sarcoma-associated herpesvirus $G$ protein-coupled receptor in mammalian cells in culture. $/$ Clin invest. 102, 1469-72

37. Gompels UA Nicholas J, Lawrence $G$, Jones $M$, Thomson $B J$, Martin ME, Efstathiou S, Craxton M, Macaulay HA. (1995) The DNA sequence of human herpesvirus-6: structure, coding content, and genome evolution. Virology. 209, 29-51.

38. Gruijthuijsen YK, Casarosa P, Kaptein SJ, Broers JL, Leurs R, Bruggeman CA, Smit M. Vink C. (2002) The rat cytomegalovirus R33-encoded $G$ proteincoupled receptor signais in a constitutive fashion. / Virol.76, 1328-38.

39. Gruijthuijsen $Y K$, Beuken EVH, Smit M, Leurs R, Bruggeman CA, Vink C. (2004) Mutational Analysis of the Rat Cytomegalovirus R33-Encoded $G$ Protein-Coupled Receptor: Identification of Amino Acid Residues Critical for Cellular Localisation and Ligand-Independent Signalling. 1. Gen. Viro/ 85, 897-909

40. Guo $H G$, Browning $P$, Nicholas J, Hayward GS, Tschachler $E$, Jiang $Y W$, Sadowska M, Raffeld M, Colombini S, Gallo RC, Reitz MS Jr. (1997) Characterization of a chemokine receptor-related gene in human herpesvirus 8 and its expression in Kaposi's sarcoma. Virology. 228:371-8.

41. Guo HG, Sadowska $M$, Reid $W$, Tschachler $E$, Hayward $G$, Reitz M. (2003) Kaposi's sarcoma-like tumors in a human herpesvirus 8 ORF74 transgenic mouse. JVirol. 77, 2631-9.

42. Hill A, Jugovic $P$, York $I$, Russ $G$, Bennink $J$, Yewdell J, Ploegh $H_{t}$ Johnson D. (1995) Herpes simplex virus turns off the TAP to evade host immunity. Nature. 375, 411-5.

43. Holst PJ, Rosenkilde MM, Manfra D, Chen SC, Wiekowski MT, Holst B, Cifire F. Lipp M. Schwartz TW, Lira SA. (2001) Tumorigenesis induced by the HHV8-encoded chemokine receptor requires ligand modulation of high constitutive activity. I Clin Invest. 108, 1789-96.

44. Horuk R. (1994) Molecular properties of the chemokine receptor family. Trends Pharmacol Sci. 15, 159-65.

45. Isegawa $Y$, Mukai $T$, Nakano $K$, Kagawa $M$, Chen I, Mori $Y$, Sunagawa $T$, Kawanishi K, Sashihara J, Hata A, Zou P, Kosuge $H$, Yamanishi K. (1999) Comparison of the complete DNA sequences of human herpesvirus 6 variants $A$ and B. / Virol. 73, 8053-63.

46. Kaptein SI, Beisser PS, Gruijthuijsen YK, Savelkouls $K G$, van Cleef KW, Beuken $E$, Grauls GE, Bruggeman CA, Vink C. (2003) The rat cytomegalovirus $R 78 \mathrm{G}$ protein-coupled receptor gene is required for production of infectious virus in the spleen. J Gen Virol. 84, 2517-30.

47. Kirshner JR, Staskus K, Haase A, Lagunoff M, Ganem D. (1999) Expression of the open reading frame 74 (G-protein-coupled receptor) gene of Kaposi's sarcoma (KS)-associated herpesvirus: implications for $\mathrm{KS}$ pathogenesis. I Virol. $73,6006-14$. 
48. Kledal TN, Rosenkilde MM: Schwartz TW. (1998) Selective recognition of the membrane-bound $\mathrm{C} \times 3 \mathrm{C}$ chemokine, fractalkine, by the human cytomegalovirus-encoded broad-spectrum receptor US28. FEBS Lett. 441. 209-14

49. Kuhn DE, Beall CJ, Kolattukudy PE. (1995) The cytomegalovirus US28 protein binds multiple CC chemokines with high affinity. Biochem Biophys Res Commun. 21\%, 325-30.

50. Lee B], Koszinowski UH, Sarawar SR, Adler H. (2003) A gammaherpesvirus G protein-coupled receptor homologue is required for increased viral replication in response to chemokines and efficient reactivation from latency. I immunol. $170,243-51$.

51. Lupu-Meiri $M$, Silver RB, Simons AH, Gershengorn MC, Oron $Y$. (2001) Constitutive signaling by Kaposi's sarcoma-associated herpesvirus G-proteincoupled receptor desensitizes calcium mobilization by other receptors. I Biol Chem. 276, 7122-8.

52. Margulies BJ, Browne $H$, Gibson W. (1996) Identification of the human cytomegalovirus G protein-coupled receptor homologue encoded by UL33 in infected cells and enveloped virus particles. Virology. 225, 111-25.

53. McGeoch DJ, Cook S, Dolan A, Jamieson FE, Telford EA. (1995) Molecular phylogeny and evolutionary timescale for the family of mammalian herpesviruses. / Mol Biol. 247, 443-58.

54. Menotti L, Mirandola P, Locati M. Campadelli-Fiume G. (1999) Trafficking to the plasma membrane of the seven-transmembrane protein encoded by human herpesvirus 6 U51 gene involves a cell-specific function present in T lymphocytes. J Virol. 73, 325-33.

55. Micheison S, Dal Monte P, Zipeto D, Bodaghi B, Laurent L, Oberlin E, Arenzana-Seisdedos F, Virelizier $J$, Landini MP. (1997) Modulation of RANTES production by human cytomegalovirus infection of fibroblasts. $/$ Virol. 71, 6495-500.

56. Milne RS, Mattick C, Nicholson L, Devaraj P, Alcami A, Gompels UA. (2000) RANTES binding and down-regulation by a novel human herpesvirus- 6 beta chemokine receptor. J/mmunol. 164, 2396-404.

57. Minisini R, Tulone C, Luske A, Michel D, Mertens T, Gierschik P, Moepps B. (2003) Constitutive inositol phosphate formation in cytomegalovirus-infected human fibroblasts is due to expression of the chemokine receptor homologue puS28. J Virol. 77, 4489-501.

58. Mokros T, Rehm A Droese J, Oppermann M, Lipp M. Hopken UE. (2002) Surface expression and endocytosis of the human cytomegalovirus-encoded chemokine receptor US28 is regulated by agonist-independent phosphorylation. J Biol Chem. 277:45122-8.

59. Montaner S, Sodhi A, Pece S, Mesri EA, Gutkind IS. (2001) The Kaposi's sarcoma-associated herpesvirus $G$ protein-coupled receptor promotes endothelial cell survival through the activation of Akt/protein kinase B. Cancer Res. 61, 2641-8.

60. Moore JP, Trkola A, Dragic T. (1997) Co-receptors for HIV-1 entry. Curr Opin Immunol. $9.551-62$. 
61. Moorman NJ, Virgin HW 4th, Speck SH. (2003) Disruption of the gene encoding the gammaHV68 V-GPCR leads to decreased efficiency of reactivation from latency. Virology 307, 179-90.

62. Munshi N, Ganju RK, Avraham 5. Mesri EA Groopman JE. (1999) Kaposis sarcoma-associated herpesvirus-encoded G protein-coupled receptor activation of c-jun amino-terminal kinase/stress-activated protein kinase and lyn kinase is mediated by related adhesion focal tyrosine kinase/proline-rich tyrosine kinase 2. 1 Biol Chem. 274, 31863-7.

63. Murphy PM, Baggiolini M, Charo IF, Hebert CA. Horuk $R$, Matsushima $K$, Miller LH, Oppenheim J), Power CA. (2000) International union of pharmacology. XXII. Nomenclature for chemokine receptors. Pharmacol Rev. 52, 145-76.

64. Nador RG, Milligan LL, Flore $O$, Wang $X$, Arvanitakis $L$, Knowles DM, Cesarman E. (2001) Expression of Kaposi's sarcoma-associated herpesvirus $G$ protein-coupled receptor monocistronic and bicistronic transcripts in primary effusion lymphomas. Virology 287, 62-70.

65. Nakano K, Tadagaki K, Isegawa Y, Aye MM, Zou P, Yamanishi K. (2003) Human herpesvirus 7 open reading frame $\mathrm{U} 12$ encodes a functional betachemokine receptor. / Virol. $77,8108-15$.

66. Neote K, DiGregorio D, Mak JY, Horuk R, Schall TJ. (1993) Molecular cloning, functional expression, and signaling characteristics of a $\mathrm{C}-\mathrm{C}$ chemokine receptor. Cell. 72:415-25.

67. Nicholas J, Cameron KR, Honess RW. (1992) Herpesvirus saimiri encodes homologues of $G$ protein-coupled receptors and cyclins. Nature 355, 362-5.

68. Nicholas J. (1996) Determination and analysis of the complete nucleotide sequence of human herpesvirus. / Virol. 70, 5975-89.

69. Ohagen A, Li L, Rosenzweig A, Gabuzda D. (2000) Cell-dependent mechanisms restrict the HIV type 1 coreceptor activity of US28, a chemokine receptor homalog encoded by human cytomegalovirus. AIDS Res Hum Retroviruses. 16,27-35.

70. Oliveira SA, Shenk TE. (2001) Murine cytomegalovirus M78 protein, a G protein-coupled receptor homologue, is a constituent of the virion and facilitates accumulation of immediate-early viral mRNA. Proc Nat/ Acad SciUS A. $98,3237-42$.

71. Pati S, Cavrois M, Guo HG, Foulke IS Jr, Kim J, Feldman RA, Reitz M. (2001) Activation of NF-kappaB by the human herpesvirus 8 chemokine receptor ORF74: evidence for a paracrine model of Kaposi's sarcoma pathogenesis. I Virol. $75,8660-73$.

72. Pati S, Foulke IS Jr, Barabitskaya O, Kim J, Nair BC, Hone D, Smart J, Feldman RA, Reitz M. (2003) Human herpesvirus 8-encoded vGPCR activates nuclear factor of activated $T$ cells and collaborates with human immunodeficiency virus type 1 Tat. $J$ Virol. $77,5759-73$.

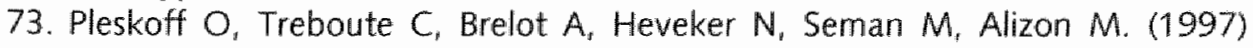
Identification of a chemokine receptor encoded by human cytomegalovirus as a cofactor for HIV-1 entry. Science. 276, 1874-8 
74. Pleskoff O, Treboute C, Alizon M. (1998) The cytomegalovirus-encoded chemokine receptor US28 can enhance cell-cell fusion mediated by different viral proteins. / Virol 72, 6389-97.

75. Polson $A G$. Wang $D$, DeRisi J, Ganem D. (2002) Modulation of host gene expression by the constitutively active $G$ protein-coupled receptor of Kaposi's sarcoma-associated herpesvirus. Cancer Res. 62, 4525-30.

76. Randolph-Habecker IR, Rahill B, Torok-Storb B, Vieira J, Kolattukudy PE, Rovin

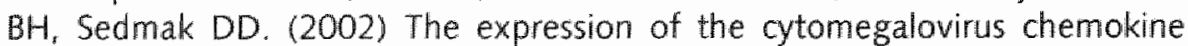
receptor homolog US28 sequesters biologically active CC chemokines and alters IL-8 production. Cytokine. 19,37-46.

77. Rawlinson WD, Farrell HE, Barrell BG. (1996) Analysis of the complete DNA sequence of murine cytomegalovirus. I Virol. 70, 8833-49.

78. Rochford R, Lutzke ML. Alfinito RS, Clavo A, Cardin RD. (2001) Kinetics of murine gammaherpesvirus 68 gene expression following infection of murine cells in culture and in mice. J Virol. 75, 4955-63.

79. Rosenkilde MM, Kledal TN, Brauner-Osborne H, Schwartz TW. (1999) Agonists and inverse agonists for the herpesvirus 8-encoded constitutively active seven-transmembrane oncogene product, ORF-74. I Biol Chem. 274, 956-61.

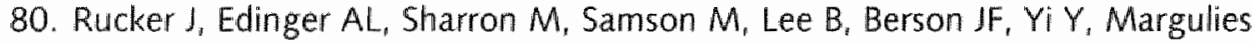
$B$, Collman $R G$, Doranz BJ, Parmentier $M$, Doms RW. (1997) Utilization of chemokine receptors, orphan receptors, and herpesvirus-encoded receptors by diverse human and simian immunodeficiency viruses. J Virol. 71, 8999-9007.

81. Schirmer EC, Wyatt LS, Yamanishi K, Rodriguez WJ, Frenkel N. (1991) Differentiation between two distinct classes of viruses now classified as human herpesvirus 6. Proc Nat/ Acad Sci U S A. 88, 5922-6.

82. Schwarz $M$, Murphy PM. (2001) Kaposi's sarcoma-associated herpesvirus $G$ protein-coupled receptor constitutively activates NF-kappa B and induces proinflammatory cytokine and chemokine production via a C-terminal signaling determinant. J Immuno/. 167, 505-13.

83. Shepard $L W$, Yang $M$, Xie $P$, Browning DD, Voyno-Yasenetskaya $T$, Kozasa $T$, Ye RD. (2001) Constitutive activation of NF-kappa B and secretion of interleukin-8 induced by the $G$ protein-coupled receptor of Kaposi's sarcomaassociated herpesvirus involve $G$ alpha(13) and RhoA. I Biol Chem. 276. 45979-87.

84. Smit MJ, Verzijl D, Casarosa P, Navis M. Timmerman H, Leurs R. (2002) Kaposi's sarcoma-associated herpesvirus-encoded $G$ protein-coupled receptor ORF74 constitutively activates p44/p42 MAPK and Akt via $G(i)$ and phospholipase C-dependent signaling pathways. J Virol. 76, 1744-52.

85. Sodhi A, Montaner S, Patel V, Zohar M, Bais C, Mesri EA, Gutkind IS. (2000) The Kaposi"s sarcoma-associated herpes virus $G$ protein-coupled receptor upregulates vascular endothelial growth factor expression and secretion through mitogen-activated protein kinase and p38 pathways acting on hypoxiainducible factor 1 alpha. Cancer Res. 60, 4873-80.

86. Streblow DN, Soderberg-Naucler C, Vieira J, Smith P, Wakabayashi $\mathbb{E}_{r}$ Ruchti F, Mattison K, Altschuler Y, Nelson JA. (1999) The human cytomegalovirus 
chemokine receptor US28 mediates vascular smooth muscle cell migration. Cell. $99,511-20$.

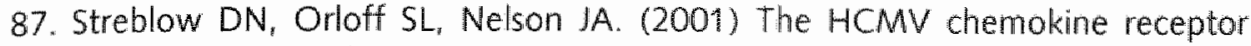
US28 is a potential target in vascular disease. Curr Drug Targets infect Disord. 1, $151-8$.

88. Streblow DN, Vomaske J, Smith P, Melnychuk R, Hall LA, Pancheva D. Smit $M$. Casarosa P, Schlaepfer DD. Nellson JA. (2003) Human cytomegalovirus chemokine US28 induced SMC migration is mediated by focal adhesion kinase and Src. I Biol Chem. 278, 50456-65

89. Telford EA, Watson MS, Aird HC, Perry J, Davison AJ. (1995) The DNA sequence of equine herpesvirus 2. $/$ Mol Biol. 249, 520-8.

90. Venkatesan S, Petrovic A, Locati $M$, Kim YO, Weissman D, Murphy PM. (2001) A membrane-proximal basic domain and cysteine cluster in the $C$ terminal tail of CCR5 constitute a bipartite motif critical for cell surface expression. J Bio/ Chem. 276, 40133-45.

91. Vieira $P$, de Waal-Malefyt $R$, Dang $M N$, Johnson $K E$, Kastelein $R$, Fiorentino DF, deVries JE, Roncarolo MG, Mosmann TR, Moore KW. (1991) Isolation and expression of human cytokine synthesis inhibitory factor CDNA clones: homology to Epstein-Barr virus open reading frame BCRFI. Proc Nat/ Acad SCi US A. 88, 1172-6.

92. Vieira I, Schall TJ, Corey L, Geballe AP. (1998) Functional analysis of the human cytomegalovirus US28 gene by insertion mutagenesis with the green fluorescent protein gene. J Virol. 72, 8158-65.

93. Vink C, Beisser PS, Bruggeman CA. (1999) Molecular mimicry by cytomegaloviruses. Function of cytomegalovirus-encoded homologues of $G$ protein-coupled receptors, MHC class I heavy chains and chemokines. intervirology. 42, 342-9.

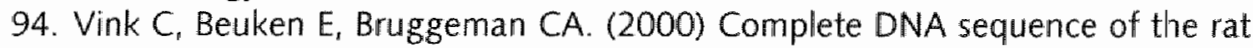
cytomegalovirus genome. J Virol. 74, 7656-65.

95. Wakeling MN, Roy DJ, Nash AA, Stewart JP. (2001) Characterization of the murine gammaherpesvirus 68 ORF74 product: a novel oncogenic G proteincoupled receptor. J Gen Virol. 82, 1187-97.

96. Waldhoer $M$, Kledal TN, Farrell $H$, Schwartz TW. (2002) Murine cytomegalovirus (CMV) M33 and human CMV US28 receptors exhibit similar constitutive signaling activities. $J$ Virol. 76,8161-8.

97. Waldhoer $M$, Casarosa $P$, Rosenkilde $M M$, Smit $M$, Leurs $R$, Whistler $U$, Schwartz TW. (2003) The carboxyl terminus of human cytomegalovirusencoded 7 transmembrane receptor US28 camouflages agonism by mediating constitutive endocytosis. J Bio/ Chem. 278, 19473-82.

98. Yang TY, Chen SC, Leach MW, Manfra D, Homey B, Wiekowski M, Sullivan L,

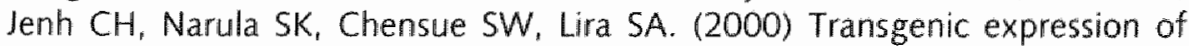
the chemokine receptor encoded by human herpesvirus 8 induces an angioproliferative disease resembling Kaposi's sarcoma. J Exp Med. 191, 445. 54. 
GPCRs encoded by members of the CMV UL33 gene family 


\section{CHAPTER 3}

The Rat Cytomegalovirus R33-Encoded G Protein-Coupled Receptor Signals in a Constitutive Fashion

J. Virol. (2002) 76:1328-1338 


\section{Abstract}

The rat cytomegalovirus (RCMV) $R 33$ gene is conserved among all betaherpesviruses and encodes a protein ( $P R 33$ ) that shows sequence similarity with chemokine-binding $G$ protein-coupled receptors (GPCRs). Previously, the physiological significance of the R33 gene was demonstrated by the finding that an RCMV strain with R33 deleted is severely attenuated in vivo and is unable to either enter or replicate in the salivary glands of infected rats. Here, we report that RCMV pR33 is expressed as functional GPCR that signals in an agonistindependent manner in both $\operatorname{COS}-7$ and Rat 2 cells. Transient expression of $p R 33$ in COS-7 cells results in constitutive activation of phospholipase $C$ (PLC) due to coupling to $G$ proteins of the $G_{G / 11}$ class. Interestingly, PLC activation is partially inhibited by cotransfection with Ga-transducin subunits, which indicates the involvement of GßY as well as Ga subunits in pR33-mediated signaling. Surprisingly, PLC activation is also partially inhibited by addition of pertussis toxin (PTX), suggesting that pR33 activates not only Gq but also $G_{i j o}$ proteins. The constitutive activation of $G_{i / 0}$ proteins by $p R 33$ is further demonstrated by the PTX-sensitive decrease of CRE-mediated transcription and the PTX-sensitive increase of both NF-KB- and SRE-mediated transcription. In contrast to its homolog of human herpesvirus 6B ( $\mathrm{PU} 12$ ), pR33 does not bind RANTES.

\section{Introduction}

Cytomegaloviruses (CMVs) are species-specific betaherpesviruses that cause acute, persisting, and latent infections in both humans and animals. The ability of CMVs to induce lifelong, latent infections implies that these viruses are highly adapted to their hosts. Specifically, they will have to employ sophisticated strategies in order to remain hidden from their host"s immune system. Among the CMV genes that are likely to be involved in these strategies are those encoding homologs of crucial immume effector or regulatory proteins of the host, such as $G$ protein-coupled receptors (GPCRs). These genes have probably been pirated by the wirus during the long coevolution of pathogen and host. GPCRs form a large and diverse family of receptors that function in signal transduction through cell membranes. They are composed of a central core domain consisting of seven transmembrane helices connected by three intracellular and three extracellular loops. The majority of these receptors activate $G$ proteins and are capable of transducing a wide variety of messages. Within the genomes of all sequenced CMVs, genes have been identified that potentially encode homologs of host cellular GPCRs. Human CMV (HCMV) carries four of these genes: US27, US28, UL33, and UL78 $(13,14)$. Only two of these, UL33 and UL78, were found to have counterparts in rat CMV (RCMV) (R33 and R78, respectively $[4,5,52]$ ) as well as murine CMV (MCMV) (M33 and M78, respectively $[17,41]$ ). Of the predicted amino acid sequences derived from the CMV GPCR-like genes, those encoded by HCMV US27 and US28 were found to have the highest similarity to chemokinebinding GPCRs (chemokine receptors). HCMV US28 was demonstrated to encode 
a functional chemokine receptor ( $p$ US28) which binds the $C C$ (or $\beta$-) chemolkines RANTES, MCP-1, MCP-3, MIP-1 $\alpha$, and MIP-1 $\beta(7,8,22,31,37)$ as well as the only known member of the $\mathrm{CX} 3 \mathrm{C}$ (or $\delta$-) chemokine family, $\mathrm{CX} 3 \mathrm{CL} 1$ (also known as fractalkine or neurotactin), which is a membrane-associated chemokine with a cytoplasmic domain (29). Upon CC-chemokine binding, pUS28 was shown to engage in intracellular signaling by the mobilization of intracellular calcium and activation of extracellular signal-related kinase $2(7)$. Remarkably, puS28 was also found to signal in the absence of exogenously added chemokines, by activating phospholipase C (PLC) as well as NF- $\mathrm{KB}$ in transiently transfected COS-7 cells (11). This constitutive, agonist-independent activity of pUS28 can be modulated by fractalkine, which acts as a partial inverse agonist, whereas $C C$-chemokines appear to function as neutral antagonists (11). Another intriguing property of pUS28 was identified by Streblow and colleagues (49). They demonstrated that HCMV infection of primary arterial smooth muscle cells (SMCs) resulted in cellular migration, whereas an HCMV recombinant that lacks a functional US28 gene was unable to promote migration. The expression of pUS28 in SMCs in the presence of CC-chemokines was sufficient to induce migration. It was hypothesized by Streblow et al. that HCMV may be using SMCs as a cellular vehicle to disseminate the virus in vivo (49). As described above, the HCMV UL33 gene has homologs inall sequenced betaherpesviruses, which underlines the biological relevance of the UL33 gene family. At present, this family consists of six members: HCMV UL33 (13, 14), MCMV M33 (41), and RCMV R33 (5) and the U12 genes of human herpesvirus $6 \mathrm{~A}(\mathrm{HHV}-6 \mathrm{~A})(24), \mathrm{HHV}-6 \mathrm{~B}(19,25)$, and $\mathrm{HHV}-7$ (38). The predicted amino acid sequences of the proteins encoded by the UL33-like gene family were found to comprise several features characteristic of chemokine receptors $(5,17)$. In addition, we found limited but significant sequence similarity between the UL33 family members and mammalian chemokine receptors CCR3 and, in particular. CCR10 (54). The biological significance of the UL33 family members has previously been demonstrated in studies using recombinant CMV's that carry either a disrupted UL33 (33), M33 (17), or R33 gene (5) in their genomes. In cell culture, each of these mutant wiruses replicated with similar efficiency as the corresponding wild-type (WT) viruses $(5,17,33)$. However, during in vivo infection, significant differences were observed between animals infected with the recombinants and those infected with the WT viruses. In contrast to their WT counterparts, viruses with M33 and R33 deleted could not be detected within the salivary glands of infected mice and rats, respectively $(5,17)$. This indicated that $M 33$ and $R 33$ play a role in virus dissemination to or replication in the salivary glands $(5,17)$. Furthermore, it was shown in the RCMV-rat model that R33 also has a more general function: a significantly lower mortality was seen among rats infected with RCMV from which R33 was deleted (RCMVAR33) than among those infected with WT RCMV (5). These results stressed the importance of the UL33-like genes in the pathogenesis of CMV infection. Although the HHV-6B member of the UL33 family, pU12, was reported to be a calcium-mobilizing receptor for several CCchemokines (25), not much is known about the biochemical, immunological, and pharmacological processes in which the CMV members of this protein family may function. We therefore set out to study the putative signaling properties of the 
RCMV R33-encoded protein (pR33). We report here that pR33 is a functional GPCR that signals in an agonist-independent, constitutive fashion in COS-7 as well as Rat2 cells.

\section{Materials and Methods}

Expression constructs. The sequence containing RCMV open reading frames (ORFs) R32 (partially), R33, and R34 (partially) (position 24384 to 29545 of the RCMV genome sequence [53]) was cloned as a PSA fragment into vector pUC119, generating plasmid RPst5. This plasmid was digested with $P_{V L}$, and the resulting $2.9 \cdot \mathrm{kb}$ fragment, which contains the complete R33 ORF, was treated with T4 DNA polymerase in the presence of deaxynucleoside triphosphates (dNTPs) in order to generate blunt ends. Subsequently, the blunt-ended fragment was cloned into the Hincll restriction site of pUC119. generating plasmid 0375. Then, a PCR-based procedure was used to change the sequence around the translation initiation codon of R33, 5'-CGGTATGGAC-3', into the sequence $5^{\prime}$ CGCCATCGAC-3", which contains an NCO restriction site (indicated in italiCs). This was carried out as follows. First, the $5^{\prime}$ end of R33 was amplified by means of PCR using primers R33.N-F and R33.N-R (Table 1) and p375 as a template. Then, the 228-bp PCR product was treated with T4 DNA polymerase and cloned into the Hincll site of pUC119, creating plasmid pre-379. The sequence upstream of R33 was amplified by PCR using primers R32.N-F and R32.N-R (Table 1) and p375 as a template. The 745-bp PCR product was treated with T4 DNA polymerase and subsequently digested with $\mathrm{Ncol}$. The resulting Ncol-blunt fragment was cloned into pre-379 by using the Smal site of the polylinker and the introduced $N$ col site at the translation initiation codon of R33, resulting in plasmid p379. Finally, the 946-bp Bglll-BsrGl fragment from $\mathrm{p} 375$ was exchanged for the Bg/l-Bs/Gl fragment from $\mathrm{p} 379$, which contains the introduced $\mathrm{NCO}$ site at the start codon of R33, generating plasmid $\mathrm{p} 383$. The 2.1-kb Bam HI-Smal fragment from p383, containing ORF R33 with the introduced Ncol site, was cloned into BamHII- and Hindl-digested pUC119. Subsequently, the $331 \mathrm{bp}$ BamHI-Ncol fragment inmediately upstream of R33 was deleted from the plasmid by digestion with BamH HI and NCol and treatment with the Klenow fragment of DNA polymerase I (Klenow) with dNTPS, followed by closing of the linear vector with T4 DNA ligase, resulting in plasmid pUC119/R33dN. The R33 expression vector pCDNA3/R33 was then generated by cloning the 1,680-bp Kon fragment containing ORF R33 from pUC119/R33dN into Kpnl-digested pcDNA3 (Invitrogen, Groningen, The Netherlands). The Kpn sites of pUC119/R33dN are derived from the pUC119 polylinker, located $5^{\prime}$ of the translation initiation codon of ORF R33, and the RCMV sequence downstream of the ORF R33 stop codon (corresponding to position 27950 of the RCMV sequence). The orientation of ORF R33 in pCDNA3/R33 was checked by restriction enzyme analysis.

The expression vector PCDNA3/EGFP was generated by digestion of pEGFP-N4 (Clontech, Palo Alto, Calif.) with BamHII and Not and cloning the resulting 739-bp fragment into BamHI- and Not-digested pcDNA3. For the 
construction of expression vector PCDNA3/EGFP-R33, a BspHI site was introduced immediately downstream of the enhanced green fluorescent protein (EGFP) ORF. This was carried out by means of PCR with primers GFP.CN.F and EGFP.N1-R (Table 1), using pEGFP-N1 as a template. The amplified fragment of 829 bp was treated with T4 DNA polymerase and the blunt-ended fragment was subsequently cloned into Hindl-digested pUC119, generating pUC119-EGFP. Then, the 720-bp NCol-BspHI fragment from PUC119/EGFP was cloned into the introduced NCol site at the translation initiation codon of $R 33$ within plasmid $p 383$, resulting in plasmid $p 383$-EGFP. The orientation of the EGFP ORF was checked by restriction enzyme analysis. Then, p383-EGFP was digested with Ncol and treated with Klenow. Subsequently, the DNA was digested with Apal to generate a $2.4-\mathrm{kb}$ blunt-Apal fragment which contains the EGFP ORF fused to R33. This fragment was cloned into ECORV- and Apal-digested pCDNA3, resulting in the expression vector PCDNA3/EGFP-R33.

TABLE 1. PCR primers used in this study

\begin{tabular}{|c|c|c|c|c|c|}
\hline Prinier & Sequence ${ }^{*}$ & $\begin{array}{l}\text { Restriction } \\
\text { site(s) }\end{array}$ & Somine & Positions & \\
\hline GFP CNF & 5-ATAAGAATTCCACATCCGCTAGCGCTACCG-3" & Econi & PECFP.NH & $574-6033$ & + \\
\hline ECFPNA & 5- TATATCGCGACTCATGAACTIGT ACAGCTCOTCC-3" & Nhut, Bspthi & DECPP-NH & $1380-1403$ & \\
\hline R32.NF & 5'-TCOCACATCTCCCOCCACCCC- $3^{\prime}$ & & RCMV Benone & $25535-25555$ & 4 \\
\hline N32NR & 5.TATACCATGGCGOTCCCGTCTCCOTC-3' & Acol & RCMV genorne & $29253-26290$ & 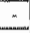 \\
\hline FA3.NF & 5-TAATCCATGGACGTGCTGCTGGGGAC-3' & $\mathrm{MCO}$ & RCMV genonie. & $26271-26290$ & + \\
\hline R33.NR & 5-GGTTCGTCATGIACAGGOTCGGEGTK-3' & & RCMV genome & $26474-26499$ & \\
\hline $\mathrm{R3} 33 . \mathrm{CF}$ & 5-RCOTGGTGGTOCAGACGCCGTTE-3' & & RCMV pename & $27025-27047$ & t" \\
\hline $\mathrm{R} 33, \mathrm{CR}$ & 5-CGTCTAGACAGTTCGGCGGCGCAC-3* & $x b a b l$ & RCMV genante & $27415-27438$ & \\
\hline R3A.CF & $5^{\circ}$ ACTOICTAGACGOCAGATCGCCGCC.3' & Mball & RCMV genorne & $27427-27451$ & + \\
\hline R34.CR & $3^{\prime}$ - GCTTCTCCGTCTCCCCOCGCC-3" & & RCMV Bename & $28024-28044$ & \\
\hline
\end{tabular}

a Underined sequences indicate restriction enzyme recognition sites; sequences in boldface type differ from that of the original sequence as described in the columns for source and positions. $t$, orientation of the sequence is identical to the published sequence between the indicated positions; sequence is complementary to the published sequence between the indicated positions.

In order to generate the pCDNA3/R33-EGFP expression vector, a pUC119 vector was created in which the $S p h$ and $X b a l$ sites of the polylinker were destroyed (pre-376). This was carried out as follows. pUC119 was digested with Sphl and treated with T4 polymerase in the presence of dNTPs, and the linear vector was closed with T4 DNA ligase. Subsequently, the vector was digested with $X b a l$, treated with Klenow, and closed with T4 DNA ligase, generating plasmid pre-376. The previously described $2.9-\mathrm{kb}$ P $\mathrm{k}$. fragment containing the complete R33 ORF was cloned into the Hind site of pre-376, generating plasmid p376. Then, a PCR-based procedure was used to modify the sequence around the stop codon of R33, 5'-TGCTGAGTCG-3", into the sequence 5'-TGTCTAGACG-3', which contains an $X 6$ al restriction site (in italics) and changes the R33 stop codon to a leucine codon. This was performed as follows. First the $3^{\prime}$ end of ORF R33 was amplified by PCR with primers R33.C.F and R33.C-R (Table 1), using p375 as a template. The 413-bp PCR product was digested with Sph and $X b a l$ and cloned into Sph- and Xbal-digested pUC119, generating plasmid pre-380 (the 5ph restriction site in $\mathrm{R} 33$ corresponds to position 27134 of the RCMV sequence). Then, the sequence downstream of the ORF R33 stop codon was amplified by PCR with primers R34.C-F and R34.C-R (Table 1), using P375 as a template. The 
amplified fragment of 617 bp was digested with Asp718 and Xbal and cloned into the corresponding sites of pre-380, resulting in plasmid p380 (the Asp 718 site in R34 corresponds to position 27947 of the RCMV sequence). Finally, the 737-bp Sph-Nrul fragment of p376 (the Nrul restriction site corresponds to position 27872 of the RCMV sequence) was exchanged for the Sph-Nrd fragment of p380, which contains the introduced $X b a$ al site in the R33 ORF, resulting in plasmid p384. Before the EGFP ORF could be cloned immediately downstream of R33, a part of the sequence upstream of the EGFP ORF in PEGFP-N1 was deleted. This was carried out by digestion of plasmid pEGFP-N1 with BamHI and BgII and subsequent closing of the linearized vector, resulting in plasmid $\mathrm{p} 368$. Then, the 768 -bp Nhel Xbal fragment from plasmid $p 368$, which contains the EGFP ORF, was cloned into the introduced Xbal site of $R 33$ in p384, resulting in plasmid p384-EGFP. The orientation of the EGFP ORF was checked by restriction enzyme analysis. Plasmid p384-EGFP was digested with BamHI and Noti, and the resulting 2.3-kb fragment containing the R33 ORF fused to EGFP was cloned into BannHIand Not-digested pcDNA3, resulting in the expression vector pcDNA3/R33-EGFP.

The cDNA encoding HCMV US28 (AD169 strain) in pCDNA3 (pCDNA3) US28) (11) was obtained from R. Doms (University of Pennsylvania, Philadelphia). The cDNA encoding human CCR10 (26) in pCDNA3 (PCDNA3/CCR10) was obtained from C. Gerard (Ina Sue Perlmutter Laboratory, Boston, Mass.). The CDNA of human CCR3 in PCDNA1 was provided by C. Tensen (Free University, Amsterdam, The Netherlands). The CCR3 CDNA was recloned in pcDNA3 by cutting the CCR3 fragment out of pCDNA1 using the flanking Xbal and Hindil sites in the PCDNA1 polylinker and cloning the fragment in the corresponding polylinker sites of pcDNA3, creating pCDNA3/CCR3. The pCDNA3-derived vectors expressing $G$ protein receptor kinase $2\left(G R K_{2}\right)$ (pCDNA3/GRK $)$ and $G R K_{2}{ }^{K 220 R}$ (pCDNA3/GRK ${ }_{2}{ }^{K 220 R}$ ) (18) were provided by S. Cotecchia (University of Lausanne, Lausanne, Switzerland). The $G \alpha_{1}, G \alpha_{q}, G \alpha_{11}$, and $G \alpha_{16}$ expression vectors (pcDNA3/G $\alpha_{r}, p c D N A 3 / G \alpha_{c}, p C M V 5 / G \alpha_{11}$, and $\mathrm{pC} 1 \mathrm{H} 1 / \mathrm{G} \alpha_{16}$, respectively) were

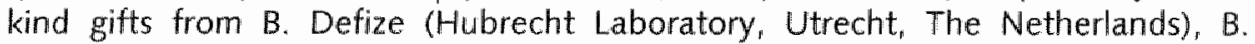
Conklin (University of California, San Francisco), H. Umemori (University of Tokyo, Tokyo, Japan), and S. Rees (University of Glasgow, Glasgow, United Kingdom), respectively. The reporter plasmids pTLNC-21CRE and pTLNC-3SRE (21) were obtained from W. Born (National Jewish Medical and Research Center , Denver, Colo.). The pNF-kBLuc vector was purchased from Stratagene (La Jolla, Callif). The integrity of all DNA constructs was verified by sequence analysis.

Cell culture and transfection. COS-7 cells (ATCC CRL-1651) and Rat2 cells (TK; ATCC CRL-1764) were cultured as described previously $(4,11)$. Transfection of Rat2 cells was performed on $80 \%$ confluently grown monolayers by using DEAE-dextran (final concentration, $0.4 \mathrm{mg} / \mathrm{ml}$ ) in serum-free Eagle's minimal essential medium with Earle's balanced salt solution (EMEM) supplemented with 2 $\mathrm{mM} \mathrm{L-glutamine}$, and 1 nonessential amino acids (NEAA). After $2 \mathrm{~h}$ of incubation at $5 \% \mathrm{CO} 2$ and $37^{\circ} \mathrm{C}$ the transfection medium was aspirated and the cells were treated with 10\% dimethyl sulfoxide in phosphatebuffered saline (PBS) for $1 \mathrm{~min}$. Subsequently, the cells were washed three times with PBS and further grown at 
$5 \% \mathrm{CO}$ and $37^{\circ} \mathrm{C}$ in serum-free EMEM containing $2 \mathrm{mM} \mathrm{L}$-glutamine and 1 NEAA. Transfection of COS-7 cells was carried out as described previously (11).

Confocal imaging. Transiently transfected cells (COS.7 or Rat2) were grown on glass coverslips and were fixed for 20 min with $3.7 \%$ Formol in PBS 48 $h$ after transfection. To stain the trans-Golgi complex, cells were washed three times with PBS and incubated with $1 \mathrm{M}$ Bodipy TR ceramide (Molecular Probes, Leiden, The Netherlands) and 1\% bovine serum abumin (BSA) (Sigma) in PBS for $30 \mathrm{~min}$ at $4^{\circ} \mathrm{C}$. For staining of the endoplasmic reticulum (ER), cells were permeabilized with $0.05 \%$ NP-40 (Boehringer Mannheim, Mannheim, Germany) in PBS for $20 \mathrm{~min}$ and subsequently incubated at $37^{\circ} \mathrm{C}$ for $1.5 \mathrm{~h}$ with mouse monoclonal antibody IID8 (directed against SERCA 2) (ABR, Golden, Collo) in PBS containing $1 \%$ BSA, washed three times with PBS, and incubated for $1.5 \mathrm{~h}$ at $37^{\circ} \mathrm{C}$ with rabbit anti-mouse-rhodamine (1:50 in PBS; DAKO, Glostrup, Denmark). Thereafter cells were washed three times with PBS and the coverslips were mounted in $90 \%$ glycerol containing $0.02 \mathrm{M}$ Tris $\mathrm{HCl}\left(\mathrm{pH} \mathrm{8.0)}, 0.002 \% \mathrm{NaN}_{3}\right.$, and $2 \%$ DABCO [1,4-diazabicyclo- $(2,2,2)$-octane; Merck, Darmstadt, Germany]. Confocal images were collected at wavelengths of 488 and $568 \mathrm{~nm}$ using an $\mathrm{MRC}$ 600 confocal microscope equipped with an oil immersion objective (40 magnification, numerical aperture 1.3; Bio-Rad, Hemel Hempstead, United Kingdom) as described previously (9). The digital images were projected and merged using Confocal Assistance software from Bio-Rad (Veenendaal, The Netherlands). EGFP-based monolayer enzyme-linked immunosorbent assay (ELISA). Transfected cells were seeded in 48-well plates (Costar). After $48 \mathrm{~h}$ of incubation, the monolayers were washed once with Tris-buffered saline (TBS) (50 $\mathrm{mM}$ Tris, $150 \mathrm{mM} \mathrm{NaCl}[\mathrm{pH} 7.5]$ ) and fixed for $30 \mathrm{~min}$ with $4 \%$ paraformaldehyde in PBS. Subsequently, cells were washed three times with TBS and permeabilized with $0.5 \%$ NP-40 in TBS. After $30 \mathrm{~min}$, the permeabilization solution was replaced with blocking buffer $\left(1 \%\right.$ fat-free milk, $0.1 \mathrm{M} \mathrm{NaHCO}_{3}[\mathrm{pH}$ 8.6]) and the cells were incubated for $4 \mathrm{~h}$ at room temperature. Then, the blocking buffer was replaced with the primary antibody solution containing a 1:100 dilution of anti-EGFP polyclonal antibody (Clontech) in TBS with $0.1 \%$ BSA. The cells were incubated overnight at $4^{\circ} \mathrm{C}$ with shaking. The monolayers were washed three times with TBS, after which the secondary antibody containing a 1:2,500 dilution of goat anti-rabbit-horseradish peroxidase conjugate (Bio-Rad) was added. After 2 $h$ of incubation at room temperature, the cells were washed three times with TBS and the OPD substrate solution ( $5 \mathrm{mM}$ O-phenylenediamine [Sigma], $0.03 \%$ $\mathrm{H}_{2} \mathrm{O}_{2}$ in $0_{.1} \mathrm{M}$ citrate-phosphate buffer [pH 5.0]) was applied for approximately $10 \mathrm{~min}$. The coloring reaction was stopped by the addition of $1 \mathrm{M} \mathrm{H}_{2} \mathrm{SO}_{4}$, samples were taken from the supernatants, and the optical density was measured in a victor2 Wallac multilabel counter at $490 \mathrm{~nm}$.

PHJinositol phosphate production. Inositol phosphate production in transfected COS-7 cells was determined as described previously (11).

Reporter assays. COS-7 cells were transiently transfected with one of the following reporter plasmids: pNF-KB-LUC (NF-KB assay), pTLNC-21CRE (cyclic 
AMP [CAMP]-responsive element [CRE] assay), pTLNC-3SRE serum-responsive promoter element [SRE] assay) ( $5 \mathrm{~g} / 10^{6}$ cells), and one of the GPCR expressing plasmids. Transfected cells were seeded in 96-well white plates (Costar) in serumfree medium either in the presence or absence of pertussis toxin (PTX) (100 $\mathrm{ng} / \mathrm{ml}$ ) (all assays) or human or rat RANTES (100 nM, NF-KB and SRE assay). To cells cotransfected with the CRE reporter plasmid, $10 \mathrm{M}$ forskolin was added $24 \mathrm{~h}$ after transfection, either in the presence or absence of human or rat RANTES (100 $\mathrm{nM}$ ). After a 6 -h incubation, luciferase activity was assayed by aspiration of the culture medium and addition of 251 of luciferase assay reagent $(0.83 \mathrm{mM} \mathrm{ATP}$, $0.83 \mathrm{mM}$ D-luciferin [Duchefa Biochemie B.V., Haarlem, The Netherlands], 18.7 $\mathrm{mM} \mathrm{MgCl}, 0.78 \mathrm{M} \mathrm{Na}_{2} \mathrm{H}_{2} \mathrm{P}_{2} \mathrm{O}_{7}, 38.9 \mathrm{mM}$ Tris [pH 7.8], $0.39 \%$ [vol/vol] glycerol, $0.03 \%$ [vol/vol] Triton $X-100$, and $2.6 \mathrm{M}$ dithiothreitol). After a 5-min incubation, the relative luminescence was measured for $3 \mathrm{~s}$ using a Victor ${ }^{2}$ Wallac multilabel counter. For cells transfected with either the NF-кB or the SRE reporter constructs, luciferase activity was measured $48 \mathrm{~h}$ after transfection using the same protocol.

Chemokine binding assay. Human and rat RANTES were labeled with ${ }^{125}$ using the lodo-gen method (Pierce, Rockford, III.) according to the manufacturer's protocol. ${ }^{125}$ I-labeled RANTES was separated from free iodine $(99 \%)$ using a 25 $\mathrm{cm}, 10-\mathrm{ml}$ Sephadex G-25 gel filtration column (ICN Pharmaceuticals Inc., Costa Mesa, Calif.). lodine incorporation and specific activity were determined via precipitation of the protein by the trichloroacetic acid (TCA) method (6). Transiently transfected cells were seeded in 24-well plates. in saturation experiments, binding was performed $48 \mathrm{~h}$ after transfection on whole cells for $3 \mathrm{~h}$ at $4^{\circ} \mathrm{C}$ using different concentrations of ${ }^{125}$ l-labeled human or rat RANTES (from 0.1 to $6 \mathrm{nM}$ ) in binding buffer (50 mM HEPES [pH 7.4], $1 \mathrm{mM} \mathrm{CaCl}, 5 \mathrm{mM}$ $\mathrm{MgCl}_{2}$, and $0.5 \% \mathrm{BSA}$ ). Nonspecific binding was determined in the presence of $0.1 \mathrm{M}$ unlabeled competitor (human or rat RANTES). In competition experiments, cells were incubated with $0.6 \mathrm{nM}{ }^{125}$-labeled human RANTES and various amounts of unlabeled human or rat RANTES. After incubation, cells were washed four times with binding buffer supplemented with $0.5 \mathrm{M} \mathrm{NaCl}$.

Statistical analysis. All data shown are expressed as mean standard error. Statistical analysis was carried out by Student's $t$ tests. $P$ values of 0.05 were considered to indicate a significant difference.

\section{Results}

RCMV PR33 and PR33-EGFP signal constitutively in COS-7 cells. To test whether the RCMV R33-encoded protein (pR33) functions as a GPCR in vitro, we set out to examine the effect of $\mathrm{pR} 33$ expression on the accumulation of inositol phosphates (InsP) in COS-7 cells. To this end, the cells were transiently transfected with either of four different expression constructs, which encode native RCMV pR33 (pCDNA3/R33), pR33-EGFP (pCDNA3/R33-EGFP), pEGFP-R33 (pCDNA3/EGFP-R33) or no protein (PCDNA3). At $24 \mathrm{~h}$ after transfection, the cells 
were incubated with ${ }^{3} \mathrm{H}$-labeled inositol, and at $48 \mathrm{~h}$ after transfection, the accumulation of radiolabeled InsP was measured. As shown in Fig. 1A, transfection of increasing amounts of both pCDNA3/R33 and pCDNA3/R33-EGFP resulted in increased $\left[{ }^{3} \mathrm{H}\right]$ lns $\mathrm{P}$ production within the cells. The InsP production in cells transfected with pCDNA3/R33 and PCDNA3/R33-EGFP only ( $4.0 \mathrm{~g} / 10^{6}$ cells) was 3.2 times higher than that in cells transfected with an equal amount of pCDNA3 only. Interestingly, a significant difference in InsP levels was not observed between pcDNA3- and PCDNA3/EGFP-R33-transfected cells (data not shown). Taken together, these data indicate that (i) these proteins activate signaling pathways leading to increased InsP production rates and (ii) these proteins signal in an agonist-independent fashion. To examine the expression levels as well as intracellular localization of the R33-encoded proteins, both ELISA and confocal microscopy were performed. Since appropriate antipR33 antibodies were unavailable, we could investigate only the expression of the EGFP fusion proteins by virtue of the presence of the EGFP tag in these proteins. The semiquantitative, ELISA-based monolayer assay showed that transfection of increasing amounts of pCDNA3/R33-EGFP resulted in increasing intracellular levels of PR33-EGFP (Fig $1 B$ ). By contrast, expression of PEGFP-R33 was not detected (data not shown). These expression data are in agreement with the activity of these EGFP-tagged proteins in the InsP accumulation assay.

The cellular expression of pR33-EGFP was studied further by confocal microscopy. Figure 1D shows that the EGFP fluorescence colocalizes with intracellular, perinuclear vesicles as well as with the cell membrane of $\mathrm{COS}_{-7} 7$ cells transfected with pcDNA3/R33-EGFP. This expression pattern differs considerably from that seen in nonfused EGFP-expressing COS-7 cells, in which EGFP is seen dispersed throughout the nucleus and cytoplasm (Fig. 1C). These results strongly suggest that PR33-EGFP is properly expressed on the cell surface of transfected cells. In order to identify the intracellular vesicles to which pR33-EGFP localized, we stained the cells either with a trans-Golgi-specific marker (Bodipy TR ceramide) or with antibodies directed against ER-specific SERCA proteins. However, as shown in Fig. $1 E$ and $F$, the EGFP signal does not colocalize with the signals that were generated with these compartmentspecific markers. This indicated that pR33-EGFP localizes to intracellular compartments other than ER or trans-Golgi. Nevertheless, other attempts to identify these compartments have not yet been undertaken. Whether the presence of $\mathrm{PR} 33$-EGFP in these compartments is the consequence of high level of expression of this protein is not known.

To evaluate the specificity of the constitutive activity of pR33 in the InsP accumulation assay, we compared the activity of this protein with that of two mammalian CC chemokine receptors, CCR3 and CCR10, with which pR33 shares some homology, and a constitutively active viral GPCR, HCMV pUS28. As shown in Fig. 1G, cells transfected with either pCDNA3/R33 or pCDNA3/US28 produced significantly higher levels of InsP than cells transfected with either pCDNA3 (mock) or the mammalian GPCR expression constructs. These data show that constitutive activity of GPCRs in the InsP assay is not a general phenomenon but rather a characteristic of a subset of receptors, as was recognized previously (11). In summary, we have found pR33-EGFP to colocalize with the cell membrane of 
A

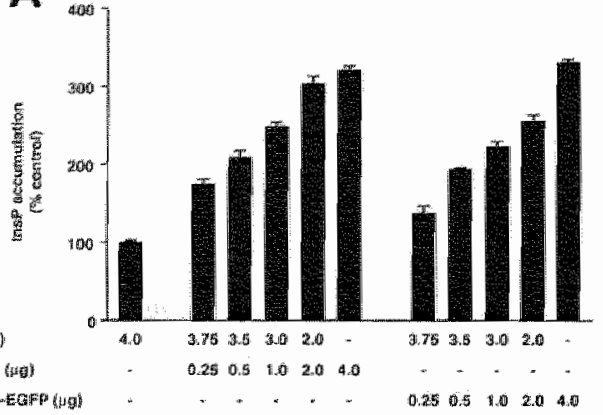

B

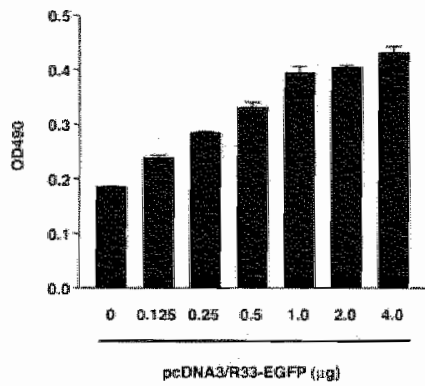

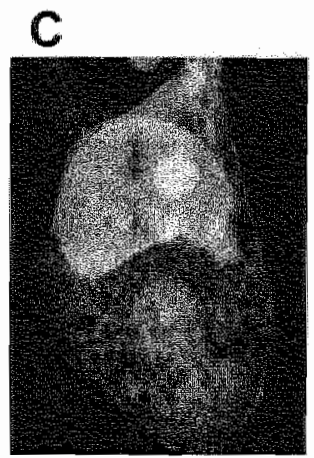
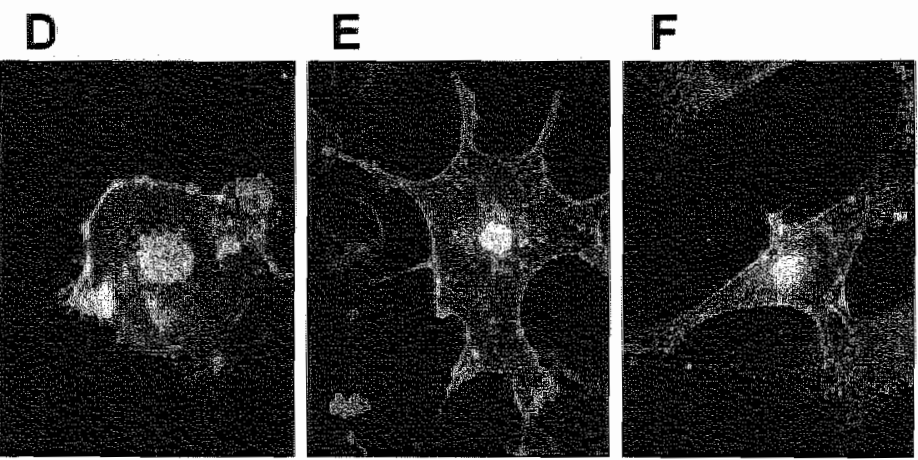

G

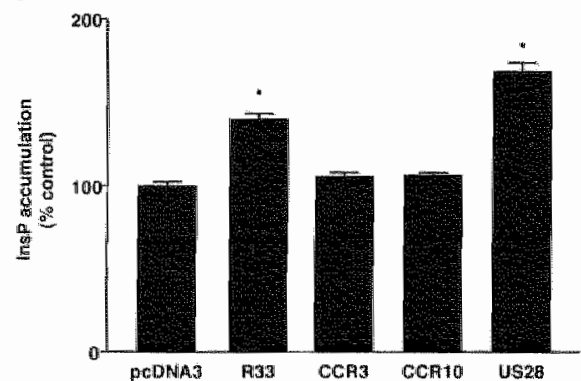

Fig. 1. PR33- and pR33-EGFP.mediated induction of inositol phosphate (InsP) accumulation. (A) CO5-7 cels $\left(10^{6}\right)$ were transiently transfected with either pCDNA3, pCDNA3/R33, or pCDNA3/R33EGFP. At $4.8 \mathrm{~h}$ after transfection, the InsP accumulation was measured. (B) Expression of pR33-EGIFP. COS-7 cells were transiently transfected with various concentrations of pCDNA3/R33-ECFP. After permeabilization, the cells were immunologically stained using an anti-EGFP polyclonal antiserum. The staining was quantified by measuring the optical density at $490 \mathrm{~nm}$ (OD 490 ) by spectrophotometry. (C and D) Cellular localization of EGFP (C) and PR33-EGFP (D) . COS-7 cells were transiently transfected with either PCDNA3/EGFP or PCDNA3/R33-EGFP, fixed, stained using propidium iodide (to visualize nucleic acids), and subjected to confocal microscopy at 488 and $568 \mathrm{~nm}$. (E) Cellular bocalization of PR33-EGFP and the ER. PCDNA3/R33-EGFPtransfected cells were stained using SERCA 2-Specific antibodies. (F)Cellular localization of PR33-EGFP and the Golgi apparatus. PCDNA3/R33-EGFPtransfected cells were stained using a trans-Golgi marker. (G) Modulation of Ins P accumulation by various receptors. The InsP accumulation was determined after transient transfection of COS-7 cells with either pCDNA3, PCDNA3/R33 (R33), pCDNA3/CCR33 (CCR3), PCDNA3/CCR10 (CCR10), or pcDNA3/US28 (US28) at $0.5 \mu \mathrm{g}$ of DNA $10^{6}$ cells. A representative experiment performed in triplicate is shown. Each experiment was repeated at least twice. The asterisks indicate a statistically significant difference (P 0.05) with data from pCDNA3-transfected cells. Error bars, standard error of the mean. 
transfected COS-7 cells and to induce signaling pathways in an expression leveldependent fashion, leading to the production of insP. Since both pCDNA3/R33 EGFP-and PCDNA3/R33-transfected cells demonstrate similar activities in the InsP assay, we infer that PR33 is expressed on the surface of transfected cells in a similar fashion as was demonstrated for pR33-EGFP.

$p R 33$ couples to $G$ proteins of the $G_{i q}$ and $G_{i 0}$ classes. An intracellular rise in Ins P levels is predominantly achieved following activation of PLC by G protein $\alpha$ subunits of the q class $\left(G \alpha_{q}\right)$. In addition, PLC activity can be stimulated by free $G$ protein $B$ y subunits (16). To investigate whether the constitutive rise in InsP accumulation that is seen in cells expressing pR33 and pR33/EGFP is indeed mediated through the interaction of these proteins with heterotrimeric $G$ proteins, COS-7 cells were transfected with both $\mathrm{pCDNA3/R33}$ and constructs expressing either the $G \alpha$ transducin subunit $\left(G \alpha_{1}\right)$, GRK , or $G R K_{2}{ }^{K 22013}$. Go $\alpha_{1}$ is known to sequester $\beta \gamma$ subunits, whereas both $\mathrm{GRK}_{2}$ and $\mathrm{GRK}_{2}{ }^{\mathrm{K} 220 \mathrm{R}}$ not only scavenge $\beta \gamma$ subunits but also specifically inhibit $G \alpha_{q}$ activation $(10,20,40)$. In addition, in contrast to $\mathrm{GRK}_{2}{ }^{\mathrm{K} 22 \mathrm{O}}$, $\mathrm{GRK}_{2}$ can phosphorylate GPCRs, leading to internalization and degradation of the receptors (18). As shown in Fig. 2A, cotransfection of pcDNA3/R33 and pcDNA3/Go, resulted in a lower level of InsP accumulation $(80 \%)$ than transfection of pCDNA3/R33 (basal) alone $(100 \%)$. However, even lower levels of InsP were seen after cotransfection of pCDNA3/R33 and either pcDNA3/GRK ${ }_{2}$ or $\mathrm{PCDNA3/} \mathrm{GRK}_{2}{ }^{\mathrm{N} 220 \mathrm{R}}$ (25 and $40 \%$, respectively). These InsP levels are similar to those measured in pCDNA3-transfected cells $(30 \%)$. Together, these results suggest that the InsP production is mediated via coupling of $p R 33$ to $B \gamma$ as well as $G a_{q}$ subunits. Since COS-7 cells endogenously express only two members of the $G_{q}$ class, $G_{q}$ and $G_{11}(56)$, it is likely that the pR33-induced PLC activation is mediated by the $\alpha$ subunits of $G_{q}$ and/or $G_{11}$. In order to confirm this interaction of $\mathrm{pR} 33$ with the $\alpha$ subunits of $\mathrm{G}_{\mathrm{q} / 11}$ and to investigate the putative interaction with another member of the Go $\alpha_{9}$ family, $G \alpha_{16}$, which is not expressed endogenously by COS-7 cells, cells were cotransfected with both pCDNA3/R33 and constructs expressing either $G \alpha_{q^{\prime}} G \alpha_{11}$, or $G \alpha_{16}$. As shown in Fig. 2B, cotransfection of $\mathrm{pCDNA3/R33}$ with $\mathrm{pCMV} 5 / \mathrm{G} \alpha_{1}$ resulted in a higher level of Ins $\mathrm{P}$ production $(145 \%)$ than transfection of PCDNA3/R33 alone $(100 \%)$, whereas cotransfection of pcDNA3/R33 with either $\mathrm{pCDNA3} / \mathrm{G} \alpha_{9}$ or $\mathrm{pC} 1 \mathrm{H} 1 / \mathrm{G} \alpha_{16}$ did not change InsP production levels significantly compared to $p C D N A 3 / R 33$ alone.

These findings suggest that pR33 specifically activates $G_{11}$ in a constitutive fashion but does not couple constitutively to $G_{q}$ or $G_{16}$. Previously, it has been reported that PLC-activating $\beta \gamma$ subunits can be released by $G$ proteins of the $G_{i, 0}$ class (16). To examine if these $G_{i, 0}$ proteins are also involved in pR33-mediated constitutive PLC activation, we incubated pCDNA3- and pCDNA3/R33-transfected cells in the presence of a $G_{i j 0}$ inhibitor (PTX), and measured the InsP accumulation. Figure 2A shows that the InsP accumulation level in pcDNA3/R33-transfected cells is significantly lower in the presence of PTX $(75 \%)$ than in the absence of PTX $(100 \%)$, indicating that at least part of the pR33-induced InsP production is mediated via $G_{i / 0}$ proteins. 
A

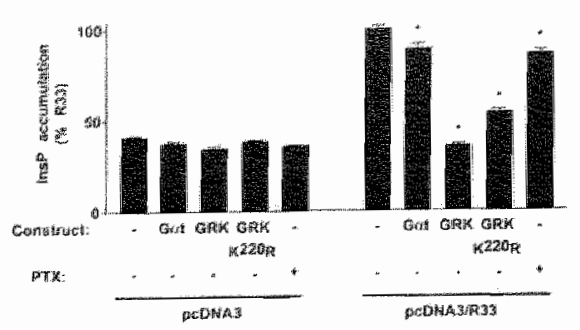

B

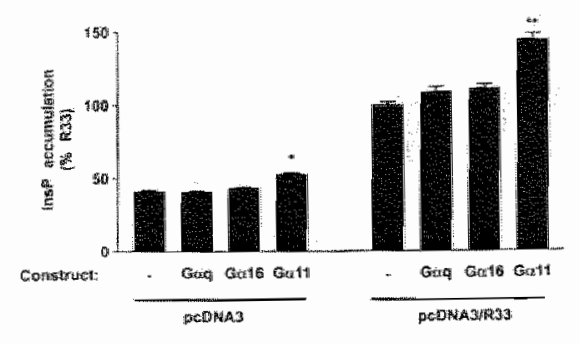

Fig. 2. (A) Effects of Ga transducin subunits, GRKs, and PTX on pR33-mediated InsP accumulation. COS 7 cells were transiently transfected with either PCDNA3 or PCDNA3/R33 in the presence of either PCDNA3/Gat (Gat), pCDNA3/GRK2 (GRK $)$, or pICNA/GRK $2^{K 220 R}\left(G R K_{2}{ }^{K 22 R R}\right.$ ) teach canstruct at $2.0 \mu \mathrm{g}$ of DNA $/ 10^{6}$ cells). The ins $P$ accumulation was subsequently assessed either in the presence $(+)$ on absence (-) of PTX in the culture medium. (B) Effects of $G \alpha_{2 x} G \alpha_{16}$ and $G \alpha_{11}$ on pR33-mediated insP accumulation. CO5-7 cells were transiently transfected with either PCDNA3 or PCDNA3/R33 in the presence of either pCDNA3/Goq, $\mathrm{CC} 1 \mathrm{H} 1 / \mathrm{G \alpha} 16$, or $\mathrm{pCMV5} / \mathrm{G \alpha 11}$, and the InsP accumulation was assessed after $48 \mathrm{~h}$. Representative experiments performed in triplicate are shown. Each experiment was repeated at least three times. The asterisks indicate statistically significant differences $(P<0.05)$ between specific results and the result from pCDNA3/R33-transfected cells. Statistically significant differences $(P<0.05)$ were not found between results from the PCDNA3-transfected cells. Error bars, standard error of the mean.

pR33-induced inhibition of CRE-mediated transcription. The interaction of pR33 with $G$ proteins of the $G_{i / 0}$ class was studied in more detail using the CRE reporter assay. This assay allows detection of the inhibitory effect of activated $G \alpha_{i j o}$ subunits on adenylate cyclase (AC). The CRE assay is based onthe artificial stimulation of $A C$ with forskolin, which results in an increase of intracellular CAMP levels. The CAMP activates the CRE-binding protein (CREB), which can then bind and activate a CRE that controls transcription of a reporter gene (the luciferase gene). Hence, stimulation of cells carrying the CRE-luciferase gene with forskolin leads to increased production of luciferase transcripts and, subsequently, to higher levels of the luciferase protein, which can be quantified by measuring its activity. As described above, activated $G \alpha_{i, 0}$ subunits inhibit $A C$. Consequently, activation of these subunits by a GPCR in the CRE assay will result in lower luciferase levels and, thus, lower luciferase activity. To investigate whether pR33 can activate $G \alpha_{i / 0}$ subunits, we transfected COS-7 cells with the CRE-luciferase reporter construct and with either PCDNA3, pCDNA3/R33, or PCDNA3/R33-EGFP. Figure $3 A$ shows a plasmid concentration-dependent inhibition of luciferase activity in both PCDNA3/R33- and pCDNA3/R33-EGFP-transfected cells, which indicates that pR33 can indeed constitutively activate $G \alpha_{i / 0}$ subunits. As expected, this activation can be inhibited by PTX, as shown in Fig. 3B. In order to study the specificity of this activity, we also tested constructs expressing either CCR3, CCR10, or US28 in the CRE assay. However, in contrast to PCDNA3/R33, these constructs did not induce an activity significantly different from that induced by PCDNA3 alone (Fig. 3 C). 


\section{A}

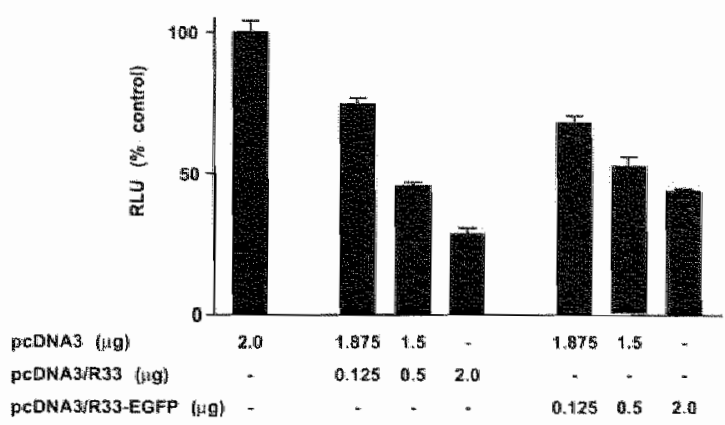

B

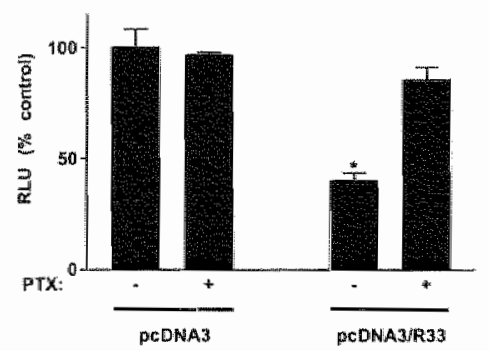

C

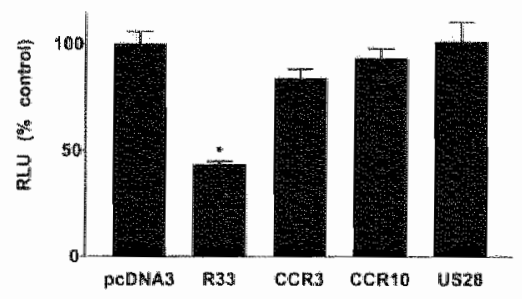

Fig. 3. pR33-mediated inhibition of forskolin-induced, CRE-driven luciferase expression. (A) COS-7 cells (105) were transiently transfected with reporter plasmid $p$ TLNC-21CRE (5.0 $\mu \mathrm{g}$ of DNA $/ 10^{5}$ cells) and with various amounts of either PCDNA3, PCDNA3/R33, or PCDNA3/R33-EGFP (in total, $2.0 \mu \mathrm{g}$ of DNA $10^{5}$ cells). When amounts of pCDNA3/R33 or PCDNA3/R33-EGFP lower than 2.0 $\mu \mathrm{g}$ were used, PCDNA3 was added to include a total of $2 \mathrm{~kg}$ of pcDNA3-derived plasmid peir transfection. At $18 \mathrm{~h}$ after transfection, the cells were stimulated with forskolin. Six hours later, the CRE-driven luciferase expression and activity was quantified, and expressed as relative light units (RLU). (B) Influence of PTX on the pR33-mediated inhibition of CRE-driven expression. PTX (100 $\mathrm{ng} / \mathrm{ml}$ ) was added to the culture medium at $2 \mathrm{~h}$ after transfection. (C) Influence of warious receptors on forskolin-stimulated, CRE-driven expression. The luciferase activity was deternined similarly aus described above, after transient transfection of COS-7 cells with either DCDNA3, PCDNA3/R33 (R33). PCDNA3/CCR3 (CCR3), PCDNA3/CCR10 (CCR10), or pCDNA3/US28 (US28) at $0.5 \mu \mathrm{g}$ of DNA/10 cells. Data are presented as percentages of the result for the control (pcDNA3-transfected cells in the absence of PTX). Representative experiments performed in triplicate are shown, and each experiment was repeated at least three times. An asterisk indicates data that are statistically significantly different $(P<0.05)$ from that for the control. Error bars, standard error of the mean.

pR33-mediated activation of NF-KB- and SRE-driven transcription. To assess the effect of constitutive pR33 signaling on the $N F-\kappa B$ promoter element and SRE, two additional reporter assays were used. In these assays, plasmid constructs are used in which the luciferase gene is placed under the control of either multiple SREs or the $N F-\kappa B$ promoter element. If receptor signaling induces upregulation of the intracellular concentration of activated $N F-\kappa B$ or serum response factor (SRF), an increase in activity will be measured in the $N F-\kappa B$ and 
SRE assay, respectively. Figure $4 A$ shows that PCDNA3/R33-transfected cells have a significantly higher activity in the NF-kB assay than pCDNA3-transfected celis. As in the CRE assay, the pR33-induced activity was completely blocked in the presence of PTX (Fig. 4A). A similar observation was made for the activity of pR33-EGFP in the NF- $k B$ assay (data not shown). We conclude that $p R 33$ induces an upregulation of activated $N F-K B$ that is mediated via a $G_{i / 0}$ protein-dependent pathway(s). Of the other GPCRs that we tested in the NF-KB assay, only pUS28 was found to be active (Fig. 4A). As described previously, the activation of $N F-\kappa B$ by pUS28 is dependent not on $G_{i, 0}$ protein-dependent pathways (since it is unaffected by the addition of PTX) but rather on $G_{q / 11}$ protein-dependent pathways (11).

Figure $4 B$ shows that pCDNA3/R33-transfected cells also have a significantly higher activity in the SRE assay than pCDNA3-transfected cells. Again, this activity as well as the activity of PCDNA3/R33-EGFP-transfected cells (data not shown) was blocked in the presence of PTX, indicating that pR33 induces an upregulation of activated SRF that is mediated via a $G_{i / 0}$ protein-dependent pathway(s). A moderate but significant activity in the SRE assay was also measured in cells transfected with constructs expressing pUS28 (Fig. 4B). However, in contrast to the activity of PR33, the activity of pUS28 was not significantly affected by addition of PTX.

A

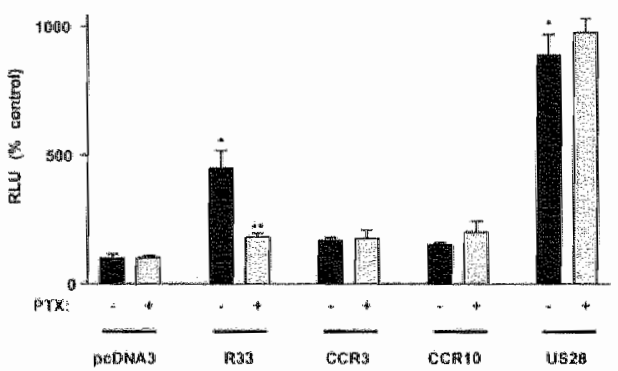

B

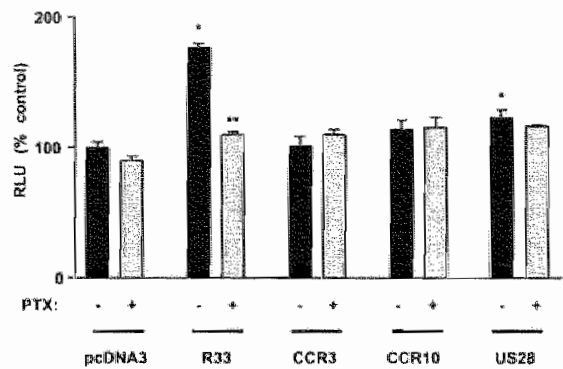

Fig. 4. pR33-mediated NF-kB and SRE activation. COS-7 cells $\left(10^{6}\right)$ were transiently transfected with either reporter plasmid $\mathrm{pNF}-K B$-LUC (A) or PTLNC-3SRE (B) $15.0 \mu \mathrm{g}$ DNA/10 cells) and with either PCDNA3, pCDNA3/R33 (R33), pCDNA3/CCR3 (CCR3), pCDNA3/CCR10 (CCR10), or pcDNA3/US28 (US28) at $0.5 \mu \mathrm{g}$ of DNA $10^{f}$ cells. At $48 \mathrm{~h}$ after transfection, luciferase activity was measured. The experiments were carried out either in the presence $(+)$ or absence $(-)$ of PTX in the culture medium. Representative experiments performed in triplicate are shown, and each experiment was repeated at least thee times. Single asterisks indicate differences statistically significant ( $P<0.05$ ) from data from PCDNA3-transfected cells (in the absence of PTX). Double asterisks (**) indicate statistically significant differences $(P<0.05)$ between data from PTX-treated and -untreated cells that were transfected with the same expression construct. Error bars, standard error of the mean.

pR33 is unable to bind RANTES. We previously reported that $p R 33$ shows similarity with CC-chemokine-binding GPCRs $(5,54)$. In addition, the PR33 homolog from HHV-6B, pU12, was shown to bind CC-chemokine RANTES (24). To test whether RANTES could also bind to and/or modulate the constitutive 
activity of $p R 33$, we transfected COS-7 cells with $P C D N A 3 / R 33$ and, as a positive control, pCDNA3/pUS28 and monitored the binding of either ${ }^{125}$-labeled human or rat RANTES by the transfected cells. Although pUS28 was found to bind human and rat RANTES with a moderate affinity $\left(K_{i}=0.9\right.$ and $15.8 \mathrm{nM}$, respectively) (Fig. 5B), binding of these chemokines by pR33 was not detected (Fig. 5A). Furthermore, the addition of human or rat RANTES in the culture medium of pCDNA3/R33-transfected COS-7 cells did not modulate the activity of pR33 in the InsP production, $N F-\kappa B$, and SRE assays (Fig. 5C). The addition of rat RANTES in

A

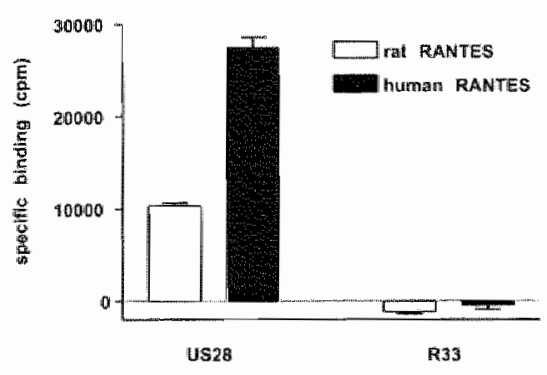

C

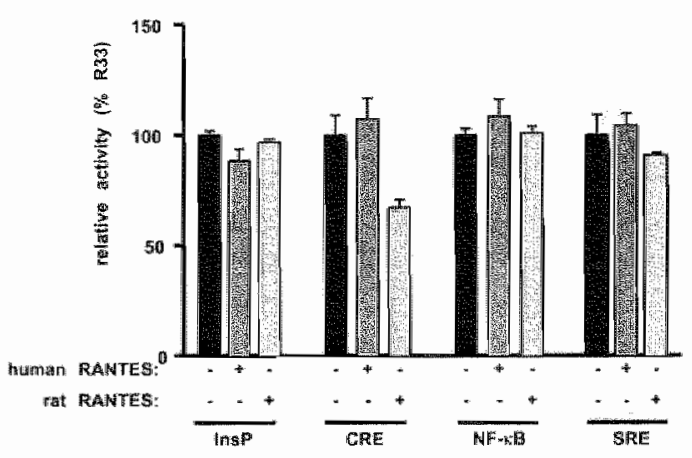

B

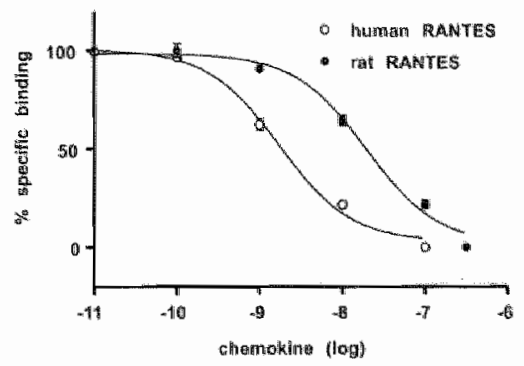

D

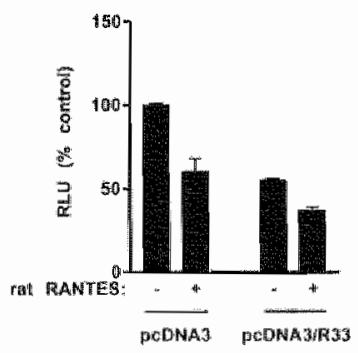

Fig. 5. pR33 does not bind rat RANTES. (A) Binding of human and rat RANTES by pUS28 and pR33. COS-7 cells were transiently transfected with either PCDNA3, pCDNA3/US28 (US28), or pCDNA3/R33 (R33). Binding was performed 48 h after transfection on whole cells using $6 n M M^{125}$. labeled human or rat RANTES. Nonspecific binding was determined in the presence of $0.1 \mu M$ unlabeled competitor thuman or rat RANTES). (B) Human and rat RANTES competition curves on pUS28. COS-7 cells were transiently transfected with pCDNA3/US28 and incubated with $0.6 \mathrm{nM}$ 125. labeled human RANTES and various amounts of unlabeled human or rat RANTES. (C) Influence of human and rat RANTES on PR33-mediated constitutive signaling, COS-7 cells were transiently transfected with either PCDNA3 or PCDNA3/R33. Human or rat RANTES was added to the supernatants, both in the [3H] inositol phosphate production assay (insP) and in the reporter gene assays (CRE, NF-KB, and SRE). Data are presented as percentages of pR33 activity $(100 \%)$. (D) Influence of rat RANTES on pCDNA3-- and pCDNA3/R33-transfected cells in the CRE assay. Error bars, standard error of the mean. 
the CRE assay resulted in a further inhibition of CRE-mediated transeription in pCDNA3/R33-transfected cells (Fig. 5C). However, a similar inhibitory effect of rat RANTES was seen in pcDNA3-transfected cells (Fig. 5D), indicating that this was not a specific pR33-mediated effect. Taken together, these findings suggest that, unlike HHV -6B pU12, RCMV pR33 does not bind and is not responsive to RANTES. In addition, several human chemokines of the CC (eotaxine, Teck, MCP-1), CX, C (fractalkine), and CXC class (IP-10, IP-9, GRO- $\alpha$, and interleukin-8 [IL-8]) were not able to change the activity of pR33 significantly in any of the signaling assays used in this study (data not shown).

\section{pR33- and PR33-EGFP-Induced stimulation of SRE-mediated transcription} in Rat2 cel/s. In previous experiments, GPCR activity was measured in COS-7 cells, which are well characterized and highly suitable for signal transduction studies. However, since these cells are not likely to represent appropriate hosts for efficient replication of the species-specific RCMV, we set out to test the activity of $p R 33$, PR33-EGFP, and pEGFP-R33 in rat cells (Rat2). These cells have previously been demonstrated to support full replication of RCMV (e.g., see reference 51). We first investigated the expression of PR33-EGFP in Rat2 cells by confocal microscopy and found the expression pattern of this protein to be similar to that in COS-7 cells (data not shown). This suggests that $p R 33$-EGFP may be properly expressed as a functional GPCR in Rat2 cells.

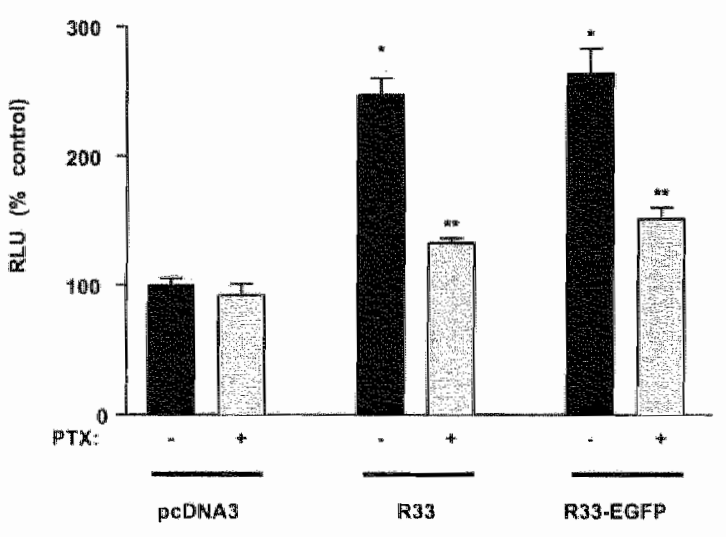

Fig. 6. PR33- and pR33-EGFP-mediated SRE activation in Rat2 cells. Rat2 cells $\left(10^{5}\right)$ were transiently transfected with reporter plasmid PTLNC-3SRE $\left(5.0 \mu \mathrm{\mu g}\right.$ of DNA/10 $0^{6}$ cells) and with either pCDNA3, pCDNA3/R33 (R33), or PCDNA3/R33-EGFP (R33-EGFP) at $0.5 \mu \mathrm{g}$ of DNA $/ 10^{6}$ cells. At $48 \mathrm{~h}$ after transfection, luciferase activity was measured. The experiment was done in six replicates, either in the presence (4) or absence $(-)$ of PTX in the culture medium. Single asterisks indicate differences statistically significant $(P<0.05$ ) from data from PCDNA3-transfected cells (in the absence of PTX). Double asterisks indicate statistically significant differences $(\mathbb{P}<0.05)$ between data from PTX-treated and -untreated cells that were transfected with the same expression construct. Error bars, standard error of the mean. 
To test whether pR33-EGFP and pR33 are capable of signaling in Rat2 cells, we transfected these cells with either PCDNA3/R33 or pCDNA3/R33-EGFP and tested their activity in the SRE assay. Indeed, both PR33 and PR33-EGFP were found to signal in an agonist-independent, constitutive fashion in Rat2 cells (Fig. 6). leading to a PTX-sensitive activation of SRE-driven transcription. Thus, pR33 and pR33-EGFP induce an upregulation of SRF that is mediated via a $G_{1: 0}$ proteindependent pathway(s) in both COS-7 and Rat2 cells. As of yet, we have not been able to detect pR33 activity in Rat2 cells in any of the other reported assays.

\section{Discussion}

The biological significance of the RCMV R33-like genes in the pathogenesis of CMV infections has previously been demonstrated in studies with recombinant viruses $(5,17)$. In contrast to their WT counterparts, RCMV and MCMV mutant viruses lacking a functional R33 or M33 gene, respectively, were unable to replicate in the salivary glands and displayed lower mortality rates in infected animals $(5,17)$. Although these findings illustrated the importance of the R33-like genes, not much was known about the biochemical or pharmacological properties of the proteins encoded by these genes. Here, we report that R33 encodes a membrane-associated protein that functions as a GPCR. Furthermore, we demonstrate for the first time that a member of the R33-like gene family encodes a constitutively active receptor that activates multiple signaling pathways in both COS-7 and Rat2 cells.

Currently, the concept of constitutive signaling by GPCRs is well accepted. It has been demonstrated for multiple endogenously expressed CPCRs, such as the $\mathrm{H} 3$ receptor in the rat brain (36). Although the biological relevance is still poorly understood, it is clear that constitutive activity can be of major pathophysiological significance. Various diseases, including proliferative disorders, have been described that are caused by GPCRs that are constitutively active due to naturally occurring mutations in these receptors $(42,43,46,48)$.

Previously, two other virus-encoded GPCRs were demonstrated to be constitutively active. The Kaposi's sarcoma-associated herpesvirus (KSHV) ORF74encoded GPCR (KSHV GPCR) and HCMV pUS28 both signal in an agonistindependent fashion, resulting in constitutive activation of various signaling pathways $(2,3,11,35,45,47)$. KSHV is thought to be the causative agent of AIDS- and non-AIDSrelated Kaposi's sarcoma as well as Castleman's disease (12), and the KSHV-GPCR has been proposed as a key mediator of both the proliferative and angiogenic properties of $\operatorname{KSHV}(2,3,12,28,35,45,47,57)$. As described in the introduction, several interesting pUS28 activities have been suggested to be of importance in the pathogenesis of HCMV infections. However, it is still unclear which role constitutive signaling by pUS28 plays in these activities. Similarly, the physiological importance of constitutive pR33 signaling remains speculative.

Both RCMV pR33 and HCMV pUS28 were found to constitutively induce activation of PLC. Upon ligand binding, chemokine receptors, also activate PLC, and this is predominantly achieved by release of $\beta y$ subunits from activated, PTX- 
sensitive $G_{i}$ proteins, which stimulate the PLC isoform PLC- $\beta 2(30,50)$. In addition, some chemokine receptors can activate PLC by direct interaction with the $\alpha$ subunits of $G_{q}$ class proteins like $G \alpha_{q^{\prime}} G \alpha_{11}, G \alpha_{14}, G \alpha_{15}$, or $G \alpha_{16}(1,30,50)$. Similarly, the constitutive pR33-induced PLC activation involves $G_{q}$ as well as $G_{i / 0}$ classes of $G$ proteins, whereas constitutive pU528-mediated PLC activation is solely dependent on $G_{q}$ class proteins (11). Additionally, pR33 shows a remarkable level of selectivity for $G \alpha_{11}$ over $G \alpha_{q}$ while pUS28 interacts both with $G \alpha_{q}$ and $G \alpha_{11}$ to entance PLC activity in COS-7 cells. A wide variety of GPCRs, including chemokine receptors, can couple to PLC via activation of $\mathrm{Ga}_{16}$ a hematopoesisspecific member of the $G_{i 4}$ class (34). Even receptors that selectively couple to $G_{i / 0}$ proteins, like the muscarinic acetylcholine $M 2$ receptor, induce InsP production in the presence of PTX when Ga $a_{16}$ is present (34). Surprisingly, pR33-mediated constitutive PLC activation is not enhanced by expression of $G \alpha_{16}$. Since GPCRinduced PLC activation via $G \alpha_{16}$ has been demonstrated as an agonist-mediated response, it is possible that $p R 33$ might interact with $G \alpha_{16}$ only upon ligand binding and not in a ligand-independent fashion. On the other hand, pR33 might not be capable of $\mathrm{Gon}_{16}$ activation at all, as has been shown previously for certain CC-chemokine receptors (30). Nevertheless, we were not able to investigate these notions because at present no ligands for pR33 have been identified.

As indicated above, pR33 constitutively couples to $G_{i}$ proteins, and this interaction stimulates the pR33-induced PLC activity. Like PLC stimulation by $G_{1}$ coupled chemokine receptors, this effect might be mediated by the release of $G_{i} \beta \gamma$ subunits, because the PR33-induced PLC activity in the presence of PTX was similar to that seen in the presence of $\beta y$ scavengers. Since COS-7 cells lack the PLC isoform that is most sensitive to stimulation by $G_{i}$-derived $\beta \gamma$ subunits (PLC$\beta 2$ ), it is likely that the pR33-induced $\beta \gamma$-mediated signal activates other PLC isoforms expressed in COS-7 cells, i.e., PLC- $\beta 1$ and PLC- $\beta 3(16,27,56)$.

In addition to PLC activation, both $\mathrm{pR} 33$ and pUS28 also induce NF-kBmediated transcription in a constitutive fashion. In the case of pUS28, this constitutive effect is due to the activation of $G_{q}$ proteins via the release of $G_{q} B \gamma$ subunits (11). Interestingly, $\mathrm{pR} 33$-mediated NF- $\mathrm{KB}$ transcription is completely inhibited by PTX, indicating that this activity of PR33 is mainly due to the activation of $G_{i / 0}$ proteins. Similarly, pR33 induces SRE-mediated transcription and inhibits CRE-mediated transcription in a PTX-sensitive, constitutive fashion. These two signaling parameters, however, are not affected by pUS28. Together with the PLC data, these findings illustrate that although pR33 and pUS28 are both virusencoded receptors which signal constitutively, they are completely different with regard to their respective signaling profiles. It is likely that the PTX-sensitive, pR33-induced signaling to CRE, SRE, and NF-kB, may be mediated by the $G_{i 2}$ protein, since COS-7 cells do not endogenously express any other PTX-sensitive $G$ proteins apart from $G_{12}(27)$. Previously, signaling by $G_{12}$ has been demonstrated to be linked to downregulation of cytokine expression (32). Additionally, PTXsensitive NF-KB-mediated transcription has been shown to influence the expression of cytokines, chemokines, growth factors, and cell adhesion molecules as well as some acute-phase proteins (15). The induction of NF-kB-mediated transcription has also been linked to inflammatory events associated with various 
disease states, such as autoimmune diseases and atherosclerosis (15). Whether or not (the constitutive activity of) pR33 plays a role in any of these processes during RCMV infection in vivo will have to be addressed in future studies.

A factor that may influence the effect of (constitutive) PR33 signaling in vivo is the presence of endogenous ligands. Interaction of pR33 with endogenous ligands may modulate constitutive activity as well as (de)activate additional signaling pathways. Previously, modulation of constitutive activity by agonists and inverse agonists has been demonstrated for KSHV GPCR and PUS28 in vitro. The constitutive activity of the KSHV GPCR is modulated positively by GRO- $\alpha$ and negatively by $\mathrm{P}-10$ and SDF-1 $\alpha$, which are thus acting as agonist and inverse agonists, respectively $(23,35,44,45)$. Nevertheless, not all ligands that bind to a certain GPCR also affect the constitutive activity of that GPCR. This was previously shown for the KSHV GPCR ligand IL-8 $(23,44)$. Similarly. PUS28 binds and responds to various $\mathrm{CC}$-chemokines, whereas none of these $\mathrm{CC}$-chemokines have been reported to modulate the constitutive activity of pUS28. By contrast. fractalkine was identified as a partial inverse agonist for pUS28, inhibiting both constitutive PLC activation and NF- $\mathrm{KB}$-mediated transcription (11).

The identification of agonists and, in particular, inverse agonists of constitutive viral GPCR signaling might provide valuable tools for elucidation of the role of this constitutive activity in the pathogenesis of viral infection. In addition, inverse agonists may be regarded as putative leads for antiviral drug design. In order to identify potential (inverse) agonists of pR33, we tested several chemokines for modulation of pR33-mediated constitutive activity. However, neither the human chemokines of the CC (RANTES, eotaxine, Teck, MCP-1), CX 3 C (fractalkine) or CXC class (IP-10, IP-9, GRO- $\alpha, I L-8)$ nor the CC-chemokine rat RANTES was able to change the activity of pR33 significantly in any of the signaling assays used in this study. In addition, pR33 was unable to bind RANTES, in contrast to its homolog from HHV-6B ( $p \cup 12$ ). The latter protein was shown to bind RANTES, MCP-1, and MIP- $1 \alpha$ as well as MiP-1 $\beta$, resulting in an intracellular calcium flux (25). These findings illustrate that individual members of the R33 family can have significantly different ligand-binding characteristics.

Taken together, we found pR33 to activate and inhibit various signaling pathways in the absence of exogenously added ligands. However, it cannot be ruled out that the activity of pR33 is the result of binding of yet-unidentified, endogenously produced ligands. In this respect it is interesting that a novel CC. chemokine was identified, CCL28, which is a ligand for both CCR10 and CCR3 $(39,55)$. This chemokine, also known as mucosa-associated epithelial chemokine, is expressed in human and murine epithelial cells of diverse mucosal tissues and directs chemotaxis of CCR10-expressing lymphoid cells. Interestingly, CCL28 transcripts are most abundant in the salivary glands (39). With respect to the sequence similarity between CCR10, CCR3, and PR33, we hypothesized that the ability of RCMV to establish a successful infection within the salivary glands could be dependent on the interaction of a CCL28-like chemokine with pR33 (54). This putative interaction of pR33 with the rat homolog of CCL28 is currently under investigation. 


\section{Acknowledgments}

Y.K.G. and P.C. contributed equally to this work. We are grateful to C. Gerard and D. Bota for providing us with plasmid pCDNA3/CCR10. We thank Patrick Beisser for critically reading the manuscript and Erik Beuken for DNA sequencing. Y.K.G. is supported by a grant (901-02-224) from The Netherlands Organization for Scientific Research (NWO, medical sciences). C.V. and M.J.S. are supported by a fellowship of the Royal Netherlands Academy of Arts and Sciences (KNAW).

\section{References}

1. Arai $H$, Charo IF. (1996). Differential regulation of G-protein-mediated signaling by chemokine receptors. J. Biol. Chem. 271:21814-21819.

2. Arvanitakis $L_{8}$ Geras-Raaka $E_{i}$ Varma $A_{x}$ Gershenghorn $M C$, Cesarman $E$. (1997). Human herpesvirus KSHV encodes a constitutively active Gprotein-coupled receptor linked to cell proliferation. Nature 385:347-350.

3. Bais C, Santamasso B, Coso O, Arvanitakis L, Geras-Raaka E, Silvio Gutkind J. Asch AS, Cesarman E, Gershenghorn MC, Mesri EA. (1998). G-proteincoupled receptor of Kaposi's sarcoma-associated is a viral oncogene and angiogenesis activator. Nature 391:86-89. (Erratum, 392:210.)

4. Beisser P $S_{x}$ Grauls GELM. Bruggeman CA, Vink C. (1999). Deletion of the $R 78 \mathrm{G}$ protein-coupled receptor gene from rat cytomegalovirus results in an attenuated, syncytium-inducing mutant strain. J. Virol. 73:7218-7230.

5. Beisser PS, Vink C, van Dam JG, Grauls GELM, Vanherle SJF, Bruggeman CA. (1998). The R33 G protein-coupled receptor gene of rat cytomegalovirus plays an essential role in the pathogenesis of viral infection. J. Virol. 72:2352-2363.

6. Bennett GL, Horuk R. (1997). lodination of chemokines for use in receptor binding analysis. Methods Enzymol. 288:134-148.

7. Billstrom $M A$, Johnson $\mathrm{GL}$, Avdi NJ Worthen S. (1998). Intracellular signaling by the chemokine receptor US28 during human cytomegalovirus infection. J. Virol. 72:5535-5544.

8. Bodaghi $B$, Jones TR, Zipeto $D$, Vita $C$, Sun L, Laurent L, ArenzanaSeisdedos F, Virelizier J, Michelson S. (1998). Chemokine sequestration by viral chemoreceptors as a novel viral escape strategy: withdrawal of chemokines from the environment of cytomegalovirus-infected cells. J. Exp. Med. 188:855-866.

9. Broers J L, Machiels BM, van Eys GJ, Kuijpers HJ, Manders EM, van Driel R, Ramaekers FC. (1999). Dynamics of the nuclear lamina as monitored by GFP-tagged A-type lamins. J. Cell Sci. 112:3463-3475.

10. Carman $C V$, Parent $J$, Day $P W$, Pronin AN, Sternweis $P M$, Wedegaertner $P B$, Cilman $A G$, Benovic $I L$, Kozasa $T$. (1999). Selective regulation of 
Ga(q/11) by an RGS domain in the G protein-coupled receptor kinase, GRK2. J. Biol. Chem. 274:34483-34492.

11. Casarosa $P$, Bakker RA, Verzij $D$, Navis $M$, Timmerman $H$, Leurs $R$, Smit MJ. (2001). Constitutive signaling of the human cytomegalovirus-encoded chemokine receptor US28. J. Biol. Chem. 276:1133-1137.

12. Cesarman $E_{n}$ Nador $R G_{n}$ Bai $F$, Bohenzky RA, Russo Jd, Moore PS, Chang $Y$, Knowles DM. (1996). Kaposi's sarcoma-associated herpesvirus contains Gprotein-coupled receptor and cyclin D homologs which are expressed in Kaposi's sarcoma and malignant lymphoma. J. Virol. 70:8218-8223.

13. Chee MS, Bankier AT, Beck $S$, Bohni $R$, Brown $C M$, Cerni $R$, Horsnell $R$, Hutchison CA, Kouzarides T, Martignetti JA, Preddie E, Satchwell SC, Tomlinson $\mathrm{P}$, Weston KM, Barell BG. (1990). Analysis of the protein-coding content of the sequence of human cytomegalovirus strain AD169. Curr. Top. Microbiol. Immunol. 154:125-169.

14. Chee MS, Satchwell SC, Preddie E, Weston KM, Barell BG. (1990). Hum. cytomegalovirus encodes three $G$ protein-coupled receptor homologues. Nature 344:774-777.

15. Chen $F$, Castranova $V$, Shi $X$, Demers $L M$. (1999). New insights into the role of nuclear factor- $\mathrm{\kappa B}$, a ubiquitous transcription factor in the initiation of diseases. Clin. Chem. 45:7-17.

16. Clapham DE, Neer EJ. (2000). G protein $\beta \gamma$ subunits. Annu. Rev. Pharmacol. Toxicol. 37:167-203.

17. Davis-Poynter $N$ J, Lynch DM, Vally $H$, Shellam GR, Rawlinson WD, Barell $B G$, and H. E. Farrell. (1997). Identification and characterization of a $G$ protein-coupled receptor homolog encoded by murine cytomegalovirus. J. Virol. 71:1521-1529.

18. Diviani D, Lattion AL, Larbi N, Kunapuli P, Pronin A, Benovic J, Cotecchia S. (1996). Effect of different $G$ protein-coupled receptor kinases on phosphorylation and desensitization of the $\alpha 1 \mathrm{~B}$-adrenergic receptor. J. Biol. Chem. 271:5049-5058

19. Dominguez G, Dambaugh TR, Stamey FR, Dewhurst S, Inoue N, Pellett PE. (1999). Human herpesvirus 6B genome sequence: coding content and comparison with human herpesvirus 6A. J. Wirol. 73:8040-8052.

20. Federman AD, Conklin BR, Schrader KA, Reed RR, Bourne HR. (1992).

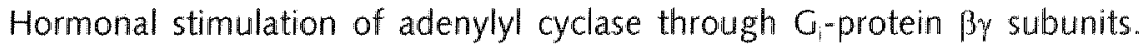
Nature 356:159-161.

21. Fluhmann B, Zimmermann U, Muff R, Bilbe G, Fischer JA, Born W. (1998). Parathyroid hormone responses of cyclic AMP-, serum- and phorbol esterresponsive reporter genes in osteoblast-like UMR-106 cells. Mol. Cell. Endocrinol. 139:89-98.

22. Gao J, Murphy PM. (1994). Human cytomegalowirus open reading frame US28 encodes a functional $\alpha$ chemokine receptor. I. Biol. Chem. 269:28539-28542.

23. Geras-Raaka E, Varma A, Ho H, Clark-Lewis I, and Gershenghorn MC. (1998). Human interferon- $\gamma$-inducible protein 10 (IP-10) inhibits constitutive signaling of Kaposi's sarcoma-associated herpesvirus G protein- 
coupled receptor by protein kinases in mammalian cells in culture. 1. Exp. Med. 188: 405-408.

24. Gompels $U A$, Nicholas J, Lawrence $G$, Jones $M$, Thomson $B J$, Martin $M E_{\text {, }}$

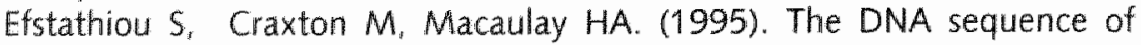
human herpesvirus-6: structure, coding content, and genome evolution. Virology $209: 29-51$.

25. Isegawa $Y$, Ping $Z$, Nakano $K$, Sugimoto $N$, Yamanishi $K$. (1998). Human herpesvirus 6 open reading frame $U 12$ encodes a functional $\beta$-chemokine receptor. J. Virol. 72:6104-6112.

26. Jarmin DI, Rits $M$, Bota D, Gerard NP, Graham GJ, Clark-Lewis I, Gerard C. (2000). Cutting edge: identification of the orphan receptor G-proteincoupled receptor 2 as CCR10, a specific receptor for the chemokine ESkine. J. Immunol. 164:3460-3464.

27. Katz A, Wu D, Simon MI. (1992). Subunits beta gamma of heterotrimeric $G$ protein activate beta 2 isoform of phospholipase C. Nature 360: 686689.

28. Kirshner JR, Staskus K, Haase A, Lagunoff M, Ganem D. (1999). Expression of the open reading frame of Kaposi's sarcoma (KS)-associated herpesvirus: implications for KS pathogenesis. J. Virol. 73:6006-6014.

29. Kledal TN, Rosenkilde MM. Schwartz TW. (1998). Selective recognition of the membrane-bound $\mathrm{C} \times 3 \mathrm{C}$ chemokine, fractalkine, by the human cytomegalovirus-encoded broad-spectrum receptor US28. FEBS Lett. $441: 209-214$.

30. Kuang $Y$, Wu $Y$, Jiang $H$, Wu D. (1996). Selective $G$ protein coupling by $C$ C chemokine receptors. J. Biol. Chem. 271:3975-3978.

31. Kuhn DE, Beall Cl, Kollattukudy PE. (1995). The cytomegalovirus US28 protein binds multiple CC chemokines with high affinity. Biochem. Biophys. Res. Commun. 211:325-330.

32. Luther SA, Cyster JG. (2001). Chemokines as regulators of $T$ cell differentiation. Nat. Immunol. 2:102-107.

33. Margulies BJ, Browne $H$, Gibson W. (1996). Identification of the human cytomegalovirus G-protein-coupled receptor homologue encoded by UL33 in infected cells and enveloped virus particles. Virology 225:111-125.

34. Milligan $G_{n}$ Marshall $F$, Rees S. (1996). G16 as a universal $G$ protein adapter: implications for agonist screening strategies. Trends Pharmacol. Sci. 17:235-237.

35. Montaner S, Sodhi A, Pece S, Mesri EA, Gutkind IS. (2001). The Kaposi's sarcoma-associated herpesvirus $G$ protein-coupled receptor promotes endothelial cell survival through the activation of AKT/protein kinase $B$. Cancer Res. 61:2641-2648.

36. Morisset $S$, Rouleau A, Ligneau $X$, Gbahou F, Tardivel-Lacombe F, Stark $H_{\text {v }}$ Schunack, Ganelli CR, Schwartz JC, Arrang IM. (2000). High constitutive activity of native $\mathrm{H} 3$ receptors regulates histamine neurons in brain. Nature 408:860-864. 
37. Neote K, DiGregorio D, Mak $Y$, Horuk R, Schall TI. (1993). Molecular cloning, functional expression, and signaling characteristics of a $\mathrm{C}-\mathrm{C}$ chemokine receptor. Cell 72:415-425.

38. Nicholas J. (1996). Determination and analysis of the complete nucleotide sequence of human herpesvirus. J. Virol. 70:5975-5989.

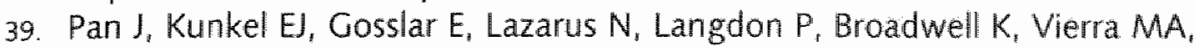
Genovese MC, Butcher EC, Soler D. (2000). A novel chemokine ligand for CCR10 and CCR3 expressed by epithelial cells in mucosal tissues. J. Immunol. 165:2943-2949.

40. Premont RT, Inglese J, Lefkowitz RJ. (1995). Protein kinases that phosphorylate activated G protein-coupled receptors. FASEB J. 9:175-182.

41. Rawlinson WD, Farrell HE, Barrell BG. (1996). Analysis of the complete DNA sequence of murine cytomegalovirus. J. Virol. 70:8833-8849.

42. Robbins LS, Nadeau JH, Johnson KR, Kelly MA, Roselli-Rehfuss L, Baack E, Mountjoy KG, Cone RD. (1993). Pigmentation phenotypes of variant extension locus alleles result from point mutations that alter $\mathrm{MSH}$ receptor function. Cell 72:827-834.

43. Robinson PR, Cohen GB, Zhukovsky EA, Oprian DD. (1992). Constitutively active mutants of rhodopsin. Neuron 9:719-725.

44. Rosenkilde MM, Kledal TN, Brauner-Osborne H, Schwartz TW. (1999). Agonists and inverse agonists for the herpesvirus 8-encoded constitutively active seven-transmembrane oncogene product. J. Biol. Chem. 274:956961.

45. Schwarz M. Murphy PM. (2001). Kaposi"s sarcoma-associated herpesvirus $G$ protein-coupled receptor constitutively activates NF-KB and induces proinflammatory cytokine and chemokine production via a C-terminal signaling determinant. J. Immunol. 167:505-513.

46. Shenker A, Laue L, Kosugi S, Merendino JJ, Minegishi Jr. T, Cutler, Jr. GB. (1993). A constitutively activating mutation of the luteinizing hormone receptor in familial male precocious puberty. Nature 365:652-654.

47. Sodhi A, Montaner S, Patell V, Zohar M, Bais C, Mesri EA, Gutkind IS. (2000). The Kaposi's sarcoma-associated herpesvirus G protein-coupled receptor upregulates vascular endothelial growth factor expression and secretion through mitogen-activated protein kinase and p38 pathways acting on hypoxia-inducible factor $1 \alpha$. Cancer Res. 60:4873-4880.

48. Spiegel AM. (1996). Defects in G protein-coupled signal transduction in human disease. Annu. Rev. Physiol. 58:143-170.

49. Streblow DN, Soderberg-Naucler C, Vieira J, Smith P. Wakabayashi E, Ruchti F, Mattison K, Altschuler Y, Nelson JA. (1999). The human cytomegalovirus chemokine receptor US28 mediates vascular smooth muscle cell migration. Cell 99:511-520.

50. Thelen M. (2001). Dancing to the tune of chemokines. Nat. Immunol. 2:129-134.

51. Vink C, Beuken E, Bruggeman CA. (1997). Cloning and functional characterization of the origin of lytic-phase DNA replication of rat cytomegalovirus. J. Gen. Virol. 78:2963-2973. 
52. Vink C, Beisser PS, Bruggeman CA. (1999). Molecular mimicry by cytomegaloviruses. Function of cytomegalovirus-encoded homologues of $G$ protein-coupled receptors, MHC class 1 heavy chains and chemokines. intervirology 42:342-349.

53. Vink C, Beuken E, Bruggeman CA. (2000). Complete DNA sequence of the rat cytomegalovirus genome. J. Virol. 74:7656-7665.

54. Vink C. Smit MJ Leurs R, Bruggeman CA. (2001). The role of cytomegalovirus-encoded homologs of $\mathrm{G}$ protein-coupled receptors and chemokines in manipulation of and evasion from the immune system. J. Clin. Virol. 23:43-55.

55. Wang $W$, Soto $H$, Oldham, Buchanan ME, Homey $B$, Catron $D$, Jenkins $N$, Copeland NG, Gilbert DI, Nguyen N, Abrams J, Kershenovich D, Smith K, McClanahan T, Vicari AP, Zlotnik A. (2000). Identification of a novel chemokine (CCL28), which binds CCR10 (GPR2). J. Biol. Chem. 275:22313-22323.

56. Wu D, Katz A, Simon MI. (1993). Activation of phospholipase $C$ beta 2 by the alpha and beta gamma subunits of trimeric GTP-binding protein. Proc. Natl. Acad. Sci. USA 90:5297-5301.

57. Yang TY, Chen SC, Leach MW, Manfra D, Momey B, Wiekowski $M$, Sullivan L, Jenh $\mathrm{CH}$, Narula SK, Chensue SW, Lira SA. (2000). Transgenic expression of the chemokine receptor encoded by human herpesvirus 8 induces an angioproliferative disease resembling Kaposi's sarcoma. J. Exp. Med. 191:445-453. 


\section{CHAPTER 4}

Constitutive Signaling of the Human Cytomegalovirus-Encoded Receptor pUL33 Differs From That of Its Rat Cytomegalovirus Homolog pR33 by Promiscuous Activation of G Proteins of the

$G_{q / 11}, G_{i / 0}$ As Well As $G_{s}$ class

J. Biol. Chem. (2003) $278: 50010-23$ 


\section{Abstract}

The human cytomegalovirus (HCMV) UL33 gene is conserved among all betaherpesviruses and encodes a protein that shows sequence similarity with chemokine receptors belonging to the family of $G$ protein-coupled receptors. Here, we show that HCMV UL33 is predominantly transcribed as a spliced mRNA of which the $5^{\prime}$ terminus is localized 55 bp upstream of the start codon. Like its homolog from rat cytomegalovirus (RCMV), R33, UL33 activates multiple signaling pathways in a ligandindependent manner. Although both receptors constitutively activate phospholipase $C$ via $G_{q / 11}$, and partially via $G_{i / 0}$-mediated pathways, they exhibit profound differences in the modulation of CAMPresponsive element (CRE) activation. R33 constitutively inhibits, whereas UL33 constitutively enhances CRE-mediated transcription. For R33, the inhibition of CRE-driven transcription is entirely $G_{i / 0}$-mediated. For UL33, however, CREmediated transcription is modulated not only through coupling to $\mathrm{G}_{\mathrm{i} / \Omega}$ but also through coupling to Gas. In addition, UL33 was found to enhance CRE activation through the Rho/p38 pathway, via $G \beta \gamma$. Interestingly, by studying chimeric UL33/R33 proteins, we found the C-terminal cytoplasmic tail of UL33, but not that of R33, to be responsible for the activation of $G_{i / \%}$ proteins. A UL33deficient variant of HCMV was generated to analyze UL33-signaling properties in a physiologically relevant model system. Data obtained with infected cells show that HCMV induces CRE activation, and this effect is, at least in part, dependent on UL33 expression. Taken together , our data indicate that constitutive signaling of UL33 differs from that of R33 by promiscuous activation of $G$ proteins of the $G_{q}, G_{i / o}$ as well as $G_{5}$ class. Thus, HCMV may effectively use UL33 to orchestrate multiple signaling networks within infected cells.

\section{Introduction}

A large number of viruses appear to have pirated genes encoding key regulatory cellular proteins ( 30$)$. It is likely that these genes play important roles in strategies that are aimed at the subversion of antiviral challenges by the immune system of the viral host. One of the most prominent examples of such strategies is employed by representatives from the alpha- and betaherpesvirus subfamilies. Sequence analysis of the genomes of human cytomegalovirus (HCMV), Kaposi's sarcoma-associated herpes virus (KSHV), and human herpesvirus 6 and 7 (HHV-6 and $H H V-7)$ revealed the existence of genes encoding proteins with high homology to chemokine receptors, belonging to the family of $G$ protein-coupled receptors (GPCRs) (reviewed in Ref. 35). Because GPCRs play a crucial role in cellular communication, and chemokine receptors in particular are essential for leukocyte trafficking, the virus-encoded GPCRs (vGPCRs) may be crucial determinants of viral pathogenesis. Expression of VGPCRs may play a prominent role in immune evasion, promote virus dissemination, or modulate cellular responses of infected cells. 
The betaherpesvirus HCMV can cause life-threatening systemic infections in immunocompromised individuals and has also been recognized as a risk factor for vascular diseases, like arterial restenosis and atherosclerosis (43). Within the HCMV genome, four genes encoding. GPCRs have previously been identified (US27, US28, UL33, and UL78) (14). Recently, it has been suggested that the HCMV genome may contain additional putative GPCR genes (34). The US28encoded receptor has been characterized most extensively and was shown to bind CC chemokines and the $C X_{3} C$ chemokine fractalkine $(24,25)$. In addition, we and others have recently shown that US28 signals in a constitutive manner in both transfected and HCMV-infected cells $(12,13,29)$, suggesting a physiological relevance of this property.

For the other three HCMV-encoded GPCR-like genes, little information is available. The UL33 gene has homologs in all betaherpesviruses, including rat CMV (RCMV) R33, murine CMV (MCMV) M33, and the U12 genes of HHV-6A, $H H V-6 B$, and $H H V-7$, which may illustrate the biological significance of this gene family (reviewed in Ref. 45). The UL33, M33, and R33 genes were found to be dispensable for viral growth in vitro $(10,15,28)$. However, the biological significance of the UL33 family members has been demonstrated in studies in vivo. Recombinant RCMV and MCMV strains lacking a functional R33 or M33 gene, respectively, are unable to replicate in the salivary glands and induce a lower mortality in infected animals $(10,15)$. These results underline the importance of the UL33-like genes in the pathogenesis of infection.

On the basis of sequence alignments, it was suggested that the UL33 gene family members of MCMV, HCMV, HHV-6, and HHV-7 may express spliced mRNAs (15). Indeed, transcripts of M33, UL33, as well as HHV-6B U12 were demonstrated to be spliced $(15,22)$, although a previous report suggested that transcripts of UL33 were not spliced (28). The RCMV R33 gene, on the other hand, was found to be transcribed into an unspliced mRNA (10).

We have previously demonstrated that the RCMV R33 gene, like US28, encodes a constitutively active receptor, modulating multiple signaling pathways (20). Also, the MCMV and HCMV homologs of R33, M33, and UL.33" respectively, were shown to display constitutive activity (49). However, a detailed analysis of the signaling pathways underlying the observed constitutive activity displayed by UL33 has not been performed. As yet "no chemokines were reported to bind or modulate the activity of UL33, R33, or M33 $(20,49)$. Therefore, these proteins should be regarded as orphan receptors.

In this study, we compared the pharmacological behavior of the HCMVencoded UL33 with that of its RCMV homolog R33. Because only limited information is available on the UL33 gene and protein, transcriptional analysis was performed in HCMV-infected cells, and signaling pathways activated by UL33 have been extensively delineated. Like other VGPCR5, UL33 shows a considerable level of constitutive activity and couples to a wide variety of $G$ proteins. Surprisingly, UL33 and R33 differentially modulate signaling, which was further addressed by studying UL33/R33 chimeras. Moreover, to analyze the signaling properties of the UL33 protein in HCMV-infected cells, a UL33-deficient variant of HCMV was generated and characterized. 


\section{Materials and methods}

DNA constructs: Plasmid pCDNA3/UL33(s) (gift from Dr. B. Margulies), contains the partial coding sequence of the HCMV strain AD169 UL33 gene (corresponding to position $43,253-44,425$ of the HCMV AD169 genome sequence, GenBank ${ }^{\text {TM }}$ data base accession number NC-001347) (28). Within plasmid pCDNA3/UL33(s), the UL33 open reading frame (ORF) starts with an ATG codon downstream of the UL33 intron. Thus, this plasmid encodes a short (s) version of UL33, which is truncated at its $N$ terminus. The expression vector PCDNA3/UL33, which contains the full-length coding UL33 CDNA sequence (15), was generated as follows. First, PCR amplification was performed of the UL33 5 coding region (corresponding to positions 43,066-43,089 and 43,211-43,394 of the HCMV AD169 genome) using HCMV AD169 CDNA as template and primers $5^{\prime}$-CAGGATCCTGGTGGGCGTCG-3' (the sequence in bold type is complementary to the sequence corresponding to position $43,377-43,394$ of the HCMV genome; the underlined sequence indicates the position of the BamHI site) and 5:GAGGTACCACGATGGACACCATC-3' (the sequence in bold type corresponds to position 43,061-43,077 of the HCMV genome; the underlined sequence indicates the position of the Asp718 site). The resulting 220-bp PCR product was then digested with BamHI and $A s p 718$, and subsequently used to replace the BamHIAsp 718 fragment containing the $5^{\prime}$ coding region of UL33(s) in plasmid pcDNA3$U L 33(s)$, thus resulting in expression vector pCDNA3/UL33.

To enable subsequent C-terminal tagging of the UL33 and UL33(s) gene products with enhanced green fluorescent protein (EGFP), a PCR-based procedure was used to modify the sequence surrounding the stop codons of UL33 and UL33(s). Using this procedure, the sequence $5^{\prime}$-CTATGAGCT-3' (corresponding to position $44,420-44,428$ of the HCMV genome), in which the sequence in italics represents the UL33 and UL33(s) stop codons, was changed into the sequence 5 GTGCTAGCG-3', in which the stop codon is disrupted and a unique Nhel restriction site (in italics) is introduced. Subsequently, the 768-bp Nhel $X$ bal fragment from plasmid $\mathrm{p} 368$, which contains the EGFP ORF (16), was cloned inframe into the introduced Nhel sites at the 3 '-end of the UL33 and UL33(s) ORFs, generating expression vectors pCDNA3/UL33-EGFP and PCDNA3/UL33(s)-EGFP, respectively.

A PCR-based procedure was used to generate vectors pCDNA3/R33-RUL33, pCDNA3/R33-Y-UL33, pCDNA3/UL33-R-R33, and pCDNA3/UL33-Y-R33, which express $\mathrm{pR33} / \mathrm{pUL} 33$ chimeric proteins as schematically depicted below in Fig. 3. The vectors pCDNA3/R33-Y-UL33-EGFP, pCDNA3/R33-R-UL33-EGFP, PCDNA3/UL33- $\gamma-R 33$, and PCDNA3/UL33-R-R33-EGFP, expressing the respective chimeric receptors with a C-terminal EGFP tag, were generated in a similar fashion as described above for the UL33 expression constructs. The integrity of all DNA constructs was verified by sequence analysis.

The expression vectors pcDNA3/EGFP, pCDNA3/R33, and pCDNA3/R33EGFP have been described previously (20). The reporter plasmid pTLNC-21CRE 
was obtained from W. Born (National Jewish Medical and Research Center, Denver, $C O$ ). Gifts of pCDNA3-based expression vectors containing the CDNAs of $G \alpha_{a}$ (Dr. B. Conklin), $G \alpha_{11}$ and $G \alpha_{11}{ }^{*}\left(\mathrm{O}^{209} \mathrm{~L}\right.$, Dr. H. Umemori), $G \alpha_{s}$ and $G \alpha_{3}{ }^{*}$ $\left(R^{201} E\right.$, Dr. R. lyengar), $G \alpha_{16}$ (Dr. S. Rees), $G \alpha_{12}$ and $G \alpha_{13}$ (Dr. N. Dhanasekaran), $G \alpha_{\xi}$ (Dr. H. Bourne), PTX-insensitive $\left(C^{351 / 2} \mathrm{G}\right) \mathrm{G} \alpha_{0,} G \alpha_{11}, G \alpha_{i 2}$ and $G \alpha_{i 3}$ mutants (Dr. G. Milligan), the C3 exoenzyme (Dr. S. Narumiya), and GRKz ${ }^{K 20}$ (Dr. 5. Cotecchia) are gratefully acknowledged.

Cell culture and transfection. COS-7 cells were grown and transfected as previously described (12). The astrocytoma cell line U373 was grown in Dulbecco's modified Eagle's medium supplemented with $10 \%$ fetal calf serum.

Determination of CDNA ends. Propagation of human embryo lung fibroblasts (HEL) and HCMV AD169 was performed as previously described ( 9 , 19). HEL were infected with HCMV AD169 at a multiplicity of infection (m.o.i) of 0.1 as described earlier (9). At $72 \mathrm{~h}$ postinfection, infected as well as uninfected HEL were detached from culture flasks by using a cell scraper. Approximately $10^{7}$ cells per sample were subjected to poly $(A)^{+}$RNA extraction by using a QuickPrep Micro mRNA purification kit (Amersham Biosciences, Roosendaal, The

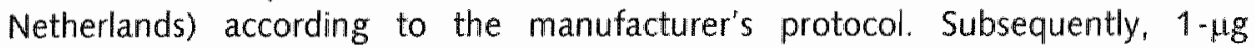
portions were used for CDNA synthesis and PCR using a SMART ${ }^{\text {MM }}$ RACE CDNA amplification kit (Clontech/Westburg, Leusden, The Netherlands) according to the manufacturer's protocol. For the amplification of UL33-specific CDNA, a genespecific primer with the sequence $5^{\text {'- }}$ AAGCGGTTGTGGCATAACTGTTGAAGATCA-3' (complementary to GenBank ${ }^{\text {m }}$ accession NC-001347, bases 43,976-44,424) was included in the reaction. The PCR reaction mixtures were incubated in a GeneAmp Systems 9600 thermal cycler (PerkinElmer Life Sciences, Nieuwerkerk aan de IJssel, The Netherlands) with the following settings: 5 cycles of $5 \mathrm{~s}$ at $94^{\circ} \mathrm{C}$, and 3 min at $72^{\circ} \mathrm{C}, 5$ cycles of $5 \mathrm{~s}$ at $94{ }^{\circ} \mathrm{C}, 10 \mathrm{~s}$ at $70^{\circ} \mathrm{C}$, and $3 \mathrm{~min}$ at $72{ }^{\circ} \mathrm{C}$, and 22 cycles of $5 \mathrm{~s}$ at $94{ }^{\circ} \mathrm{C}, 10 \mathrm{~s}$ at 68 ${ }^{\circ} \mathrm{C}$, and $3 \mathrm{~min}$ at $72{ }^{\circ} \mathrm{C}$. Subsequent to the incubation, 5-pl samples from each of the PCR mixtures was analyzed by agarose gel electrophoresis and ethidium bromide staining. In addition, a 1- $\mu$ l sample from the UL33-specific PCR mix was used for cloning of the PCR product into vector pGEM(B)-T Easy (Promega Benelux BV, Leiden, The Netherlands). The resulting plasmids were transformed in Escherichia coli TOP10 cells. Plasmids from several $E$. colicolonies were sequenced by using a Thermo Sequenase cycle sequence kit (Amersham Biosciences) and standard M13 forward and reverse sequencing primers. Finally, the sequences were compared with sequences from the non-redundant nucleotide sequence data base at the National Center for Biotechnology Information (NCBI, Bethesda, MD) using the Basic Local Alignment Search Tool (3).

Confocal imaging. Transiently transfected COS-7 cells were grown on glass coverslips. After $48 \mathrm{~h}$, the cells were fixed for $10 \mathrm{~min}$ with $3.7 \%$ formol in phosphate-buffered saline, and the coverslips were mounted for subsequent 
confocal imaging. Confocal images were collected at a wavelength of $488 \mathrm{~nm}$ and processed as described previously (20).

Reporter gene assay. COS-7 cells transiently co-transfected with the reporter plasmid pTLNC-21CRE (containing 21 CAMP-responsive elements upstream of the luciferase CDNA) and either pCDNA3 (mock) or any of the expression constructs were seeded in 96-well white plates in serum-free culture medium in the presence or absence of PTX $(80 \mathrm{ng} / \mathrm{ml})$. After $24 \mathrm{~h}$, selected samples were stimulated with forskolin $(1 \mu \mathrm{M})$ for a period of $6 \mathrm{~h}$. Incubation was stopped by aspiration of the medium, and cells were assayed for luminescence as described previously. Luminescence was measured for 35 in a Wallac Victor ${ }^{2}$ multilabel plate reader (PerkinElmer Life Sciences, Boston, MA).

[H]/nositol phosphate production. Experiments in COS-7 cells were performed as previously described (12).

BAC mutagenesis. Recombinant UL33-deficient HCMV genome was generated in $E$. coli using a recently established new method that relies on homologous recombination of a linear PCR fragment with the HCMV BAC plasmid $(5,46,48)$. The PCR product was generated with the primer pair prim5'-UL33 5'CCGCCCAGACCCGCAACAACACTCCTCCGCACATCAATGACACTTGCAACCGTC GTGGAATGCCTTCGAATTC-3' prim 3'-UL33 and 5'GGGAAATGGCGACGGGTTCTGGTGCTITCTGAATAAAGTAACAGGAAAGCACAA GGACGACGACGACAAGTAA-3" (sequences homologous to the PSLFRTKn plasmid are underlined). The amplicon contained homologies of $\sim 50$ bp upstream or downstream of the positions of the deleted UL33 ORF using the plasmid pSLFRTKn $(5,46,48)$ (kindly provided by Dr. M. Wagner, Munich) as template DNA. After purification and Dprit digestion (46) this PCR fragment was inserted into pHB5 (5) by homologous recombination in E. coli, which was mediated by the recombination plasmid PKD46 leading to deletion of the native UL33 start and stop codons and the insertion of a kanamycin cassette that is flanked by Flp recombination target sites. The kanamycin gene was excised via the flanking Fip recombination target sites by Flp-mediated recombination as described previously (5, 46, 48) generating the HCMV BAC plasmid pUL33del. BAC DNA pUL33del was isolated from E. colicultures with an alkaline lysis procedure (37) and purified with NucleoBond PC 500 columns (Macherey-Nagel, Düren, Germany). Correct mutagenesis was confirmed by PCR analysis using the primer pair UL33ATG, $5^{\circ}$ CGCACATCAATGACACTTGC $-3^{\prime}$ TGAATAAAGTAACAGGAAAGC-3'.

Reconstitution of UL33-deficient HCMV. Mutant viruses were reconstituted by transfection of BAC DNA pUL33del into human foreskin fibroblasts (HFF) with the Superfect transfection reagent (Qiagen. Hilden, Germany, according to the manufacturer"s instructions. Briefly, $5 \mu \mathrm{g}$ of BAC DNA was incubated with $150 \mu \mathrm{l}$ of medium without serum and $30 \mu \mathrm{l}$ of SuperFect transfection reagent. The mixture was added to $\sim 3 \times 10^{5} \mathrm{HFF}$ cells. Cells were 
washed with phosphate-buffered saline $2 \mathrm{~h}$ later, cultured with fresh medium. Cells were passaged 7 days after transfection. Infectious supernatants were harvested when $100 \%$ of cells showed cytopathic effects. Virus stocks were prepared on HFF. All virus titers were determined by standard assays. DNA of reconstituted virus mutants was analyzed in parallel by Southern blotting and PCR to prove the correct deletions of the UL33 gene.

Viral nucleic acid isolation and analysis. Fibroblasts were infected at an m.o.i. of 1 , harvested 3 days post infection when cultures reached $100 \%$ cytopathic effect, and collected by centrifugation. Cells were lysed in a solution containing $50 \mathrm{mM}$ Tris- $\mathrm{HCl}(\mathrm{pH} 8.0), 10 \mathrm{mM}$ EDTA, and $0.5 \%$ SDS. Proteinase $\mathrm{K}$ digestion $(500 \mu \mathrm{g} / \mathrm{ml})$ was performed for $3 \mathrm{~h}$ at $56^{\circ} \mathrm{C}$. Total DNA was extracted with phenol-chloroform and precipitated with isopropanol. Southern blot analysis was performed as described previously (47).

CRE activation in HCMV-infected cells. U373 cells were plated in six-well plates $(\sim 250,000$ cells/well) and transiently transfected with the reporter gene pTLNC-21CRE with the calcium phosphate method. $16 \mathrm{~h}$ later, cells were infected with HCMV (strain AD169) or AD169-AUL33 at an m.o.i. of 3. At different time points after infection, cells were lysed and assayed for luciferase activity (12).

Data analysis. Data were analyzed using the program Prism (GraphPad Software, Inc., San Diego, CA). Data are expressed as mean \pm S.E.

\section{Results}

Transcriptional analysis of UL33 in HCMV-infected cel/s. Although HCMV UL33 was originally thought to express an unspliced mRNA (28), Davis-Poynter and coworkers demonstrated that UL33 is transcribed as a spliced mRNA (15) (Fig. 1A). As a consequence, the UL33 gene encodes a protein that is 22 amino acids longer than the protein that was previously predicted to be encoded by UL33 (28). Nevertheless, it has not yet been established whether UL33 can also be transcribed into unspliced mRNAs, potentially coding for alternative protein products.

To investigate this possibility, fibroblasts were infected with HCMV AD169. After purification of mRNA from the cells, the $5^{\prime}$ termini of the UL33 transcripts were assessed by rapid amplification of CDNA ends (RACE). First, the integrity of the CDNA samples was checked by using primers specific for the human transferrin receptor (TFR). As expected, the TFR-control 5'-RACE reaction produced a major DNA fragment of $2.3 \mathrm{~kb}$ (Fig. 1B, lane 1). Subsequently, a $5^{\prime}$ RACE reaction was performed using the UL33-specific antisense primer. This reaction resulted in the amplification of a major DNA species with a length of 0.9 kb (Fig. 1B, lane 2). Several minor, smaller fragments were also observed in this sample. To determine the sequence of these fragments, a portion of the 5'-RACE sample was used for subcloning into a sequencing vector. Plasmids purified from 15 independent bacterial colonies were sequenced. The resulting sequences were 

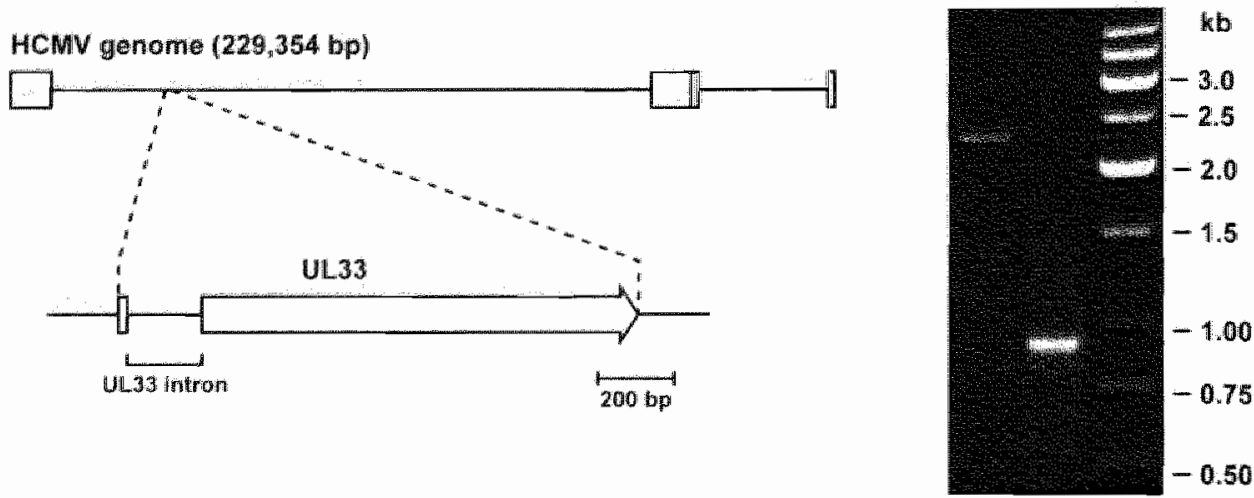

c

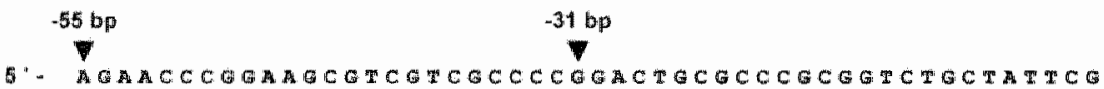

123

Z

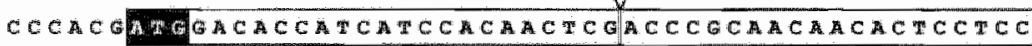

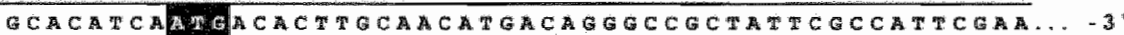

Fig. 1. The structure of the $5^{\prime}$-ends of HCMV UL33 transcripts. (A) the position of the UL33 locus. on the HCMV genome. The HCMV genome is indicated by a horizontal black line. Genomic repeat regions are indicated by white boxes. The UL33 gene is superimposed below the indicated genome. Here, the coding region of UL33 is indicated by a white box (coding region within exon 1) and a white arrow (coding region within exon 2). The arrow indicates the polarity of UL33. (B) rapid amplification of HCMV UL33-specific and human transferrin receptor (TFR)-specific CDNA ends (RACE). The figure shows an ethidium bromide-stained agarose gef containing $5^{\prime}$-TFR-specific (lane 1) and $5^{\prime}$-UL33specific reaction mixtures (lane 2). The sizes of the molecular weight marker bands (lane 3) are indicated at the right-hand side of the agarose gel in $\mathrm{kb}$. (C) the $5^{\circ}$ cDNA sequence of RACE-derived UL33-specific tragments. The UL33 coding sequence is enclosed in a white box. The UL33 start codon. as well as a second, downstream ATG codon, are enclosed in black boxes. The black arrowheads indicate the positions of the first bases found in the 5'-untranslated region of the UL33-specific RACE fragments. The white arrowtiead indicates the junction where the UU.33 intron has been excised.

compared with those of the GenBank ${ }^{\mathrm{rM}}$ nucleotide sequence data base. This comparison indicated that all 15 clones contained UL33-specific sequences. The length of the insert in 8 out of 15 clones corresponded to that of the major, 0.9. kb PCR product in Fig. 1B (lane 2). Each of these inserts was found to be the product of splicing, similarly as described previously (15).

Out of these eight clones, seven were found to have the same $5^{\prime}$ cDNA end. This end was localized 55 bp upstream of the UL33 start codon (Fig. 1O), whereas one of these eight terminated at $31 \mathrm{bp}$ upstream of the first start codon (Fig. 1C). The inserts from the other seven out of 15 clones were likely derived from the minor PCR products seen in Fig. 1B (lane 2), because these were all smaller than $0.9 \mathrm{~kb}$. The $5^{\prime}$ cDNA ends of two of these clones were at 22 and 3 bp, respectively, upstream of the "second" UL33 ATG codon, localized downstream of the intron sequence (Fig. 1C). The $5^{\prime}$ cDNA termini of the other 
five clones were at significantly larger distances downstream from the second ATG codon (at 140,200,258,259, and $283 \mathrm{bp}$, respectively).

The differences in structure of the last seven CDNA clones suggest that the corresponding CDNA fragments were the result of amplification of either truncated transcripts or truncated first-strand CDNA species. Given the relative abundance of the 0.9-kb 5'-RACE product, which constitutes $\sim 85 \%$ of the total population of amplified products (Fig. 1B, lane 2), we conclude that HCMV UL33 predominantly encodes a spliced transcript of which the $5^{\prime}$ terminus is localized 55 bp upstream of the start codon within UL33 exon 1. Because cDNA corresponding to unspliced UL33 transcripts were not detected, we conclude that such mRNA species do not play a role in HCMV infection. For completeness of the study, however, a plasmid containing the CDNA corresponding to the unspliced UL33 ORF variant, designated UL33(s), was included in the signal transduction assays.

Expression of and constitutive signaling by UL33, UL33(s), and R33. To investigate the signaling properties of UL33, we transfected COS-7 cells with CDNAs coding for full-length UL33 and for the unspliced, shorter variant, UL.33(s), which lacks the N-terminal 22 amino acids. The RCMV homolog of UL33, R33, previously found to display constitutive activity (20), was used in the different assays for comparison.

Transfection of increasing amounts of DNA encoding UL33 in COS-7 cells was accompanied by an agonist-independent increase in $\left[{ }^{3} \mathrm{H}\right]$ inositol phosphates (InsPs) production, comparable to that observed for R33 (Fig. 2A). In contrast to the observed constitutive activity displayed by UL33, UL33(s) did not induce an increase in InsP production upon transfection of either $2 \mu \mathrm{g}$ (Fig. 2A) or $5 \mu \mathrm{g}$ (data not shown) CDNA. To monitor the expression of UL33 and UL33(s), both proteins were tagged C-terminally with EGFP. These proteins, UL33-EGFP and UL33(s)EGFP, displayed similar signaling activities as their native counterparts (data not shown). Their expression, as well as that of EGFP and R33-EGFP, was studied by confocal microscopy of transfected cells. Fig. 3A shows that the fluorescence within cells expressing native EGFP is seen dispersed throughout the nucleus and cytoplasm. However, in cells expressing either UL33-EGFP or R33-EGFP, the fluorescent signal clearly co-localized with the cell membrane as well as with intracellular, perinuclear vesicles (Fig. 3, B and C). This indicates that UL33-EGFP, like R33-EGFP, is properly expressed on the cell surface of transfected cells. By contrast, the fluorescence in cells expressing UL33(5)-EGFP did not co-localize with the cell membrane, and seemed to be confined to intracellular compartments (Fig. 3D). This observation shows that UL33(s)-EGFP is retained intracellularly and thus explains the observed lack of constitutive signaling for UL33(s).

UL33-mediated inositol phosphate accumulation is a $G_{0 / y^{-}}$and partially $G_{i / j}$-dependent process. Accumulation of InsP can be achieved following activation of phospholipase $C$ by $G \alpha$ subunits of the $G_{q / 11}$ family as well as by $G \beta \gamma$ subunits (26). Previously, we have shown that the R33-mediated increase in InsP accumulation is partially mediated by the $G \beta \gamma$ subunits of activated $G_{i, 0}$ proteins (20). Also for UL33, the observed increase of InsP accumulation can be partially 
A

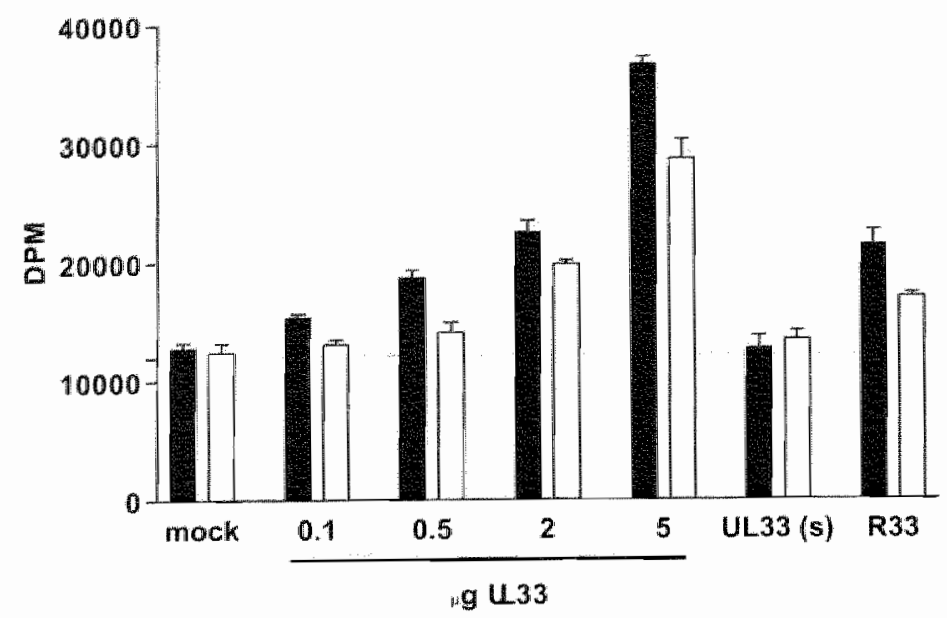

B

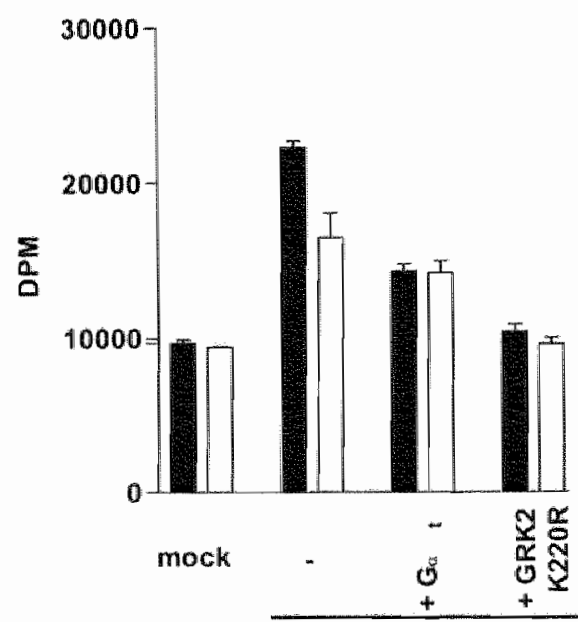

UL33

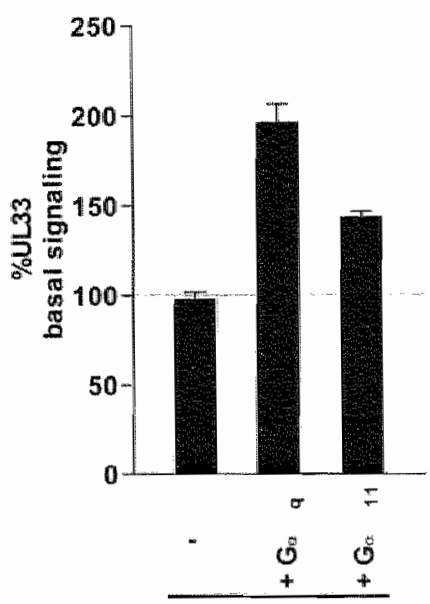

UL33

Fig. 2. UL33 and R33 induction of inositol phosphate accumulation. (A) $\operatorname{COS.7}$ cells $\left(10^{5}\right.$ cells) were transiently transfected with increasing amounts of CDNA encoding UL33, $2 \mu g$ of UL33(s), and 2 $\mu \mathrm{g}$ of R33. Cells were incubated in the presence (white bars) or absence (black bars) of PTX $\langle 80 \mathrm{ng} / \mathrm{ml})$. 48 hafter transfection Ins. accumulation was measured. (B) COS-7 cells were transiently transfected with empty vector (mock) or UL33 $\left(1 \mu \mathrm{g} / 10^{6}\right.$ cells) in the presence of either Ga transducin or the kinase-deficient GRK ${ }^{\mathrm{K} 2 \mathrm{FGR}}$ (1 $\mu \mathrm{g} / 10^{6}$ cells). Cells were incubated in the presence (white bars) or absence (black bars) of PTX $(80 \mathrm{ng} / \mathrm{ml})$. $48 \mathrm{~h}$ after transfection InsP accumulation was measured. (C) COS-7 cells were transiently transfected with UL33 $\left(1 \mu \mathrm{g} / 10^{\circ}\right.$ cells) together with CDNAs encoding Gaq or Ga11 subunits ( $1 \mu \mathrm{g} / 10^{6}$ cells); $48 \mathrm{~h}$ after transfection ins accumulation was measured. Data are presented as percentages of UL33-mediated response, defined as absolute increase of UL33mediated InsP accumulation above values obtained for mock transfected cells. 

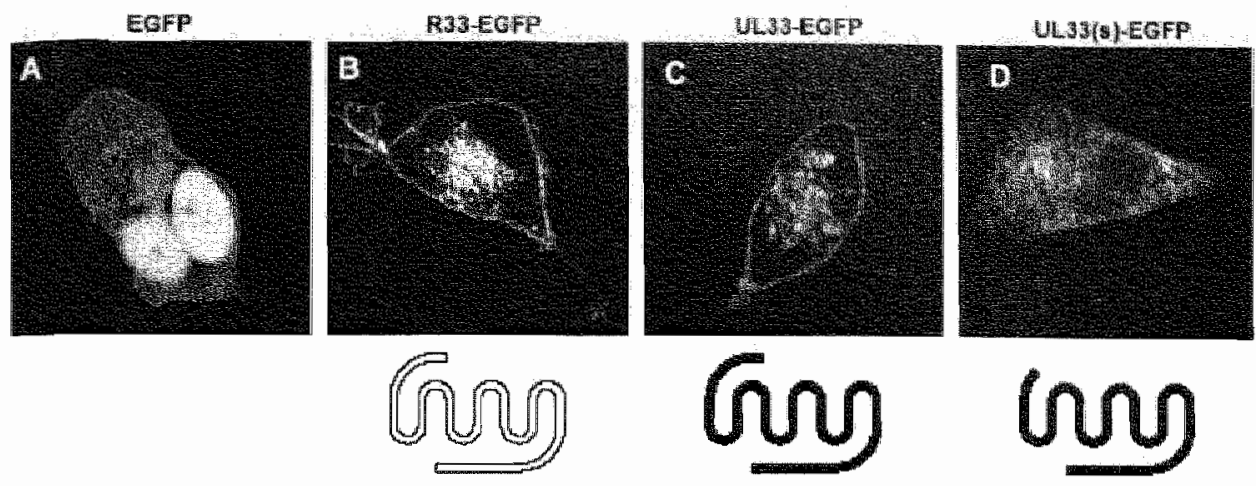
$E$

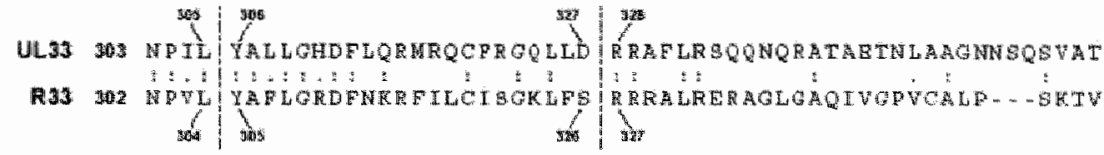

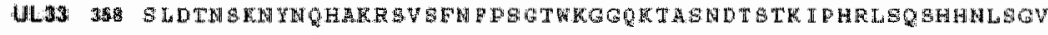

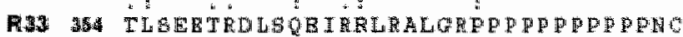
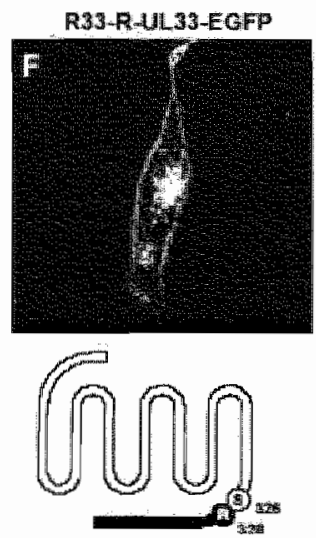

R33-Y-UL33-EGFP
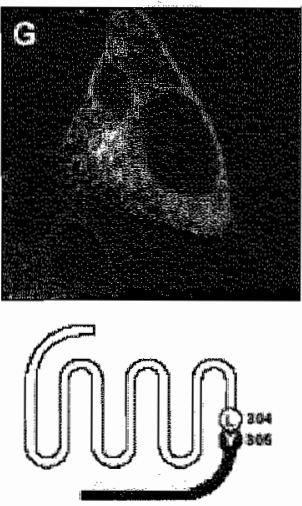

UL33-R-AR33-EGFP
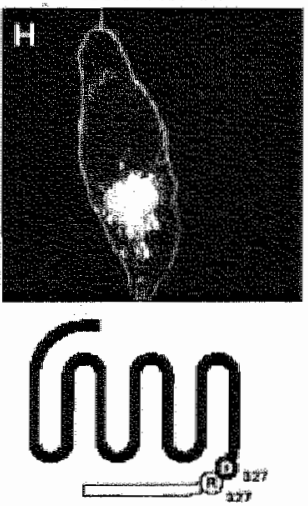

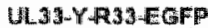
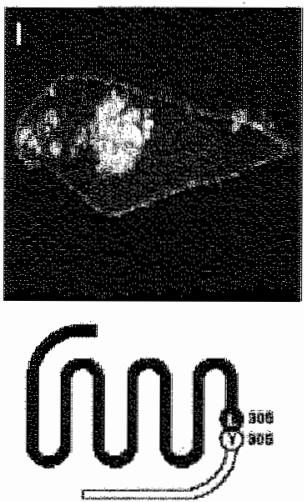

Fig. 3. Expression of R33, UL33, and UL33/R33 chimeras. (AmD) confocal images of cells expressing EGFP, R33-EGFP, UL33-EGFP, and UL33(S)-EGFP. COS-7 cells were transiently transfected with either PCDNA3/EGFP (A), pCDNA3/R33-EGFP (B), PCDNA3/UL33-EGFP (C), or PCDNA3/UL33(S)-EGFP (D) (2 $\mathrm{\mu g} / 10^{\circ}$ cells), fixed after $48 \mathrm{~h}$ and subjected to confocal microscopy at $488 \mathrm{~nm}$. (E) alignment of the C-terminal portions of UL33 and R33 amino acid sequences. Identical resiclwes are indicated by ":". simillar residues are indicated by ".", and a dashed vertical line indicales the position where a UL33/R33 or R33/UL33 junction was created to generate the chimeric receptors. (F-1) confocal images of cells expressing. EGFP-tagged, UL33/R33 chimeras. COS-7 cells were transiently transfected with either DNA3/R33-R-UL33-EGFP (F), PCDNA3/R33-Y-UL33-EGFP (G), PCDNA3/UL33-R-R33-EGFP

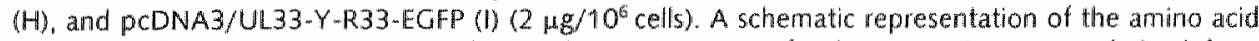
sequence of each receptor is given below the respective confocal images. Sequences derived from UL33 are depicted in black, and R33-derived sequences are depicted in white. Residues flanking UL33/R33 or R33/UL33 junctions are depicted as encircled letters accompanied by the number corresponding to their position in the original amino acid sequence of UL33 or R33 (see E). 
attributed to involvement of $G_{i \%}$ proteins. Incubation of cells expressing UL33 with pertussis toxin (PTX) $(24 \mathrm{~h}, 80 \mathrm{ng} / \mathrm{ml})$ led to a $40 \pm 5 \%(n=6)$ decrease of InsP production (Fig. 2, A and B). Coexpression of UL33 and Gat, known to sequester GPy subunits, resulted in a $43 \pm 6 \%(n=2)$ attenuation of InsP production, similar to that observed for PTX treatment (Fig. 2B). PTX treatment did not further abrogate the InsP production in cells co-expressing UL33 and Coat; suggesting that $G \beta y$ subunits from $G_{i / o}$ are in part responsible for the observed increase in InsP production.

The remaining increase in InsP production may be ascribed to the involvement of Ga proteins of in particular the $G_{q / 11}$ family. Co-expression of UL33 with either $G \alpha_{q}$ or $G \alpha_{11}$ proteins enhanced the UL33-mediated production of $\left[{ }^{3} \mathrm{H}\right]$ InsP (196 $\pm 14 \%$ and $144 \pm 4 \%$ of UL33 basal signaling, respectively, $n=3$; Fig. $2 \mathrm{C}$ ). The contribution of both $G \alpha_{q / 1}$ as well as $G \beta \gamma$ subunits of the $G_{i / 2}$ family in the UL33-mediated accumulation of InsP production was further corroborated by use of the kinasedeficient $\mathrm{GRK}_{2}{ }^{\mathrm{K} 220 \mathrm{R}}$ mutant (17). This mutant has been reported to scavenge both $G \alpha_{q / 11}$ via interaction with its $R G S$ domain and $G \beta \gamma$ subunits via binding to its pleckstrin homology domain (17). As anticipated, coexpression of the kinasedeficient $\mathrm{GRK}_{2}{ }^{\mathrm{K} 22 \mathrm{O} R}$ mutant resulted in a complete inhibition of UL33-mediated InsP production ( $n=3$; Fig. 2B).

$G$ proteins involved in UL33-mediated constitutive modulation of CRE. Although R33 and UL33 both constitutively activate phospholipase $C$, these receptors differentially regulate CRE-mediated transcription. Expression of UL33 resulted in a concentration-dependent increase in CRE-mediated transcription (Fig. 4A). As expected, UL33(s) did not modulate CRE activity. R33, however, inhibited the forskolin-induced CRE transcription in a concentration-dependent fashion (Fig. 4B). Because basal CAMP levels are low in COS-7 cells, forskolin, known to activate adenylyl cyclase, was used to allow detection of inhibitory signaling to CRE (2). This decrease in R33-mediated CRE activation can be ascribed to involvement of $G_{i \neq 0}$ proteins, because PTX markedly reversed the R33-induced inhibition of forskolin-mediated CRE transcription. Interestingly, inactivation of $G_{i j o}$ by PTX in UL33-expressing cells led to a potentiation of the basal increase in CRE transcription (Fig. 4A), indicating that the UL33-mediated stimulation of CRE transcription is the result of the activation of both inhibitory and stimulatory pathways that converge at the level of CRE. The observed inhibition of UL33mediated signaling to CRE can be attributed to coupling of the receptor to either $\mathrm{Go}_{\alpha_{1}}$ or $\mathrm{G} \alpha_{13}$, as co-expression of the respective subunits resulted in a complete inhibition of UL33-induced signaling (Fig. 5A). Coexpression of $G \alpha_{0}$ or $G \alpha_{i 2}$ had no effect on UL33-mediated signaling, suggesting selectivity of coupling for UL33 within this class of proteins. All used $G_{i / 0}$ constructs are PTX-insensitive (via a mutation of Cys $s^{351 / 2}$ to Gily), and consequently, no increase was observed upon PTX treatment for $G \alpha_{i 1}$ or $G \alpha_{i 3}$. Similarly, R33 showed preferential coupling to $G \alpha_{i 1}$ or $G \alpha_{i 3}$ (Fig. 6A). All $G \alpha_{i / \%}$ subunits were previously shown to be properly expressed and able to signal in the presence of the adenosine $A_{1}$ receptor (50) or the histamine $H_{3}$ receptor (Casarosa, Bongers, Leurs, \& Smit, unpublished observations). 
A

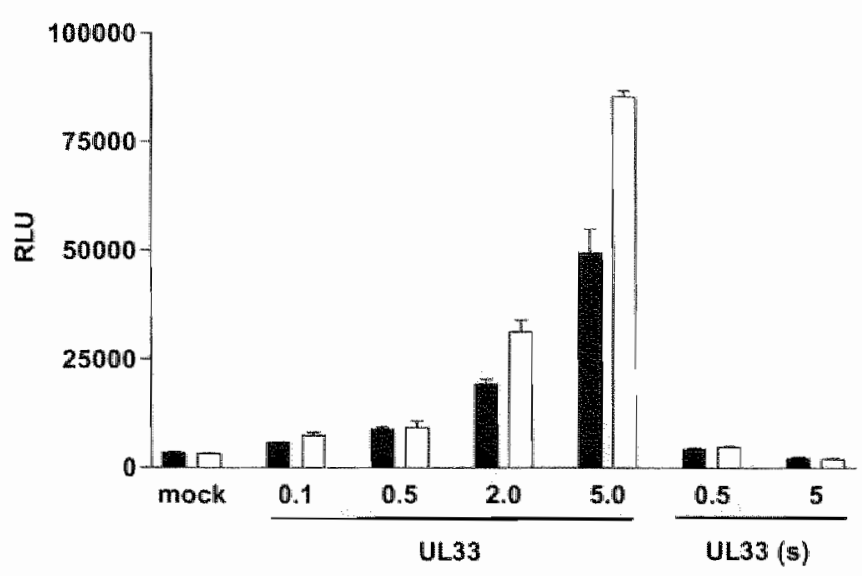

B

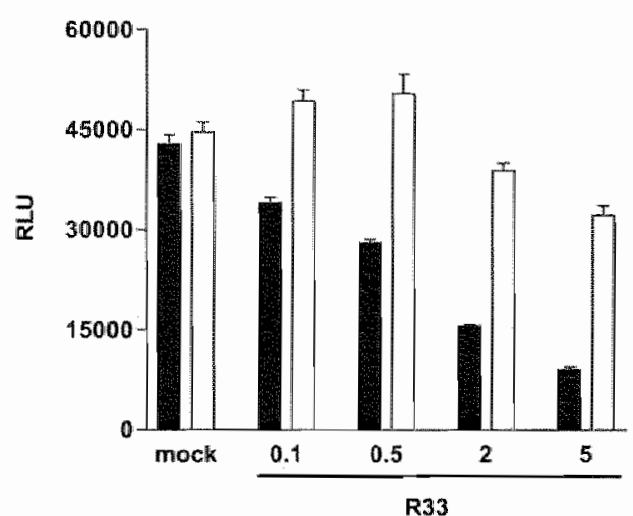

Fig. 4. Different behavior of UL33 and R33 in CRE-mediated transcription. (A) COS-7 cells (10 cells) were transiently transfected with the reporter plasmid PTLNC-21CRE (containing 21 CAMP responsive elements in front of CDNA encoding luciterase; $5 \mu \mathrm{g} / 10^{\circ}$ cells) and increasing amounts of CDNA encoding UL33, or UL33(s). Cells were incubated in the presence (white bars) or absence (black bars) of $\mathrm{PTX}(80 \mathrm{ng} / \mathrm{ml})$. One day after transfection. CRE-driven luciferase expression was measured. (B) COS-7 cells were transiently transfected with pTLNC-21 CRE and increasing amounts of CONA encoding R33. Cells were incubatted in the presence (white bars) or absence (black bars) of PTX (80 $\mathrm{ng} / \mathrm{m})$. A.fter $24 \mathrm{~h}$, cells were stimulated with forskolin (1 $\mu \mathrm{M}$ ) for additional $6 \mathrm{~h}$, then CRE-driven luciferase expression was measured. Results are presented as relative light units RLUS).

To understand which other G proteins might be involved in UL33mediated CRE activation, another panel of $G \alpha$ subunits was tested. Expression of the different $G \alpha$ subunits did not significantly alter the basal or forskolin-induced CRE transcription in mock cells (data not shown). Co-expression of $G x_{16}, G \alpha_{12}$, and $\mathrm{G} \alpha_{13}$, did not modulate the constitutive signaling induced by UL33 (Fig. 5B). On the other hand, co-expression of $G \alpha_{q^{u}}$ for which coupling to UL33 was already shown in the InsP assay, decreased UL33-mediated CRE transcription (Fig. 5B). To investigate whether activation of $\mathrm{G} \alpha$ subunits of the ${ }_{q / 11}$ class might be responsible for a negative regulation of CRE-mediated transcription, the CRE-reporter gene 
A

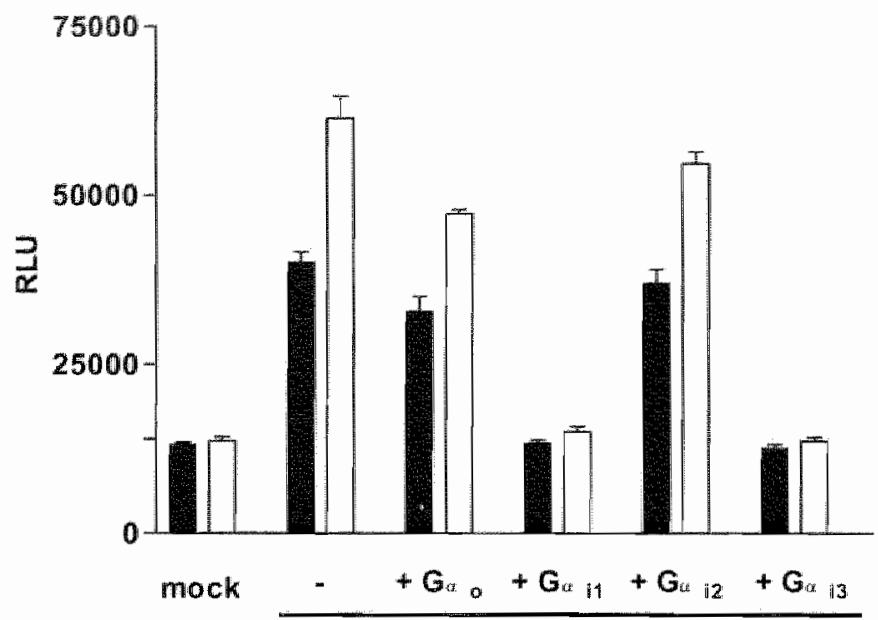

UL33

B

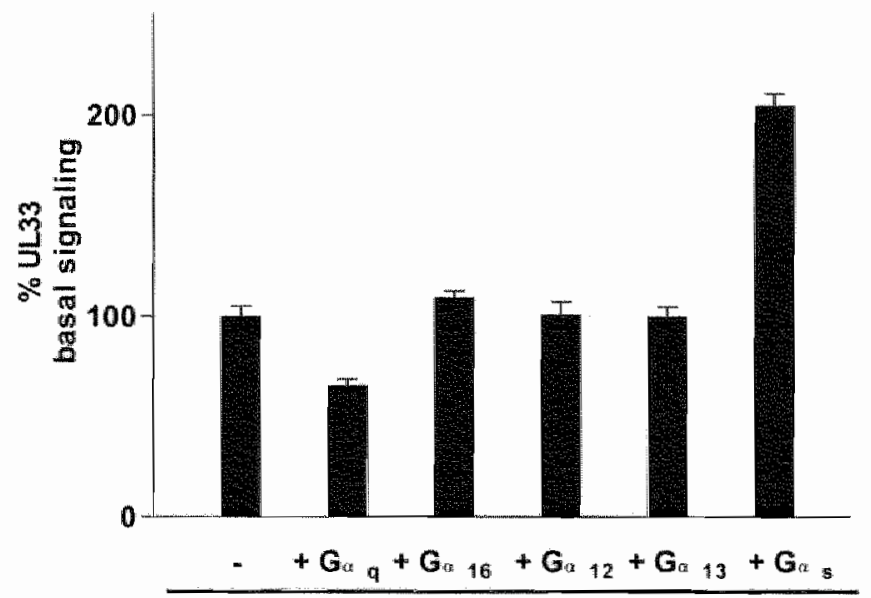

UL33

Fig. 5. Effect of various Ga subunits on the UL33-mediated CRE activation. (A) COS-7 cells were transfected with pTLNC.21CRE and either pCDNA3 (mock) or UL33 (1 $\mu \mathrm{g} / 10^{5}$ cells), together with CDNAs encording the indicated $G \alpha$ subunits $\left(1 \mu \mathrm{g} / 10^{6}\right.$ cells). Cells were incubated in the presence (white bars) of absence (black bars) of PTX $(80 \mathrm{ng} / \mathrm{ml})$. One day after transfection CRE-driven luciferase expression wars measured. Data are presented as relative light units (RLUs). (B) COS-7 cells were transfected with priLC-21CRE and UL33 (1 $\mu \mathrm{g} / 10^{6}$ cells), together with cDNAs encoding the indicated Go subunits ( $1 \mu \mathrm{g} / 10^{\circ}$ cells). One day after transfection CRE-driven luciferase expression was measured. Data are presented as percentage of UL33-mediated response, defined as absolute increase of UL33-mediated CRE transcription above values obtained for mock transfected cells. 
A

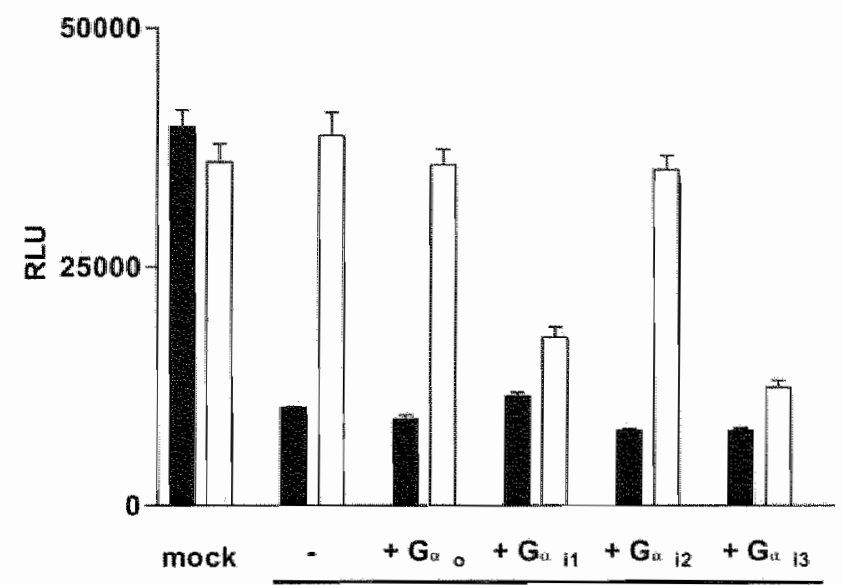

$\mathbb{R} 33$

B

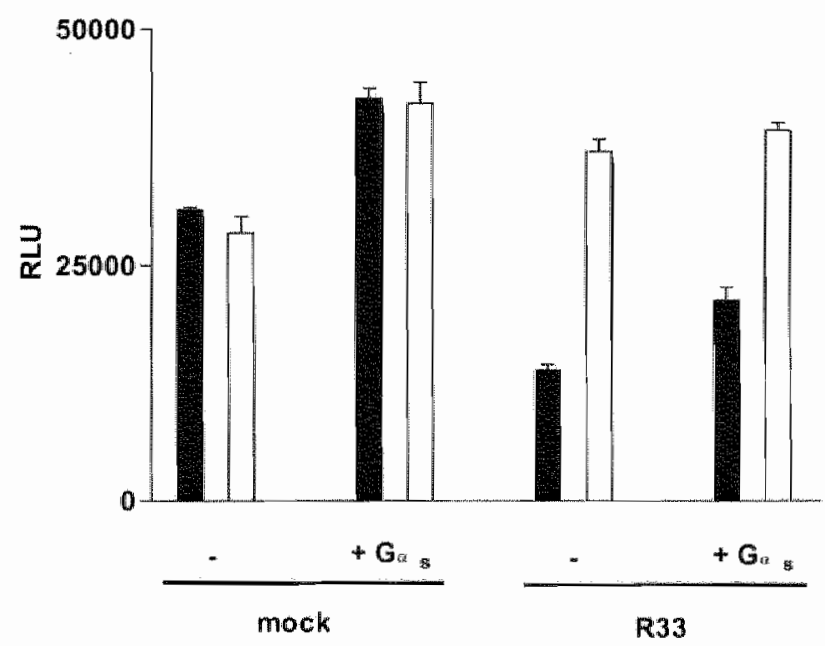

Fig. 6. Effect of various Go subunits on the R33-mediated CRE activation. (A) COS-7 cells were transfected with PTLNC-21CRE and either pCDNA3 (mock) or R33 (1 $\mu \mathrm{g} / 10^{6}$ cells), together with CDNAs encoding the indicated Go subunits $\left(1 \mu \mathrm{g} / 10^{6}\right.$ cells). Cells were incubated in the presence (white bars) or absence (black bars) of PTX $(80 \mathrm{ng} / \mathrm{ml}$ ). After $24 \mathrm{~h}$. cells were stimulated with forskolin $(1 \mu M)$ for additional $6 h$, then CRE-driven luciferase expression was measured. Data are presented as relative light units (RLUS). (B) COS-7 cells were transfected with PTLNC-21CRE and either PCDNA3 (mock) or R33 (1 $\mu \mathrm{g} / 10^{6}$ cells), together with cDNA encoding the Gas subunit $\left(1 \mu \mathrm{g} / 10^{6}\right.$ cellls). Cells were incubated in the presence (white bars) or absence (black bars) of PTX $(80 \mathrm{ng} / \mathrm{ml})$. After $24 \mathrm{~h}$, cells were stimulated with forskolin $(1 \mu M)$ for additional $6 \mathrm{~h}$, then CRE-driwen luciferase expression was measured. Data are presented as relative light units (RLUs). 
was co-transfected with a constitutively active $G \alpha_{11}$ subunit $\left(G \alpha_{11}-Q^{209} L_{;} G a_{1 ;}^{*}\right)$. Expression of $\mathrm{Ga}_{19}{ }^{*}$ did not alter basal or forskolin-induced activation of CRE when compared with mock transfected cells (data not shown). Similarly, activation of protein kinase $C$ (PKC) by phorbol 12-myristate 13-acetate (PMA, $300 \mathrm{nM}$ ) did not induce any change in the transcriptional activation of CRE (data not shown). Taken together, these data imply that activation of the $\mathrm{G}_{q / 41}-\mathrm{PKC}$ signaling pathway is not modulating CRE activation.

Interestingly, co-expression of $\mathrm{G} \alpha_{5}$ increased UL33-mediated signaling to CRE ( $204 \pm 9 \%$ of UL33 basal signaling, $n=6$, Fig. 5B), suggesting that UL33 coupling to $\mathrm{G} \alpha_{s}$ is, at least in part, responsible for CRE activation. As a control, the effect of $G \alpha_{s}$ was monitored in R33-transfected cells. Only a minor increase in CRE activation was detected for both mock and R33-transfected cells (Fig. 6B), suggesting that R33, differently from UL33, is not coupling to $G \alpha_{s}$. The small increase in signaling in the presence of $G \alpha_{s}$ might be due to basal activity of this $\alpha$ subunit or to its coupling to receptors endogenously present in COS-7 cells.

Additional downstream signaling components involved in UL33 signaling to CRE. CRE transcription is known to be regulated by elevation of CAMP following $G \alpha_{5}$ activation, leading to activation of protein kinase $A$ (PKA), which subsequently phosphorylates CREB, initiating CRE transcription (30). However, besides PKA also other signaling entities, including, e.g. PKC, MAPKs (p44/p42, p38, and JNK), and small $G$ proteins, are known to regulate CRE transcription in a tissue-specific manner (39). UL33-mediated increase in CRE transcription is not mediated via $\mathrm{p} 44 / \mathrm{p} 42$ MAPK, phosphoinositide 3 -kinase, or protein kinase $C$ signaling pathways as their respective specific inhibitors U0126 (MEK inhibitor), wortmannin (phosphoinositide 3-kinase inhibitor), and bisindolylmaleimide (PKC inhibitor) did not abrogate the UL33-induced signaling to CRE (Fig. 7A). These inhibitors, however, do inhibit signaling of the KSHV-encoded receptor ORF74 to p44/p42 MAPK in COS-7 cells, indicating proper effectiveness (41). The specific inhibitor of $\mathrm{p} 38, \mathrm{SB} 203580$, on the other hand, markedly inhibited the UL33 effect $(43 \pm 5 \%$ inhibition of UL33 basal signaling, $n=3$; Fig. $7 \mathrm{~A}$ ).

Upstream activators of $\mathrm{p} 38$ are, among others, small $G$ proteins of the Rho family $(16,27)$. Co-expression of C3 exoenzyme, which is known to inactivate these $G$ proteins (by ADP-ribosylation of Asn41) (38), resulted in a marked inhibition of UL33-induced activation of CRE transcription ( $40 \pm 3 \%$ inhibition of UL33 basal signaling, $n=3$ ), similar to that obtained with the $p 38$ inhibitor $5 B 203580$ (Fig. 7B). Co-expression of C3 exoenzyme or treatment with the p38 inhibitor SB203580 did not alter R33 signaling (data not shown). These data suggest that LL33, differently from R33, engages the Rho/p38 pathway in its signaling to CRE (Fig. 7B). To examine whether the $G \alpha_{s}$ and Rho pathway are connected, we determined the effect of the $\mathrm{C} 3$ toxin on $\mathrm{G} \alpha_{s}$-mediated signaling. Co-expression of $\mathrm{C} 3$ exoenzyme did not abrogate the increase in CRE transcription induced by expression of constitutively active $G \alpha_{s}\left(G \alpha_{s} R^{20:} E_{;} G \alpha_{s}{ }^{*}\right)$, indicating that the $G \alpha_{s}$ and Rho pathways do not coincide (Fig. $7 \mathrm{C}$ ).

Next, we investigated which upstream signaling components were involved in UL33-mediated activation of Rho. $G \alpha_{12 / 3}$ and $G \alpha_{q / 1,}$, known to 
A

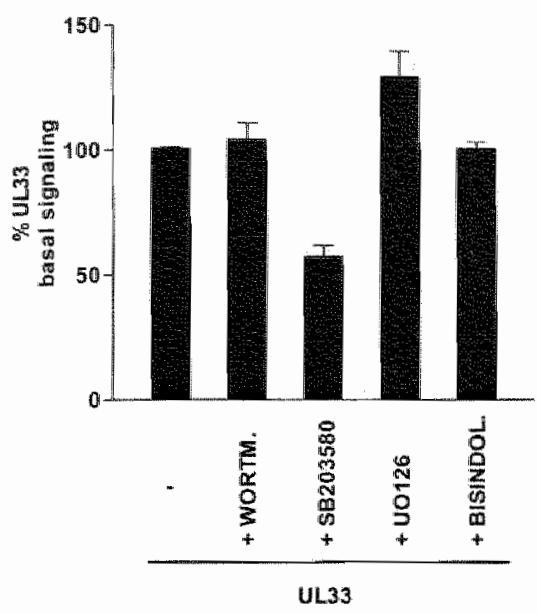

B

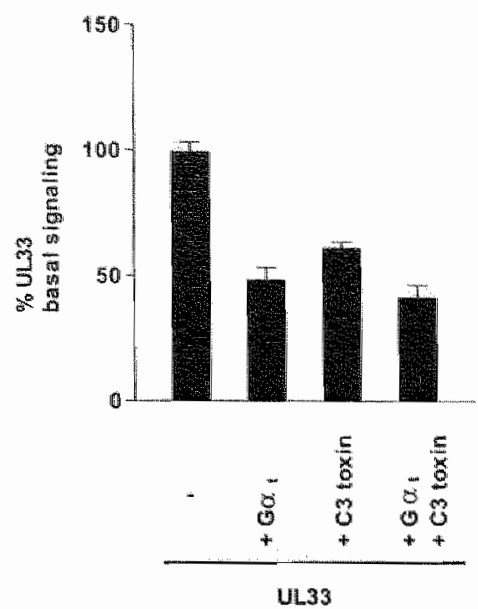

C

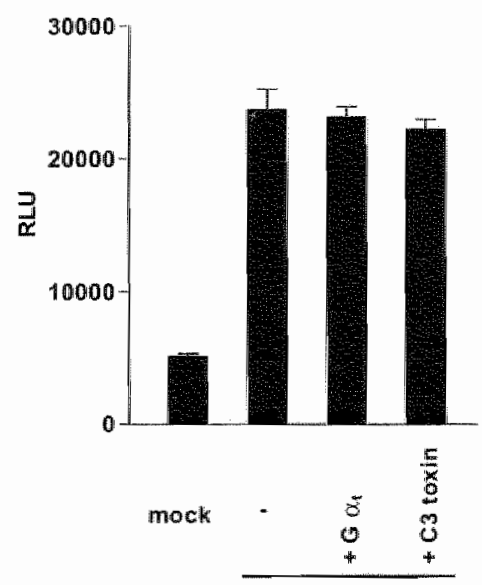

G alpha s:

Fig. 7. Additional pathways involved in the UL33-mediated CRE activation. (A) COS-7 cells were transfected with pTLNC-21CRE and UL33 ( $1 \mathrm{\mu g} / 10^{6}$ cells). Cells were incubated in the presence of different specific imhibitors (purchased from Calbiochem, San Diego, CA): wortmannin (phosphatidylinositol 3-kinase inhibitor; $100 \mathrm{nM}$ ), SB203580 (p38 inhibitor; $2 \mu M$ ), UO126 (MEK inhibitor; $1 \mu \mathrm{M}$ ), and bisindolylmaleimide (PKC inhibitor; $100 \mathrm{nM}$ ). One day after transfection, CREdriven luciferase expression was measured. Data are presented as percentages of UL33-mediated response. (B) COS-7 cells were transfected with pTLNC-21CRE and UL33 $\left(1 \mu \mathrm{\mu g} / 10^{\circ}\right.$ cells), together with combinations of CDNAs encoding $G \alpha$ transducin and $C 3$ toxin $(1 \mu \mathrm{g} / 106$ cells for each construct). One day after transfection, CRE-driven luciferase expression was measured. Data are presented as. percentages of UL33-mediated response. (C) COS-7 cells were transfected with PTLNC-21CRE and either pCDNA3 (mock) or Gos (corresponding to Gas-R201E, constitutively active mutant: $1 \mu \mathrm{g} / 10^{6}$ cells), together with cDNAs encoding Ga transducin or C3 toxin $\left(1 \mu g / 10^{\text {s }}\right.$ cells). One day after transfection CRE-driven luciferase expression was measured. Data are presented as relative light units (RLUS). 
activate Rho (36), did not play a role in the UL33-mediated increase in CRE transcription, as can be seen in Fig. 5B. It has previously been reported that also $G \beta Y$ subunits can activate small GTPases of the Rho family, resulting in activation of p38 (51). Consequently we determined the role of GBY subunits in UL33mediated activation of CRE by co-expression of $\mathrm{Go}_{i}$. As can be seen in Fig. 7 (B and C), Goc markedly attenuated the UL33-induced transcription of CRE ( $49 \pm 5 \%$ inhibition of UL33 basal signaling, $\mathrm{n}=3$ ), while not affecting $\mathrm{G} \alpha_{s}{ }^{*}$ signaling, used as a control. Co-expression of $\mathrm{C} 3$ toxin and $\mathrm{Ga}_{\mathrm{i}}$ did not lead to a further decrease in UL33-mediated signaling, suggesting that $G \beta y$ subunits, through activation of the Rho/p38 pathway, may lead to activation of CRE-mediated transcription (Fig. 7B).

Signaling by UL33 and R33 chimeric protein. Because the C-terminal tail is an important determinant of receptor signaling in general, and UL33 and R33 exhibit marked differences in their C-tails, we constructed receptor chimeras in which their C-tails were either partially or completely exchanged (Fig. 3E). Exchange of the entire $C$-terminal tails was made at a conserved tyrosine residue at positions 306 and 305 in UL33 and R33, respectively (R33-Y-UL33 and UL33$Y$-R33), and the partial exchange of the $C$ terminus was made at a conserved arginine residue at positions 328 and 327 in UL33 and R33, respectively (R33-RUL33 and UL33-R-R33). To confirm proper expression of the chimeric receptors, we also generated $\mathrm{C}$-terminal EGFP-tagged variants of these proteins, which were studied by confocal microscopy. As shown in Fig. $3\left(\mathrm{~F}, \mathrm{H}_{1}\right.$ and $\left.\mathrm{I}\right)$, the fluorescence patterns of the EGFP-tagged chimeras, R33-R-UL33-EGFP, UL33-R-R33-EGFP, and UL33-Y-R33-EGFP were similar to that seen for UL33-EGFP and R33-EGFP, showing co-localization with the cell membrane of transfected cells as well as with intracellular vesicles. However, in cells expressing R33-Y-UL33-EGFP, fluorescence was seen exclusively within intracellular compartments (Fig. $3 G$ ), indicating that R33-Y-UL33-EGFP is not properly delivered to the cell membrane.

Subsequently, the chimeric proteins were tested in the various signaling assays. In each of these assays, the activity of the chimeric receptors was similar to that of their EGFP-fused counterparts (data not shown). Fig. 8A shows that, in comparison with UL33, UL33-R-R33 is impaired in activation of $\mathrm{G}_{\mathrm{i} / \mathrm{o}}$ proteins, leading to an increased basal level of CRE activation (Fig. 8A) as well as an impaired accumulation of InsP (Fig. 8C). This impairment is even more pronounced for the chimera UL33-Y-R33, which appears to be completely incapable of $G_{1 / \%}$ coupling. In agreement with these observations, UL33-R-R33 showed a lower sensitivity to PTX than UL33, whereas the activity of UL33-Y-R33 was not significantly influenced by PTX. The activity of R33-R-UL33, both in the CRE reporter gene assay (Fig. 8B) and in the InsP assay (Fig. 8D), was not significantly different from that of R33. By contrast, replacement of the entire $C$-terminal tail of $R 33$ by that of UL33 resulted in a mutant (R33-Y-UL33) that did not display activity in any of the assays used (Fig. 8, B and D). As shown above (Fig. 3G), this lack of activity can be attributed to the inability of R33-Y-UL33 to be expressed on the cell membrane. 
A

B
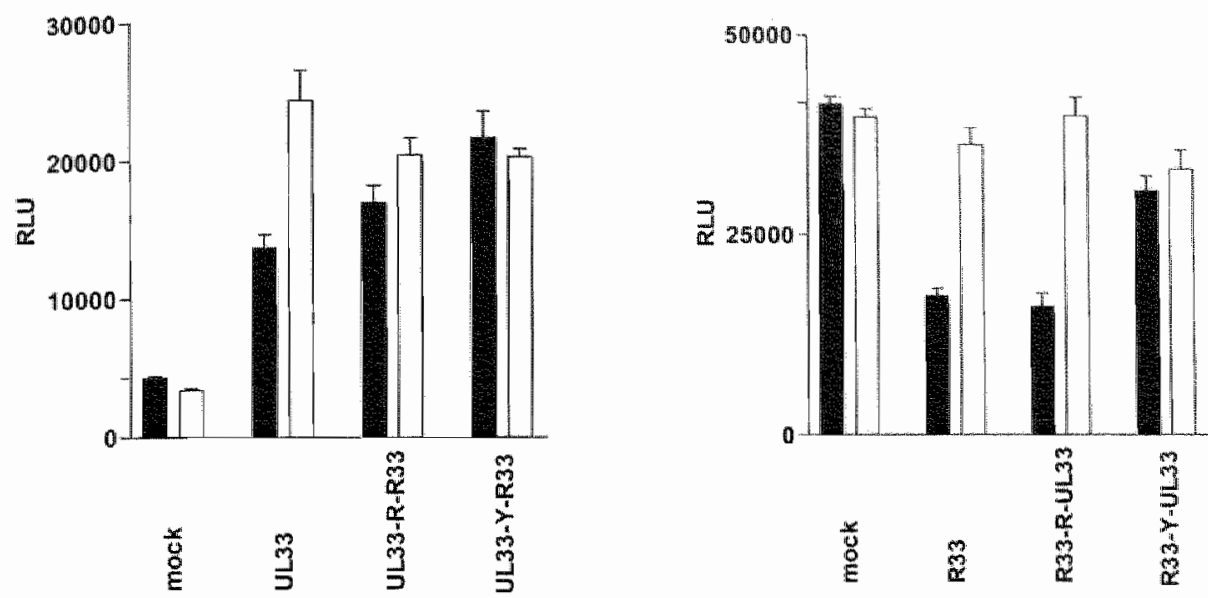

C

D
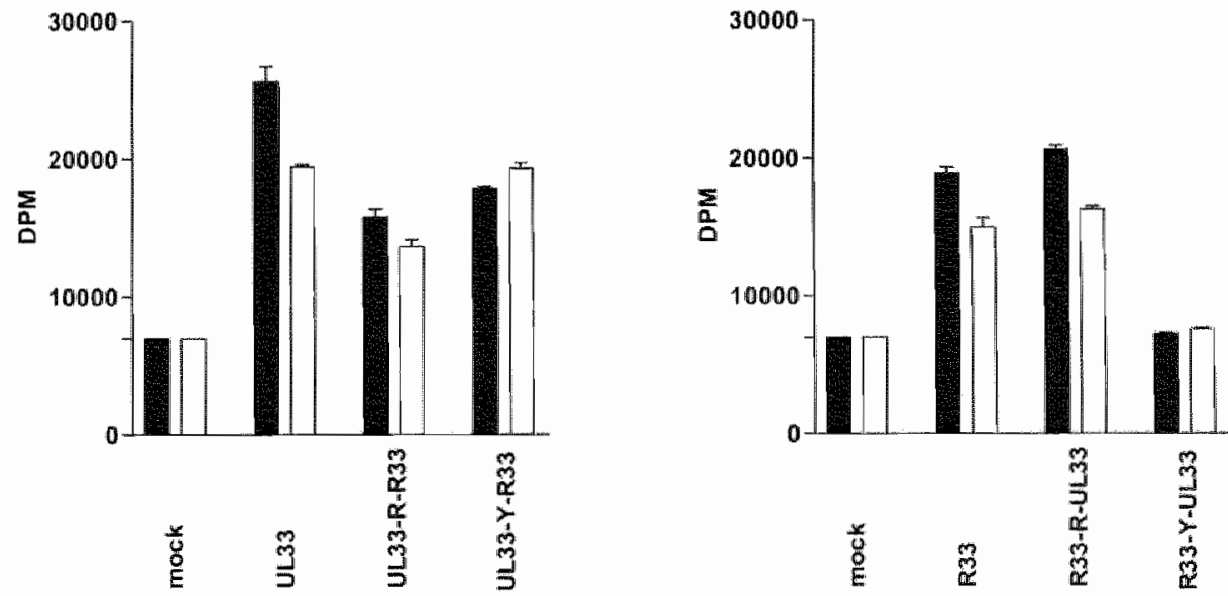

Fig. 8. Role of the $C$ terminus in UL33- and R33-mediated signaling. ( $A$ and B) COS-7 cells were transiently transfected with the reporter plasmid pTLNC-21CRE and CDNA encoding UL33, R33, or the different indicated chimeras $\left(1 \mu \mathrm{g} / 10^{5}\right.$ cells; for schematic representation of chimeric proteins, see Fig. 3). Cells were incubated in the presence (white bars) or absence (black bars) of PTX $(80 \mathrm{ng} / \mathrm{m} /)$. One day after transfection, CRE-driven luciferase expression was measured. For R33-WT and chimeras (B), cells were stimulated with forskolin for the last $6 \mathrm{~h}$. (C and D) COS 7 cells $\left(10^{6}\right.$ cells) were transiently transfected with cDNA encoding UL33, R33, or the different indicated chimeras. Cells were incubated in the presence (white bars) or absence (black bars) of PTX $(80 \mathrm{ng} / \mathrm{mll}) .48 \mathrm{~h}$ after transfection, ins $\mathrm{P}$ accumulation was measured. 
Construction of the deletion mutant HCMV AD169-AUL33. To analyze the function of the UL33 protein in HCMV-infected cells, a UL33-deficient variant of HCMV AD169 (AD169- $\triangle$ UL33) was generated by mutagenesis of the AD169 genome as infectious $B A C$ in $E$. coli. To this end, nearly the entire coding region of UL33 was deleted (Fig. 9A). The recombinant virus AD169- $\Delta$ UL33 was reconstituted in fibroblasts, as described under "Material and methods." To confirm the deletion of UL33 ORF in the mutant genome, Southern blot analysis was performed. Viral DNA was extracted from fibroblasts infected either with HCMV AD169 or AD169- $\triangle$ UL33, digested, separated, and hybridized with the entire UL33 coding region, used as probe. As can be seen in Fig. 9B, no signal was detected for the mutant strain, proving that the UL33 gene has been deleted. As a positive control, the integrity of the US28 and the UL78 ORFs was checked with the respective probes (Fig. 9B). No differences could be detected in the fragment length of both regions. Propagation of the recombinant AD169-AUL33 virus also revealed that the UL33 gene product is not essential for viral growth in tissue culture, because the titers of wild-type and mutant virus stocks produced by infection of fibroblasts were identical (Fig. 9C).

Analysis of UL33-mediated signaling in HCMV-infected cells. We next investigated whether UL33 is capable of activating CRE in HCMV-infected cells, as suggested by results obtained in transfected COS-7 cells.To this end, U373 cells were transiently transfected with the reportergene pTLNC-21CRE and subsequently infected with HCMV AD169 or AD169-AUL33 or mock infected. CRE activation was measured at 6, 24, and $48 \mathrm{~h}$ post-infection (Fig. 9, D-F). As internal control for transfection, some samples of mock infected cells were stimulated with forskolin $(10 \mu \mathrm{M})$ for the last $6 \mathrm{~h}$ before each read-out. Forskolininduced CRE activation was comparable at the different time points $(\sim 60,000$ relative light units), suggesting that no major changes in transfection efficiency among the different time points are present.

Most interestingly, we found a marked increase of CRE activation in AD169-infected cells compared with mock infected cells (Fig. 9, D-F). Virusinduced CRE activation is already present at the early time point $(12 \pm 1$-fold over mock infected cells; Fig. 9D) and is further increased at later time points (430 \pm 50 - and $318 \pm 20$-fold over mock infected cells at 24 and $48 \mathrm{~h}$, respectively; Fig. 9. E and F). Importantly, cells infected with AD169-AUL33 showed a lower activation of CRE at each time point examined (Fig. 9, D-F): the residual CRE activation is $47 \pm 3 \%, 62 \pm 1 \%$, and $45 \pm 3 \%$ of WT-HCMV-induced signaling at 6,24 and $48 \mathrm{~h}$ after infection, respectively. These data strongly imply that UL33 is at least in part responsible for virus-induced CRE activation.

\section{Discussion}

Viruses have evolved various ways to alter intracellular signaling pathways (30). By means of expression of pirated GPCRs, viruses are suggested to coordinate and regulate cellular signal transduction both spatially and temporally 
to enhance the degree of signal specificity according to its own needs. As such, vGPCRs would significantly contribute to viral pathogenesis. Direct evidence that VGPCRs indeed contribute to pathology is available for several of these receptors. For instance, KSHV ORF74 was found to act as an oncogene (7). Moreover, transgenic expression of ORF74 induces an angioproliferative disease resembling Kaposi's sarcoma (52). Furthermore, the GPCR genes of RCMV (R33 and R78) and MCMV (M33 and M78) were each found to play a crucial role in the pathogenesis of viral infection $(8,10,15,32)$.

Our current data and those reported earlier by us and others $(12,13,20$, 29.49) indicate that CMV effectively uses VGPCRs to orchestrate signaling networks within the cell during its viral life span. Previously, four genes encoding vGPCRs have been identified in the HCMV genome (US27, US28, UL33, and UL78) (14). Although a recent study has suggested that the HCMV genome contains an additional 11 genes that putatively encode proteins possessing 7 transmembrane domains (34), these genes seem to lack other sequences characteristic of the family of GPCR genes. Of the four putative HCMV genes, only US28 and UL33 have hitherto been demonstrated to encode functional GPCRs (Refs. 12 and 49, and this study). Previously, US28 has been shown to constitutively activate a variety of signal transduction cascades, including PLC (12), MAPK pathways (11), and various transcription factors $(12,49)$. Moreover, we and others have recently shown that also in HCMV-infected fibroblasts US28 constitutively activates PLC (13, 29), further emphasizing the physiological relevance of the constitutive signaling of US28 after viral infection. Here, we show that another HCMV-encoded receptor, UL33, displays constitutive signaling in transfected as well as in HCMV-infected cells.

Until now, the structure of the UL33 CDNA was predicted on the basis of sequence analyses as well as the finding of an intron near the $5^{\prime}$ end of the UL33 open reading frame. In this study, we have shown that UL33 predominantly encodes a spliced transcript of which the $5^{*}$ terminus is located 55 bp upstream of the start codon. No evidence was found for the existence of an unspliced UL33 transcript, which could potentially encode a shorter version of UL33 such as the one used in this study, i.e. UL33(s). The observed lack of membrane expression and signaling of UL33(s) indicates that it is indeed unlikely that this hypothetical UL33 gene product is relevant in HCMV infection.

As reported previously $(4,20,29,49)$, our present results with UL33 indicate that a high level of constitutive activity appears to be an important property of VGPCRs. Viruses might exploit this inherent GPCR property to modulate homeostasis of infected cells. UL33 is, like R33, M33, and US28, positively coupled to PLC, generating an increase in inositol phosphate production. For both $U L 33$ and $R 33$, activation of PLC is mediated not only by $G_{0 / 10}$ proteins, but also partially by $G_{i / a}$ proteins (Fig. 10A). $G \alpha_{\alpha / 11}$ and $G \beta \gamma$ subunits from $G_{i / o}$ appear to be the most likely components activating PLC. UL33 and its RCMV counterpart R33 differ, however, in their ability to modulate activation of CRE transcription. $R 33$ constitutively inhibits signaling to $C R E$, measured as a reduction of forskolin-induced signaling. Inhibition of CRE-driven transcription by R33 is entirely $G_{i / 0}$-mediated (Fig. 10B), preferably through $G_{i 1}$ and $G_{i 3}$ (Fig. 6A). By 
A

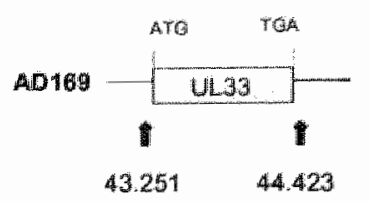

D

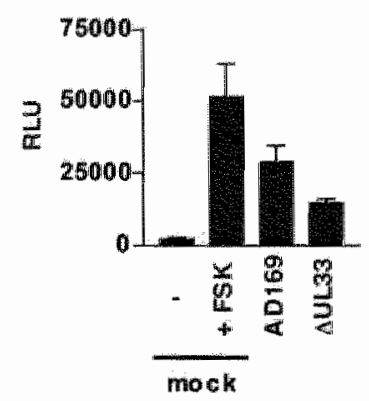

B
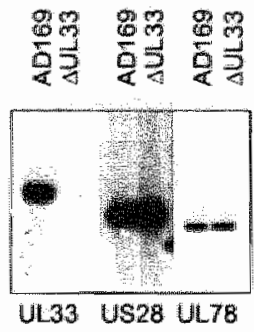

probe

E

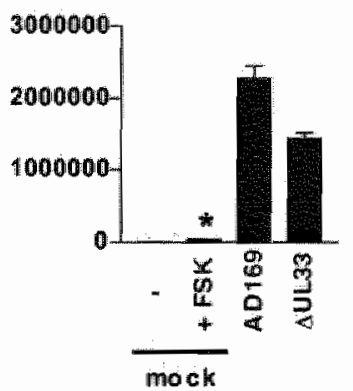

C

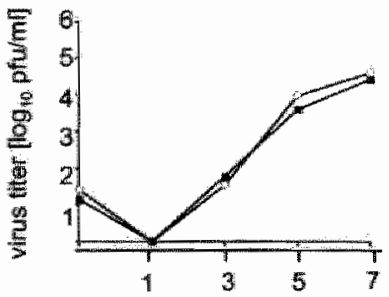

$\mathbf{F}$

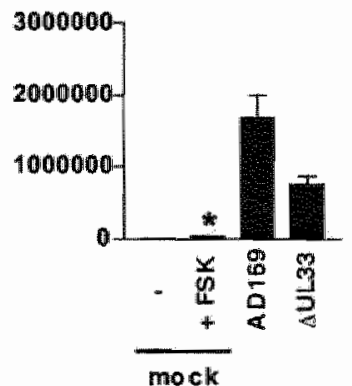

Fig. 9. UL33 activates CRE in HCMV-infected cells. (A) construction of the deletion mutant HCMV AD169-AUL33, schematic representation of the protocol. The coding region of UL33 is shown as a horizontal bar. The region deleted is indicated in between solid arrows. The nucleotide numbering corresponding to EMBL/GenBank ${ }^{\mathrm{M}}$ accession no. X17403 is shown. (B) Southern blot analysis in HCMV-infected fibroblasts. Viral DNA was extracted from cells infected with either wild-type HCMV AD169 or AD169-AUL33. DNA was digested (with ECORI for UL33 and US28; with BamHH for UL78), fractionated by gel electrophoresis, and hybridized with the corresponding radiolabeled probes. (C) virus yield kinetics. Fibroblasts were infected at an m.0.i. of 0.01 with either wild-type HCMV AD169 or AD169-AUL33. The graphs show the wirus titers determined in the culture medium obtained with AD169 (open circles) and AD169-AUL33 (closed boxes). (D-F) role of UL33 in HCMV-induced CRE activation. U373 cells were transiently transfected with the reporter plasmid pTLNC-21CRE and subsequently infected with wild-type HCMV AD169. AD169-AUL33 at an m.0.i. of 3 or mock infected. CRE-driven luciferase expression was measured 6 (D), 24 (E), and $48 \mathrm{~h}(\mathrm{~F})$ after infection. Some samples of mock infected cells were stimulated with forskolin (indicated as FSK; $10 \mu M$ ) for the last $6 \mathrm{~h}$ before read-out. Data are presented as relative light winits (RLUs).

contrast, UL33 appears to possess a broader range of $G$ protein coupling. Although UL33 interacts with $G$ proteins of the $\alpha_{i / 0}$ class (most likely $G_{i 1}$ and $G_{i 3}$ ), additional signal transduction routes play a more prominent role with respect to CRE activation; as a result, the overall effect of UL33 signaling is a transcriptional activation of CRE (Fig. 1OB). CREB is regulated by a concerted action of various signaling kinases such as PKA, PKC, MAPKs, including p44/p42 and p38 (30), many of which are up-regulated early after CMV infection (11). UL33-mediated transcriptional activation of CRE appears to be mediated by coupling to $G \alpha_{5}$, on one hand, and signaling through Rho and $\mathrm{p} 38$, via $G \beta \gamma$, on the other. Because coexpression of $\mathrm{G} \alpha_{1}$ and $\mathrm{C} 3$ excenzyme does not result in a further decrease in UL33-mediated signaling to CRE, it is likely that signaling pathways converge. Rho 
is known to activate $\mathrm{p} 38$ via $M K K 3 / 6(51)$, leading to phosphorylation of CREB, passibly via MSK-1 (16).

Interestingly, we noticed that co-expression of G $\alpha_{3}$ reduced UL33mediated CRE transcription. Apparently, this effect was not due to a direct negative regulation of $C R E$, as shown by data obtained either with the constitutively active $G \alpha_{11}$, subunit or in the presence of PKC activator PMA. As an alternative explanation, we suggest that overexpression of $G \alpha_{q}$ is actually scavenging the receptor from coupling to $G_{s}$ subumits, resulting in a reduction of CRE activation. In line with this hypothesis, we found that overexpression of $G \alpha_{\text {s }}$ strongly reduced UL33-mediated InsP accumulation (data not shown). Similar results were previously shown for the $\alpha_{2}$-adrenoreceptor which can couple to both $G \alpha_{i}$ and $G \alpha_{s}$ subunits. Co-expression of either $G \alpha_{i}$ or $G \alpha_{5}$ subunits resulted in an agonist-mediated inhibition or increase of CAMP levels, respectively (31). The interaction with an overexpressed $G$ protein excludes interaction with others; therefore, the availability of $G$ proteins of different classes can significantly alter the signaling response for broadly coupled receptors.

The apparent divergent and opposite signaling properties of the UL33 and $R 33$ receptors prompted us to investigate the differences between these proteins in more detail. Sequence comparison indicated that the observed differences in activity might be due to their divergent $C$-terminal tails. The predicted amino acid sequence of UL33 has a relatively long C-terminal tail in comparison with R33. Remarkably, R33 contains a unique stretch of 11 consecutive Pro residues (polyproline stretch) near the $C$ terminus. Although polyproline motifs have previously been shown to mediate binding to a variety of conserved protein domains, such as Sre homology $3(\mathrm{SH} 3)$ and WW domains (33), the role of this motif in the function of $R 33$ is yet unknown. To investigate the role of the $C$ terminal tails in the differential signaling profiles of UL33 and R33, we generated UL33/R33 chimeras. Interestingly, the study of these chimeras showed that the Cterminal tail of UL33 appears to be the determinant for signaling of UL33 via $G_{i / \%}$. Exchanging (part of) the $C$ terminus of UL33 for the C terminus of R33, resulted in a loss of $G_{i / 0}$ coupling, as observed in both the InsP accumulation assay and CRE reporter gene assay.

Conversely, exchange of the C terminus of R33 for that of UL33, did not significantly alter R33-mediated signaling, suggesting that sequences other than the $C$ terminus are important for coupling of $R 33$ to $G_{i / 0}$. It is interesting to note that $R 33$ contains a basic motif (including ${ }^{314}{ }^{4} R F^{316}$ ) that has recently been shown to play a crucial role in proper receptor expression of CCR5 (44). It was found that substitution of the C-terminal tail of CCR5, which comprises this basic motif, for that of CXCR4, which lacks it, resulted in a mutant that was defective in trafficking to the cell surface, whereas the CXCR4 chimera that exchanged the $C$ terminus for that of CCR5 displayed a normal, cell surface expression pattern. In analogy, the lack of the basic motif from chimera R33-Y-UL33 may explain the inability of this protein to be expressed properly on the cell surface and, thus, its inactivity in any of the signaling assays. Additionally, the UL33 tail contains an RXR motif $\left({ }^{316} \mathrm{RMR}^{318}\right)$, known to be implicated in protein retention in the endoplasmic reticulum (40). It is possible that this motif is masked in the UL33 receptor, but is 
exposed within chimera R33-Y-UL33, thereby conferring endoplasmic reticulum localization.

To date, UL33 homologs from rodent CMVS, R33 and M33, remain orphan receptors, as chemokines, which either modulate the activity of, or bind to, these receptors, have not yet been found $(20,49)$. Similarly, the $C C$ chemokines RANTES (regulated on activation normal T cell expressed and secreted), and MIP$1 \alpha$ did not modulate UL33 constitutive activity nor showed any binding to this receptor (data not shown). The recent identification of a small non-peptidergic inverse agonist for US28 by its modulating effect on US28-mediated constitutive signaling (13), demonstrates that the UL33-mediated signaling assays described in this study may be suitable screening systems for the identification of ligands acting at UL33. The availability of such a ligand would be of help in elucidating the role of UL33 in HCMV infection.

Little is known about the mechanisms underlying the pathogenesis of human cytomegalovirus. It is known that, following CMV infection, effector responses such as inositol lipid hydrolysis, kinase activation, and arachidonic acid metabolism are increased within the host cell and are required to direct and control early viral gene expression and DNA replication (1).

Here we show that HCMV also induces a strong activation of CRE, at early and late times post infection. In this regard, it is important to note that the HCMV major immediate-early promoter contains four consensus CRE sites (21, 42). Because the immediate-early promoter of HCMV constitutes a primary genetic switch, essential for the progression of viral infection and reactivation, regulation of CRE activation during the infectious course might be of (patho)physiological importance. Importantly, data obtained with the deletion mutant virus $A D 169-\triangle U L 33$ strongly indicate that UL33 is involved in virusinduced CRE activation. At all time points, AD169-AUL33 induces approximately only half the response of WT virus. These results cannot be ascribed to an impaired infectivity of the deletion mutant virus, because we have shown that viral growth kinetics are essentially the same for WT and $\triangle U$ L33-HCMV (Fig. 9C). These findings confirm the UL33-mediated CRE activation in a physiologically relevant model system. Infection of cells with HCMV offers a significant model for the pharmacological study of UL33, because in this condition UL33 expression is regulated by the virus and its constitutive signaling is not a potential artifact due to overexpression. Interestingly, UL33 contribution to CRE activation was already present at early time post infection. Because UL33 is mainly transcribed at late times of infection (15), it is likely that UL33 expression on the virion envelope, as described previously $(18,28)$, activates signal transduction pathways immediately upon infection, after fusion of the viral envelope with the cell membrane. Comparison of CRE activation in cells infected with $\triangle \mathrm{UL} 33$ HCMV or mock infected also indicates that UL33 is not the only player involved in HCMV-induced CRE activation. It is suggestive to propose US28 as a candidate for the residual CRE activation, because it was shown that this receptor can also activate CRE in transiently transfected COS-7 cells, similarly to UL33 (49). We are currently investigating in more detail the signaling pathways engaged by HCMV in CRE activation. Interestingly, it was recently shown that HCMV infection induces $\mathrm{p} 38$ 
A

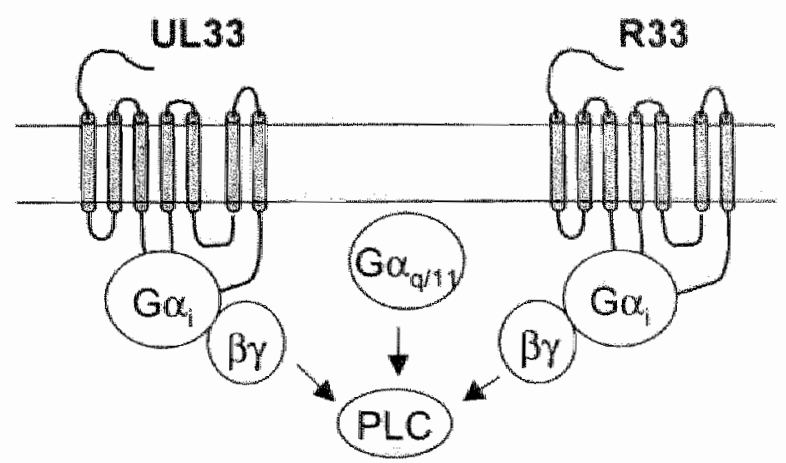

B

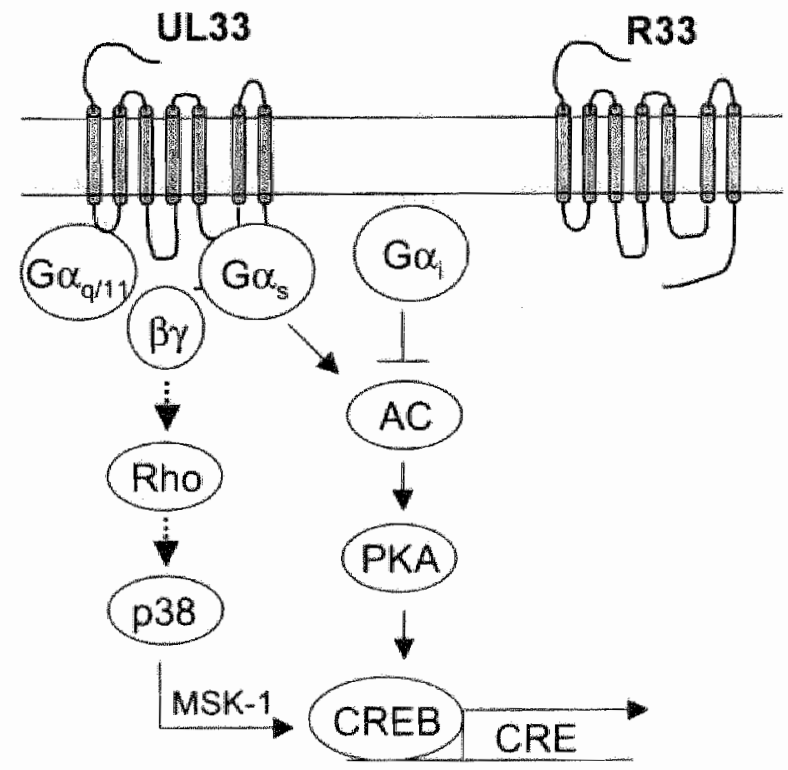

Fig. 10. Proposed model of UL33 and R33-mediated signalling. (A) UL33 and R33 activate PLC vha coupling to $\mathrm{G} \alpha_{\mathrm{q}, 4}$, subunits and via py subunits released from $\alpha_{\mathrm{i} \%}$ proteins. (B) UL33 and R33 differentially regulate CRE-mediated transcription. Whereas both receptors show a Go, inhibition of CAMP levels, Ull33 also couples to Go, which activates adenyly cyclase (AC). Additionally, By subunits are partly responsible for UL33-mediated CRE activation. We suggest that this pathway involves the activation of Rho/p38, finally leading to the phosphorylation of CREB. 
phosphorylation (23). The role of UL33 and US28 in HCMV-induced p38 activation and its possible link to CRE activation, as suggested by results obtained in COS-7 cells, will be further examined.

In conclusion, it is apparent from these and earlier studies that CMVencoded receptors regulate cellular signaling via the constitutive activation of a range of $G$ proteins. In this study, we show that UL33 constitutively modulates several pathways via promiscuous activation of $G$ proteins of different classes. Initial experiments performed with HCMV-infected cells suggest that the signaling properties of UL33 are of physiological relevance and that HCMV may effectively use UL33 and US28 to orchestrate multiple signaling networks within infected cells.

\section{Acknowledgments}

We thank E. Beuken for sequencing the RACE products and 1 . Broers for his assistance with the confocal microscopy. D.M. acknowledges Dr. M. Wagner for the kind gift of the plasmids for the BAC technology and the help during the time of establishing the method in the laboratory.

\section{References}

1. Albrecht $T$, Boldogh I, Fons $M$, AbuBakar S, Deng CZ. (1990) Cell activation signals and the pathogenesis of human cytomegalovirus. Intervirology 31, 68-75

2. Alewijnse $A E$, Smit $M J$, Rodriguez Pena MS, Verzijl D, Timmerman $H$, Leurs R. (1997) Modulation of forskolin-mediated adenylyl cyclase activation by constitutively active $G(s)$-coupled receptors. FEBS Lett. 419 , $171-174$

3. Altschul SF, Gish W, Miller W, Myers EW, Lipman DI. (1990) Basic local alignment search tool. J. Mol. Biol. 215, 403-410

4. Arvanitakis L, Geras-Raaka $E_{i}$ Varma A, Gershengorn MC, Cesarman E. (1997) Human herpesvirus KSHV encodes a constitutively active Gprotein-coupled receptor linked to cell proliferation. Nature 385, 347-350

5. Atalay $R$, Zimmermann $A$, Wagner $M$, Borst $E_{r}$ Benz $C$, Messerle $M$, Hengel H. (2002) Identification and expression of human cytomegalovirus transcription units coding for two distinct Fc gamma receptor homologs. J. Virol. $76,8596-8608$

6. Aznar S, Lacal, J. C. (2001) Rho signals to cell growth and apoptosis. Cancer Lett. 165, 1-10

7. Bais C, Santomasso B, Coso O, Arvanitakis L, Raaka EG, Gutkind JS, Asch AS, Cesarman E, Gershengorn MC, Mesri EA, (1998) G-protein-coupled receptor of Kaposi's sarcoma-associated herpesvirus is a viral oncogene and angiogenesis activator. Nature 391, 86-89 
8. Beisser PS, Grauls G, Bruggeman CA, Vink C. (1999) Deletion of the R78 $G$ protein-coupled receptor gene from rat cytomegalovirus results in an attenuated, syncytium-inducing mutant strain. J. Virol. 73, 7218-7230

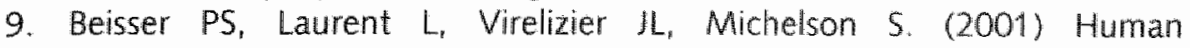
cytomegalovirus chemokine receptor gene US28 is transcribed in latently infected THP-1 monocytes. J. Virol. 75, 5949-5957

10. Beisser PS, Vink C, Van Dam JG, Grauls G, Vanherle SJ, Bruggeman CA. (1998) The R33 G protein-coupled receptor gene of rat cytomegalovirus plays an essential role in the pathogenesis of viral infection. 1. Virol. 72 . $2352-2363$

11. Billstrom MA, Johnson GL, Avdi NJ, Worthen GS. (1998) Intracellular signaling by the chemokine receptor US28 during human cytomegalovirus infection. J. Virol. 72, 5535-5544

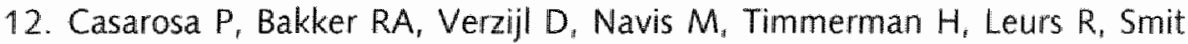
M. (2001) Constitutive signaling of the human cytomegalovirus-encoded chemokine receptor US28. J. Biol. Chem. 276, 1133-1137

13. Casarosa $P$, Menge $W M$, Minisini $R$, Otto $C$, van Heteren I Jongejan $A_{*}$ Timmerman $H$, Moepps B, Kirchhoff $F$, Mertens $T$, Smit M J, Leurs $R$. (2003) Constitutive signaling of the human cytomegalovirus-encoded receptor UL33 differs from that of its rat cytomegalovirus homolog $R 33$ by promiscuous activation of $\mathrm{G}$ proteins of the $\mathrm{Gq}, \mathrm{Gi}$, and Gis classes. J. Bial. Chem. 278, 5172-5178

14. Chee MS, Satchwell SC, Preddie E, Weston KM, Barrell BG. (1990) Human cytomegalovirus encodes three $G$ protein-coupled receptor homologues. Nature 344, 774-777

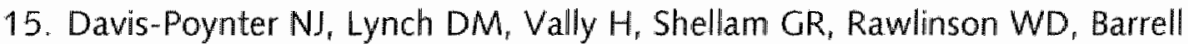
BG, Farrell HE. (1997) Identification and characterization of a $G$ proteincoupled receptor homolog encoded by murine cytomegalovirus. I. Virol. 71. 1521-1529

16. De Cesare D. Firria GM. Sassone-Corsi P. (1999) Signaling routes to CREM and CREB: plasticity in transcriptional activation. Trends Biochem. Sci. $24,281-285$

17. Diviani D, Lattion AL, Larbi N, Kunapuli P, Pronin A, Benovic JL, Cotecchia 5. (1996) Effect of different $G$ protein-coupled receptor kinases on phosphorylation and desensitization of the alphat B-adrenergic receptor. $J$. Biol. Chem. 271, 5049-5058

18. Fraile-Ramos A, Pelchen-Matthews A, Kledal TN, Browne $H$, Schwartz TW. Marsh M. (2002) Localization of HCMV UL33 and US27 in endocytic compartments and viral membranes. Traffic 3, 218-232

19. Goossens VJ, Blok M. Christiaans MH, Sillekens P, Middeldorp IM, Bruggeman CA. (2000) Early detection of cytomegalovirus in renal transplant recipients: comparison of PCR, NASBA, pp65 antigenemia, and viral culture. Transplant Proc. 32, 155-158

20. Gruijthuijsen $Y K$, Casarosa P, Kaptein SJ Broers $I_{\text {. }}$, Leurs $R$, Bruggeman $\mathrm{CA}_{\text {u }}$ Smit M. Vink C. (2002) The rat cytomegalovirus R33-encoded $G$ 
protein-coupled receptor signals in a constitutive fashion. J. Virol. 76, $1328-1338$

21. Hunninghake GW, Monick MM, Liu B, Stinski MF. (1989) The promoterregulatory region of the major immediate-early gene of human cytomegalovirus responds to T-lymphocyte stimulation and contains functional cyclic AMP-response elements. J. Virol. 63, 3026-3033

22. Isegawa $Y$, Ping $Z$, Nakano $K$, Sugimoto $N$, Yamanishi K. (1998) Human herpesvirus 6 open reading frame $U 12$ encodes a functional betachemokine receptor. J. Virol. 72, 6104-6112

23. Johnson RA, Huong $S M_{1}$ Huang ES. (2000) Activation of the mitogenactivated protein kinase $\mathrm{p} 38$ by human cytomegalovirus infection through two distinct pathways: a novel mechanism for activation of p38. J. Viral. $74,1158-1167$

24. Kledal TN, Rosenkilde $M M_{\text {s }}$ Schwartz TW. (1998) Selective recognition of the membrane-bound $C \times 3 C$ chemokine, fractalkine, by the human cytomegalovirus-encoded broad-spectrum receptor US28. FEBS Lett. 441, 209-214

25. Kuhn DE, Beall Cl, Kolattukudy PE. (1995) The cytomegalovirus US28 protein binds multiple $\mathrm{CC}$ chemokines with high affinity. Biochem. Biophys. Res. Commun. 211, 325-330

26. Lee SB, Shin SH, Hepler JR, Gillman AG, Rhee SG. (1993) Activation of phospholipase C-beta 2 mutants by $G$ protein alpha $q$ and beta gamma subunits. J. Biol. Chem. 268, 25952-25957

27. Lopez-llasaca M. (1998) Signaling from G-protein-coupled receptors to mitogen-activated protein (MAP)-kinase cascades. Biochem. Pharmacol. $56,269-277$

28. Margulies BJ, Browne $H$, Gibson W. (1996) Identification of the human cytomegalovirus $G$ protein-coupled receptor homologue encoded by UL33 in infected cells and enveloped virus particles. Virology 225, 111125

29. Minisini R, Tulone C, Luske A, Michel D, Mertens T, Gierschik P, Moepps B. (2003) Constitutive inositol phosphate formation in cytomegalovirusinfected human fibroblasts is due to expression of the chemokine receptor homologue pUS28. J. Virol. 77, 4489-4501

30. Murphy PM. (2001) Viral exploitation and subversion of the immune system through chemokine mimicry. Nat. Immunol. 2, 116-122

31. Nasman J Kukkonen IP, Ammoun S, Akerman KE. (2001) Different roles for $\mathrm{Gi}$ and Go proteins in modulation of adenylyl cyclase type-2 activity. Biochem. Pharmacol. 62, 913-922

32. Oliveira SA, Shenk TE. (2001) Murine cytomegalovirus M78 protein, a $G$ protein-coupled receptor homologue, is a constituent of the virion and facilitates accumulation of immediate-early viral mRNA. Proc. Natl. Acad. Sci. U. S. A. $98,3237-3242$

33. Pawson T, Scott JD. (1997) Signaling through scaffold, anchoring, and adaptor proteins. Science 278, 2075-2080 
34. Rigoutsos I, Novotny J, Huynh T, Chin-Bow ST, Parida L, Platt D, Coleman D. Shenk $T$ (2003) In silico pattern-based analysis of the human cytomegalovirus genome. J. Virol. 77, 4326-4344

35. Rosenkilde MM, Waldhoer M, Luttichau HR, Schwartz TW. (2001) Virally encoded 7TM receptors. Oncogene 20, 1582-1593

36. Sah VP, Seasholtz TM, Sagi SA, Brown JH. (2000) The role of Rho in G protein-coupled receptor signal transduction. Annu. Rev. Pharmacol. Toxicol. 40, 459-489

37. Sambrook 1, Russell DW. (2001) Molecular Cloning: A Laboratory Manual, Cold Spring Harbor Laboratory, Cold Spring Harbor, NY

38. Sekine A, Fujiwara M, Narumiya, S. (1989) Asparagine residue in the tho gene product is the modification site for botulinum ADP. ribosyltransferase. J. Biol. Chem. 264, 8602-8605

39. Shaywitz AJ, Greenberg ME. (1999) CREB: a stimulus-induced transcription factor activated by a diverse array of extracellular signals. Annu. Rev. Biochem. 68, 821-861

40. Shikano S, Li M. (2003) Membrane receptor trafficking: evidence of proximal and distall zones conferred by two independent endoplasmic reticulum localization signals. Proc. Natl. Acad. Sci. U. S. A. 100, 57835788

41. Smit MJ, Verzijl D, Casarosa P, Navis M, Timmerman H, Leurs R. (2002) Kaposi's sarcoma-associated herpesvirus-encoded $G$ protein-coupled receptor ORF74 constitutively activates $\mathrm{p} 44 / \mathrm{p} 42$ MAPK and Akt via G(i) and phospholipase C-dependent signaling pathways. J. Virol. 76, 17441752

42. Sun B, Harrowe G, Reinhard C, Yoshihara C, Chu K, Zhuo S. (2001) Modulation of human cytomegalovirus immediate-early gene enhancer by mitogen-activated protein kinase kinase kinase-1. J. Cell. Biochem. 83, 563-573

43. Sweet C. (1990) in Topley and Wilson's Principles of Bacteriology, (Collier LS, and Timbury MC, eds) Vol. 4, 8th Ed., pp. 105-130, Edward Arnold, London

44. Venkatesan S, Petrovic A, Locati M, Kim YO, Weissman D, Murphy PM. (2001) A membrane-proximal basic domain and cysteine cluster in the $C$ terminal tail of CCR5 constitute a bipartite motif critical for cell surface expression. J. Biol. Chem. 276, 40133-40145

45. Vink C, Smit MJ Leurs R, Bruggeman CA. (2001) The role of cytomegalovirus-encoded homologs of $G$ protein-coupled receptors and chemokines in manipulation of and evasion from the immune system. J. Clin. Virol. 23, 43-55

46. Wagner $M$, Koszinowski UH. (2004) in Methods in Molecular Biology (Zhao, S., ed) Vol. 23, Humana Press, Totowa, NI, in press

47. Wagner $M$. Michel $D$, Schaarschmidt $P$, Vaida $B$, Jonjic S, Messerle $M$, Mertens $T$, Koszinowski U. (2000) Comparison between human cytomegalovirus pUL97 and murine cytomegalovirus (MCMV) pM97 
expressed by MCMV and vaccinia virus: $p M 97$ does not confer gancidovir sensitivity, J. Virol. 74, 10729-10736

48. Wagner M, Ruzsics $Z$, Koszinowski UH. (2002) Herpesvirus genetics has come of age. Trends Microbiol. 10, 318-324

49. Waldhoer M, Kledal TN, Farrell HE, Schwartz TW. (2002) Murine cytomegalovirus (CMV) M33 and human CMV US28 receptors exhibit similar constitutive signaling activities. J. Virol. 76, 8161-8168

50. Wise $A$, Sheehan $M$, Rees 5 , Lee $M$, Milligan G. (1999) Comparative analysis of the efficacy of $\mathrm{A} 1$ adenosine receptor activation of Gi/o alpha $G$ proteins following coexpression of receptor and $G$ protein and expression of A1 adenosine receptor-Gi/o alpha fusion proteins. Biochemistry 38, 2272-2278

51. Yamauchi J. Tsujimoto $G$, Kaziro $Y$, Itoh $H$. (2001) Parallel regulation of mitogen-activated protein kinase kinase 3 (MKK3) and MKK6 in Gqsignaling cascade. I. Biol. Chem. 276, 23362-23372

52. Yang TY, Chen SC, Leach MW, Manfra D, Homey B, Wiekowski $M$, Sullivan L, Jenh $\mathrm{CH}_{\text {, Narula }}$ KK, Chensue SW, Lira SA. (2000) Transgenic expression of the chemokine receptor encoded by human herpesvirus 8 induces an angioproliferative disease resembling Kaposi's sarcoma. J. Exp. Med. 191, 445-454 


\section{CHAPTER 5}

Mutational Analysis of the Rat Cytomegalovirus R33-Encoded G Protein-Coupled Receptor: Identification of Amino Acid Residues

Critical for Cellular Localization and Ligand-Independent

Signaling

J. Gen. Virol. (2004) 85:897-909 


\section{Abstract}

The rat cytomegalovirus (RCMV) R33 gene encodes a $G$ protein-coupled receptor (GPCR), pR33, which possesses agonist-independent, constitutive signalling activity. To characterize this activity further, we generated a series of point and deletion mutants of pR33. Both expression of and signalling by the mutants was evaluated. Several point mutants were generated that contained modifications in the NRY motif. This motif, at aa 130-132 of pR33, is the counterpart of the common DRY motif of GPCRs, which is known to be involved in $G$ protein coupling. We found that mutation of the asparagine residue within the NRY motif of $p R 33\left(N^{130}\right)$ to aspartic acid resulted in a mutant $\left(N^{40} D\right)$ with similar signalling characteristics to the wild-type (WT) protein, indicating that $N^{130}$ is not the determinant of constitutive activity of pR33. Interestingly, a mutant carrying an alanine at aa $130\left(N^{130} \mathrm{~A}\right)$ was severely impaired in $\mathrm{G}_{q / 11}$-mediated, constitutive activation of phospholipase $C$, whereas it displayed similar levels of activity to pR33 in $\mathrm{G}_{i / 0}$-mediated signalling. Another protein that contained a modified NRY motif, $R^{131} A$, did not show constitutive activity, whereas mutants $Y^{132} \mathrm{~F}$ and $Y^{132} \mathrm{~A}$ displayed similar activities to the $W T$ receptor. This indicated that residue $R^{131}$ is critical for $p R 33$ function in vitro, whereas $Y^{132}$ is not. Finally, we identified two consecutive arginines within the C-terminal tails of both pR33 and its homologue from human CMV, pUL33, which are important for correct cellsurface expression of these receptors.

\section{Introduction}

Cytomegaloviruses (CMVs) are species-specific betaherpesviruses that cause acute, persistent and latent infections in both humans and animals. The ability of CMVs to induce lifelong latent infections implies that these viruses are highly adapted to their hosts. Specifically, they employ a wide array of sophisticated strategies aimed at subversion of the host's antiviral defence mechanisms. Among the CMV genes that are thought to be involved in these strategies are those encoding homologues of crucial immune effector or regulatory proteins of the host, such as G protein-coupled receptors (GPCRs).

GPCRs form a large and diverse family of receptors that function in signal transduction across cell membranes. They are composed of a central core of seven transmembrane (7-TM) helices connected by three intracellular and three extracellular loops. The majority of these receptors activate $G$ proteins and thereby transduce a wide variety of extracellular messages into intracellular responses. Within the genomes of all sequenced CMVs, genes have been identified that encode homologues of cellular GPCRs. Human CMV (HCMV) carries four such genes: US27, US28, UL33 and UL78 $(7,8)$. Only two of these UL33 and UL78, have been found to have counterparts in rodent CMVs: rat CMV (RCMV; R33 and $R 78$, respectively; $1,2,30,31$ ) and murine CMV (MCMV; M33 and M78, respectively; 10,23 ). 
The fact that the HCMV UL33 gene has homologues in all currently known betaherpesvirus genomes underlines the biological relevance of the UL33 gene family. The best-characterized members of this family are HCMV UL33 $(7,8$, 32), MCMV M33 $(10,23,32)$, RCMV R33 $(1,16,18)$ and the U12 genes of human herpesvirus (HHV)-6A (15), HHV-6B $(12,17)$ and $H H V-7(21,22)$. The biological significance of the UL33-like genes thas previously been demonstrated in studies using recombinant CMVs that carry either a disrupted M33 (10) or R33 gene (1) in their genomes. In cell culture, each of these mutant viruses replicated with similar efficiency to the corresponding wildtype (WT) viruses $(1,10,19)$. However, during in vivo infection, significant differences were observed between animals infected with the recombinants and those infected with the WT viruses. In contrast to their WT counterparts, M33- and R33-deleted viruses could not be detected within the salivary glands of infected mice and rats, respectively, indicating that $\mathrm{M} 33$ and $\mathrm{R} 33$ play a role in virus dissemination to, or replication in, the salivary glands $(1,10)$. Furthermore, it was shown that, in the RCMV/rat model, R33 also has a more general function: a significantly lower mortality was seen among rats infected with R33-deleted RCMV compared with those infected with WT RCMV (1).

The predicted amino acid sequences of the proteins encoded by the UL33like genes have been found to comprise several features characteristic of a distinct subfamily of GPCRs, the chemokine receptors $(1,10)$. In accordance with these characteristics, both HHV $-6 \mathrm{~B}$ pU12 and HHV-7 pU12 have been reported to act as chemokine receptors. In response to binding of various $C C$ chemokines, HHV $-6 B$ pU12 mediated the release of calcium from intracellular stores (17). Recently, Nakano et al. (21) demonstrated that HHV-7 pU12 is also a calcium-mobilizing receptor in response to binding of CC chemokine macrophage inhibitory protein $3 \beta$. In contrast to the pU12 proteins of HHV-6B and HHV-7, the other pUL33 family members have not been demonstrated to bind chemokines. Nevertheless, pUL33 and pR33 as well as pM33 are functional GPCRs, as they signal in a ligandindependent, constitutive fashion, activating a broad range of $G$ proteins $(16,32)$.

Constitutive signalling by pR33 is marked by activation of $G$ proteins of the $G_{p / 11}$ and the $G_{i / 0}$ class. The pR33-mediated activation of $G_{q, 11}$ stimulates phospholipase $C$ (PLC) resulting in an intracellular rise of diacylglycerol and inositol phosphates (InsPs). Constitutive activation of pertussis toxin (PTX)-sensitive $G_{i / 0}$ proteins by $\mathrm{pR} 33$ inhibits adenylate cyclase and results in a reduced activation of cyclic AMP-responsive element (CRE)-driven transcription. At the same time, the interaction of pR33 with $G_{i / 0}$ enhances NF-kB activation and co-stimulates PLC activity (16). Constitutive signalling by HCMV pUL33 differs in some respects from that of pR33. Both receptors stimulate PLC but, like pM33, pUL33 enhances CREmediated transcription via the activation of $\mathrm{p} 38$ mitogen-activated protein kinase, as opposed to the $p R 33$-mediated inhibition of CRE-driven transcription $(16,32)$.

Currently, it is well established that the pLL33-like receptors signal in a constitutive fashion and are capable of influencing various signalling pathways in vitro. Nevertheless, data concerning structure-function relationships are lacking for these receptors. We therefore set out to identify structural determinants that are responsible for the differential constitutive activity of these proteins. To this 
purpose, a series of pR33 point and truncation mutants were generated and tested for cellular localization and constitutive activity in various signal transduction assays. Additionally, a panel of six pR33/pUL33 chimeric receptors was generated in which each of the intracellular loops was exchanged to create either "gain' or "loss of function" mutants with respect to constitutive signalling to the CRE.

\section{Materials and Methods}

Cel/ culture and transfection. COS-7 cells (ATCC CRL-1651) were cultured and transfected as described previously (5).

DNA constructs. Expression vectors pCDNA3/EGFP, pCDNA3/R33. pCDNA3/R33-EGFP, pCDNA3/UL33 and pCDNA/UL33-EGFP have been described previously $(5,16)$. Reporter plasmid pTLNC-21 CRE (13) was obtained from Dr W. Born (National Jewish Medical and Research Centre, Denver, CO, USA). The pNF. $\kappa B-L u c$ vector was purchased from Stratagene.

Plasmids

PCDNA3/R131A-EGFP, PCDNA3/R133A-EGFP,
PCDNA3/N130D-EGFP,

PCDNA3/Y132A-EGFP, PCDNA3/R327A-EGFP and
PCDNA3/N130A-EGFP, PCDNA3/ $Y 132 F-E G F P$, PCDNA3/R328AEGFP encoding C-terminal EGFP-tagged PR33 point mutants were generated by primerdirected mutagenesis using plasmid pUC119/R33-EGFP as the template. Plasmid pUC119/R33-EGFP was constructed by digestion of plasmid pCDNA3/R33-EGFP with Konl and Xbal, followed by subsequent cloning of the $2.3 \mathrm{~kb}$ fragment containing the R33-EGFP open reading frame (ORF) into the corresponding sites of pUC119. Primer-directed mutagenesis was essentially carried out as described by Deng \& Nickoloff (11) using the Scal/Stu primer and the N130D, N130A, R131A, Y132F, Y132A, R133A, R327A or R328A primer (Table 1). The resulting point-mutated pUC119/R33-EGFP derivatives were BamHI and Not digested and each $2.3 \mathrm{~kb}$ fragment containing the respective point-mutated R33-EGFP ORF was cloned in the corresponding sites of PCDNA3.

Plasmids pCDNA3/N130D, pcDNA3/N130A, pcDNA3/R131A, pcDNA3/Y132A, pCDNA3/Y132F, pcDNA3/R133A, pCDNA3/R327A and pCDNA3/R328A, which encoded untagged pR33 point mutants, were generated by ECO47III and $X$ bal digestion of PCDNA3/N130DEGFP.

PCDNA3/N130A-EGFP, pCDNA3/R131A-EGFP, pCDNA3/Y432A-EGFP, PCDNA3/Y132F-EGFP, PCDNA3/R133A-EGFP, pCDNA3/R327A-EGFP or PCDNA3/R328A-EGFP, respectively, followed by Klenow treatment and self ligation of the linearized plasmids. In this way, the $0.8 \mathrm{~kb}$ Eco47III-Xbal fragment containing the EGFP sequence was removed and an in-frame stop codon was introduced at the $3^{\prime}$ end of the mutated R33 ORF in each plasmid. Expression vectors pcDNA3/C $\triangle 13$, pcDNA3/C $\triangle 44$ and pCDNA3/CA61 encoding pR33 mutants with $C$-terminal truncations of $13(C \Delta 13), 44(C \Delta 44)$ and $61(C \Delta 61)$ aa, respectively, were generated by PCR with primers FR33X and RR33CD13, RR33CD44 or RR33CD61, respectively (Table 1), using PCDNA3/R33 as the template. Subsequently, expression vectors pCDNA3/CA13-EGFP, PCDNA3/CA44- 
EGFP and PCDNA3/CA61-EGFP, encoding the respective truncated receptors with a C-terminal EGFP tag, were constructed by Nhel and Xbal digestion of plasmid $p 368$ (16) and subsequent in-frame cloning of the 768 bp fragment containing the EGFP' sequence, in the unique Nhel site at the $3^{i}$ end of the mutated R33 ORF in plasmids pCDNA3/CA13, pCDNA3/C $C 44$ and $p C D N A 3 / C \triangle 61$, respectively.

Expression vectors pCDNA3/R33i1, pCDNA3/R33i2, pCDNA3/R33i3. pCDNA3/UL33i1, pCDNA3/UL33i2 and pCDNA3/UL33i3 encoded either pR33- or pUL33-based chimeric receptors, in which either the first, second or third intracellular loop was replaced by the corresponding loop of pUL33 or PR33, respectively (see Figs 1 and 5 ). The chimeric sequences were generated by means of an overlapping PCR procedure. For the pR33-based chimeras, this PCR procedure was carried out with primers FR33X, RR33E and overlapping primer pair RRi1/FRi1, RRi2/FRi2 or RRi3/FRi3 (Table 1), using pCDNA3/R33 and PCDNA3/UL33 as templates. For the pUL33-based chimeras, the PCR procedure was carried out with primers FUL33, RUL33E and overlapping primer pair RULi1/FULi1, RULi2/FULi2 or RULi3/FULi3 (Table 1), again using pCDNA3/R33 and PCDNA3/UL33 as templates.

Plasmids pcDNA3/R33i1-EGFP, pcDNA3/R33i2-EGFP, pCDNA3/R33i3EGFP, pCDNA3/UL3311-EGFP, pCDNA3/UL33i2-EGFP and pcDNA3/UL33i3-EGFP encoding C-terminal EGFP-tagged chimeric receptors were generated in a similar fashion, as described above for the truncation mutant expression constructs. The integrity of all DNA constructs was verified by sequence analysis.

Confocal imaging. Transiently transfected cells (COS-7) were grown on glass coverslips. After $48 \mathrm{~h}$, the cells were fixed for $10 \mathrm{~min}$ with $3.7 \%$ formol in PBS and the coverslips were mounted for subsequent confocal imaging. Confocal images were collected at a wavelength of $488 \mathrm{~nm}$ and processed as described previously (16).

Signal transduction assays. Inositol phosphate production in transfected COS-7 cells was determined as described previously (16). For the reporter gene assays, $\operatorname{COS}-7$ cells were transiently transfected with either reporter plasmid $\mathrm{pNF}$ KBLUC (NF- $\mathrm{kB}$ assay) or pTLNC-21CRE (CRE assay) (5 mg per $10^{6}$ cells) and one of the GPCR-expressing plasmids. Transfected cells were seeded in 96-well white plates (Costar) with serum-free medium in either the presence or absence of PTX $(100 \mathrm{ng} / \mathrm{ml})$. Luciferase activity was measured $48 \mathrm{~h}$ after transfection for cells transfected with the NF-KB reporter construct. For cells transfected with the CRE reporter construct, luciferase activity was assayed $30 \mathrm{~h}$ after transfection, either with or without stimulation with forskolin at a concentration of $10 \mathrm{mM}$ for $6 \mathrm{~h}$, as described previously (16).

Statistical analysis. All data shown are expressed as mean \pm SE. Statistical analysis was carried out using Student's t-test. Values of $P<0.05$ were considered to indicate a significant difference. 
Table 1. PCR primers used in this study

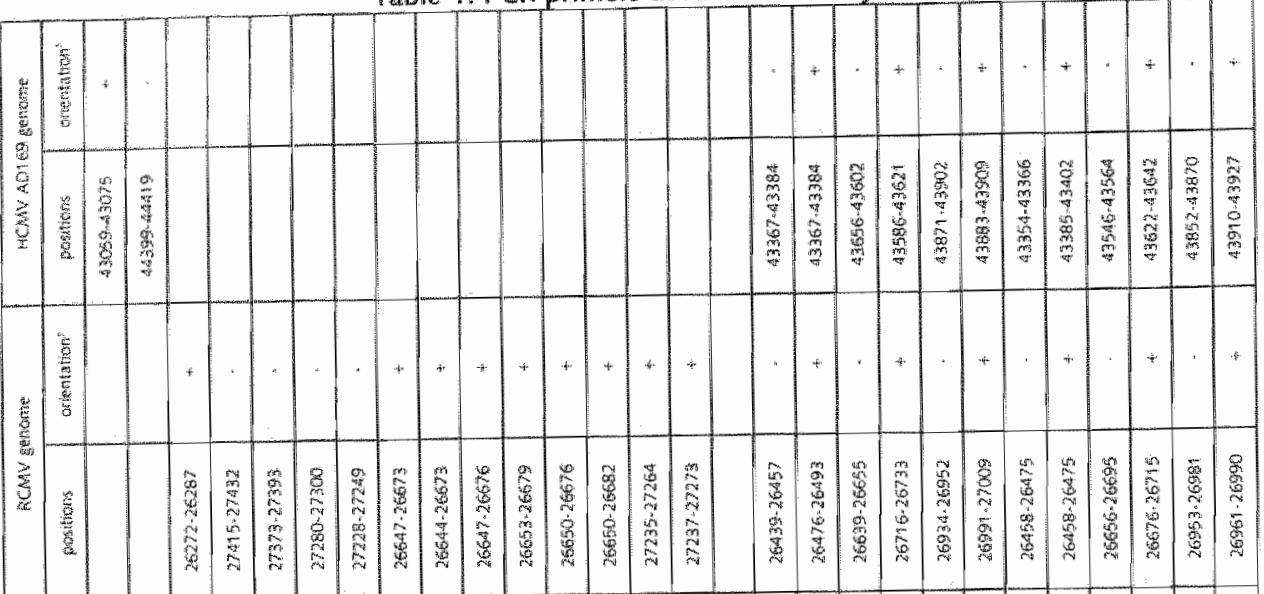

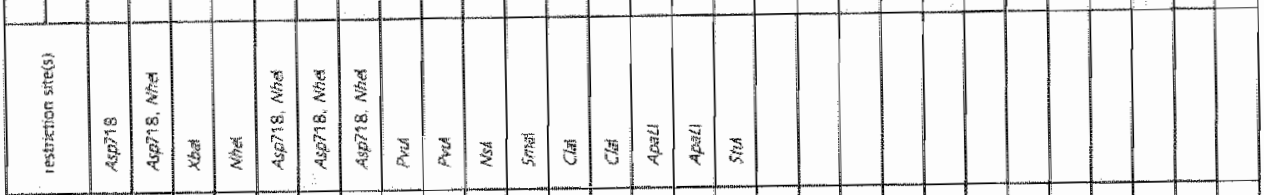

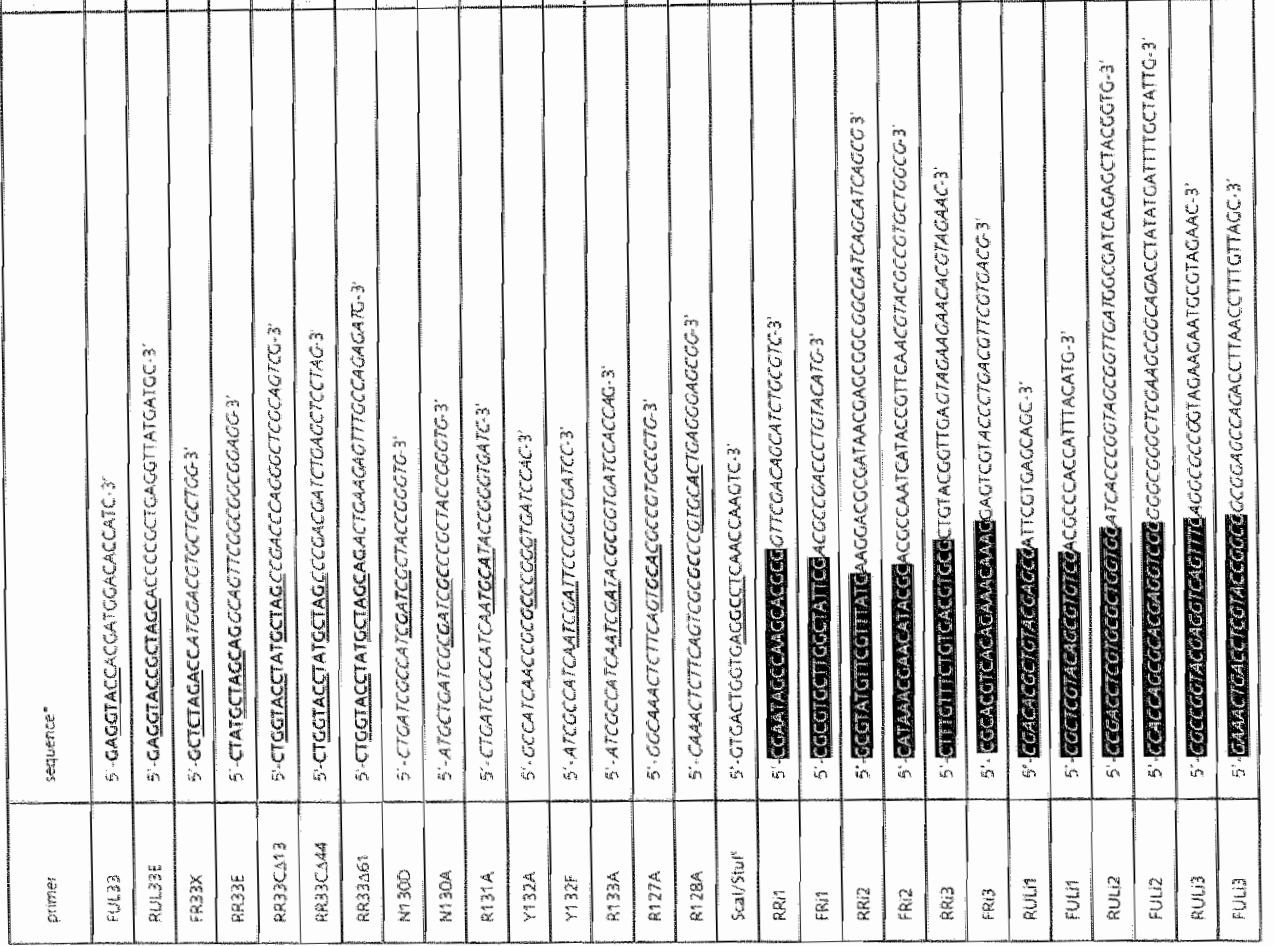

"Underlined sequences indicate restriction enzyme recognition sites; sequences in bold type differ from that of the original sequences as decribed in the 'Positions' column; sequences derived from the RCMV genome are indicated in italic type; sequences derived from the HCMV genome are indicated in nomal type: white letters on black indicate parts of the sequence that represent the reverse complement per primer pair. "The orientation of the sequence was identical to (t) or complementary to (2) the published sequence between the indicated positions. The sequence of the Scal/stal primer is identical to the published pUC119 sequence between nt 2165 and 2190 . 


\section{Results}

Constifutive signalling by pR33 C-terminal truncation mutants. In genera. the intracellular C-tail of GPCRs is an important determinant of the signalling activity of these proteins. In the case of the pUL33 family members, the C-terminal sequences are highly divergent. Previously, we reported the $\mathrm{C}$-tail of pR33 to comprise a unique motif consisting of 11 consecutive prolines (1). To investigate the role of this proline stretch in pR33-mediated signalling, we generated truncated pR33 variants, $C \Delta 13, C \Delta 44$ and $C \Delta 61$, which lacked 13,44 and 61 aa, respectively, from the $C$ terminus (Fig. 1). To monitor receptor expression and localization, each truncated mutant was also tagged C-terminally with EGFP. Expression of these tagged mutants, as well as that of EGFP and pR33-EGFP, was studied by confocal microscopy of transiently transfected CO5-7 cells (Fig. 2). Fluorescence within cells expressing EGFP was seen dispersed throughout the nucleus and cytoplasm (Fig. 2A). However, in cells expressing either pR33-EGFP (Fig. 2B), CA13-EGFP (Fig. 2C) or CA44-EGFP (Fig. 2D), fluorescence clearly colocalized with the cell membrane, as well as with intracellular perinuclear vesicles. This indicated that the mutant receptors CA13-EGFP and C $444-E G F P$, like $p R 33$ EGFP, were correctly expressed on the surface of transfected cells. In contrast, the fluorescent signal within cells expressing mutant receptor CA61-EGFP did not colocalize with the cell surface, but appeared to be retained intracellularly (Fig. 2E).

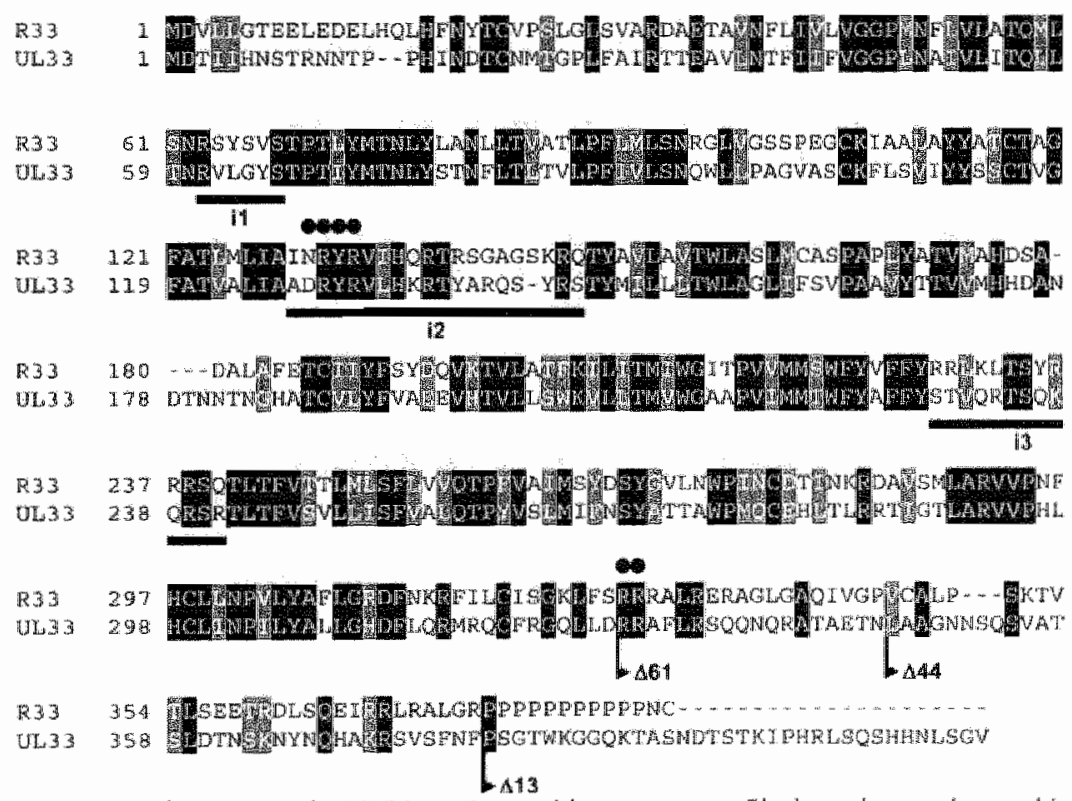

Fig. 1. Alignment of pR33 and pUL33 amino acid sequences. Black and grey boxes highlight identical and similar amino acid residues, respectively. Black dots above the sequences indicate pr33 residues that were been point mutated in this study. The residues that were swapped between pre33 and pUL33i to generate chimeric receptors pR33i1 and pUL33i1 (i1), pR33i2 and pUL33i2 (i2), pR33i3 and pUL3313 (i3) are indicated by a black line below the sequences. The final C-terminal residue of each truncated $\mathrm{PR} 33$ mutant is indicated by an arrow and shows the number of residues that were dieleted from the sequence. 
Subsequently, the signalling characteristics of the truncated receptors $C \Delta 13, C \Delta 44$ and $C \triangle 61$ were compared with those of $p R 33$ using the InsP accumulation assay (Fig. 2F) as well as the NF-KB- and CRE-driven reporter gene expressionassays (Fig. 2G and $\mathrm{H}$, respectively). As described previously (16), pR33 constitutively activated the production of InsP (Fig. 2F). Cells expressing pR33 showed an approximately twofold increase in InsP accumulation compared with basal InsP accumulation in cells transfected with an 'empty' vector ( $p C D N A 3)$. A similar increase in InsP accumulation was seen for cells expressing the truncated receptors $C \Delta 13$ and $C \Delta 44$. Cells expressing $C \Delta 61$, however, showed a level of ins $P$ accumulation similar to that of mock-transfected cells.

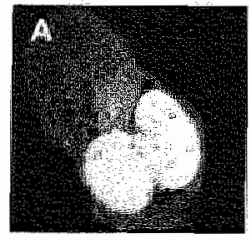

EGFP
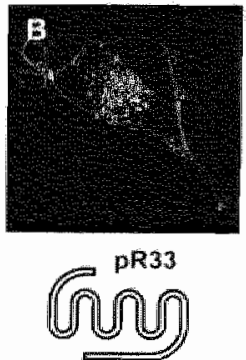
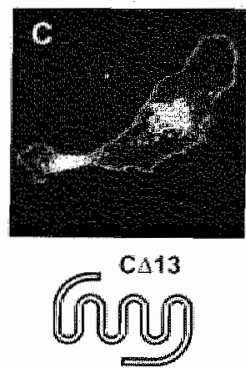

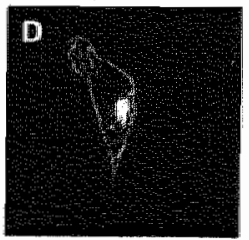

$(0 \cup \sqrt{04}$

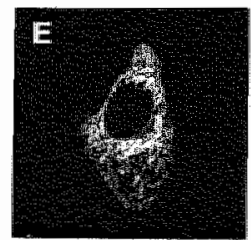

C.41

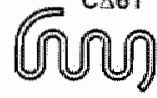

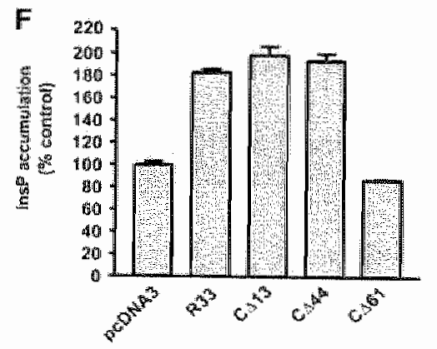
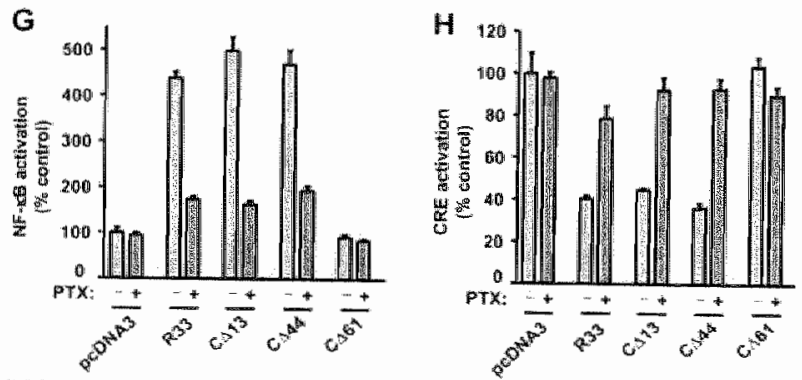

Fig. 2. Constitutive signalling by PR33 C-terminal truncation mutants. (A-E) Expression of EGFP and C-terminal EGFP tagged PR33 and PR33 mutants. COS-7 cells were transiently transfected with either pcDNA3/EGFP (A), pCDNA3/R33-EGFP (B), pCDNA3/CD13-EOFP (C), pCDNA3/CD44-EGFP (D) or pCDNA3/CD61-ECFP (E) (2 HEger $10^{6}$ cells; fixed after $48 \mathrm{~h}$ and subjected to confocall microscopy. Below the confocal images, schematic representations of the truncated mutants are given. (F) induction and accumulation of InsP. COS.7 cells $\left(10^{6}\right)$ were transiently transfected with either pcDNA3. pCDNA3/R33 pCDNA3/CD13, pCDNA3/CD44 or pCDNA3/CD61 (2 ug per $10^{6}$ cells) and insP accumulation was measured 48 h after transfection. $(C, H) N F-K B$ - and CRE-driven luciferase reporter sene assays. COS-7 cells (109) were transiently co-transfected with either pNF-KB-LUC (C) or pTLNC. $21 \mathrm{CRE}(\mathrm{H})$ and with either PCDNA3 (COntrol), pCDNA3/R33, pCDNA3/CA13, pCDNA3/CA44 or pcDNA3/CA61 $\left[2 \mu g(G)\right.$ or $0.5 \mu g(H)$ per $110^{\circ}$ celis]. For the NF-kB assay, luciferase activity was measured $48 \mathrm{~h}$ atter transtection. For the CRE assay, cells were stimulated with forskolin $24 \mathrm{~h}$ after transfection and luciterase activity was measured $30 \mathrm{~h}$ after transfection. Experiments were carried out in either the presence $(H)$ or absence $(-)$ of pertussis toxim (PTX) 
As mentioned above, pR33 constitutively enhances NF-KB-mediated transcription and reduces CRE-mediated transcription by activation of PTXsensitive $G_{1 / 0}$ proteins. Fig. $2(G)$ shows that, within cells co-transfected with the NF-KB reporter gene construct and either pCDNA3/R33, pCDNA3/C $\triangle 13$ or pCDNA3/C $\triangle 44$, luciferase activity levels were four to five times higher than in cels. co-transfected with an empty vector. As expected, the luciferase activity level within these cells was dramatically lower in the presence of PTX. In contrast, in cells co-transfected with the NF-KB reporter gene plasmid and pCDNA3/C $\triangle 61$. luciferase activity levels were similar to those in mock-transfected cells in either the presence or the absence of PTX.

In the CRE reporter gene assay (Fig, $2 H$ ), the luciferase activity levels in cells expressing pR33, pCA13 or pCA44 were approximately $40 \%$ of the levels in mock-transfected cells. The inhibitory effect of these proteins could be completely blocked by the addition of PTX. As in the other assays, mutant pC $\triangle 61$ did not show any activity in the CRE reporter gene assay. In all three assays, the EGFPtagged receptors displayed similar activities to their native counterparts (data not shown).

Taken together, these data demonstrated that deletion of up to 44 aa from the $C$ terminus of $p R 33$ influences neither expression nor constitutive activity of the protein. This shows that the stretch of 11 consecutive proline residues at aa 375-385 is dispensable for pR33 signalling to PLC, NF-KB and CRE in vitro. Deletion of 61 aa from the C-terminus, however, resulted in an inactive mutant: (CA61). This inactivity was most likely due to intracellular retention of the protein, as demonstrated for its EGFP-tagged counterpart, CA61-EGFP (Fig. 2E). Therefore, we hypothesize that the sequence between aa 327 and 344 contains residues critical for correct pR33 folding and/or cell-surface expression.

The pR33 C-terminal RR motif. Previously, we found that the $C$ terminus of pUL33 could replace that of pR33 without affecting expression or signalling of pR33 in vitro (6). This finding is remarlkable in light of the low level of sequence similarity between the C termini of $p R 33$ and pUL33. The alignment of $p R 33$ and pUL33 (Fig. 1) shows that the pR33 sequence between aa $R^{327}$ and $P^{3+4}$ "which represents the $C$-terminal amino acids of $C D 61$ and $C D 44$, respectively, contains only five residues that are conserved between $\mathrm{PR} 33$ and pUL33. Two of these residues, $R^{327}$ and $R^{328}$, form a basic motif that is highly conserved among the pR33 family members (31). It has been shown that positively charged motifs in the $C$ terminus of the chemokine receptor CCR5 (29) play a role in correct receptor folding and cell-surface expression. Therefore, we investigated the function of these conserved arginines in PR33 expression and signalling by the generation of two point mutants, $R^{327} A$ and $R^{328} A$.

First, the expression of EGFP tagged versions of these point mutants $\left(R^{327} A-E G F P\right.$ and $\left.R^{328} A-E G F P\right)$ was monitored by confocal microscopy. In the majority of either $R^{327} A-E G F P$ - or $R^{328} A-E G F P$-expressing cells (Fig. $3 A$ and $D$. respectively), fluorescence appeared to be confined to intracellular compartments. indicating that the mutant receptors were not correctly expressed on the cell surface. However, in a small proportion of transfected cells, corresponding to 

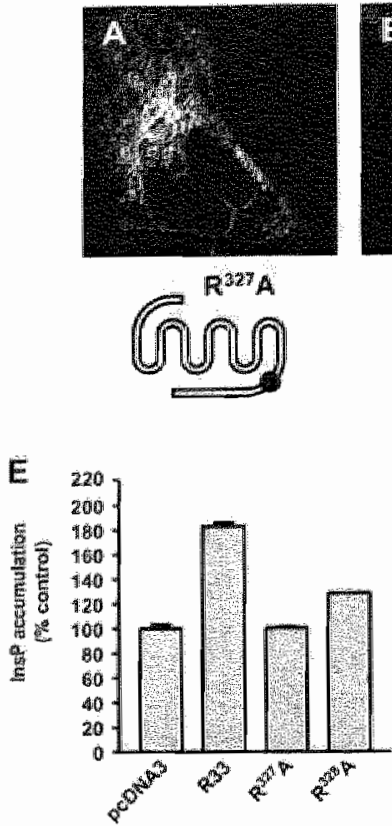
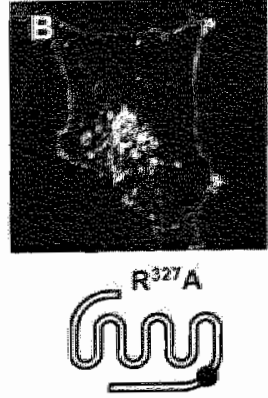

$F$

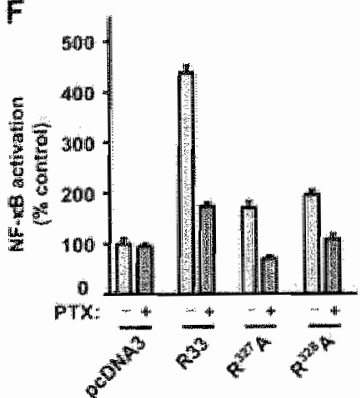

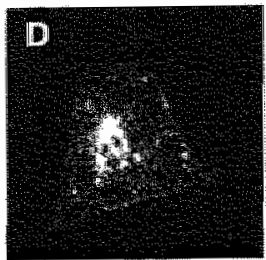

$\mathrm{R}^{\mathrm{B2E} A \mathrm{~A}}$
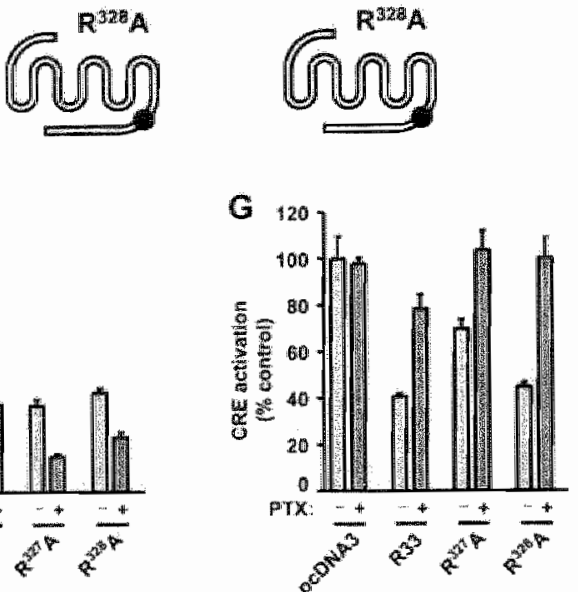

Fig. 3. Characterization of the pR33 RR motif. $(A-D)$ Expression of mutants $R^{327} A$ and $R^{328} A$. COS -7 cells were transiently transfected with either pCDNA3/R327A-EGFP (A.B) or PCDNA3/R328-EGFP (C, D) $\left(2 \mu \mathrm{g}\right.$ per $10^{6}$ cells), fixed after $48 \mathrm{~h}$ and subjected to confocal microscopy. Below the confocal images, schematic representations of the amino acid sequences of the mutants are given. The black dots indicate residues that were point mutated. (E-G) Constitutive signalling of the mutants in the ins $P$ accumulation assay $(E)$ and the NF-K.B- $(F)$ and $C R E$-driven $(G)$ luciferase reporter gene assays. COS-7 cells were transiently (Co)transfected with either pCDNA3 (control), PCDNA3/R33, PCDNA3/R327A or PCDNA3/R328 $\left[2 \mu g(F, G)\right.$ or $0.5 \mu g(H)$ per $10^{6}$ cells] and analysed in the different assays. Experiments were carfied out in either the presence $(+)$ or absence $(-)$ of pertussis toxin (PTX).

approximately $5 \%$ for $\mathrm{R}^{327} \mathrm{~A}$-EGFP and $10 \%$ for $\mathrm{R}^{328} \mathrm{~A}$-EGFP, fluorescence was found to co-localize with the cell membrane as well as with intracellular vesicles (Fig. 3B and C, respectively), as was observed for pR33-EGFP (Fig. 2B). This suggested that the mutant receptors were expressed on the cell surface in only a small proportion of the transfected cells. Interestingly, the inefficient cell-surface expression of $R^{327} A-E G F P$ and $R^{328} A-E G F P$ was reflected in the activity of these mutants in the signal transduction assays. Cells expressing $R^{327} \mathrm{~A}$ did not show a statistically significant increase in InsP accumulation levels compared with mocktransfected cells. However, $R^{328} A$ (or its EGFP-tagged version; data not shown) did display a slight but significant activity in this assay (Fig. 3E). This showed that $R^{328} A$ and $R^{328} A$-EGFP were capable of constitutively activating PLC, despite their low level of cell-surface expression. Interestingly, both $R^{327} A$ and $R^{328} A$ showed activity in the NF-KB reporter gene assay. Although these mutants induced lower levels of NF-KB-mediated transcription than pR33, these levels were significantly higher than those in mock-transfected cells (Fig. 3F). Moreover, the activity of $R^{327} A$ and $R^{328} A$ in the NF-KB assay could be blocked by PTX, indicating that these mutants, like pR33, constitutively activate $G_{i / 0}$ proteins. The activation of these $G$ 
proteins was confirmed in the CRE assay, in which both $R^{327} A$ and $R^{328} A$ inhibited CRE-mediated transcription in a PTX-sensitive fashion (Fig. 3G). In all assays, similar signalling results were obtained for either the EGFP-tagged or untagged version of each mutant (data not shown).

Taken together, we conclude that the conserved, basic RR motif within the $C$ terminus of pR33 is important for correct $p R 33$ folding and/or cell-surface expression. We deem it unlikely, however, that this motif is involved in pR33mediated constitutive signalling, since the small proportion of the R327A and R328A receptors that did appear to be expressed on the cell surface showed signalling to NF- $\mathrm{KB}$ and CRE similar to $\mathrm{pR} 33$.

The pR33 NRYR motif. The highly conserved DRY motif, located within the second intracellular (i2) loop of GPCRs, generally determines the efficiency of $G$ protein activation as well as the selectivity of receptor/G protein interactions (for a review, see 33 ). Moreover, constitutive activity displayed by various (mutant) receptors has been linked to the presence of different residues at the aspartic acid position within this motif $(4,26,33)$. Interestingly, the predicted amino acid sequence of pR33 contains an NRY motif instead of a DRY motif (Fig. 1). Another interesting residue in the $i 2$ loop of $p R 33$ is the arginine that directly follows the NRY motif ( ${ }^{133}$; Fig. 1). Although a positively charged residue is found at the same position within all PR33 family members, it is uncommon in other GPCRS, which instead contain a hydrophobic residue at this position (http://www.gpcr.org/7tm).

To evaluate the role of the PR33 NRYR motif in constitutive activity and $G$-protein selectivity, the following singlepoint mutants were generated: $N^{130} \mathrm{D}$, $N^{130} A, R^{131} A, Y^{132} F, Y^{132} A$ and $R^{132} A$. To monitor expression, each mutant receptor was also tagged at its $C$ terminus with EGFP. Confocal microscopy of transfected cells showed that the fluorescence patterns of all EGFP-tagged mutant receptors were similar to the fluorescence pattern of pR33-EGFP (compare Fig. 4A-F with Fig. 2B). This suggested that each mutant receptor was correctly expressed on the cell membrane.

Next, we compared the signalling characteristics of the mutant receptors with those of $p R 33$ in the InsP assay, as well as in the NF-KB and CRE reporter gene assays. As can be seen in Fig. $4(G-1)$, receptors $N^{130} D, Y^{132} F, Y^{132} A$ and $R^{133} A$ displayed similar signalling profiles to $p R 33$. Like $p R 33$, each of these mutants induced both an increase in Ins P' production (Fig. 4G) and a PTX-sensitive increase in NF- $\mathrm{KB}$-mediated transcription (Fig. $4 \mathrm{H}$ ). In addition, these receptors mediated a PTX-sensitive decrease in CRE-mediated transcription (Fig. 4I). Despite the similarities between pR33 and mutants $Y^{132} F, Y^{132} A$ and $R^{133} A$ in their signalling: profiles, a lower level of activity was observed in cells expressing the mutants compared with cells expressing the WT protein. In contrast, mutant $\mathrm{N}^{130} \mathrm{D}$ induced levels of InsP production "as well as NF- $\mathrm{KB}$ - and CRE-mediated transcription, comparable with pR33 (Fig. 4G-1). This demonstrated that mutation of $\mathrm{N}^{130}$ to an aspartic acid residue, which is found in most GPCRs, does not alter the constitutive signalling characteristics of $P R 33$. However, mutation of $N^{130}$ to alanine resulted in a dramatic change in these characteristics: mutant $\mathrm{N}^{130} \mathrm{~A}$ was found to be inactive 
in the InsP accumulation assay (Fig. 4G). This indicated that this mutant was impaired in its ability to activate PLC. Since the activation of PLC by PR33 is mediated mainly via coupling to $G_{n / 41}$ proteins, it is likely that mutant $N^{130} A$ is unable to activate this class of $G$ protein. Surprisingly, mutant $N^{130} A$ did show activity in both the NF-KB and CRE reporter gene assays. Although the signalling activity of $N^{130} \mathrm{~A}$ in the $N F-\kappa B$ assay was lower than that of pR33 (Fig. $4 \mathrm{H}$ ), the activity of this mutant in the CRE assay was similar to that of the WT receptor (Fig. 41). Moreover, the activity of $\mathbb{N}^{130} \mathrm{~A}$ in these assays could be blocked by the addition of PTX. This demonstrated that, although mutant receptor $\mathrm{N}^{130} \mathrm{~A}$ appears unable to activate $G_{a / 11}$ proteins, it is able to activate proteins of the $G_{i ; 0}$ class, resulting in activity in both the NF-KB and CRE reporter gene assays.

Only one of the NRYR point mutants, $R^{131} A$, was found to be inactive in all signal transduction assays tested (Fig. $4 G-1$ ). Since $R^{131} A-E G F P$ displayed a similar expression pattern to $\mathrm{PR} 33$, we deem it unlikely that the inactivity observed for $R^{131} A$ and $R^{131} A-E G F P$ (data not shown) was due to intracellular retention. We therefore conclude that residue $R^{131}$ is critical for constitutive signalling by pR33. Finally, the signalling characteristics of all EGFP-tagged mutants were comparable with those of their non-tagged counterparts (data not shown).

Expression and activity of pR33, UL33 chimeric receptors. As mentioned in the Introduction, pUL33 and PR33 show somewhat different signalling profiles $(16,32)$. A widely used approach to study differences in signalling activity between closely related receptors is to characterize chimeras of these proteins. We therefore constructed both pR33-based and pUL33-based chimeric receptors, in which either the first, second or third intracellular loop was exchanged (see Fig. $5 \mathrm{~B}-\mathrm{D}$ and $\mathrm{F}-\mathrm{H}$ for a schematic representation of these chimeric receptors). To monitor receptor expression, we also generated C-terminal EGFP-tagged versions of the chimeras. As shown in Fig. 5 (B and D), chimeric proteins pR33i1-EGFP and pR33i3-EGFP displayed a similarpattern of expression to pR33-EGFP (Fig. 5A). However, the expression of pR33i3-EGFP near the cell membrane was not as pronounced as that of either PR33-EGFP or PR33i1-EGFP. The third pR33-based chimera that we generated, pR33i2-EGFP, did not show localization at the cell surface. Instead, this protein was found dispersed throughout the cytoplasm of the transfected cells (Fig. 5C). Fluorescence in cells expressing either pUL33i2-EGFP (Fig. 5G) or pUL33-EGFP (Fig. 5E) co-localized with the cell membrane as well as with intracellular compartments. Fluorescence of pUL33i2-EGFP, however, was less pronounced at the cell surface and more intense in intracellular compartments compared with the fluorescence of pUL33-EGFP. In contrast, fluorescence within cells expressing either pUL33i1-EGFP (Fig. 5F) or pUL33i3-EGFP (Fig. 5H) did not co-localize with the cell membrane, but was confined to the nucleus and other intracellular compartments, indicating that these proteins are not correctly expressed on the cell surface.

Since pR33 and pUL33 both stimulate InsP production by constitutive activation of $P L C$, the functionality of the $P R 33 / p U L 33$ chimeric receptors was first evaluated in the InsP accumulation assay. Fig. 5(1) shows that pR33-based chimera PR33i1 had a similar activity to pR33 in the InsP accumulation assay. In contrast, 
chimera pR33i3 displayed a much lower level of Ins P production than pR33. Of the pUL33-based chimeric receptors, only pUL33i2 was found to be active in the InsP accumulation assay, although the level of activity of this receptor was significantly lower than that of pUL33 (Fig. 51). As expected, the chimeras in which the EGFP-tagged variants did not show appropriate cell-surface expression, i.e. pR33i2, pUL33i1 and pUL33i3, were inactive in the InsP assay. Again, the EGFPtagged receptors showed similar activities to their untagged counterparts (data not shown).

Next, we evaluated the activity of the chimeric receptors in the CRE assay. Like native pR33, chimeras $p R 33 i 1$ and $p R 33 i 3$ both induced a PTX-sensitive inhibition of CRE-mediated transcription (Fig. 5J), indicating that both chimeras activate $G_{i / 0}$ proteins. However, as in the InsP accumulation assay, chimera pR33i2 was inactive in the CRE assay (data not shown). As shown previously (32) "pUL.33 induced an increase in CRE-mediated transcription (Fig. 5K). Moreover, by eliminating the activation of $G_{i / 0}$ proteins through the addition of PTX, the CREdriven transcription levels within cells expressing pUL33 are stimulated even further (6). Although chimera pUL33i2 only induced a slight increase in the level of CRE-mediated transcription, this level was further increased in the presence of PTX, as observed for pUL33 (Fig. 5K). This indicates that, like pUL33, pUL33i2 is capable of stimulating both CRE-inhibiting and CRE-activating pathways, resulting in an overall activating effect. As in the InsP assay, chimeric proteins pUL33it and pUL33i3 were found to be inactive in the CRE assay (data not shown). Since chimeras pR33i2-EGFP, pUL33i1-EGFP and pUL33i3-EGFP did not show cellsurface expression or activity in the signal transduction assays, it is likely that the inactivity of their untagged counterparts, pR33i2, pUL33i1 and pUL33i3, respectively, is due to intracellular retention.

The results generated with the chimeras are summarized in Table 2. Taken together, we found that in only three of the six cases, the exchange of intracellular loops between pR33 and pUL33 resulted in receptors that were properly expressed on the cell surface and, concomitantlly, displayed constitutive signalling activity. Both intracellular regions 1 and 3 of pUL33 were demonstrated to functionally to replace the corresponding regions in pR33 without affecting the signalling profile of pR33. The reciprocal exchange of $i 1$ and $i 3$ between pR33 and pUL33, however, resulted in receptors that were retained intracellularly. Only a single pUL33-based chimera, pUL33i2, displayed signalling activity. Although the activity of this mutant was relatively low, its signalling profile was similar to that of WT pUL33. Our data indicate that the three intracellular regions of pR33 and pUL33 do not independently determine the differential signalling profiles of pR33 and pUL33. 

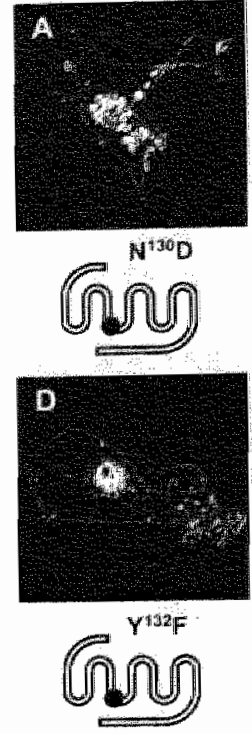
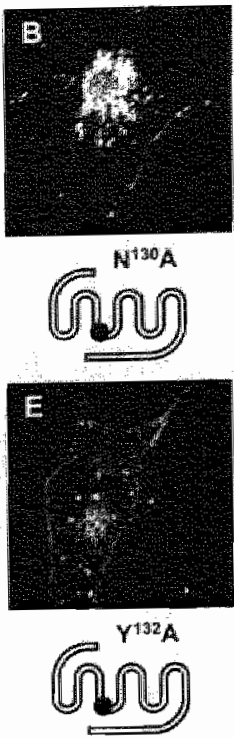
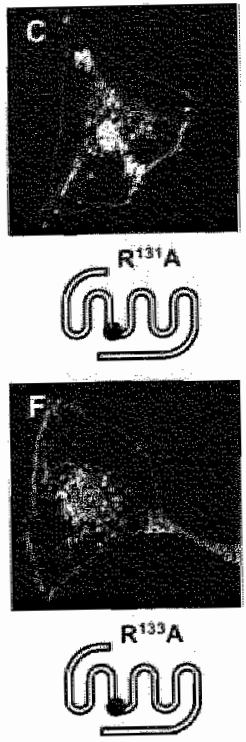
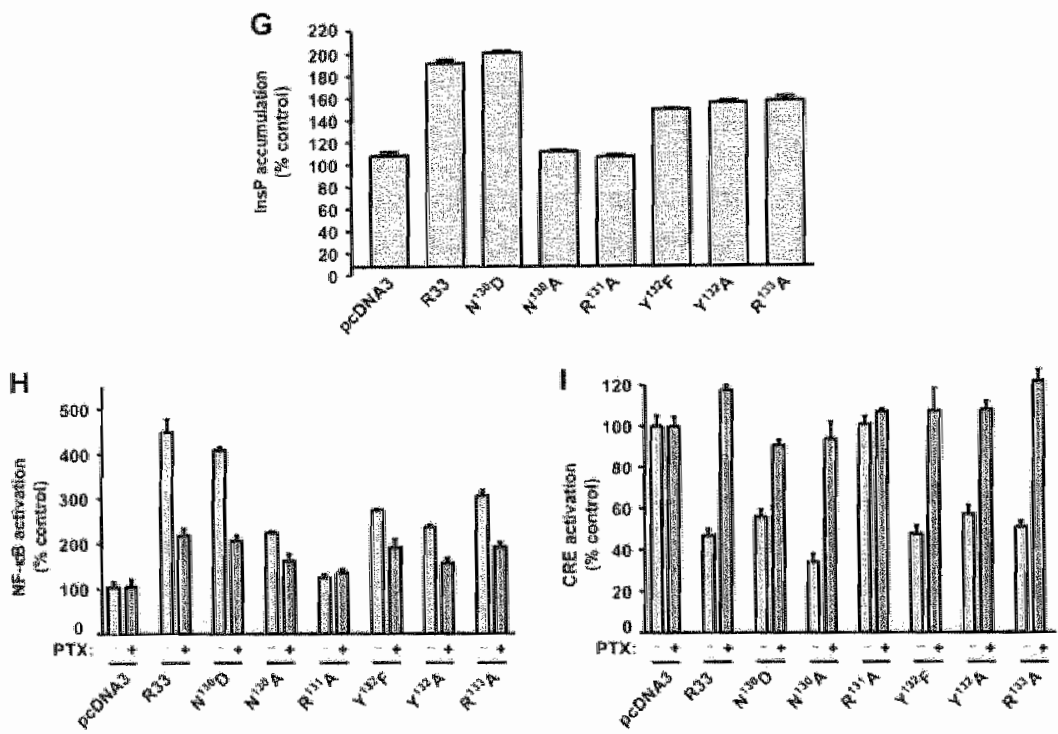

Fig. 4. Characterization of the pR33 NRYR motif. (A-F) Expression of C-terminal EGFP-tagged pR33 NRYR point mutants. CO5-7 cells were transiently transfected with pCDNA3/N130D-EGFP (A), PCDNA3/N130A-EGFP (B), pCDNA3/R131AEGFP (C), pCDNA3/Y132F-EGFP (D), PCDNA3/Y132AEGFP (E) or PCDNA3/R133A-EGFP (F) (2 wg per $10^{6}$ cells), fixed after $48 \mathrm{~h}$ and subjected to confocal microscopy. The schematic diagrams below the confocal pictures indicate the positions of the singlepoint mutations (black dots) in the respective amino acid sequences. $(G-1)$ Constitutive signalling of the mutants in the InsP accumulation assay $(G)$ and the $\mathrm{NF}-\mathrm{kB}-(\mathrm{H})$ ) and $\mathrm{CRE}$-driven (1) luciferase reporter gene assays. COS-7 cells were transiently (co)transfected with PCDNA3 (control), PCDNA3/R33. PCDNA3/N"I30D, PCDNA3/N130A, pCDNA3/R131A, pCDNA3/Y132F, pCDNA3/Y132A or PCDNA3/R133A $\left[2 \mu g(\mathrm{G}, \mathrm{H})\right.$ or $0.5 \mu \mathrm{g}(1)$ per $10^{6}$ cells] and analysed in the different assays. Experiments were carried out in either the presence $(+)$ or absence $(-)$ of pertussis toxin (PTX). 

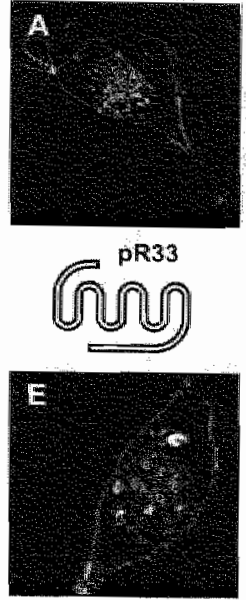

GนUก

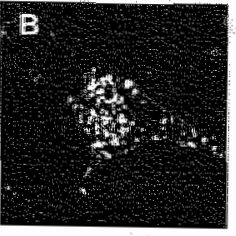

pRisit
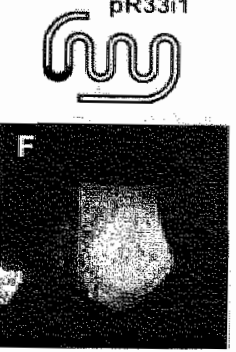

ธِّ?
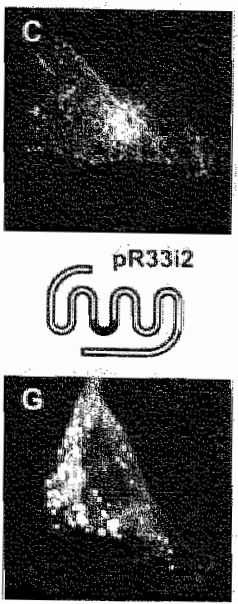

pUL33i2

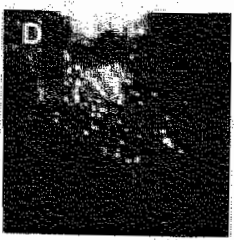

pRosis
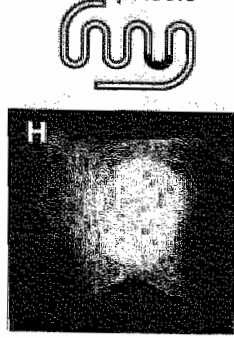

puL33i3
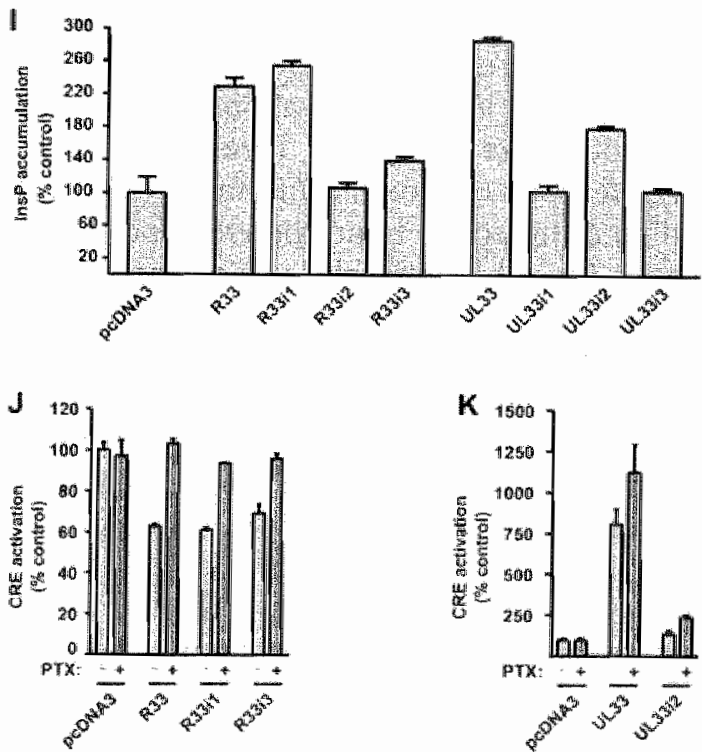

Fig. 5. Expression and activity of pR33/pUL33 chimeric receptors. (A-H) Expression of C-terminal EGFP-tagged PR33, pUL33 and pR33/pUL33 chimeras. CO5-7 cells were transiently transfected with PCDNA3/R33-EGFP (A), PCDNA3/R33i-EGFP (B), PCDNA3/R33i2-EGFP (C), PCDNA3/R333-EGFP (D), pCDNA3/UL33-EGFP (E), pCONA3/UL33i1-EGFP (F), pIDNA3/UL33i2-EGFP (G) or PCDNA3/UL333-EGFP (H) (2 $\mu \mathrm{g}$ per $10^{6}$ cells), fixed after 48 h and subjected to confocal microscopy. A schematic representation of each chimeric amino acid sequence is given below the respective confocal pictures. The amino acid sequences of pUL 33 and pR33 are clepicted in black and white, respectively. (1-K) Characterization of constitutive signalling by pR33, pUL33 and pR33/pULL33 chimeras in the linsP accumulation assay (1), forskolin-stimulated, CRE-driven liciferase expression assay (V) and unstimulated CRE-driven luciferase expression assay (K). Cells were (co)transfected with pCDNA3 (control), PCDNA3/R33, pCDNA3/UL33, pCDNA3/R33i, pCDNA3/R33i2, pCDNA3/R33i3" pCDNA3/UL33it, pCDNA3/UL33i2 or PCDNA3/UL33i3 $\left[2 \mu g(1, K)\right.$ or $0.5 \mu g(0)$ per $10^{5}$ cells]. The assays were performed in either the presence $(+)$ or absence $(-)$ of pertussis toxin (PTX). 


\section{Discussion}

RCMV pR33, MCMV PM33 and HCMV pUL33 are functional GPCRs that signal in a ligand-independent, constitutive fashion (6, 32). By activation of various classes of $G$ proteinis, these receptors modulate PLC activity as well as NF-kB- and CREmediated transcription in vitro. Previously, we reported that pR33 enhances PLC activity via stimulation of $G$ proteins of the $G_{q / 11}$ class. In addition, $p R 33$ activates $G$ proteins of the $G_{i / 2}$ class, which results in an upregulation of NF-kB- and downregulation of CRE-mediated transcription (16). By mutational analysis of the PR33 NRY motif, we have identified two residues, $N^{130}$ and $R^{13}$, that are critical for constitutive $\mathrm{G}$ proten activation. Although replacement of $\mathbb{N}^{130}$ by an aspartic acid residue did not change the constitutive behaviour of the resulting mutant $N^{130} \mathrm{D}$, replacement of the residue by alanine did. In contrast to pR33, mutant $N^{130} \mathrm{~A}$ was unable to stimulate PLC. As PR33 predominantly stimulates PLC via activation of $G_{q / 11}$ proteins, we concluded that $N^{130} A$ is impaired in its ability to activate $G_{q / 11}$. In contrast, PTX-sensitive signalling of $\mathbb{N}^{130} \mathrm{~A}$ to $C R E$ was unaltered, indicating that the ability to activate $G_{i / 0}$ was preserved. These data imply that $N^{130}$ of $p R 33$ is critical for activation of $G_{q / 11}$ but not $G_{i / 0}$. However, it appears that proper $G_{a / 11}$ activation is not determined by the specific presence of an asparagine residue at position 130 , but rather by the presence of a polar residue at this position, since mutant $\mathrm{N}^{130} \mathrm{D}$ was not impaired in PLC activation. It is known that the polar residues within DRY motifs are generally involved in stabilizing receptor conformations that form receptor/ $G$ protein interfaces (33). This stabilization is mediated by the formation of hydrogen bonds between polar residues of the DRY motif and polar residues in the other intracellular loops as well as transmembrane regions (26). Therefore, substitution of the polar asparagine in $p R 33$ by another polar residue, i.e. aspartic acid might result in formation of similar hydrogen bonds to native pR33, thereby preserving the active conformation of the receptor. In contrast, replacement of the polar $\mathrm{N}^{130}$ residue by a non-polar residue, such as alanine, would be expected to alter the hydrogen bond network between the intracellular regions of $\mathrm{pR} 33$, which may have a profound effect on the receptor's conformation and, consequently, on its interaction with specific subtypes of $G$ protein. Also, since the NRY motif is situated near the "bottom' of the third transmembrane domain of $\mathrm{pR} 33$, the introduction of a hydrophobic residue at position $\mathrm{N}^{130}$ might pull the NRY motif further into the cellular membrane, making it less accessible for certain $G$ proteins. Both mechanisms would predict an altered conformation of $N^{130} \mathrm{~A}$ compared with native $\mathrm{PR33}$ or mutant $\mathrm{N}^{130} \mathrm{D}$. While this altered conformation of $N^{430} A$ would result in a failure to activate $G_{q / 1}$ proteins, it would still allow proper $\mathrm{G}_{i / 0}$ activation.

Previously, various class I GPCRs, including the chemokine receptor CXCR2, have been shown to gain constitutive activity upon substitution of the aspartic acid of the DRY motif by hydrophobic or neutral residues $(4,26,33)$. Interestingly, while a neutral residue is present at the aspartic acid position in the PR33 NRY motif, $N^{130}$ " this residue is not essential for constitutive signalling activity, as demonstrated by the WT characteristics of signalling by mutant $\mathrm{N}^{130} \mathrm{D}$. Similar findings have been reported for the HHV-8 (Kaposi's sarcoma-associated 
herpesvirus) GPCR in which mutation of the corresponding hydrophobic residue valine $\left(\mathrm{V}^{142}\right)$ to aspartic acid did not eliminate its constitutive activity (25). In addition, the results with our mutant $\mathbb{N}^{130} \mathrm{D}$ demonstrated that the asparagine residue of pR33 is not the structural determinant for the observed differences in constitutive signalling by PR33 and pUL33, as was previously suggested by Waldhoer et al. (32). Instead, it is likely that residues other than $N^{130}$ of pR33 (and $D^{128}$ of pUL33) are responsible for the signalling differences between these receptors. One of the residues from the pR33 NRY motif, $R^{131}$, was found to be essential for constitutive activity of the receptor. A mutant in which $R^{131}$ was replaced by alanine $\left(R^{131} A\right)$ was unable to stimulate either $G_{q / 14}$ - or $G_{i ; 0}$-mediated pathways. This observation is in agreement with the finding that the arginine from the DRY motif, as found in most class I GPCRs, is essential for high-affinity binding of G proteins (33).

TABLE 2. Expression and constitutive activity of $\mathrm{PR} 33, \mathrm{pUL3} 3$ and the mutant receptors

Activity ${ }^{\prime}$

Receptor Expression*

InsP $\quad \mathrm{CRE} \quad \mathrm{NF}-\mathrm{KB}$

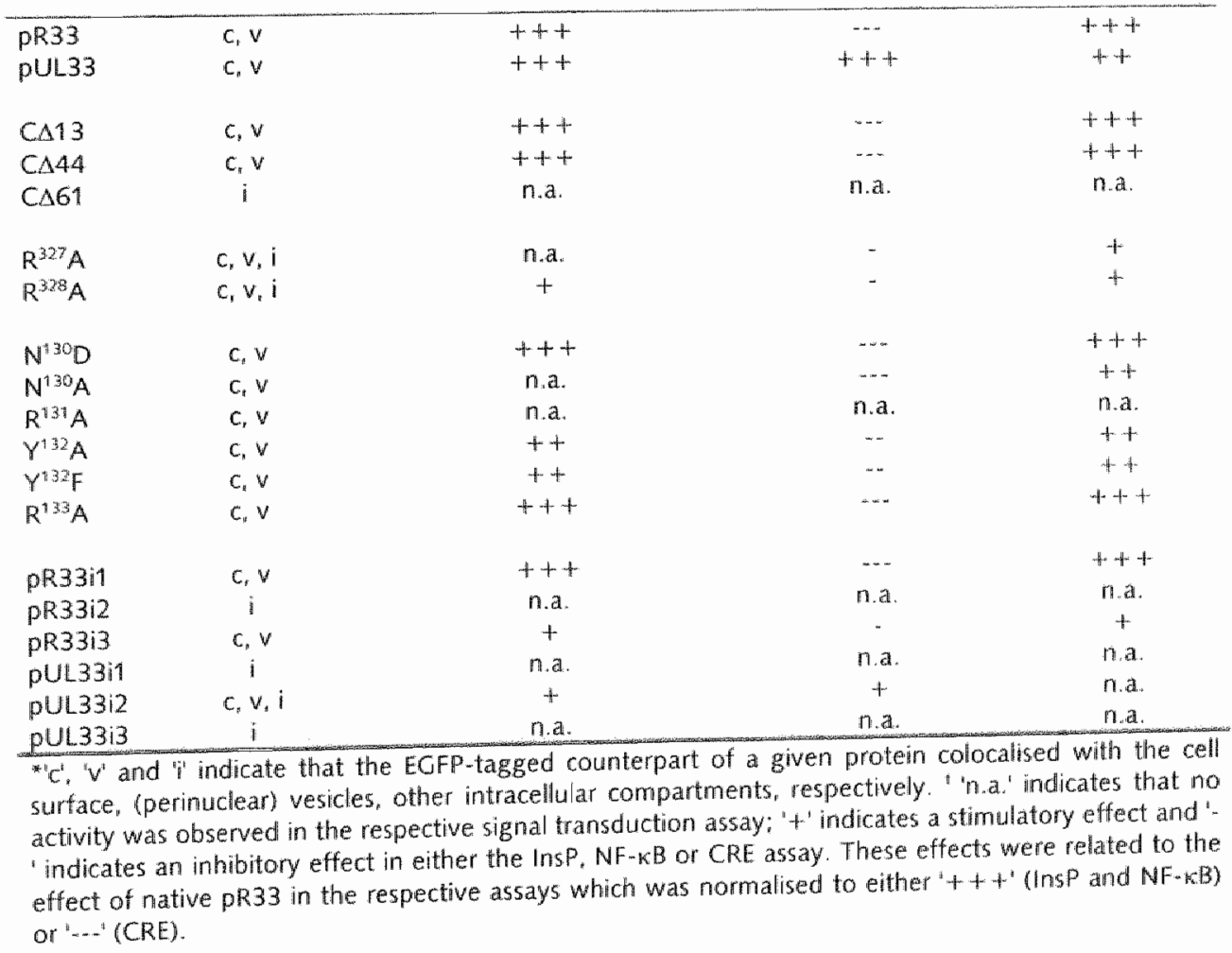


Mutation of the tyrosine residue of the pR33 NRY motif to either phenylalanine or alanine did not result in receptors with characteristics significantly different from those of the WT protein. For some chemokine receptors, such as CCR2, the tyrosine residue was found to be crucial for ligand-induced $G_{i 00^{-}}$ mediated responses $(9,20,24)$. Currently, it is not possible to test whether or not pR33 residue $V^{32}$ plays a similar role, since a ligand for $p R 33$ has not been identified. Nevertheless, we may conclude that the tyrosine residue of the NRY motif is not essential for constitutive activation of $G_{i / 0}$ and $G_{q / 11}$ by pR33.

Within the pR33 amino acid sequence, a basic residue, $R^{133}$, follows the NRY motif. A basic residue is also present at the corresponding positions within the betaherpesvirus homologues of pR33 (31). Interestingly, most other GPCRs contain a hydrophobic residue at the position corresponding to $R^{133}$ (http://www.gpcr.org/7tm). It has been reported that the hydrophobic residue following the DRY motif might be involved in $G_{i, 0}$ activation, as was demonstrated for CXCR1 (9). Nevertheless, we found mutant $R^{133} A$ to have a similar profile of expression, as well signalling, to $\mathrm{pR} 33$.

By analysis of C-terminally truncated mutants of pR33, we were able to show that the C-terminal 44 aa of pR33, including the polyproline motif, are dispensable for constitutive signalling by $P R 33$ in vitro. This supports the general idea that membrane-distal parts of the GPCR C-tail are not directly involved in efficient G-protein coupling (33). Interestingly, truncation of the pR33 C-tail, up to residue $R^{327}$, resulted in a mutant that was not properly expressed on the cell surface, but was mainly retained intracellularly. This inefficient cell-surface expression could largely be attributed to the lack of residues $R^{327}$ and $R^{328}$. Point mutation of either of these residues resulted in mutants $\left(R^{327} A\right.$ and $\left.R^{328} A\right)$ that were predominantly retained intracellularly. Interestingly $R^{327}$ and $R^{328}$ are conserved among the divergent C-terminal sequences of all $p R 33$ family members. These residues form part of a larger conserved motif, $R \times x \times x C \times \times G \times L \times x R R \times x L$, which is located between residues 315 and 331 of the pR33 amino acid sequence (30) Previously, theimportance of basic residues within the $C$ termini of GPCRs for correct cell-membrane expression has also been demonstrated for human chemokine receptors CCR5 and CCR2B (29). It is possible that these positively charged basic residues are involved in the interaction of GPCRs with the negatively charged phospholipid heads in the cellular membrane. This interaction may subsequently allow palmitoylated cysteine residues to stabilize the GPCR/membrane association by anchoring into the membrane and facilitating correct receptor folding and transport (29). Alternatively, the basic amino acid motifs may play a role in the interaction between the GPCRs and proteins that guide correct GPCR expression (reviewed by 3 ).

In contrast to pR33 (16), pUL33 was found to stimulate CRE-mediated transcription (32). This activity of pUL33 could not be transferred to pR33 by replacing either the first or third intracellular loop of $p R 33$ with those of pUL33. The chimeric receptors $\mathrm{pR} 33 \mathrm{i1}$ and $\mathrm{pR} 33 \mathrm{i} 3$ displayed similar activities to native $p R 33$. Additionally, we previously found that the stimulatory effect of pUL33 in the CRE assay was not solely determined by the $C$ terminus (6). Therefore, we conclude that stimulation of CRE by pUL33 is mediated either by the second 
intracellular loop or by the interaction of multiple intracellular domains. A study on chimeric human endothelin receptors has suggested that the second intracellular loop is an absolute requirement for stimulation of cyclic AMP formation, whereas the third intracellular loop plays an ancillary role in co-stimulating cyclic AMP production (28). However, we found that the second intracellular loop of pUL33 could be substituted by the corresponding loop of pR33, without eliminating the potential of pUL33 to stimulate CRE-mediated transcription. Although only a very slight basal stimulation of CRE-mediated transcription was observed for pUL33i2, a clear stimulatory effect was seen in the presence of PTX. This indicated that both CRE-inhibitory as well as CRE-stimulatory signal transduction pathways were constitutively activated. It is likely that the relatively low signalling activity of pUL33i2 towards CRE is due to a defect of this mutant in cell-surface expression. Although cell-surface receptor densities were not quantified in this study, it was apparent from confocal microscopy that the EGFP-tagged variant, pUL33i2-EGFP, displayed low levels of fluorescence co-localizing with the cell membrane. In agreement with this, mutant pUL33i2 showed a considerably lower level of PLC activation than pUL33. We conclude that activation of CRE by pUL33 is the consequence of the concerted action of multiple intracellular regions and possibly also transmembrane domains. To specify which domains are involved, future experiments will be directed at the generation of a broader panel of pR33/pUL33 chimeric receptors in which multiple intracellular domains as well as transmembrane regions will be exchanged. Three of the chimeric receptors we studied, pUL33i1, pUL33i3 and pR33i2, were not correctly expressed on the cell surface. Possibly, incorrect folding and/or transport of these chimeras caused this defect, which could be the consequence of the inability to form specific interactions between various domains within these proteins. Indeed, it is known that certain residues and domains within the intracellular loops of GPCRs interact. to stabilize receptor conformation and ensure correct receptor folding (33). It was noted in our study that, in particular, those chimeric receptors that comprised the second intracellular loop of pUL33 in combination with either the first or the third loop of pR33 were intracellularly retained. Together, these observations suggest that the interactions between the intracellular loops within both pR33 and pUL33 are of importance for correct receptor folding and/or transport, but that the specific amino acid residues that are involved in these interactions are not conserved between PR33 and pUL33.

To date, it is clear that most herpesvirus-encoded GPCRs are capable of constitutively modulating a wide variety of intracellular signal transduction pathways $(5,14,16,27,32)$. However, despite extensive speculation, it is still unclear if and how these viruses benefit from these and possibly other activities mediated by their GPCRs. Here, we have demonstrated the complexity of the intramolecular interactions within pUL33-like GPCRs that are required for efficient signalling and cellular expression. Of particular interest is the finding that mutation of a single residue may result in impaired constitutive activity in specific intracellular signalling pathways. For example, alteration of residue $\mathrm{N}^{130}$ to alanine eliminated the ability of pR33 to constitutively activate $G_{q / 1}$ - but not $G_{i / 0^{-}}$ mediated pathways. Introduction of such mutations in the RCMV genome may 
contribute to the identification of viral GPCR-mediated signalling routes that are crucial in the pathogenesis of virus infection.

\section{Acknowledgements}

Y.K.G. is supported by a grant (no. 901-02-224) from the Netherlands Organization for Scientific Research (NWO, medical sciences). C.V. and M.J.S. are supported by fellowships from the Royal Netherlands Academy of Arts and Sciences (KNAW).

\section{References}

1. Beisser PS, Vink $C$, van Dam JG, Grauls GELM, Vanherle SJV, Bruggeman CA. (1998). The R33 G protein-coupled receptor gene of rat cytomegalovirus plays an essential role in the pathogenesis of viral infection. J Virol 72, 2352-2363.

2. Beisser PS, Grauls GELM, Bruggeman CA, Vink C. (1999). Deletion of the R78 G protein-coupled receptor gene from rat cytomegalovirus results in an attenuated, syncytium-inducing mutant strain. J Virol 73, 7218-7230.

3. Brady AE, Limbird LE. (2002). G protein-coupled receptor interacting proteins: emerging roles in localization and signal transduction. Cell Signal $14,297-309$.

4. Burger $M$, Burger JA, Hoch RC, Oades $Z$, Takamori $H$, Schraufstatter IU. (1999). Point mutation causing constitutive signaling of CXCR2 leads to transforming activity similar to Kaposi's sarcoma herpesvirus- $G$ proteincoupled receptor. J Immunol 163, 2017-2022.

5. Casarosa $P_{r}$ Bakker RA, Verzijl D, Navis $M_{*}$, Timmerman $H_{r}$ Leurs $R_{r}$ Smit MJ. (2001). Constitutive signaling of the human cytomegalovirus-encoded chemokine receptor US28. I Biol Chem 276, 1133-1137.

6. Casarosa P. Gruijthuijsen YK, Michel D, Casarosa, Beisser PS, Holl I, Fitzsimons CP, Verzijl D, Bruggeman CA, Mertens $T$, Leurs R, Vink C, Smit MJ. (2003). Constitutive signaling of the human cytomegalovirus-encoded receptor UL33 differs from that of its rat cytomegalovirus homolog R33 by promiscuous activation of $G$ proteins of the $G_{q}, G_{i r}$ and $G_{s}$ class. I Biol Chem 278, 50010-50023.

7. Chee MS, Bankier AT, Beck S, Bohni R, Brown CM, Cerny R, Horsnell T, Hutchison CA 3rd, Kouzarides T, Martignetti JA, et al. (1990a). Analysis of the protein-coding content of the sequence of human cytomegalovirus strain AD169. Curr Top Microbiol Immunol 154, 125-169.

8. Chee MS, Satchwell SC, Preddie E, Weston KM, Barell BG. (1990b). Human cytomegalovirus encodes three $G$ proteincoupled receptor homologues. Nature 344, 774-777.

9. Damaj BB, MCColl SR, Neote $K$, Songqing $N$, Ogborn KT, Hebert CA, Naccache PH. (1996). Identification of G-protein binding sites of the 
human interleukin-8 receptors by functional mapping of the intracellular loops. FASEB $110,1426-1434$.

10. Davis-Poynter NI, Lynch DM, Vally $H$, Shellam GR, Rawlinson WD, Barell $B G$, Farrell HE. (1997). Identification and characterization of a $G$ proteincoupled receptor homolog encoded by murine cytomegalovirus. I Virol $71,1521-1529$.

11. Deng WP, Nickoloff JA. (1992). Site-directed mutagenesis of virtually any plasmid by eliminating a unique site. Anal Biochem 200, 81-88.

12. Dominguez $G$, Dambaugh $T R$, Stamey $F R$, Dewhurst 5 , Inoue $N$, Pellett PE. (1999). Human herpesvirus $6 \mathrm{~B}$ genome sequence: coding content and comparison with human herpesvirus 6A. J Virol 73, 8040-8052.

13. Fluhmann $B$, Zimmermann $U$, Muff $R$, Bilbe $G$, Fischer JA, Born W. (1998). Parathyroid hormone responses of cyclic AMP-, serum- and phorbol esterresponsive reporter genes in osteoblast-like UMR-106 cells. Mol Cell Endocrinol 139, 89-98.

14. Geras-Raaka E, Varma AHOH, Clark-Lewis I, Gershenghorn MC. (1998). Human interferon-c-inducible protein 10 ( $(\mathrm{P}-10)$ inhibits constitutive signaling of Kaposi's sarcoma-associated herpesvirus $G$ protein-coupled receptor by protein kinases in mammalian cells in culture. J Exp Med 188 , 405-408.

15. Gompels UA, Nicholas J, Lawrence $G$, Jones $M$, Thomson BJ, Martin ME, Efstathiou S, Craxton Mr Macaulay HA. (1995). The DNA sequence of human herpesvirus-6: structure, coding content, and genome evolution. Virology 209, 29-51.

16. Gruijthuijsen YK, Casarosa $P$, Kaptein SJF, Broers JL, Leurs R, Bruggeman CA, Smit MJ \& Vink C. (2002). The rat cytomegallovirus R33-encoded G protein-coupled receptor signals in a constitutive fashion. I Virol 76 , $1328-1338$.

17. Isegawa $Y$, Ping $Z$, Nakano $K$, Sugimoto $N$, Yamanishi K. (1998). Human herpesvirus 6 open reading frame $\mathrm{U} 12$ encodes a functional $\beta$-chemokine receptor. J Virol 72,6104-6112.

18. Kaptein SJF, Beisser PS, Gruijthuijsen YK, Savelkouls KGM, van Cleef KWR, Beuken $E_{n}$ Grauls GELM, Bruggeman CA, Vink C. (2003). The rat cytomegalovirus $R 78 \mathrm{G}$ protein-coupled receptor. J Gen Virol 84, 25172530 .

19. Margulies BJ, Browne $H$, Gibson W. (1996). Identification of the human cytomegalovirus G-protein-coupled receptor homologue encoded by UL33 in infected cells and enveloped virus particles. Virology 225, 111125.

20. Mellado $M$, Rodriguez-Frade $M$, Aragay $A$, del Real $G$, Martin $A M$, VilaCoro AJ Serrano A, Mayor F Jr. Martinez-A. C. (1998). The chemokine monocyte chemotactic protein 1 triggers Janus kinase 2 activation and tyrosine phosphorylation of the CCR2B receptor. J Immunol 161, 805813. 
21. Nakano K, Tadagaki K, Isegawa $Y$, Aye MM, Zou P, Yamanishi K. (2003). Human herpesvirus 7 open reading frame $\mathrm{U} 12$ encodes a functional betachemokine receptor. $\rfloor$ Virol $77,8108-8115$.

22. Nicholas ) (1996). Determination and analysis of the complete nucleotide sequence of human herpesvirus. I Virol 70, 5975-5989.

23. Rawlinson WD, Farrell HE, Barrell BG. (1996). Analysis of the complete DNA sequence of murine cytomegalovirus. J Virol 70, 8833-8849.

24. Rodriguez-Frade JM, Vila-Coro Al, Martin A, Nieto M, Sanchez-Madrid F, Proudfoot AE, Wells TN, Martinez-A. C. Mellado M. (1999). Similarities and differences in RANTES- and (AOP)-RANTES-triggered signals: implications for chemotaxis. J Cell Biol 144, 755-765.

25. Rosenkilde MM, Kledal TN, Holst PI. Schwartz TW. (2000). Selective elimination of high constitutive activity or chemokine binding in the human herpesvirus 8 encoded seven transmembrane oncogene ORF74. I Biol Chem 275, 26309-26315.

26. Scheer A, Fanelli F, Costa T, De Benedetti PG, Cotecchia S. (1997). The activation process of the alpha1B-adrenergic receptor: potential role of protonation and hydrophobicity of a highly conserved aspartate. Proc Natl Acad Sci U S A 94, 808-813.

27. Schwarz M, Murphy PM. (2001). Kaposi's sarcoma-associated herpesvirus $G$ protein-coupled receptor constitutively activates $\mathrm{NF} \cdot \mathrm{kB}$ and induces proinflammatory cytokine and chemokine production via a C-terminal signaling determinant. I Immunol 167, 505-513.

28. Takagi $Y$, Ninomiya $H$, Sakamoto A, Miwa S, Masaki T. (1995). Structural basis of $G$ protein specificity of human endothelin receptors. A study with endothelinA/B chimeras. J Biol Chem 270, 10072-10078.

29. Venkatesan S, Petrovic A, Locati M, Kim YO, Weissman D, Murphy PM. (2001). A membrane-proximal basic domain and cysteine cluster in the $C$ terminal tail of CCR5 constitute a bipartite motif critical for cell surface expression. I Biol Chem 276, 40133-40145.

30. Vink C. Beisser PS, Bruggeman CA. (1999). Molecular mimicry by cytomegaloviruses. Function of cytomegalovirus-encoded homologues of $G$ protein-coupled receptors, MHC class I heavy chains and chemokines. Intervirology 42, 342-349.

31. Vink C, Smit MJ, Leurs R, Bruggeman CA. (2001). The role of cytomegalovirus-encoded homologs of G protein-coupled receptors and chemokines in manipulation and evasion from the immune system. I Clin Virol 23, 43-55.

32. Waldhoer $M_{i}$ Kledal TN, Farrell HE, Schwartz TW. (2002). Murine cytomegalovirus (CMV) M33 and human CMV US28 receptors exhibit similar constitutive signaling activities. J Virol 76,8161-8168.

33. Wess 1. (1998). Molecular basis of receptor/G-protein-coupling selectivity. Pharmacol Ther 80, 231-264. 


\title{
CHAPTER 6
}

\author{
Summary and General Discussion
}

Samenvatting en Algehele Discussie 


\section{Summary and General Discussion}

Like all herpesviruses, CMVs have very large genomes and exhibit complex patterns of gene expression. The vast majority of herpesvirus genes produce unspliced transcripts of which the expression is regulated by promotorcontrol regions upstream of the transcription initiation site. Although nested transcripts which share either polyadenylation sites or cap sites are commonly found, spliced herpesvirus transcripts are rare. One of the few herpesvirus genes that expresses spliced transcripts is HSV-1 UL15 $(8,9)$. This gene is conserved among all herpesvirus genomes sequenced to date.

In the first chapter of this thesis, we demonstrated that the RCMV R89 counterpart of HSV-1 UL15 is expressed as a spliced transcript. Moreover similar to HSV-1 UL15, the R89 gene contains additional genes within its intron sequence which are transcribed as mono- and polycistronic mRNAs in the direction opposite to that of R89 (Chapter 1). Among these RCMV genes are R93 and R94, which represent highly conserved herpesvirus genes as well (Chapter 1). The conserved nature of the R89, R93 and R94 genes implies that these genes play a crucial role in herpesvirus biology. In agreement with this notion, the HSV-1 homologs of UL15 as well as UL16 and UL17, which represent the homologs of R93 and R94, respectively, have been demonstrated to be of importance for virus replication (1, $2,19,20,22,23,24,29)$. In light of the similarities in sequences and genomic structure, it is anticipated that the RCMV R89, R93 and R94 genes serve similar, essential functions.

During herpesvinus replication, the viral DNA is synthesized at intranuclear sites as concatemers, which consist of long continuous chains of head to tail-linked viral genomes. Following the synthesis of concatemers, unit-length viral genomes are packaged into preformed capsids and subsequently cleaved from the concatemer by the herpesvirus-encoded terminase proteins. Mature nucleocapsids then proceed to become so-called viral assemblons, which constitute intraceliular sites of advanced virion assembly. The small tegument/capsid-associated proteins encoded by members of the HSV-1 UL16 gene family, probably play a supplemental role during these latter stages of virion maturation. They facilitate the co-localization of various virion constituents, like nucleocapsids and tegument proteins, at the viral assemblons $(2,14,17,18,33)$. The tegument associatedproteins encoded by members of the HSV-1 UL17 gene family, are essential at the earlier stages of nucleocapsid maturation. They target the major and minor capsid proteins as well as preformed capsids, to sites of viral DNA replication, cleavage and packaging $(22,23,29)$. The HCMV UL89-encoded protein forms, together with the HCMV UL56-encoded protein, the herpesviral terminase. Both terminase subunits are responsible for the ATP-dependent translocation of the replicated DNA into pre-assembled capsids and the final cleavage of the viral genome from the concatemers $(3,4,13,26,27,31)$.

Since inhibitors of the terminase subunits would prevent the formation of new virions through an early block of capsid maturation, the proteins encoded by HSV-1 UL15 and HCMV UL89, are regarded as attractive anti-viral targets. Moreover, inhibitors of these terminase subunits are predicted to be safe and 
highly selective therapeutic agents, since mammalian cell DNA replication does not involve the (sequence specific) cleavage of concatemeric DNA. At present, two sorts of such novel anti-HCMV agents have been developed. Both the benzimidazole ribonucleoside analogs and the BAY 38.466 compound appear to effectively inhibit HCMV DNA maturation through the involvement of the UL89 and UL56 gene products $(5,7,11,12,13,15,21,30,31)$. However, it is not clear how these compounds affect the UL89- and UL56-encoded proteins. Furthermore, little is known about the putative interference of these compounds, either with each other or with the more traditional anti-CMV agents like foscarnet and ganciclovir, during combination therapies (10). Moreover, little information is currently available concerning the development of (multi)drug-resistance during treatment with these compounds in vivo. Since the RCMV R89-encoded protein shows $64.3 \%$ overall identity with the HCMV UL89-encoded protein (Chapter 1), the RCMV/rat model may be used to further elucidate the precise mechanism of action of these two novel classes of anti-viral agents, both in vitro and in vivo. Furthermore, the RCMV/rat model may aid the ongoing research addressing the problems of (multidrug) resistance and interference with respect to benzimidazole, BAY 38-466 and more traditional anti-herpesvirus agents in vivo.

The herpesvirus-encoded GPCRs might represent yet another group of attractive anti-viral targets. As reviewed in Chapter 2 , both the gamma- and betaherpesvirus genomes were found to comprise genes encoding GPCRs. Some of these genes are conserved among the genomes of all members of a specific herpesvirus subfamily. These include the ORF74-like genes from the rhadinoviruses, the BILF1-like genes from the lymphocryptoviruses and both the UL33- and UL78-like genes of the betaherpesviruses. By contrast, some other herpesvirus GPCR-encoding genes, such as HCMV US28 and US27, are only present on the genomes of closely related herpesvirus species.

By using recombinant, knock-out virus strains, it has been demonstrated that the GPCR-encoding members of the rhadinovirus ORF74 gene family, as well as the betaherpesvirus UL78 and UL33 families, are of vital importance for the establishment of productive infections (Chapter 2). This illustrates that the GPCRs encoded by these genes might indeed represent interesting pharmaceutical targets to prevent or control the development of herpesvirus-induced disease. In the past, GPCRs have already been proven to be successful drug targets, due to their ideal localization on cellular membranes and their ability to modulate defined (intra)cellular responses through interaction with highly selective ligands. At present, GPCRs belong to the most favored group of drug targets of pharmaceutical industries and approximately $50 \%$ of the currently marketed drugs interact with these proteins.

As mentioned in the introduction of this thesis, herpesviruses can establish life-long persisting infections in otherwise healthy hosts. This indicates that herpesvirus replication, persistence and dissemination may take place in the face of a normal functioning immune system, which implies that herpesviruses are welladapted to the antiviral strategies of this immune system. In this respect it is interesting to note that most of the herpesvirus-encoded GPCRs were found to show high levels of sequence similarity with members of the GPCR subfamily of 
chemokine receptors (Chapter 2). Chemokine receptors are essential for the orchestration of cell-mediated immune responses. In accordance with the sequence similarities between the herpesvirus GPCRs and chemokine receptors, most of the currently characterized herpesvirus GPCRs were found to bind and respond to chemokines, either as broad spectrum or highly selective receptors (Chapter 2). These receptors include the KSHV ORF74-, HCMV US28-, HHV-7 U12- HHV-6 U12 and U51-encoded GPCRs. It is tempting to speculate that these herpesvirus receptors function by subverting the host's immune defenses through interference with chemokine signaling pathways.

In addition to chemokine-mediated signaling, several herpesvirus GPCRs, including the KSHV ORF74- and HCMV US28-encoded receptors, were found to signal in a ligand-independent, constitutive fashion. This constitutive activity could be modulated either positively or negatively through binding of their respective chemokine ligands, which thus acted as agonists and inverse agonists, respectively. At present, the biological significance of constitutive signaling by the herpesvirus GPCRs still remains enigmatic. Since constitutive signaling by various endogenous mammalian GPCR mutants has been related to a variety of pathophysiological conditions (28), it has been suggested that constitutive signaling by herpesvirus GPCRs may likewise be involved in the development of herpesvirus-induced pathologies. Some of the GPCRs encoded by the ORF74-like genes of the oncogenic rhadinoviruses were found to possess tumorigenic properties. In addition, their ability to induce tumor formation was shown to be dependent on their constitutive as well as ligand-dependent signaling activities. However none of the other identified (constitutively active) herpesvirus GPCRs have yet been directly associated with specific manifestations of herpesvirus-associated diseases. Furthermore, it is still unclear how the intrinsic properties of these receptors contribute to the pathogenesis of viral infection.

since the majority of the herpesvirus-encoded GPCRs was still uncharacterized at the time the work presented in this thesis was initiated, we set out to investigate the putative GPCRs encoded by members of the betaherpesvirus UL33-like gene family. As described in Chapters 3 and 4 , the RCMV R33 and HCMV UL33 genes were found to encode functional GPCRs that signal in a ligand-independent, constitutive fashion. The R33- and UL33-encoded proteins, pR33 and PUL33, respectively, were found to interact with $G$ proteins of various classes and to constitutively modulate multiple intracellular signal transduction cascades. Both receptors were demonstrated to stimulate PLC through the activation of the $G$ proteins of the $G_{q / 11}$ class. In addition, each receptor was shown to regulate CRE-driven transcription. Interestingly, PR33 and pUL33 were found to modulate this activity in a different manner. While RCMV PR33 induced a downregulation, HCMV pUL33 invoked an upregulation of CRE-mediated transcription. This inhibitory activity of $\mathrm{pR} 33$ is mediated by constitutive activation of $G$ proteins of the $G_{i / 0}$ class. Like pR33, pUL33 activates the inhibitory $G_{i \neq 0}$ proteins. In addition, pUL33 stimulates $\mathrm{G}_{5-}$ and RhoA-p38MAPK-mediated signaling pathways that are not activated by pR33. Therefore, the netto result of constitutive pUL33-mediated signaling is a strong upregulation of CRE-driven transcription 
Like the other members of the betaherpesvirus pUL33 receptor family, pR33 and pLL33 share the highest level of similarity with CC chemokine receptors (CCRs). In correspondence with this similarity to CCRs, both the HHV-6B and HHV 7 counterparts of HCMV pUL33 (pU12) were found to bind and respond to CC chemokines (CCLs). HHV- $6 B$ was reported to be a broad spectrum CCR and to mediate calcium mobilization upon binding of RANTES, Mip-1 $\alpha$, Mip-1p and MCP-1 (CCL5, CCL3, CCL4 and CCL2, respectively). However, RANTES-binding was not observed for pR33 and pUL33. In addition, neither RANTES nor other tested chemokines were able to modulate constitutive signaling by either receptor (Chapters 3 and 4). This indicated that, in contrast to HHV-6B pU12, PR33 and pUL33 may represent highly selective chemokine receptors. Interestingly, HHV -7 pU12 was recently shown to be a highly selective receptor, responding exclusively to CCL19 (Mip-3B) (16). It is not yet known whether the other receptors from the pUL33 family are similarly able to interact with CCL19. Hitherto, however, no interaction of this or any other (chemokine) ligand has been reported for $p R 33$ and pUL33. Both receptors are therefore still regarded as orphan GPCRs. One of the main challenges of future research is to 'de-orphanize' the CMV-encoded, pUL33like GPCRs, and to establish whether these GPCRs represent true chemokine receptors.

In order to delineate the structural requirements for the constitutive behavior of pR33 on one hand, and to identify the structural basis for the differential constitutive signaling by PR33 and pUL33 on the other, mutagenesis studies were performed (Chapters 4 and 5). Part of these studies focused on the conserved DRY motif. This motif is found in most GPCRs analysed to date, and is known to be important for the coupling to and activation of $G$ proteins (32). Although pUL33 possesses a 'normal' DRY motif, pR33 contains an NRY motif. It has been noted that mutation of the aspartic acid residue (D) of the DRY motif in some GPCRs, results in a constitutively active receptor $(6,25,32)$. Nevertheless, the wild type signaling characteristics of the pR33 mutant containing a 'regular' DRY motif $\left(N^{130} D\right)$ showed that the neutral asparagine residue $(N)$ in the pR33 motif is not critical for its constitutive signaling and does not represent a structural determinant for differential signaling by PR33 and pUL33. Interestingly, we did find the asparagine of the NRY motif of pR33 to be critical for the constitutive activation of $G$ proteins of the $G_{q / 1}$ class. By contrast, this residue was not essential for the pR33-mediated activation of the $G$ proteins of the $G_{i / 0}$ class. The arginine residue (R) within the DRY or NRY motif, is the best conserved GPCR residue, and was found to be critical for $G$ protein-coupling (32). In line with this, we found the pR33 mutant in which the arginine residue (R) of the NRY motif was mutated, was unable to modulate either PLC or CRE activation.

To further characterize which other intracellular regions of pR33 and pUL33 might be of structural importance for the (different) constitutive signaling profiles of these receptors, each of the intracellular domains were exchanged between pR33 and pUL33 (Chapters 4 and 5). Surprisingly, none of the previously identified differential constitutive signaling characteristics of pR33 or pUL33 could be specifically eliminated from one receptor nor transferred from one receptor to the other by substitution of a single intracellular loop. It was noted, however, that 
the C-terminal tail of pUL33 might contain several domains that could be involved in the stimulation of $G_{i / 0}$ proteins. By contrast, the $C$ terminus of $p R 33$ seemed to lack these domains, since the pUL33 domains could not be substituted by the (nonconserved) sequence of the pR33 C-terminal tail. Taken together, these data imply that the constitutive signaling characteristics of pR33 and pUL33 are the consequence of the concerted actions of multiple domains in the intracellular and perhaps also transmembrane regions.

Through the pR33 and pUL33 C-termini exchange studies, a membrane proximal region in the pR33 $C$ terminus was identified that might govern $p R 33$ cell surface expression (Chapter 4). This membrane proximal KRF motif is conserved between $\mathrm{pR} 33$ and $\mathrm{pM} 33$, but is absent from pUL33. A similarly located KRF motif was reported to be involved in proper expression of CCR5 on the cell surface. Nevertheless, a direct involvement of the KRF motif in cell surface expression of pR33 or pM33 has not yet been confirmed. A role in proper cell surface expression of $p R 33$, however, was established for two consecutive arginine residues (RR) in the more distal part of the $C$ terminus, as demonstrated by the analysis of point mutants in this dipeptide motif (Chapter 5). In light of the conserved nature of these residues among the highly divergent $C$-terminal sequences of the betaherpesvirus pR33 counterparts, it is likely that the RR motif of the other pUL33 family members plays a similar role as that of $\mathrm{pR} 33$.

The findings regarding the constitutive signaling properties, the regulation of subcellular expression and the differences between closely related CMV receptors with respect to these properties, are intriguing. Nevertheless, it remains to be investigated whether these in vitro activities reflect functional properties of pR33 and pUL33 that are of biological significance in vivo. Due to the strict species-specificity of CMVs as well as ethical considerations, it is difficult to evaluate the putative functions of the human herpesvirus-encoded GPCRs, like pUL33, in vivo. In addition, it is not useful to investigate the role of these proteins during in vitro infections, since these proteins are, in general, dispensable for viral replication in cell culture. Therefore, future studies aimed at further characterization of these and other herpesvirus-encoded receptors as well as the identification and evaluation of putative anti-viral compounds targeted at these GPCRs, will be confronted by the need to develop new in vivo assays. In the case of the HCMV pUL33 receptor, it could be envisaged that a recombinant RCMV strain which expresses pUL 33 instead of pR33 may be very useful for in vivo (rat) studies. Another approach has been reported for the KSHV GPCR, which was expressed in transgenic mice (Chapter 2). Of course, each of these surrogate models suffer from specific shortcomings, such as the putative lack of proper ligands for a specific GPCR expressed by a transgene. Regardless, in vitro assays have proven to be and will remain to be of considerable value to increase our knowledge on the signaling characteristics, pharmacological profiles and structurefunction relationships of these receptors. 


\section{Samenvatting en algehele discussie}

Net als alle andere herpesvirussen, bezitten cytomegalovirussen een zeer groot genoom en vertonen een gecompliceerd gen expressiepatroon. De meeste herpesvirusgenen vormen ongesplitste transcripten waarvan de expressie gereguleerd wordt door direct stroomopwaarts van de transcriptiestart gelegen promotor-controle complexen. Overlappende transcripten worden ook gevonden en deze delen meestal of het poly-adenylatie- of het cappingsignaal. Gesplitste herpesvirustranscripten daarentegen zijn zeldzaam. Een van de weinige herpesvirusgenen dat als een gesplitst transcript tot expressie komt is het herpes simplex virus type 1 (HSV-1) UL15 gen $(8,9)$. Dit gen is geconserveerd op/voor alle herpesvirusgenomen waarvan de basevolgorden op dit moment bepaald zijn.

In het eerste hoofdstuk van deze thesis hebben we aangetoond dat het aan HSV-1 UL15 verwante gen van rat CMV, het R89 gen, ook tot expressie komt als een gesplitst transcript. Bovendien bevat het R89 gen, evenals het HSV-1 UL15 gen, in zijn intronsequentie additionele genen, die in de aan R89-tegengestelde richting, als mono- en polycistrone mRNAs worden getranscribeerd (Hoofdstuk 1). Twee van deze genen, R93 en R94, vertegenwoordigen eveneens sterk geconserveerde herpesvirus genen (Hoofdstuk 1). De hoge mate van geconseerveerheid van de R89, R93 en R94 genen in de herpesvirusfamilie, geeft aan dat deze genen een cruciale rol vervullen in de biologie van herpesvirussen. In overeenstemming met dit idee is gevonden dat de HSV UL15, UL16 en UL17 genen, die homoloog zijn aan respectievelijk de RCMV R89, R94 en R93 genen, van bellang zijn voor virus replicatie $(1,2,19,20,22,23,24,29)$. Het is te verwachten dat in verband met de overeenkomsten in sequentie en genomische structuur van deze genen, de RCMV R89, R93 en R94 genen vergelijkbare, essentiële functies vervullen.

Tijdens herpesvirusreplicatie wordt het virale DNA in de celkern gesynthetiseerd in de vorm van een concatemeer. Een concatemeer bestaat uit een lange continue aaneenschakeling van kop-staart gekoppelde virale genomen. $\mathrm{Na}$ synthese worden de afzonderlijke virale genomen verpakt in voorgevormde capsiden en uit de concatemeer geknipt door de zogenaamde herpesvirus terminases. De zo ontstane nucleocapsiden verwijderen zich van de plek van de nucleocapsidenmaturatie en verworden tot virale-assemblonen. Deze assemblonen vormen de intracellulaire centra waar de verdere virion assemblage plaatsvindt. De door de leden van de HSV-1 UL16 genfamilie gecodeerde, kleine tegument/capside geassocieerde eiwitten, spelen waarschijnlijk een aanvullende rol tijdens deze laatste fasen van de virion maturatie. Deze eiwitten maken het namelijk mogelijk dat de verschillende virion bestanddelen, zoals de nucleocapsiden en tegument eiwitten, allemaal in de virale assemblonen colocaliseren $(2,14,17,18$, 33). De tegument geassocieerde eiwitten die door de leden van de HSV-1 UL17 genfamilie worden gecodeerd, zijn van essentieel belang tijdens eerdere stadia van de nucleocapside maturatie. Zij zorgen ervoor dat de major en minor capside eiwitten, zich net als de voorgevormde capsiden verzamelen op de locaties waar replicatie, restrictie en verpakking van het virale DNA plaatsvindt $(22,23,29)$. Het HCMV UL89-gecodeerde eiwit vormt, tezamen met het HCMV UL56 gecodeerde 
eiwit, het herpesvirus terminase. Deze beide terminase subunits zinn verantwoordelik voor de ATP afhankelike translocatie van het gerepliceerde DNA in voorgevormende capsiclen en het afsplitsen van de afzonderlike virale genomen uit de concatemeer $(3,4,13,26,27,31)$.

De eiwitten die worden gecodeerd door HSV-1 UL15 en HCMV UL89. worden gezien als aantrekkelike anti-virale aangrijpingspunten. Door een voortijdige blokkering van capside maturatie zouden de eventuele remmers van herpesvirus terminases namelik de vorming wan nieuwe virionen kunnen voorkomen. Bovendien wordt verwacht dat zulke terminase remmers, veilige en zeer selective agentia zullen zijn omdat bij de DNA replicatie in zoogdiercellen het knippen van concatemerisch DNA niet woorkomt. Momenteel zijn twee van dit soort nieuwe anti-HCMV agentia ontwikkeld. Dit zijn de benzimidazol ribonucleosiden analogen en de stof BAY 38-466, en zij blijken in staat de HCMY DNA maturatie effectief te remmen door een interactie met de UL89 en UL56 genproducten $(5,7,11,12,13,15,21,30,31)$. Het is echter nog onduidelijk hoe deze middelen de UL89 en UL56 gecodeerde eiwitten beinvloeden. Ook is er nog slechts weining bekend over de mogelijke wisselwerking van deze stoffen met elkaar, of met de meer traditionele anti-CMV middelen zoals foscarnet en gancyclovir, wanneer deze tijdens combinatie therapieen met elkaar gebruikt zouden worden (10). Bovendien is er momenteel te weinig informatie beschikbaar met betrekking tot de ontwikkeling van (meervoudige) resistentie tegen deze agentia gedurende de behandeling met deze middelen in vivo. Aangezien de aminozuursequentie van het R89 gecodeerde eiwit voor $64 \%$ identiek is aan die van het HCMV UL89 gecodeerde eiwit (Hoofdstuk 1), zou het RCMV/rat model gebruikt kunnen worden om de precieze werkingsmechanismen van nieuwe soorten antivirale middelen zowel in vitro als in vivo, aan het licht te brengen. Verder zou het RCMV/rat model van dienst kunnen zijn in de lopende onderzoeken naar de ontwikkeling van meervoudige geneesmiddelen resistentie enerzijds en de wisselwerking tussen deze geneesmididelen anderzijds met betrekking tot benzimidazole, BAY $38-466$ en de meer traditionele antiherpesvirusmiddelen, in vivo.

De herpesvirus gecodeerde $G$ eimit gekoppelde receptoren (GPCRs) vormen mogelijk ook aantrekkelijke antivirale aangrijpingspunten. Zowel voor de genomen van de gamma- als de betaherpesvirussen, zijn genen geindentificeerd die voor GPCRs coderen (Hoofdstuk 2). Een aantal van deze genen zijn geconserveerd op de genomen van alle leden van een specifieke herpesvirussubfamilie. Dit zijn onder meer de ORF74-achtige genen van de madinovirussen, de BILF-1-achtige genen van de lymfocryptovirussen en zowel de UL33- als de UL78-achtige genen van de betaherpeswirussen. Dit is in tegenstelling tot enkele andere, voor GPCRs coderende herpesvirusgenen, zoals HCMV US28 en US27, welke enkel voorkomen op genomen van mauW verwante herpesvirus species.

Door gebruik te maken van recombinante, knock-out viruslijnen, is aangetoond dat de GPCR coderende leden van de rhadinovirus ORF74 gen familie, alsook de betaherpesvirus UL78- en UL33 families, van vitaal belang zijn om productieve virale infecties te bewerkstelligen in vivo (Hoofdstuk 2). Dit 
illustreert dat de GPCR5 die door deze genen gecodeerd worden inderdaad interessante pharmaceutische aangrijpingspunten vormen waardoor de ontwikkeling van herpesvirus- geïnduceerde ziektes voorkomen zouden kunnen worden of onder controle gebracht. In het verleden is reeds bewezen dat GPCRs succesvolle therapeutische aangrijpingspunten wormen omdat zij gelegen zijn in de cellulaire membraan en door interactie met selective liganden vaststaande (intrajcellulaire responsen kunnen moduleren. Op dit moment behoren GPCRs tot de meest favoriete therapeutische aangrijpingspunten van de pharmaceutische industrie, en ongeveer $50 \%$ van de geneesmiddelen op de huidige markt werkt in op deze eiwitten.

Zoals genoemd in de introductie van deze thesis, kunnen herpesvirussen levenslang-persisterende infecties bewerkstelligen in anderzins gezonde gastheren. Dit duidt erop dat herpesvirus replicatie "persistentie en disseminatie plaats vinden temidden van een normaal functionerend immuunsysteem. Dit impliceert dat herpesvirussen goed aan de antivirale strategieën van het immuunsysteem aangepast zullen zijn. Het is in dit opzicht interessant te vermelden dat de meeste herpesvirus GPCRs, de grootste overeenkomsten vertonen met leden van de GPCR subfamilie der chemokine receptoren. Chemokine receptoren zijn van cruciaal belang voor de regulering van cell-gemedieerde immuunresponsen. Voor de meeste, momenteel gekarakteriseerde herpesvirus GPCRs is aangetoond dat zij, overeenkomstig deze chemokine receptor gelijkenissen, chemokines binden en erop reageren, hetzij als breed spectrum hetzij als selectieve receptoren (Hoofdstuk 2). Dit geldt onder meer voor de KSHV ORF74, HCMV US28, HHV-7 U12, HHV6 U12 en U51 gecodeerde receptoren. Het is verleidelijk om te speculeren dat deze herpesvirus receptoren betrokken zijn bij het ondermijnen van het immuunsysteem van de gastheer, door verstoring van chemokinegeïnduceerde signaal transductie routes.

Naast de chemokine gemedieerde signalering, is gevonden dat verschillende herpesvirus GPCRs, waaronder de KSHV ORF74 en HCMV US28 gecodeerde receptoren, ook op een ligand onafhankelijke, zogenaamde constitutieve wijze signaleren (Hoofdstuk 2). Daarbij is aangetoond dat deze constitutieve signalering op zowel positieve als negatieve wijze gemoduleerd kan worden door binding met liganden die zich aldus respectievelijk als agonisten of inverse agonsiten gedragen. Momenteel is echter nog altijd onduidelijk wat nu de biologische significantie van deze constitutieve herpesvirusreceptor activiteit is. Voor verschiliende endogene GPCR mutanten is aangetoond dat de constitutieve activiteit die zij door hun mutaties ten toon spreiden, de oorzaak is van het onstaan van verschillende pathofysiologische condities (28). Mede hierom wordt er gesuggereerd dat constitutieve signalering door herpesvirus GPCRs op een vergelijkbare wijze betrokken zou kunnen zijn bij de ontwikkeling van herpesvirusgeassocieerde pathologieën. Zo is voor de GPCRs, die door de ORF74- genen van enkele oncogene rhadinovirussen gecodeerd worden, vastgesteld dat zij tumorigene eigenschappen bezitten (Hoofdstuk 2). Daarbij is gevonden dat hun mogelijkheid tot tumorinductie afhankelijk is van zowel hun ligand-onafhankelijke, constitutieve als ligand-afhankelijke signaleringsactiviteiten. Voor de andere tot nu toe geïndentificeerde (constitutief actieve) herpesvirus GPCRs, is echter tot op 
heden nog geen directe associatie gevonden met specifieke manifestaties van herpesvirus geassocieerde ziekten. daarbij blijtt het nog altijd onduidelijk, hoe de intrinsieke eigenschappen van deze receptoren bijdragen aan de pathogenese van de virale infectie.

Aangezien het meerendeel van de herpesvirus gecodeerde GPCRS nog niet gekarakteriseerd was, toen het werk welke in deze thesis wordt gepresenteerd, werd geinitieerd, zijn wij begonnen met het onderzoek naar GPCRs die mogelijk door de leden van de betaherpesvirus UL33 genfamilie worden gecodeerd. Zoals beschreven in Hoofdstukken 3 en 4 , is gevonden dat de RCMV R33 en de HCMV UL33 genen coderen voor functionele GPCRs welke op een ligand-onhankelijke, constitutieve wijze signaleren. De door R33 en UL33 gecodeerde receptoren, pR33 en pUL33 respectievelijk, gaan interacties aan met verschillende soorten $G$ eiwitten en moduleren meerdere intracellulaire signaaltransductiecascades op constitutieve wijze. Aangetoond werd dat beide receptoren fosfolipase $C$ (PLC) stimuleren door de activatie van $G$ eiwitten die behoren tot de $G_{q / 11}$ klasse. Bovendien werd voor beide receptoren aangetoond dat ze de CRE gemedieerde transcriptie reguleren. Het is opmerkelijk dat de modulatie van de CRE gemedieerde transcriptie door pR33 en pUL33, van elkaar verschilt. De CRE gemedieerde transcriptie wordt door pR33 geremd terwijl deze door pUL33 juist wordt gestimuleerd. De remmende invloed van pR33 wordt in gang gezet door de constitutieve activatie van $G$ eiwitten die behoren tot de $G_{i \neq 0}$ klasse. Net als pR33, activeert ook pUL33 deze remmende $G_{i / 0}$ eiwitten. Daarnaast. stimuleert pUL33 $G_{s}$ eiwitten en RhoA-MAPK geassocieerde signaaltransductie routes, welke niet door pR33 geactiveerd worden. Dit zorgt ervoor dat het netto effect van de constitutieve signalering door pUL33 een sterke stimulatie van de CRE gemedieerde transcriptie is.

Net als de andere leden van de beteherpesvirus pUL33 receptorfamily, vertonen pR33 en pUL33 de grootste overeenkomsten met de CC (beta) chemokine receptoren (CCRs). In overeenstemming met deze CCR gelijkenissen is gevonden dat de aan HCMV pUL33 verwante receptoren van zowel HHV-6, pU12, en HHV -7 , pU12, op binding van $C C$ chemokinen (CCLs) reageren. $Z$ o werd voor HHV-6 bekend gemaakt dat deze een breed spectrum CCR is, die na binding van RANTES, Mip-1 $\alpha$, Mip-1 $\beta$ of MCP-1 (CCL5, CCL3, CCL4 en CCL2, respectievelijk), de mobilisatie van intracellulair calcium induceert. RANTES binding werd echter niet waargenomen voor de nauw verwante pR33 of pUL33 receptoren. Bovendien bleek noch RANTES, noch een van de andere geteste chemokines, in staat de constitutieve activiteit een van beide receptoren te moduleren (Hoofdstukken 3 en 4). Dit impliceert dat, in tegenstelling tot HHV-6 PU12, pR33 en pUL33 mogelijk zeer selectieve chemokine receptoren zijn. Het is In dit verband interessant te vermelden dat onlangs werd aangetoond dat $\mathrm{HHV}-7$ pU12 een zeer selectieve receptor is, die enkel reageert op binding CCL19 (Mip3B) (16). Het is momenteel nog niet bekend of ook de andere receptoren van de pUL33 familie in staat zijn CCL19 te binden. Tot nu toe is er echter nog niets gepubliceerd met betrekking tot een mogelijke interactie tussen pR33 of pUL33 en hetzij CCL19 of enig ander (chemokine) ligand. Beide receptoren worden daarom nog altijd beschouwd als verweesde (orphan) GPCRs. Een van de grootste 
uitdagingen voor toekomstige onderzoek ligt dan ook in het ont-wezen (to deorphanize) van de CMV-gecodeerde, pUL33-achtige GPCRs en het vaststellen of deze GPCRs wel of niet tot de subfamilie der chemokine receptoren behoren.

Om de structurele eisen voor de constitutieve pR33 activiteit te ontrafelen en om de structurele basis van het verschil in constitutieve pR33 en pUL33 activiteit te achterhalen, werden mutagenese studies uitgevoerd (Hoofdstukken 4 en 5). Een deel van deze studies concentreerde zich op het het geconserveerde DRY motief. Dit motief wordt in de aminozuur sequenties van de meeste tot nu toe geanalyseerde GPCRs gevonden en is van belang voor de koppeling met en de activatie van G eiwitten (32). Hoewel pUL33 een 'normaal" DRY motief bezit, bevat de pR33 sequentie een NRY motief. Het is opvallend dat bij sommige GPCRs de mutatie van het aspartaat residu (D) van het DRY motif resulteert in een constitutief actieve receptor $(6,25,32)$. De wild type-achtige signaleringskarakteristieken van de pR33 mutant, welke een regulier DRY motief bezit $\left(N^{i 30} D\right)$, laten echter zien dat het neutrale asparagine residu $(N)$ in plaats van een aspartaat residue (D) niet de oorzalak is van de constitutieve signalerings activiteit van pR33. Bovendien laat dit zien dat dit residu niet de structurele determinant vormt voor het verschil in signalering tussen pR33 en pUL33. Opvallend genoeg vonden we dat de asparagine van het $p R 33$ NRY motief wel betrokken is bij de constitutieve activatie van $G$ eiwitten behorende tot de $G_{q / 11}$ klasse. Terwijl voor de pR33 gemedieerde activatie van de $G$ eiwitten van de $G_{i, o}$ klasse, dit residu weer niet van essentieel belang lijkt te zijn. Het arginine residue $(R)$ in thet DRY of NRY motief, is het meest geconserveerde GPCR residue en is essentieel voor $G$ eiwit koppeling (32). In overeenstemming hiermee vonden we dat de PR33 mutant waarin het arginine residue (R) van het NRY motief was gemuteerd, niet meer in staat bleek te zijn de activatie van hetzij PLC, hetzij CRE, te moduleren.

Om vervolgens na te gaan welke andere intracellulaire regionen van $\mathrm{pR} 33$ en pUL33 van structureel belang zouden kunnen zijn voor (het verschil in) de constitutieve signaleringsprofielen van deze receptoren, werden verschillende intracellulaire domeinen tussen pR33 en pUI.33 uitgewisseld (Hoofdstukken 4 en 5). Het was verrassend dat de voorheen geindentificeerde differentiële constitutive signaleringskarakteristieken, niet specifiek konden worden geëlimineerd voor pR33 of pUL33, en dat deze niet van de ene receptor op de andere overgedragen kon worden, door een substitutie van een enkele intracellulaire loop. Verder was het opvallend dat de C-terminale staart van pUL33 domeinen bevat die mogelijk betrokken zijn bij de activatie van $G_{i, 0}$ eiwitten. In de C-terminale staart van pR33, lijken deze domeinen niet aanwezig te zijn aangezien de pUL33 domeinen niet vervangen konden worden door de (niet-geconserveerde) sequentie van de $p R 33$ C-terminale staart. Samenvattend lijken deze data erop te duiden dat de differentiële constitutieve signaleringskarakteristieken van pR33 en pUL33 nworden veroorzaakt door de gecoördineerde akties van meerdere domeinen, die mogelijk gelegen zijn in de intracellulaire, en eventueel zelfs de transmembrane regio' 5 , van de deze receptoren.

Door de studies met betrekking tot de uitwisseling van de PR33 en pUL33 C-termini, werd ook een dicht bij de membraan gelegen pR33 regio 
geidentificeerd welke van belang is voor de expressie van $P R 33$ op het celoppervlak (Hoofdstuk 4). Dit proximaal tot de membraan gelegen, KRF motief is geconserveerd voor de PR33 en MVMV pM33 sequenties, maar is miet aanwezig in de pUL33 sequentie. Voor een vergelijkbaar gelegen KRF motif werd voorheen gepubliceerd dat het noodzakelijk is voor de correcte expressie van CCR5 op het celoppervlak. Een directe betrokkenheid van het KRF motief voor de celoppervlakte expressie van pR33 of $\mathrm{pM} 33$, is echter nog niet bevestigd. We hebben wel vastgesteld dat voor de correcte expressie van pR33 op het celoppervlak, de twee opeenvolgende arginine residuen (RR) die meer distaal van het transmembrane domein in de C-terminus gelegen zijn, een belangerijke rol spelen. Dit werd bevestigd door puntmutatie analyses van dit betreffende dipeptide motif (Hoofdstuk 5). In het licht van de geconserveerdheid van deze residuen tussen de zeer divergente $C$-terminale sequenties van de betaherpesvirus pR33 verwanten, is het waarschijnlijk dat het RR motief ook voor de overige leden van de pUL33 GPCR familie een vergelijkbare rol speelt.

Deze bevindingen met betrekking tot de constitutieve signaleringseigenschappen, de regulatie van de subcellulaire expressie, en de verschillen tussen de nauw aan elkaar verwante CMV receptoren in relatie tot deze eigenschappen, zijn intrigerend. Desondanks blijft het de vraag of deze in vitro activiteiten, functionele eigenschappen van pR33 en pUL33 reflecteren die in vivo van biologische significantie zijn. Vanwege de strikte species-specificiteit van de CMVs, en vanwege ethische overwegingen, is het lastig om de mogelijke in vivo functies van de humane herpesvirus gecodeerde GPCRs, zoals pUL33, na te gaan. Bovendien is het niet erg zinvol gebleken, om de rol van deze eiwitten door middel van in vitro infecties verder te onderzoeken, aangezien deze eiwitten over het algemeen niet noodzakelijk lijken te zijn voor virale replicatie in cell cultuur. Hierdoor zullen toekomstige studies, gericht op het verder karakteriseren van deze en andere herpesvirus gecodeerde receptoren, en op de identificatie en evaluatie van mogelijke anti-virale middelen die op deze GPCRs aangrijpen, zich geconfronteerd zien met de noodzaak nieuwe in vivo testen te ontwikkelen. Men zou zich kunnen voorstellen dat in het geval van HCMV pUL33, een recombinante RCMV stam die in plaats van PR33, pUL33 tot expressie brengt, bruikbaar zou kunnen zijn voor in vivo (ratten) studies. Een andere benadering werd gepubliceerd voor de KSHV GPCR, welke door en in transgene muizen tot expressie werd gebracht (Hoofdstuk 2). Natuurlijk heeft ieder van deze surrogaat modelsystemen te leiden onder specifieke tekortkomingen, zoals het mogelijke gebrek aan correcte liganden voor een specifieke GPCR die door een transgeen, of in een andere niet-natuurlijke gastheerspecies, tot expressie wordt gebracht. De in vitro assays hebben echter, ondaks alle bezwaren, ook bewezen van aanzienlijk belang te zijn, en te zullen zijn, om onze kennis met betrekking tot de signaleringskarakteristieken, de farmacologische profielen, en de structuur-functie relaties van deze receptoren te blijven vergroten. 


\section{References/ Referenties}

1. Baines JD, Poon AP, Rovnak J, Roizman B. (1994) The herpes simplex virus 1 UL15 gene encodes two proteins and is required for cleavage of genomic viral DNA. J Virol. 68:8118-24.

2. Baines JD, Roizman B. (1991) The open reading frames UL3, UL4, UL.10, and UL16 are dispensable for the replication of herpes simplex virus 1 in cell culture. JVirol. 65:938-44.

3. Bogner $E$, Reschke M, Reis B, Mockenhaupt T, Radsak K. (1993) Identification of the gene product encoded by ORF UL56 of the human cytomegalovirus genome. Virology. 196:290-3.

4. Bogner E. (2002) Human cytomegalovirus terminase as a target for antiviral chemotherapy. Rev Med Virol. 12:115-27.

5. Buerger I, Reefschlaeger J, Bender W, Eckenberg P, Popp A, Weber $O$, Graeper S, Klenk HD, Ruebsamen-Waigmann H, Hallenberger S. (2001) A novel nonnucleoside inhibitor specifically targets cytomegalovirus DNA maturation via the UL89 and UL56 gene products. $J$ Virol. 75:9077-86.

6. Burger M, Burger JA, Hoch RC, Oades Z, Takamori $H$, Schraufstatter IU. (1999) Point mutation causing constitutive signaling of CXCR2 leads to transforming activity similar to Kaposi's sarcoma herpesvirus-G proteincoupled receptor. $J /$ mmunol 163:2017-22.

7. Chulay J, Biron $K_{4}$ Wang $L$, Underwood $M$, Chamberlain S, Frick $L$, Good $S$, Davis Mr Harvey R, Townsend L, Drach J, Koszalka G. (1999) Development of novel benzimidazole riboside compounds for treatment of cytomegalovirus disease. Adv Exp Med Biol. 458:129-34.

8. Costa RH, Draper KG, Kelly TJ, Wagner EK. (1985) An unusual spliced herpes simplex virus type 1 transcript with sequence homology to EpsteinBarr virus DNA. J Virol. 54:317-28.

9. Dolan A, Arbuckle M, McGeoch DJ. (1991) Sequence analysis of the splice junction in the transcript of herpes simplex virus type 1 gene UL15. Virus Res, 20.97-104.

10. Evers DL, Komazin G, Shin D, Hwang DD, Townsend LB, Drach JC. (2002) Interactions among antiviral drugs acting late in the replication cycle of human cytomegalovirus. Antiviral Res. 56:61-72.

11. Krosky PM, Borysko KZ, Nassiri MR, Devivar RV, Ptak RG, Davis MG, Biron KK, Townsend LB, Drach JC. (2002) Phosphorylation of beta-Dribosylbenzimidazoles is not required for activity against human cytomegalovirus. Antinnicrob Agents Chemother. 46:478-86.

12. Krosky PM, Ptak RG. Underwood MR, Biron KK, Townsend LB, Drach $J C$. (2000) Differences in DNA packaging genes and sensitivity to benzimidazole ribonucleosides between human cytomegalovirus strains AD169 and Towne. Antivir Chem Chemother. 11:349-52.

13. Krosky $P M$, Underwood MR, Turk $S R$, Feng $K W$, Jain RK, Ptak RG, Westerman AC, Biron KK, Townsend LB, Drach JC. (1998) Resistance of human cytomegalovirus to benzimidazole ribonucleosides maps to two open reading frames: UL89 and UL56. 1 Virol. 72:4721-8. 
14 Loomis IS, Courtney RJ, Wills IW. (2003) Binding partners for the UL11 tegument protein of herpes simplex virus type 1. J Virol. 77.11417-24.

15. Mcsharry J, McDonough A, Olson B, Hallenberger S, Reefschlaeger J, Bender W. Drusano GL. (2001) Susceptibilities of human cytomegalovirus clinical isolates to BAY38-4766, BAY43-9695, and ganciclovir. Antimicrob Agents Chemother. 45:2925-7.

16. Nakano $K$, Tadagaki $K$, Isegawa $Y$, Aye MM, Zou P, Yamanishi K. (2003) Human herpeswirus 7 open reading frame $\mathrm{U} 12$ encodes a functional betachemokine receptor. J Virol 77:8108-15.

17. Nalwanga D, Rempel S, Roizman B, Baines JD. (1996) The UL 16 gene product of herpes simplex virus 1 is a virion protein that colocalizes with intranuclear capsid proteins. Virology. 226:236-42.

18. Oshima S, Daikoku T, Shibata S, Yamada $H$, Goshima F, Nishiyama $Y$. (1998) Characterization of the UL16 gene product of herpes simplex virus type 2. Arch Virol. 143:863-80.

19. Poon AP, Roizman B. (1993) Characterization of a temperature-sensitive mutant of the UL15 open reading frame of herpes simplex virus 1. / Virol. 67:4497-503.

20. Przech AJ, Yu D, Weller SK. (2003) Point mutations in exon 1 of the herpes simplex virus putative terminase subunit, UL15, indicate that the most conserved residues are essential for cleavage and packaging. / Virol. 77:9613-21.

21. Reefschlaeger J, Bender $W$, Hallenberger $S$, Weber $O$, Eckenberg $P$, Goldmann S, Haerter M, Buerger I, Trappe I, Herrington JA, Haebich D, Ruebsamen-Waigmann H. (2001) Novel non-nucleoside inhibitors of cytomegaloviruses (BAY 38-4766): in vitro and in vivo antiviral activity and mechanism of action. I Antimicrob Chemother. 48:757-67.

22. Salmon B, Baines JD. (1998) Herpes simplex virus DNA cleavage and packaging: association of multiple forms of $U(L) 15$-encoded proteins with $B$ capsids requires at least the $U(L) 6, U(L) 17$, and $U(L) 28$ genes. I Virol. 72:3045-50.

23. Salmon B, Cunningham C, Davison AJ, Harris WJ, Baines JD. (1998) The herpes simplex virus type $1 \mathrm{U}(\mathrm{L}) 17$ gene encodes virion tegument proteins that are required for cleavage and packaging of viral DNA. / Virol. 72:3779-88.

24. Salmon B, Nalwanga D, Fan $Y$, Baines JD. (1999) Proteolytic cleavage of the amino terminus of the $U(L) 15$ gene product of herpes simplex virus type 1 is coupled with maturation of viral DNA into unit-length genomes. I Virol. 73:8338-48.

25. Scheer A, Fanelli F, Costa T, De Benedetti $P G$, Cotecchia S. (1997) The activation process of the alpha1B-adrenergic receptor: potential role of protonation and hydrophobicity of a highly conserved aspartate. Proc Natl Acad Sci U S A. 94:808-13.

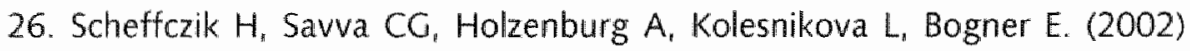
The terminase subunits pUL56 and pUL89 of human cytomegalovirus are 
DNA-metabolizing proteins with toroidal structure. Nucleic Acids Res. 30.1695-703.

27. Scholz B, Rechter S, Drach JC, Townsend LB, Bogner E. (2003) Identification of the ATP-binding site in the terminase subunit pUL56 of human cytomegalovirus. Nucleic Acids Res. 31:1426-33.

28. Spiegel AM. (1996) Defects in $G$ protein-coupled signal transduction in human disease. Annu Rev Physiol. 58.143-70.

29. Taus NS, Salmon B, Baines JD. (1998) The herpes simplex virus 1 UL 17 gene is required for localization of capsids and major and minor capsid proteins to intranuclear sites where viral DNA is cleaved and packaged. Virology. 252:115-25.

30. Townsend LB, Devivar RV, Turk SR, Nassiri MR, Drach JC. (1995) Design, synthesis ${ }_{\text {" and }}$ antiviral activity of certain 2,5,6-trihalo-1-(beta-Dribofuranosyl)benzimidazoles. / Med Chem. 38:4098-105.

31. Underwood MR, Harvey RJ, Stanat SC, Hemphill ML, Miller T, Drach JC, Townsend LB, Biron KK. (1998) Inhibition of human cytomegalovirus DNA maturation by a benzimidazole ribonucleoside is mediated through the UL89 gene product. I Virol. 72:717-25.

32. Wess J. (1998) Molecular basis of receptor/G-protein-coupling selectivity. Pharmacol Ther. 80:231-64.

33. Wing BA, Lee GC, Huang ES. (1996) The human cytomegalovirus UL94 open reading frame encodes a conserved herpesvirus capsid/tegumentassociated virion protein that is expressed with true late kinetics. $/$ Virol. 70.3339-45. 
GPCRS encoded by menbers of the CMV LU33 gere family 


\section{Dankwoord}

Zo, laat ik hier nog maar eens goed voor gaan zitten. Dat kan ik jullie overigens ook wel aanraden want ik vrees dat dit nog een aanzienlijk kluif zal gaan worden. Een passie voor schrijven heb ik namelijk (nog) (of nog steeds?) niet en dat zal vrijwel iedereen aan wie ik deze bladzijden richt, kunnen beamen. De dagen, weken, maanden, in enkel geval zelfs jaren, die ik geteisterd door het een of andere te schrijven artikel, over mijn toetsenbord gebogen zat (of beter: zou hebben moeten zitten), stelde jullie meer dan eens in de ongelukkige gelegenheid mijn minder zonnige kanten te ervaren. Alleen al voor het verduren van mijn geprikkeldheid, sarcasme, ironie en zwartgalligheid, verdienen jullie stuk voor stuk, een oprecht, persoonlijk woord van dank. De meesten van jullie deden echter zo veel meer!

Laat me daarom bij de oorsprong van dit proefschrift beginnen. De spill van mijn AlO-bestaan. Kees. Je maakte me tot een ingewijde in de mysterieuze handelingen, en vooral de geuren, van het moleculair virologisch onderzoek. Je nam altijd geduldig en immer inspirerend de taak op je, om me te coachen bij het schrijfwerk. Je moest dit helaas ook bezuren bij het eindeloze editten en soms zelfs scheppen van "mijn" teksten. Je was genadeloos bij het evalueren van de bereikte resultaten: "Wat? een halve dag voor slechts 96 preppen met knip?" "Wat is dat voor een slordige prutsgel?" "Van wie is die beroerde foto hier, Yvonne zeker?", "Tja, das duidelijk een titer van niks!" "Jaha, maar dàt staat hier niet. Hoe kan je zulke onzin schrijven". Gelukkig is je motto: "gelijke monikken, gelijke kappen", ben je rechtvaardig recht door zee en krijgt iedere kleine godheid, jezelf incluis, er dus net zo goed van langs. Nature paper of niet. Je was nooit te beroerd om voor mij of anderen, de handen uit de labjasmouwen te steken: "Is er nog iets te kloneren voor mij, een eiwitgelletje dan, moeten er niet nog wat puntmutanten gemaakt worden?", en je hield je deur altijd open zodat we het hart konden luchten en van je kookkunsten konden genieten. Je stond ons met raad en daad ter zijde in lab, tuin en leven en schonk mij vrijwel eindeloze wrijheid en vertrouwen om naar eigen goeddunken lekker aan te kunnen prutsen en uit te pluizen. Kees, ik kan alleen maar hopen dat ik later net zo'n motiverende, constructief kritische, openhartige, meelevende collega, begeleider en baas zal kunnen zijn, als jij voor me was. Uiteraard op die gevoelige neus en trotse smaakpapillen na dan.

Cathrien. Als promotor was je van constante invloed op mijn gehele aiotijd. Je vervulde deze rol echter elegant op de achtergrond en was nimmer overheersend. Je liet me, onder het waakzame oog van Kees lekker mijn gang gaan, m'n eigen ding doen en wist daarbij toch je steun en interesse doorlopend aan me over te dragen.

Suusje. Van studiegenoot tot medestagiar, van lab- en lotgenoot tot ware vriendin. Als muts en doos, door dik en dun waren we een katalysator voor elkaars geschater. Jij denkt "gewoon kameel" als we woor een raadsel staan en pruttelt 
met de moed der wanhoop "noemen ze dit een pad" als we, in plaats van op een 4-daagse snelweg, voor een avontuur blijken te gaan. Scheuren in het zelfwertrouwen werden met smeuige stamppotten gelijmd, de uitgeputte lijven met Thai in vuur en vlam gezet en de Chinees? Tja, die lag altijd en overal zomaar voor het oprapen. Je sportiviteit kende geen grenzen en je optimisme geen limiet, hoewel ze beiden enigzins te lijden hebben gehad onder lichte hoogteziekte. Je was daarom voor mij zoals de wortel voor de ezel, een kleurrijke aansporing om vol goede moed vooruit te kijken en in beweging te blijven.

Erik. De rust zelve, pragmatisch, hulpvaardig, gastvrij. De regels op het lab vrij interpreterend en elastisch hanterend zodat het er aangenaam werkbaar bleef. Je kon helaas niet ieder labtenue van me evenveel waarderen. De allesbedekkende witte combi bleef bij uitstek favoriet bij jou, maar meer nog bij die anderen. Je was ten alle tijden bereid om met ingang van gisteren nog snel iets voor me te kloneren, te sequencen, te expresseren en bleek ook onmisbaar voor werk in het weekend want "waar vind ik op ons lab ook al weer....". Als goed verstaander van het halve woord (of onvervalste melodiën) en als spontane organisator van incidentele BBQ's en petanque-partijen, was je zowel op het lab als daarbuiten een rots in de branding. lemand met wie je de beste constructen kan bouwen (en terugvinden).

Patrick. Jij ontdekt(e) het een na het andere gen voor virale corruptie. Daarmee stond je aan de wieg van al het lekkers dat in deze thesis wordt gepresenteerd. Ook dragen de meeste van de hier, en op bijeenkomsten gepresenteerde kunstwerken, deels jouw signatuur en vormde je een natuurlijke bron van en voor software-gerelateerde problematiek. Je voorzag me niet alleen even snel van het gevraagde, maar meestal ook van een scala ongevraagde extra's. Hierdoor werd menige werkdag verluchtigd met internetvarialij, herziene computerinstellingen, omvangrijke speurtochten naar ontelbare, onmisbare labhulpmiddelen en boeiende anekdotes uit het kleurijke Beisser familie- en gedachteleven. Je vormde dan ook een waar licht en verl(/z)ucht(ig)ing in mijn AlO-bestaan.

Aafke. Je werd door mij de meeste tijd onverdiend aan je studentenlot overgelaten maar droeg dit met flair. Samen met Johan Heemskerk wist je veel te mobiliseren. Gisten, schimmels, bacteriën. Maar helaas, geen calcium! Ondanks deze kleine tegenvaller leverde je door je enthousiasme, gezellige houding en doorzettingsvermogen een motiverende bijdrage aan het werk.

Voor de confocale uurtjes: Jos Broers. Je gaf het groene licht in de confocalkamer en liet het zelfs levendig schijnen. Zonder je begeleiding hadden we lang in het duister getast.

Selma, Koen en Rien. Wanneer het in ons lableven of daarbuiten berg op en af ging, werden frustraties en kilometers gemakkelijk gezamelijk weg gefietst en gewandeld. Of, gewoon vergeten bij kopje koffie, glaasje wijn, de kippies en 
een filmpje. Collegas zijn jullie helaas niet meer, vrienden zullen jullie hopelijk blijven.

Rood, geel en groen kregen er een kleurtje bij: kim. Carnaval werd dankzij jou, Vaostelaovond bij het krieken van de dag. Je uitbundigheid en levenslust redde menig saai moment.

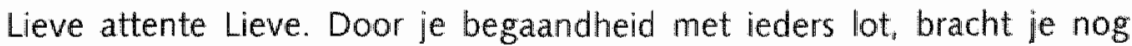
meer menselijkheid in ons lab, de kamer en wandelgangen.

Gert. Als archetype van onze virologie research, hoedster van PBS, cellen, virus en antilichamen, schrik der ratten (maar ook omgekeerd), aanvoerdster van "het labje voor", kon niemand van de virologie om je heen. Ook ik niet. De goed gevulde kweek- en glaswerkkasten, de ordelijke virusklappers, de uitgebreide kleurtechnieken vormden een goed excuus om af en toe eens op "jouw lab" te komen snuffelen en te keuvelen met al die fijne collegas van de "andere virologie": Frank, Inge, Rajaa, Jeroen, Ellen Tryfon, Manuela, Sabine, Martijn, Rick, Geoffrey en de schier eindeloze studenten.

Wil, Verius, Ans, John, Fia, José. Jullie ondersteuning was onmisbaar en veraangenaamde de dagelijkse gang van zaken. Niet alleen omdat jullie je bekommerden om randvoorwaarden zoals: bestellingen, apparatuur, printpapier, het schone steriele glaswerk, postzegels, puntjes, chemicaliën, treinkaartjes, oplossingen, faxen, vrije dagen, declaraties, messen voor vlaai, verhuisdozen, pennen, pincetten, afspraken, en verwerking van bergen kweekafval (en dat vaak zelfs nog buiten de verordonneerde tijden), maar juist door jullie persoonlijke dagelijkse inbreng zoals een opgewekt goeiemorgem, een babbeltje hier en een grapje daar.

Voor zulke momenten, de gesprekken, de getoonde interesse in mijn wel en wee, de gedeelde vlaaien, koffiekamer en apparatuur, wil ik ook de overige (voormalige) collegas van de Medische Microbiologie, research en dianostiek, secretariaat en ziekenhuishygiëne, bedanken. Jullie maakten dat het lab in Maastricht zo'n prettige werkomgeving was en bleef.

Amsterdam: Rob Leurs, Martine Smit, Paola Casarosa (who not only taught me how to unravel and interpret. constitutive signaling by GPCRs, but also how to label cells, chemokines and fingers with equal amounts of radioactivity), Dennis Verzijl, Martijn Bruijsters, Sarina Meusburger, Marion Navis, Remko Bakker, en de vele, vele andere studenten, analisten, aios, postdocs en profs van de gelijk $E$. coli's groeiende groep Farmacochemie van de VU. Met hen heb ik (in enkel geval zonder medeweten) lief, leed, ep, pipet, oplossing, ligand, glycerolstock, plasmide, bureau, werkbank, flowkast, Victor, kennis, onkunde, succes, mislukking, wijn, bier, artikelen, besmettingen, brownies en cellen mogen delen. 
En dan, buiten het lab om. Daar waren de goeie ouwe trouwe vrienden die me grootmoedig mijn gebrek aan regelmatige aandacht voor hen, telkens weer vergaven. Nic, Hil, Dort, Joep. Fred, Cham en Mirriam. Jullie huiskamers en telefoons bleken altijd beschikbaar wanneer afleiding en bemoediging het meest welkom waren.

Degenen met wie ik in het verticale (of in vrijwel horizontale gespletenheid) verbonden ben (geweest): De touwgroep. Alex, Hugo, Eelke, Arjen, Sander, Jurriaan, Suzanne en Cham. Met jullie wist ik de dalen te overwinnen. Het werden topmomenten. Mogen er nog vele volgen.

En natuurlijk mijn ouders. Anka en Arnold. Bedankt voor jullie niet aflatende, onbaatzuchtige steun in alle opzichten en de vele helpende handen door de jaren heen. Voor alle keren dat jullie dachten dat ik eindelijk definitief het huis uit was en $i k$, met de complete dierentuin, weer op de stoep stond en mocht aanschuiven.

Karl. Bergen stellen Grenze her, Forderen uns sie zu überschreiten, Trennen uns, bringen näher, Kreuz und Quer durch Raum und Zeiten. Oft waren wir weit von einander entfernt, trotzdem warst Du für mich da.

Lieve mensen, het was een geweldig tijd met jullie in Maastricht, Amsterdam. Eindhoven of onderweg en ik heb vaak gedacht, zo zou het voor altijd mogen blijven. Onbedwingbare nieuwsgierigheid, interesse en verlangen

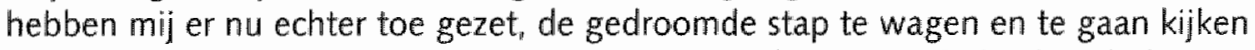
hoe groen het gras in de immunologie, hoe mooi het beloofde land in de bergen werkelijk is. Het blijtt moeilijk om het vertrouwde achter te laten, maar gesteund door jullie weet ik: Het is tijd voor een nieuw perspektief. 


\section{Curriculum vitae}

Yvonne Gruijthuijsen werd geboren te Eindhoven op 30 september 1973. In 1992 behaalde zij het VWO diploma aan het Lorentz Lyceum in Eindhoven. In hetzelfde jaar begon zij aan de studie Gezondheidswetenschappen van de Universiteit Maastricht en koos de afstudeerrichting Biologische Gezondheidskunde. Tijdens de afstudeerstage bij de capaciteitsgroep Medische Microbiologie van het Academisch Ziekenhuis Maastricht, werd moleculair biologisch onderzoek verricht aan het rat cytomegalovirus, onder leiding van dr. C. Vink en prof. dr. C.A. Bruggeman. Aansluitend werd een tweede stage bij Organon Teknika uitgevoerd, onder begeleiding van dr. A.E. Greijer en prof. dr. J.M. Middeldorp. Hierbij stonden humaan cytomegalovirus immune evasion eiwitten centraal. Van begin 1998 tot medio 1999, was zij als research analist werkzaam bij de afdeling aviaire virologie van het Instituut voor Dierhouderij en Diergezondheid. Daar was ze betrokken bij het project van $d r$. B. Peters en $\mathrm{dr}$. A. Gielkens, ter ontwikkeling van een markervaccin voor het pluimvee pathogeen, Newcastle disease virus. Direct na het behalen van het doctoraalexamen in augustus 1999, begon ze als assistent in opleiding bij de capaciteitsgroep Medische Microbiologie onder supervisie van dr. C. Vink en prof. dr. C.A. Bruggeman. Gedurende deze aanstelling werden werkbezoeken afgelegd aan de Medicinal Chemistry groep van dr. M.J. Smit en prof. dr. R. Leurs, van de Vrije Universiteit in Amsterdam. Sedert 2 februari 2004 is ze werkzaam aan de ParisLodron Universität Salzburg te Oostenrijk, waar ze in de groep Chemie en Biochemie van prof. dr. A. Duschl, moleculair biologisch onderzoek verricht naar cytokines en de rol van cytokines in de ontwikkeling van allergische reacties. 


\section{Publicaties}

Gruijthuiisen YK. Beuken E, Bruggeman CA, Vink C. (2000) Rat Cytomegalovirus R89 is a Highly Conserved Gene Which Expresses a Spliced Transcript. Virus Res. (69): $119-30$.

Peeters BP, Gruijthuijsen YK, de Leeuw OS, Gielkens AL. (2000) Genome Replication of Newcastle Disease Virus: Involvement of the Rule-Of-Six. Arch. Virol. (145):1829-45.

Gruithuijsen YK, Casarosa P, Kaptein SJ, Broers JL, Leurs R, Bruggeman CA, Smit M. Vink C. (2002) The Rat Cytomegalovirus R33-encoded G Protein-Coupled Receptor Signals in a Constitutive Fashion. J. Viro/. (76):1328-38.

Kaptein SJF, Beisser PS, Gruijthui sen YK, Savelkouls KGM, Van Cleef KWR, Beuken E, Grauls GELM, Bruggeman CA, Vink C. (2003) The Rat Cytomegalovirus R78 G Protein-Coupled Receptor Gene is Required for the Production of Infectious Virus in the Spleen. 1. Gen. Virol. (84):2517-30.

Gruijthuijsen $Y K$, Casarosa $P$, Beisser PS, Verzijl D, Bruggeman CA, Leurs R, Vink C, Smit MJ. (2003) Constitutive Signaling of the Human Cytomegalovirus-Encoded Receptor UL33 Differs From That of Its Rat Cytomegalovirus Homolog R33: By Promiscuous Activation of $G$ proteins of the $G_{i}, G_{i}$ as well as $G_{5}$ Class. \%. Biol. Chem. (278):50010-23

Gruijthuijsen $Y K_{1}$, Beuken EVH, Smit MJ, Leurs $R_{f}$ Bruggeman CA, Vink C. (2004) Mutational Analysis of Rat Cytomegalovirus R33-Encoded G protein-Coupled Receptor: Identification of Residues Critical for Localization and Intracellular Signaling. J. Gen. Virol. (85):897-909

Gruijthuijsen Y'K, Bruggeman CA, Vink C. (2004) Herpesvirus-Encoded Homologs of G Protein-Coupled Receptors: Immunomodulators, Stimulators of Viral Replication or Directors of Movement? In: Progress in protein Research F Colombus (Ed), Nova Science Publishers Inc., NY, USA. In press

Kaptein SJF, Van Cleef KWR, Gruijthuiisen YK, Beuken EVH, Van Buggenhout $G$, Beisser P5, Stassen FRM, Bruggeman CA, Vink C. (2004) The r131 Gene of Rat Cytomegalovirus Encodes a Pro-Inflammatory, CC Chemokine Homolog Which is Essential for the Production of Infectious Virus in the Salivary Glands. Virus Genes. In press

Kaptein SJF, Gruijthuijsen YK. Beisser PS, Bruggeman CA, Vink C. (2004) Cytomegalovirus-Encoded Homologs of G Protein-Coupled Receptors: Stimulators of Viral Replication, Immune Evaders or Directors of Movement? Research Advances in Virology R.M. Mohan (Ed.), Global Research Network, India "In press. 